US Army Corps of Engineers $s_{\circledast}$

Engineer Research and

Development Center

\title{
Development of Smartphone-Based Semi- Prepared Runway Operations (SPRO) Models and Methods
}

Andrew B. Ward, Anthony J. Falls, and Craig A. Rutland

November 2021

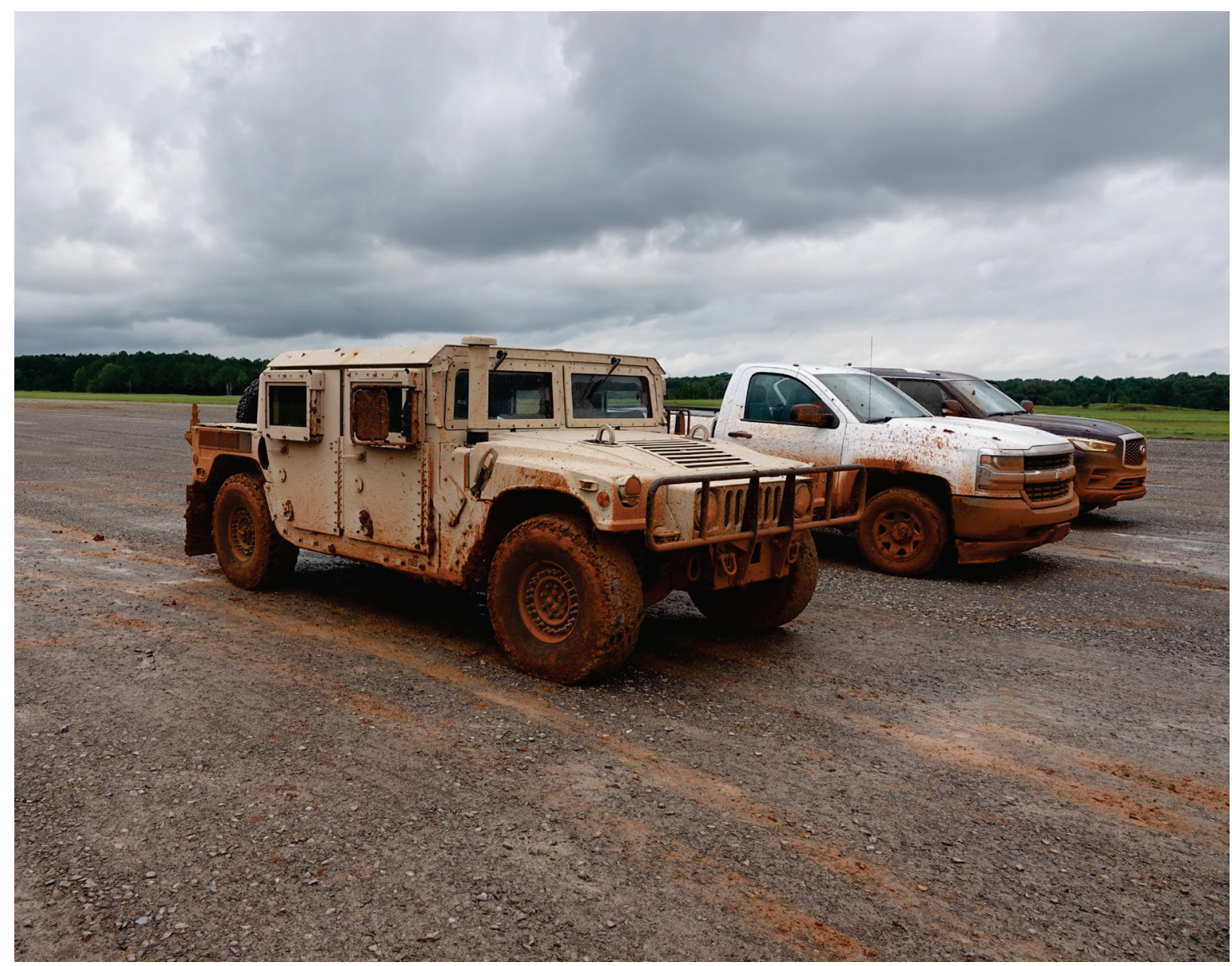


The U.S. Army Engineer Research and Development Center (ERDC) solves the nation's toughest engineering and environmental challenges. ERDC develops innovative solutions in civil and military engineering, geospatial sciences, water resources, and environmental sciences for the Army, the Department of Defense, civilian agencies, and our nation's public good. Find out more at www.erdc.usace.army.mil.

To search for other technical reports published by ERDC, visit the ERDC online library at https://erdclibrary.on.worldcat.org/discovery. 


\section{Development of Smartphone-Based Semi- Prepared Runway Operations (SPRO) Models and Methods}

Andrew B. Ward and Anthony J. Falls

Geotechnical and Structures Laboratory

U.S. Army Engineer Research and Development Center

3909 Halls Ferry Road

Vicksburg, MS 39180-6199

Craig A. Rutland

Civil Engineering Branch, Engineering Division

Air Force Civil Engineer Center

Tyndall Air Force Base, FL 32403-5319

Final report

Approved for public release; distribution is unlimited.

Prepared for Headquarters, U.S. Air Force Civil Engineer Center 139 Barnes Drive, Suite 1

Tyndall Air Force Base, FL 32403-5319

Under MIPR F4ATA49092JW01 


\section{Abstract}

The U.S. Army Engineer Research and Development Center (ERDC) has developed a method for predicting surface friction response by use of ground vehicles equipped with deceleration-based measurement devices. Specifically, the ERDC has developed models and measurement methods between the Findlay Irvine Mk2 GripTester and a variety of deceleration measurement devices: Bowmonk AFM2 Mk3, Xsens MTi-G-710, two Android smartphones, and two iOS smartphones. These models show positive correlation between ground vehicle deceleration and fixed-slip surface continuous surface friction measurement. This effort extends prior work conducted by the U.S. Army ERDC in developing highly correlative models between the Findlay Irvine Mk2 GripTester and actual $\mathrm{C}-17$ braking deceleration, measured via the runway condition rating (RCR) system. The models and measurement methods detailed here are of considerable use to semi-prepared airfield managers around the world needing to measure safe landing conditions following inclement weather. This work provides the tools necessary for airfield managers to quantify safe landing conditions for $\mathrm{C}-17$ aircraft by using easily obtainable equipment and simple test standards.

DISCLAIMER: The contents of this report are not to be used for advertising, publication, or promotional purposes. Citation of trade names does not constitute an official endorsement or approval of the use of such commercial products. All product names and trademarks cited are the property of their respective owners. The findings of this report are not to be construed as an official Department of the Army position unless so designated by other authorized documents. 


\section{Contents}

Abstract........................................................................................................................... if

Figures and Tables........................................................................................................................

Preface ...................................................................................................................... ix

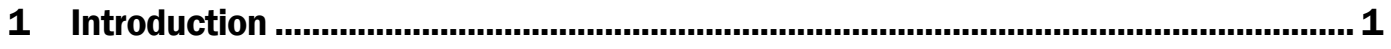

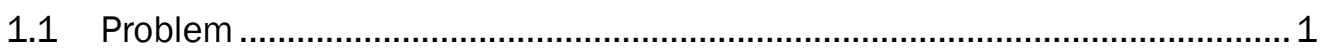

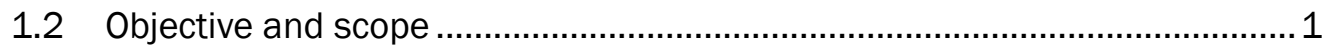

2 Literature Review ............................................................................................................ 3

2.1 Standard models of friction ......................................................................

2.1.1 Models of friction on paved surfaces................................................................... 3

2.1.2 Models of friction on unpaved surfaces ................................................................ 8

2.2 Types of friction measurement devices ....................................................10

2.2.1 Continuous friction measuring equipment ........................................................ 10

2.2.2 Deceleration-based equipment........................................................................ 11

2.3 Original SPRO effort........................................................................... 12

3 Field Test Methods..................................................................................................15

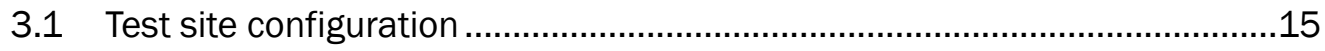

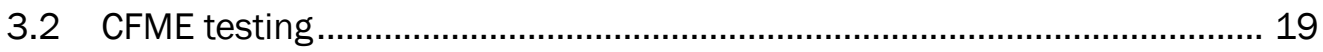

3.3 Deceleration-based testing ................................................................ 23

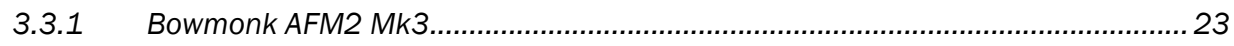

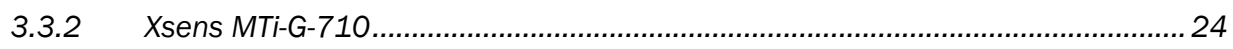

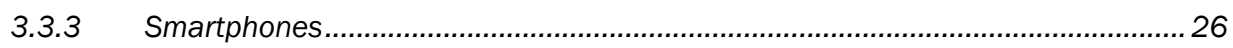

3.4 Ground vehicle configuration............................................................... 28

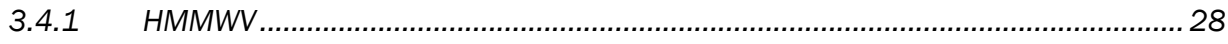

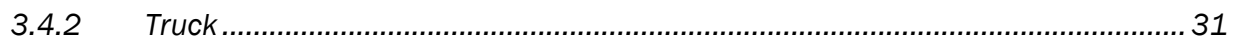

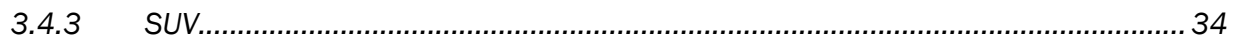

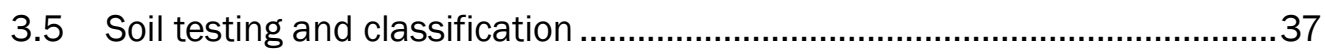

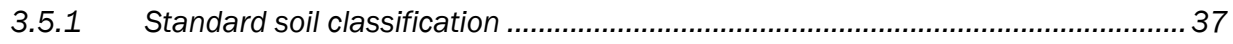

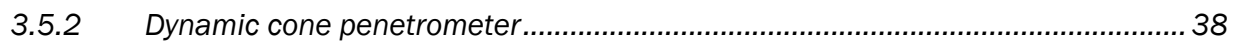

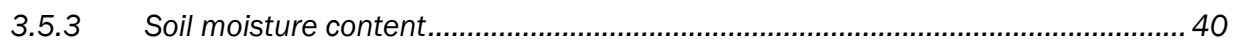

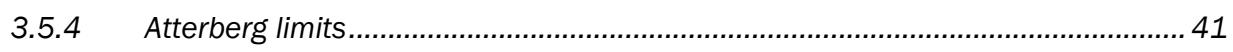

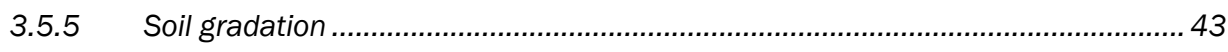

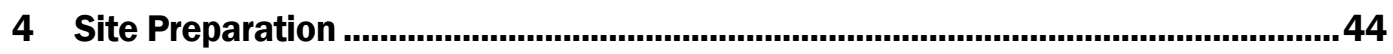

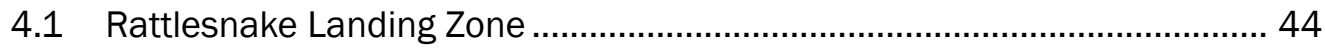

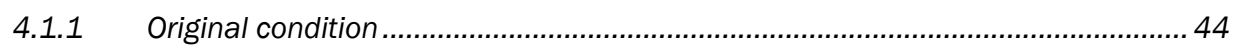

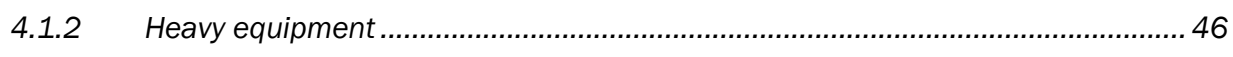

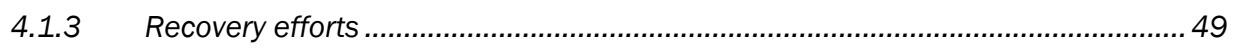




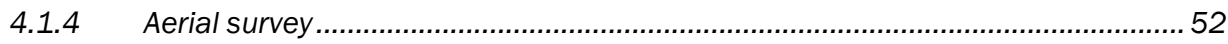

4.2 Schoonover Landing Zone ............................................................. 55

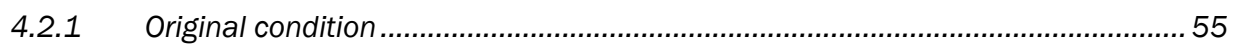

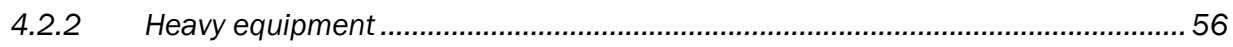

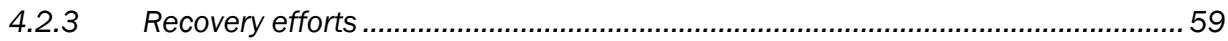

4.3 Golden Eagle Landing Zone ...................................................... 62

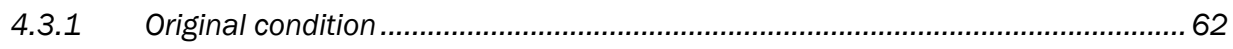

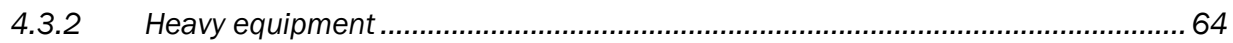

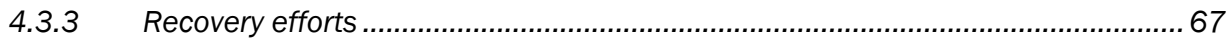

5 Site Characterization ................................................................................................. 73

5.1 Rattlesnake Landing Zone ....................................................... 73

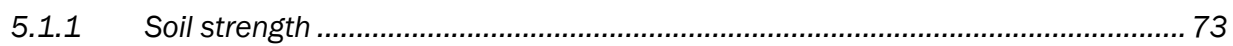

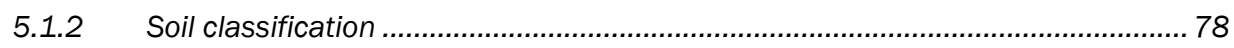

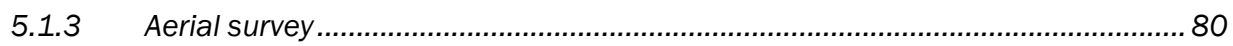

5.2 Schoonover Landing Zone ........................................................... 83

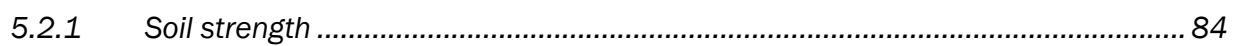

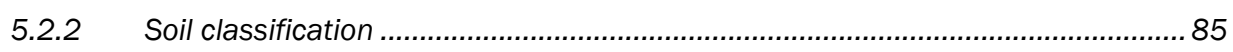

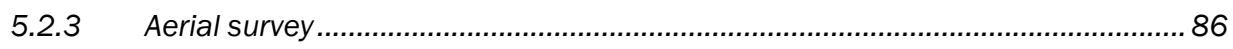

5.3 Golden Eagle Landing Zone ....................................................... 88

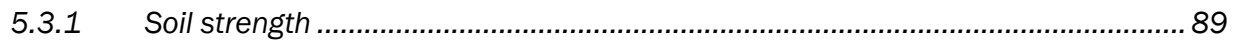

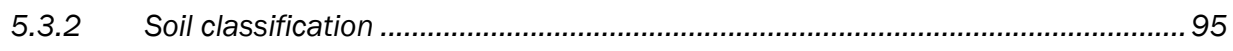

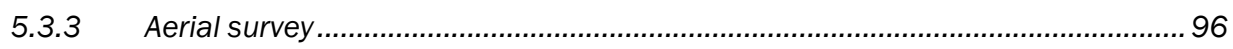

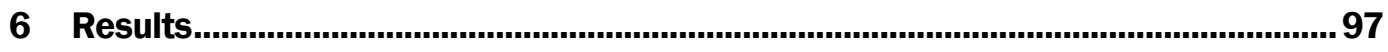

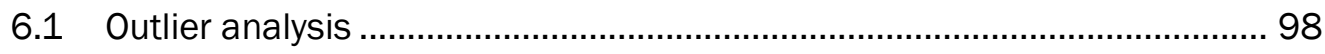

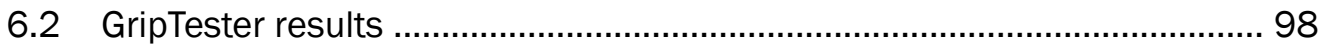

6.3 Synthesized vehicle-specific deceleration results ................................ 100

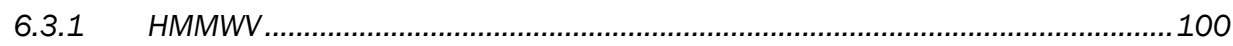

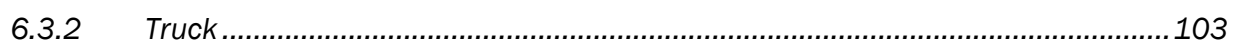

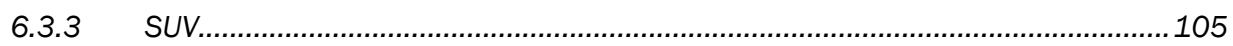

6.4 Smartphone repeatability analysis.............................................. 108

6.5 Final predictive models ......................................................................... 110

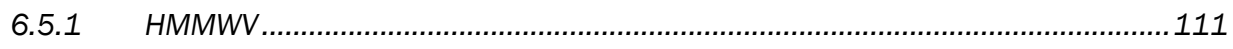

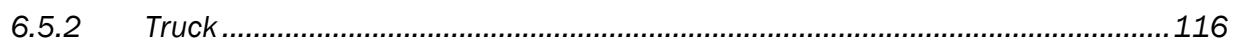

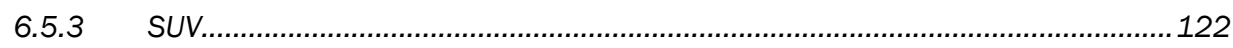

6.5.4 Synthesized deceleration-based GT predictions ............................................128

7 Conclusions and Recommendations.................................................................... 130

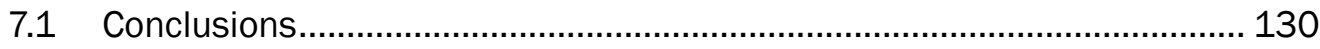

7.2 Recommendations ........................................................................ 132

References........................................................................................................................ 133

Unit Conversion Factors.................................................................................. 136

\section{Report Documentation Page}




\section{Figures and Tables}

\section{Figures}

Figure 1. Sample results from Rado (1994) exponential friction model. ............................ 6

Figure 2. Findlay Irvine Mk2 GripTester tow-behind friction survey example.................... 11

Figure 3. Bowmonk AFM2 Mk3 decelerometer installed in a ground vehicle................... 12

Figure 4. Original SPRO data and regressions (Tingle et al. 2017).................................13

Figure 5. General test site configuration outline............................................................... 16

Figure 6. General test site configuration example at Golden Eagle LZ............................ 17

Figure 7. Water truck sprayers wetting a test site at Golden Eagle LZ.............................. 18

Figure 8. Lineup of test vehicles during Golden Eagle LZ data collection. ........................19

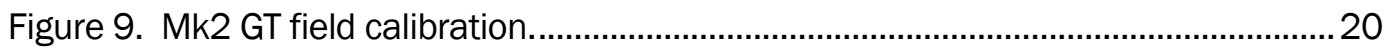

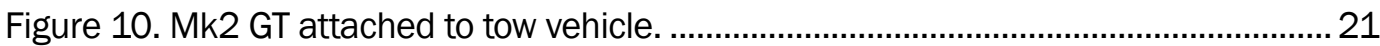

Figure 11. Top side of muddy Mk2 GT post-test................................................................ 22

Figure 12. Underside of muddy Mk2 GT post-test. .......................................................... 22

Figure 13. Bowmonk AFM2 Mk3 top-down view........................................................... 23

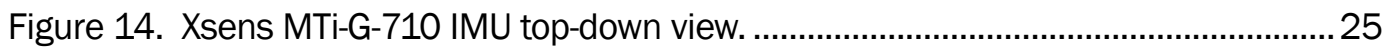

Figure 15. ERDC DECEL Android app screenshots. .......................................................26

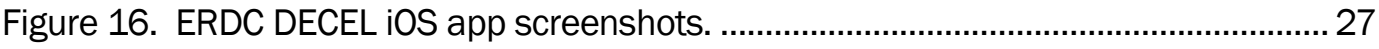

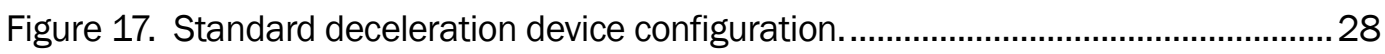

Figure 18. Two M1165A1 HMMWVs loaned by the 412 th TEC........................................29

Figure 19. HMMWV deceleration equipment mounting configuration..............................30

Figure 20. HMMWV GPS antenna mounting position. .................................................... 31

Figure 21. 2017 Chevrolet Silverado 1500 4WD 1/2-ton pickup truck.............................32

Figure 22. Floorboard mounting configuration of $1 / 2$-ton truck deceleration

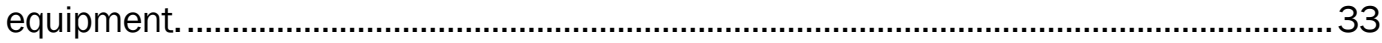

Figure 23. Mounting position of $1 / 2$-ton truck antenna..................................................... 33

Figure 24. 2019 Ford Expedition SUV at Rattlesnake LZ............................................... 34

Figure 25. 2019 Chevrolet Tahoe SUV at Schoonover LZ. .............................................35

Figure 26. 2019 Infiniti QX80 SUV at Golden Eagle LZ................................................35

Figure 27. SUV deceleration equipment floorboard mounting configuration.....................36

Figure 28. SUV antenna mounting position.................................................................... 37

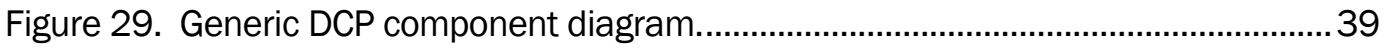

Figure 30. DCP test being performed at Rattlesnake LZ, Fort Chaffee, AR.......................40

Figure 31. Graphical representation of the Atterberg limits (Das 2010).......................... 42

Figure 32. Directions to Rattlesnake LZ from Highway AR 10 East. .................................. 44

Figure 33. Rattlesnake LZ with significant vegetative growth............................................. 45 
Figure 34. Rattlesnake LZ with cut-down vegetation......................................................46

Figure 35. John Deere 554K front-end loader. .............................................................. 47

Figure 36. John Deere 670G motor grader..................................................................... 48

Figure 37. HAMM H12i vibratory roller compactor. ........................................................... 48

Figure 38. Fort F-650 SD 2,000-gal water truck............................................................. 49

Figure 39. Motor grader and front-end loader on Rattlesnake LZ ...................................50

Figure 40. Vibratory roller compactor on Rattlesnake LZ ............................................... 51

Figure 41. Completed Rattlesnake LZ test surface........................................................... 51

Figure 42. BirdsEyeView Aerobotics FireFLY 6 PRO. ..................................................52

Figure 43. Rattlesnake LZ full runway mosaic................................................................53

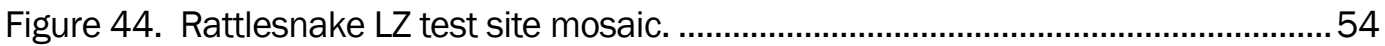

Figure 45. Satellite imagery of the Schoonover LZ and access road location. ..................55

Figure 46. Overview of Schoonover LZ main runway. .......................................................56

Figure 47. CAT 289D skid steer. .................................................................................... 57

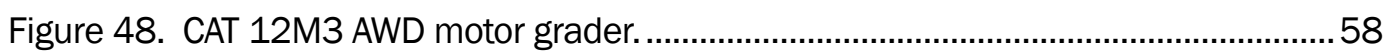

Figure 49. CAT CS56B vibratory roller compactor. ........................................................... 58

Figure 50. FREIGHTLINER 2,000-gal water truck. ............................................................ 59

Figure 51. Grade control operations at Schoonover LZ following testing. ........................ 59

Figure 52. Near-surface rocks on the Schoonover LZ main runway..................................60

Figure 53. Skid steer compaction on the Schoonover LZ main runway............................. 61

Figure 54. Vibratory roller compaction on the Schoonover LZ main runway..................... 61

Figure 55. Satellite imagery of Golden Eagle LZ and access road location. ..................... 62

Figure 56. Golden Eagle LZ main runway covered with short vegetation.......................... 63

Figure 57. Golden Eagle LZ main runway with intermittent bare soil. ............................... 63

Figure 58. Golden Eagle LZ main runway after preliminary blading by LRAM. ................. 64

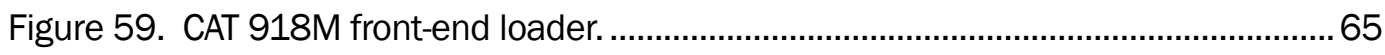

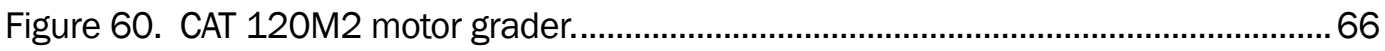

Figure 61. CAT CS56B vibratory roller compactor. .............................................................. 66

Figure 62. FREIGHTLINER 2,000-gal water truck. ......................................................... 67

Figure 63. Motor grader and compactor on Golden Eagle LZ parking apron.....................68

Figure 64. Initial grade control on the southwest end of Golden Eagle LZ.......................69

Figure 65. Initial compaction on the southwest end of Golden Eagle LZ. .........................69

Figure 66. Blading and compaction continue the length of the runway. ............................70

Figure 67. Heavy-equipment wrap-up work on Golden Eagle LZ main runway. ................ 71

Figure 68. Final state of Golden Eagle LZ main runway following all testing..................... 72

Figure 69. Plasticity chart for SPRO sites................................................................... 79

Figure 70. Gradation chart for Rattlesnake LZ soil sample. ........................................... 80

Figure 71. Rattlesnake LZ sectional chart. .................................................................. 81

Figure 72. Brake site sUAS imagery on Rattlesnake LZ. ................................................... 82 
Figure 73. Before and after of Rattlesnake LZ main runway. ............................................ 83

Figure 74. CBR vs. depth along the main runway at Schoonover LZ (Bly 2018)...............84

Figure 75. Gradation chart for Schoonover LZ soil sample................................................ 86

Figure 76. Schoonover LZ sectional chart. ................................................................... 87

Figure 77. Schoonover LZ partial runway mosaic............................................................ 88

Figure 78. Gradation chart for Golden Eagle LZ soil sample............................................95

Figure 79. Golden Eagle LZ sectional chart...................................................................96

Figure 80. Current SPRO GT values in ascending order. ...................................................99

Figure 81. Deceleration data from the HMMWV in ascending order. .............................100

Figure 82. Scatter matrix plot for HMMWV deceleration data........................................ 101

Figure 83. Deceleration data from the 1/2-ton pickup truck in ascending order...........103

Figure 84. Scatter matrix plot for truck deceleration data.............................................104

Figure 85. Deceleration data from the SUV in ascending order....................................106

Figure 86. Scatter matrix plot for SUV deceleration data................................................ 107

Figure 87. Smartphone mounting configuration during replicate testing at Golden

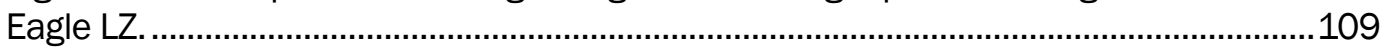

Figure 88. Replicate smartphone deceleration data from the HMMWV at Golden Eagle LZ. 110

Figure 89. Bowmonk and Xsens linear model predictions in the HMMWV....................112

Figure 90. Bowmonk and Xsens power model predictions in the HMMWV...................113

Figure 91. Smartphone linear model predictions in the HMMWV ...................................115

Figure 92. Smartphone power model predictions in the HMMWV................................116

Figure 93. Bowmonk and Xsens linear model predictions in the truck...........................118

Figure 94. Bowmonk and Xsens power model predictions in the truck. ........................119

Figure 95. Smartphone linear model predictions in the truck.........................................121

Figure 96. Smartphone power model predictions in the truck.....................................122

Figure 97. Bowmonk and Xsens linear model predictions in the SUV.............................124

Figure 98. Bowmonk and Xsens power model predictions in the SUV. .........................125

Figure 99. Smartphone linear model predictions in the SUV..........................................127

Figure 100. Smartphone power model predictions in the SUV. ......................................128

\section{Tables}

Table 1. Original SPRO test sites.................................................................................... 13

Table 2. Smartphones used during brake testing. ............................................................ 27

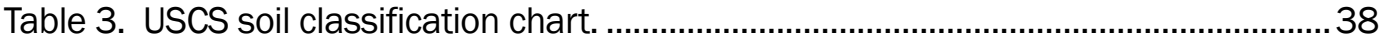

Table 4. Heavy equipment used during Rattlesnake LZ data collection.............................46

Table 5. Heavy equipment used during the Schoonover LZ data collection. .....................56

Table 6. Heavy equipment used during the Golden Eagle LZ data collection...................65

Table 7. CBR values on the Rattlesnake LZ centerline................................................. 74 
Table 8. CBR values $50 \mathrm{ft}$ north of the Rattlesnake LZ centerline.....................................75

Table 9. CBR values $50 \mathrm{ft}$ south of the Rattlesnake $\mathrm{LZ}$ centerline................................... 76

Table 10. CBR values from the recovered test site on Rattlesnake $Z Z$............................. 77

Table 11. Soil analysis data for SPRO sites................................................................... 78

Table 12. CBR values on the Golden Eagle LZ centerline. ............................................... 89

Table 13. CBR values $20 \mathrm{ft}$ north of the Golden Eagle LZ centerline.................................90

Table 14. CBR values $20 \mathrm{ft}$ south of the Golden Eagle LZ centerline. ............................... 91

Table 15. CBR values from the recovered runway on Golden Eagle LZ at the

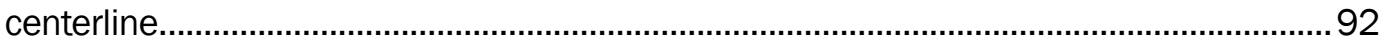

Table 16. CBR values from the recovered runway on Golden Eagle LZ $20 \mathrm{ft}$ north

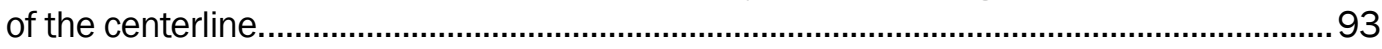

Table 17. CBR values from the recovered runway on Golden Eagle LZ $20 \mathrm{ft}$ south

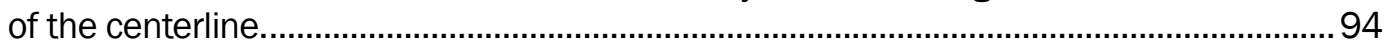

Table 18. SPRO test sites, vehicles, and devices. ........................................................... 97

Table 19. Linear model COD values for HMMWV deceleration equipment......................102

Table 20. Linear model COD values for truck deceleration equipment...........................105

Table 21. Linear model COD values for SUV deceleration equipment..............................108

Table 22. Repeatability factors for replicate smartphone data. .....................................110

Table 23. Linear and power model parameters for the HMMWV...................................114

Table 24. Linear and power model parameters for the truck. .........................................120

Table 25. Linear and power model parameters for the SUV...........................................126

Table 26. Final predictive models for all three test vehicles............................................129 


\section{Preface}

This study was conducted for the United States Air Force Civil Engineer Center (AFCEC) under MIPR F4ATA49092JW01. The technical monitor was Dr. Craig Rutland, AFCEC.

The work was performed by the Airfields and Pavements Branch (GMA) of the Engineering Systems and Materials Division (GM), U.S. Army Engineer Research and Development Center, Geotechnical and Structures Laboratory (ERDC-GSL). At the time of publication, Ms. Anna M. Jordan was Chief, GMA; Mr. Justin S. Strickler was Chief, GM; and Mr. R. Nicholas Boone, GZT, was the Technical Director for Force Projection and Maneuver Support. The Deputy Director of GSL was Mr. Charles W. Ertle II, and the Director was Mr. Bartley P. Durst.

COL Teresa A. Schlosser was the Commander of ERDC, and Dr. David W. Pittman was the Director. 


\section{Introduction}

\subsection{Problem}

Both civilian and military aeronautics agencies require the safe operation of aircraft on runway surfaces. It has been shown in numerous research efforts that surface friction is an excellent indicator of runway condition during landing and takeoff operations. While in the majority of civilian runway operations a rigid or flexible pavement structure is present, certain military efforts require the operation of aircraft in non-ideal conditions such as on semi-prepared runway surfaces. While semi-prepared surfaces are by design capable of sustaining certain traffic, inclement weather makes operating conditions much less certain. It is necessary in such circumstances that safe operating conditions be quantified in a timely manner.

\subsection{Objective and scope}

Be it known that the objectives of this research effort were to

1. Conduct a survey of various semi-prepared runway surfaces to determine suitability as surface friction testing sites.

2. Collect surface friction and deceleration data at all chosen sites with the following four devices:

○ Findlay Irvine Mk2-D GripTester (Mk2 GT)

- Bowmonk AFM2 Mk3 (Bowmonk)

- Smartphone inertial measurement units (IMUs)

○ Xsens MTi-G-710 IMU.

3. Collect deceleration data using three different ground vehicles:

- High-Mobility Multi-Purpose Wheeled Vehicle (HMMWV)

- Civilian $1 / 2$-ton pickup truck

- Civilian sport utility vehicle (SUV).

4. Determine possible correlation between ground vehicle braking deceleration and Mk2 GT.

5. Combine developed models with original semi-prepared runway operations (SPRO) power model and provide C-17 RCR predictions. 
6. Develop Android and iOS smartphone applications necessary to collect deceleration data and display runway condition rating (RCR) predictions.

7. Document findings in an ERDC technical report.

The result of this effort will provide the Air Force with more varied and affordable measures of surface friction on semi-prepared surfaces where more specialized equipment is unavailable. Furthermore, the methods and models developed here will provide a reasonable measurement of surface friction following inclement weather. These measurements will be obtained from readily accessible equipment such as government vehicles and smartphones. 


\section{Literature Review}

For decades, the frictional characteristics of pavement surfaces have been of considerable interest to both military and civilian organizations. These characteristics, among other things, dictate safe stopping distances for aircraft during landing and takeoff operations. This is even truer in expeditionary environments where semi-prepared surfaces are often used in place of rigid and flexible pavements. A number of topics require review here that contribute to the content of this report. Namely, it is important to survey various surface friction measurement devices, techniques, and models. A brief survey of these topics is detailed below.

\subsection{Standard models of friction}

Of particular interest to this study is the interaction of a rubber tire with a hard surface. A measurement of frictional force from such an interface relies on the properties of both the rubber tire and the surface itself. On paved surfaces, the tire has a much lower elastic modulus (Young's modulus) than the pavement surface, and therefore undergoes most of the deformation during the interaction. On semi-prepared surfaces in which no flexible or rigid pavement layer exists, this statement is not always true, especially following inclement weather. Separate surveys are provided below, which detail some of the differences between friction testing on paved and unpaved surfaces.

\subsubsection{Models of friction on paved surfaces}

Friction measurements on paved surfaces are affected by a number of factors such as temperature of the surface and tire, molecular makeup of surface (texture) and tire, weight distribution of the driving force behind the tire, and contamination of the pavement; however, early work by Tabor (1959), Grosch (1963), and Kummer and Meyer (1962) shows that much of this interaction can be described empirically as the sum of two distinct forces: hysteresis and adhesion, such that

$$
F_{f}=F_{h}+F_{a}
$$


where $F_{f}$ is the total force of friction,

$F_{h}$ is the hysteretic force, and

$F_{a}$ is the adhesive force.

The hysteresis force, $F_{h}$, is a result of the bulk deformation of the rubber tire about the aggregate particles present in the hard surface and the corresponding loss of kinetic energy as thermal energy. Simply stated, the hysteresis force takes into account the internal friction of the rubber tire and allows some of the tire's energy to be dissipated as heat. The adhesion force, $F_{a}$, results from the micro-scale bonding of the tire to the hard surface.

While these parameters are sufficient for a purely empirical analysis of surface friction, it will become important later to discuss the more complex aspects of rubber-pavement friction in numerical terms. In practice, however, this broad examination of rubber-pavement interaction is sufficient for analyzing important aircraft safety factors, such as rolling resistance and skid resistance.

It should be noted here that friction is rarely presented as a measure of force. It is often described, instead, as a dimensionless coefficient, written as $\mu$ or FC. This coefficient is described as the ratio of the total frictional force between an interface and the total vertical load on the interface, such that

$$
\mu=\frac{F_{f}}{F_{v}}
$$

where $F_{v}$ is the total vertical load.

In tire-surface interfaces, $F_{v}$ is the magnitude of the total gravitational force, $F_{g}$, acting on the interface. One could also write the friction coefficient as the ratio of the total friction force and the magnitude of the normal reaction force, $F_{N}$, provided by the hard surface.

\subsubsection{Penn State model}

Work was performed by Leu and Henry (1983) to develop the Penn State model of friction. This model describes the dependence of friction on slip speed by an exponential relationship: 


$$
\mu=\mu_{0} e^{-\frac{P N G}{100} S}
$$

where $\mu$ is the friction coefficient, $\mu_{0}$ is the zero-speed friction coefficient, $S$ is the slip speed, and

$P N G$ is the percent normalized gradient, where

$$
P N G=-\frac{100}{\mu} \frac{d \mu}{d S}
$$

$P N G$ has been found to correlate highly with surface macrotexture and $\mu_{0}$ was found to correlate highly with microtexture. A more compact form of the Penn State model later replaced the above form.

$$
\mu=\mu_{0} e^{-s / s_{p}}
$$

where $S_{p}$ is a speed constant empirically described as a linear relation of surface macrotexture.

\subsubsection{Rado model}

The Rado model of friction was developed to describe the behavior of friction under changing slip speed (Rado 1994). Take, for example, a car braking on a pavement surface. As the brakes are applied, the frictional force applied to the car's tire increases from a minimum to a peak. After the peak value is reached, the frictional force begins to decay exponentially as the tire reaches the locked-wheel state and the tire's slip speed matches the vehicle's speed. Rado modeled this behavior with the following exponential function

$$
\mu(s)=\mu_{\text {peak }} e^{-\left[{ }^{L n\left(S / S_{\text {peak }}\right)} / C\right]^{2}}
$$

where $\mu(S)$ is the friction coefficient as a function of slip speed, $S$, $\mu_{\text {peak }}$ is the peak friction coefficient, $S_{\text {peak }}$ is the corresponding peak slip speed, and $C$ is the shape factor of the surface texture.

Sample results from this model can be seen in Figure 1. 
Figure 1. Sample results from Rado (1994) exponential friction model.

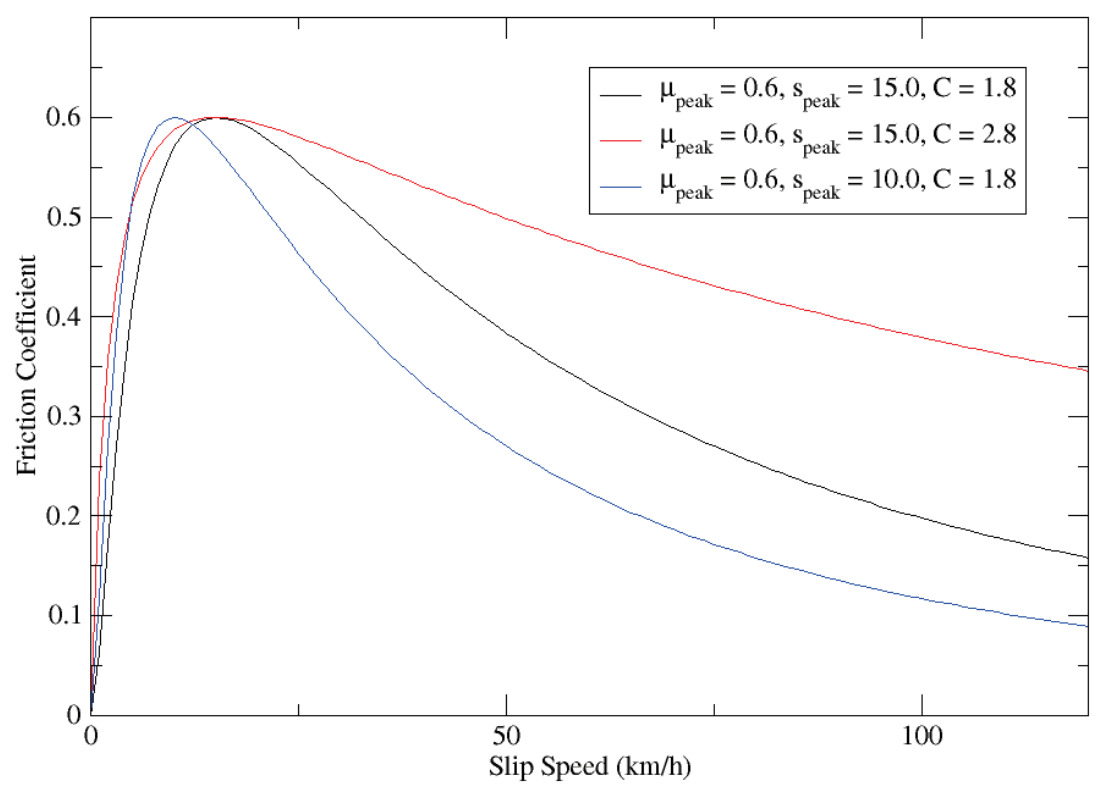

It is noteworthy here that anti-lock braking systems (ABSs) take advantage of this behavior by applying the brakes until the peak friction value is reached; releasing the brakes momentarily (slipping the tires) such that the locked-wheel state is avoided; then reapplying the brakes again until peak friction is reached.

\subsubsection{IFI model}

The wealth of technologies available for measuring and reporting surface friction presents a unique problem. With so many unique technologies, it is difficult to provide singular guidance relating safety to surface friction. In response to this issue, a harmonization effort was undertaken by the Permanent International Association of Road Congresses (PIARC), now known as the World Road Association (Wambold et al. 1995) in the development of an International Friction Index (IFI). The PIARC experiment was performed in Europe in 1992 and included participants from 14 countries and 54 test sites (Henry 2000). PIARC adopted the Penn State model of friction to develop the IFI. The Penn State model was adjusted by PIARC and represented by the following expressions 


$$
F R 60=F R S e^{(S-60) / s_{p}}
$$

where $F R 60$ is the friction value adjusted to a slip speed of $60 \mathrm{~km} / \mathrm{h}$, $F R S$ is the friction value as a function of slip speed, $S$, and $S_{P}$ is the speed constant.

The speed constant is found as a function of mean profile depth (MPD) (macrotexture measurement) as

$$
S_{p}=a+b \times T X
$$

where $T X$ is the MPD measurement and

$a$ and $b$ are constants determined by what equipment is used to make the macrotexture measurement.

If the Circular Track Meter (CTM) or similar technology is used as a macrotexture source, then $T X$ is reported as MPD, $\mathrm{a}=14.2$, and $\mathrm{b}=89.7$ (ASTM 2015). With $S_{p}$ and $F R 60$, the final step is to find the calibrated friction number, $\mathrm{F} 6 \mathrm{O}$,

$$
F 60=A+B \times F R 60
$$

Combining the equation for $F 60, S_{P}$, and $F R 60$ gives

$$
F 60=A+B \times F R S \times e^{-(60-S) /(a+b \times T X)}
$$

It is common to use the CTM for the macrotexture measurement and the dynamic friction tester (DFT) for the friction measurement at $20 \mathrm{~km} / \mathrm{h}$. The calibration constants for those two machines yield the following (ASTM 2015)

$$
\begin{gathered}
S_{p}=14.2+89.7 M P D \\
F 60=0.081+0.732 D_{D T} T_{20} e^{-40 / S_{p}}
\end{gathered}
$$

The values of $S_{P}$ and $F 60$ are reported as the IFI. The robustness of this model is in its ability to provide a measure of surface friction that relates not only to the hysteretic and adhesive properties (frictional force) of a 
pavement but also to the geometric properties of the pavement (texture). Furthermore, this model allows for a friction test measurement to be made at any slip speed. This measurement is then IFI-converted to a standard slip speed of $60 \mathrm{~km} / \mathrm{h}$. With this advantage comes a significant limitation; i.e., the IFI relies on actual surface friction data previously obtained from specific devices in specific environmental conditions on specific surfaces. As a result, Flintsch et al. (2009) later proposed to adjust the values obtained during the original PIARC experiment. Descornet (2004) has also proposed that a power model be used in place of the PIARC linear model for determination of the speed constant, $S_{P}$. The so-called HERMES project reports better speed constant results using a power model $S_{P}$ :

$$
S_{p}=a \times T X^{b}
$$

while Descornet (2004) reported better results using the power model of $S_{P}$. Flintsch et al. (2009) confirmed this only for smooth tire tests, not ribbed tire tests on certain devices. It is clear that improvements can still be made to the IFI and the correlation of friction measurements between various devices.

\subsubsection{Models of friction on unpaved surfaces}

The measurement of friction on unpaved (deformable or yielding) surfaces such as soil, sand, clay, mud, and snow is more difficult. Specifically, one of the underlying assumptions made when considering friction on a paved surface is that the rubber tire undergoes all or most of the deformation during the interaction. On less rigid surfaces, like the ones listed above, the surface undergoes a significant deformation.

\subsubsection{Friction on unpaved soil surfaces}

On an unpaved soil surface the rolling friction, or drag load, is

$$
F_{x}=\left(\mu_{0}+\frac{Z}{L_{t}}\right) F_{t}+\frac{1}{2} \rho b Z C_{D} V^{2}
$$

where $\mu_{0}$ is the rolling friction coefficient for a rigid surface, $Z$ is the dynamic sinkage, $L_{t}$ is the tire footprint length, $F_{t}$ is the vertical tire force, $\rho$ is the soil density, $b$ is the tire width, 
$C_{D}$ is the soil drag coefficient, and

$V$ is the velocity of the wheel axle (Crenshaw 1972).

The computation of dynamic sinkage relies upon the soil mobility work of the U.S. Army Engineer Waterways Experiment Station (WES) (Turnage 1967). The mobility numbers, $\Omega$, developed by WES defined the tire properties in terms of the soil condition. The WES mobility numbers were then refined by Crenshaw (1972) to include tire pressure in the sinkage calculation. The modified mobility number, $\Omega^{\prime}$, and dynamic sinkage relationships were developed for clay, $Z_{C}$, and sand, $Z_{S}$.

$$
\begin{aligned}
& Z_{c}=d\left(\frac{0.1208}{\Omega_{C}^{\prime}-0.9468}-0.0095\right) \\
& Z_{s}=d\left(\frac{0.3439}{\Omega_{S}^{\prime}-0.6239}-0.0017\right)
\end{aligned}
$$

A preliminary look at the skid resistance on soil surfaces later conducted by Lea and Jones (2007) found that the skid resistance on a soil surface depends on three key factors: inter-surface friction, sliding, and plowing. The inter-surface friction component is the familiar interaction of a tire with a rigid surface in which the surface texture is the dominant factor. The sliding component refers to a tire sliding on a thin layer of loose material. The plowing component is the interaction of a tire moving through a thick layer of loose material. While Lea and Jones (2007) gave various drag relationships with the above three factors, they are not statistically relevant enough to provide reliable skid resistance measurements. Further work is needed to confidently write the skid resistance on soil surfaces.

\subsubsection{Friction on unpaved viscous surfaces}

The rolling resistance of a tire in a supersaturated viscous mud (wet soil) on top of a hard foundation was considered by Rowe and Hegedus (1959). In their work, the wet soil is considered a fluid, and the motion of a tire through mud is considered as viscous flow around a partially submerged object. The rolling resistance, or total drag, is written as the sum of two components, friction drag and pressure drag. Rowe and Hegedus write this drag as 


$$
D=\frac{2 \mu U A_{2}}{\delta}+\frac{\gamma}{2}\left(h_{1}^{2}-h_{2}^{2}\right) b+\frac{1}{2} \rho U^{2} A_{1}
$$

where $D$ is the total drag on the tire,

$\mu$ is the viscosity,

$U$ is the velocity,

$A_{2}$ is the tire contact area with the soil also called the wetted area,

$\delta$ is the boundary layer thickness,

$\gamma$ is the specific weight,

$h_{1}$ is the elevation ahead of the tire,

$h_{2}$ is the elevation behind the tire,

$b$ is the characteristic width of the tire,

$\rho$ is the density of the fluid, and

$A_{1}$ is the projected area in the direction of motion.

Rowe and Hegedus concluded that this fluid dynamics approach to drag in loose supersaturated soil is in close agreement with experimental results conducted on rectangular, tire-shaped, and parabolic wheels.

\subsection{Types of friction measurement devices}

A number of unique, full-scale friction measurement devices operate at low and high speeds. There are a variety of friction testers available commercially. Of particular interest to the present study are two devices: continuous friction measuring equipment (CFME) and deceleration-based measuring equipment. Details for each are provided below.

\subsubsection{Continuous friction measuring equipment}

The most common types of CFME rely on a fixed-slip friction measurement system. Such a system measures surface friction by slipping a test tire to some speed, called the slip speed, which is less than the vehicle (driving) speed. The slipped test tire provides the horizontal and vertical force measurements necessary for friction measurement by use of vertically and horizontally placed load cells. This process is often described in terms of a ratio, the slip ratio, rather than speed. The braking slip ratio is defined as the ratio of the angular velocity of the tire under application of torque and the angular velocity of the tire un-braked. The slip ratio for fixed-slip CFMEs is usually held to around 10\% to 20\% (Henry 2000). Fixed-slip CFMEs generally take the form of a small trailer that is towed behind a 
ground vehicle. For use on military airfields, the most popular such CFME is the Findlay Irvine Mk2 GripTester (Mk2 GT; see Figure 2).

Figure 2. Findlay Irvine Mk2 GripTester tow-behind friction survey example.

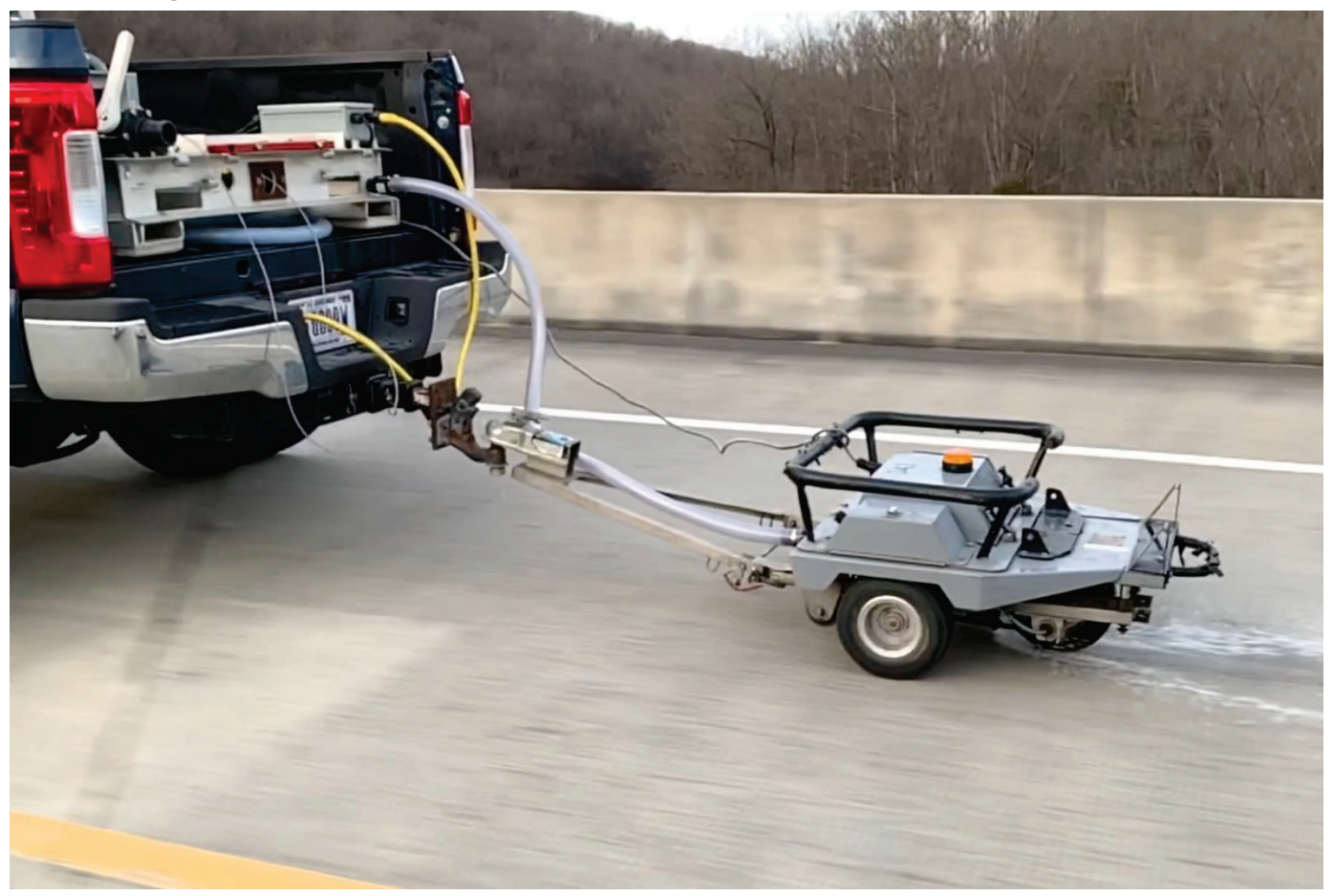

The Mk2 GT device itself consists of two driving tires on the front axle and a single load-instrumented test tire on the rear axle. The test tire is slipped by chain and allowed to skid on the test surface. Water is often used to wet the test surface just in front of the test tire. The vertical load and braking force are measured by use of load cells and reported as the instantaneous friction reading, also known as the braking force coefficient (BFC). Typically, the instantaneous friction reading is the braking force divided by the vertical load, and the BFC is the mean of multiple readings (ASTM 2021). Fixedslip CFMEs are most commonly used at military and civilian airfields.

\subsubsection{Deceleration-based equipment}

Deceleration-based friction testing equipment, often called decelerometers, were originally used in the late 1960 s and early 1970 s as a measure of aircraft stopping performance. Decelerometers measure the deceleration of a test vehicle (ground- or air-based) and report the value as a percentage of the acceleration of gravity, $\% g$. These devices were typically used to report the RCR of a pavement surface in certain conditions. The RCR value is determined by fitting a decelerometer 
securely to a test vehicle and measuring the deceleration during a braking event. The peak deceleration value is then reported as the RCR in $\mathrm{ft} / \mathrm{s}^{2}$. A typical RCR for dry pavement is 23; for wet, 12; and for icy, 5. These decelerometer measurements were known to have poor correlation with actual aircraft stopping performance in wet and flooded pavement conditions (NASA 1969; Yager et al. 1970). The RCR was known, however, to report conservative values for aircraft stopping performance on snowand ice-covered runways (Yager et al. 1970). The FAA does not approve decelerometers for friction condition surveys in wet-pavement conditions but does approve them for friction surveys during winter conditions (FAA 1997). An example of a popular deceleration-based friction measuring device, the Bowmonk AFM2 Mk3, can be found in Figure 3.

Figure 3. Bowmonk AFM2 Mk3 decelerometer installed in a ground vehicle.

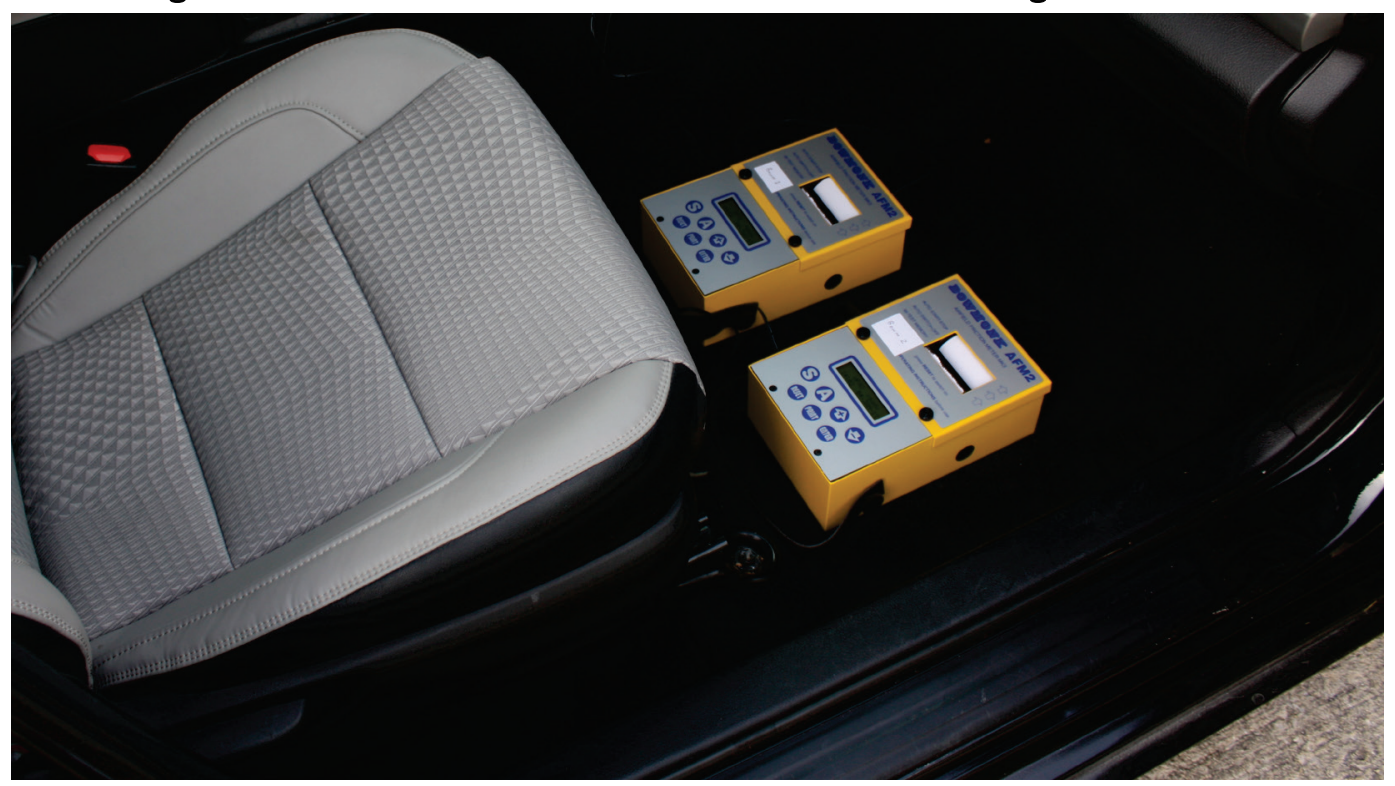

\subsection{Original SPRO effort}

The objective of the original SPRO effort was to develop a correlation between actual C-17 aircraft braking deceleration, by way of the RCR, and surface friction measurements, such as provided by the Mk2 GT. Some general results derived from the original SPRO effort will be described here; however, a more exhaustive report on that work can be found in Tingle et al. (2017).

The original SPRO effort performed C-17 takeoff and landing (braking) events along with Mk2 GT data collection at five semi-prepared runways 
(see Table 1). These sites provided a variety of climate and soil types necessary to obtain varied deceleration and surface friction measurements.

Table 1. Original SPRO test sites.

\begin{tabular}{|l|l|l|}
\hline \multicolumn{1}{|c|}{ Test Site } & \multicolumn{1}{|c|}{ Climate } & \multicolumn{1}{c|}{ Soil Type } \\
\hline $\begin{array}{l}\text { Schoonover Landing Zone (LZ), Fort Hunter } \\
\text { Liggett, CA }\end{array}$ & Semiarid & SM \\
\hline Goatman LZ, Edwards AFB, CA & Arid & CH \\
\hline Young LZ, Fort McCoy, WI & Temperate & SM \\
\hline Rattlesnake LZ, Fort Chaffee, AR & Temperate & CL \\
\hline Lakebed Runway 7-25, Edwards AFB, CA & Arid & CH \\
\hline
\end{tabular}

While the original SPRO effort found a strong linear relationship between aircraft RCR and surface friction measurement, a more conservative power model was finally presented that was also highly correlative. The results of the original authors' regressions are provided in Figure 4.

Figure 4. Original SPRO data and regressions (Tingle et al. 2017).

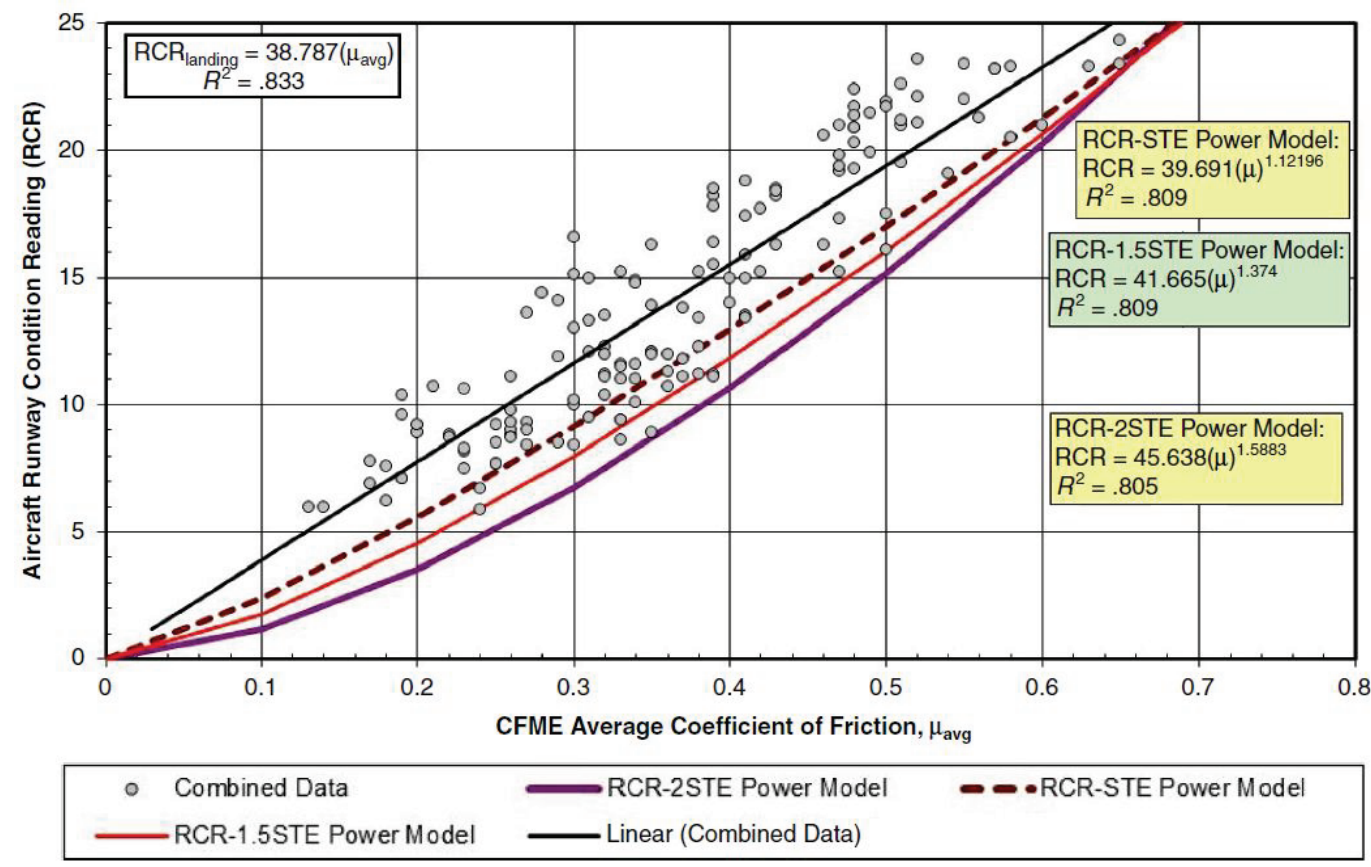

It was decided, by the original authors, that the power model minus 1.5 standard errors of the estimate (STE) provided a sufficient combination of safety and accuracy without rendering the regression needlessly conservative (see Equation 18). 


$$
R C R_{\text {landing }}=41.665 \times\left(\mu_{\text {avg }}\right)^{1.374}, R^{2}=0.809
$$

In general, the original SPRO effort resulted in a highly correlative model $\left(R^{2}\right.$ of 80.9\%) relating aircraft RCR and Mk2 GT surface friction measurement. This correlation is useful to airfield managers of semi-prepared, expeditionary runways for the purposes of determining safe landing conditions, specifically subsequent to inclement weather. One downside of this result is the low availability of the Mk2 GT. For airfields without either the cost-prohibitive device itself or the trained personnel necessary to operate it, alternative measures of safe landing conditions are desired. 


\section{Field Test Methods}

Two types of friction measurement equipment were selected for this effort: CFME-based and accelerometer-based. The CFME-based devices provide continuous measurements of surface friction, and the accelerometer-based devices provide rapid spot measurements of friction based on ground-vehicle stopping distance. The following three sections detail how these devices were utilized during testing.

\subsection{Test site configuration}

Many different test configurations were utilized at each site as weather and surface conditions required; however, one general test scheme was used throughout all testing. A test site at least 1,000 $\mathrm{ft}$ in length was recovered from the airfield surface, and at least three stations were evenly placed within the recovered area (see Figure 5 and Figure 6). While the ground vehicles used each station as a braking point, the Mk2 GT vehicle collected data continuously throughout the test area. To account for scatter in deceleration data and inaccuracies common in smartphone deceleration measurement (Ward et al. 2019), a minimum of five replicate measurements were conducted for each test configuration. More replicate measurements were collected as time and environmental factors allowed. 
Figure 5. General test site configuration outline.

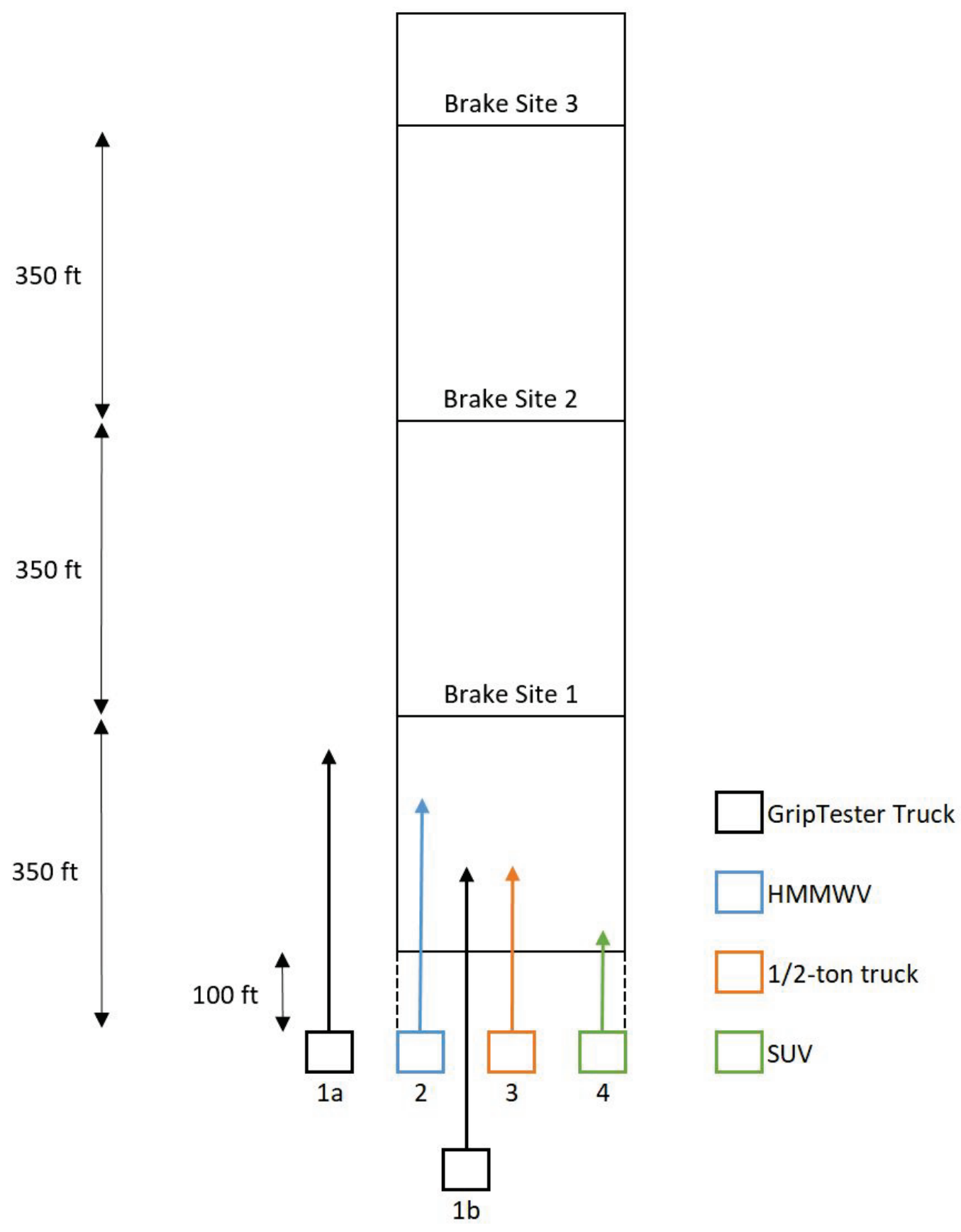


Figure 6. General test site configuration example at Golden Eagle LZ.

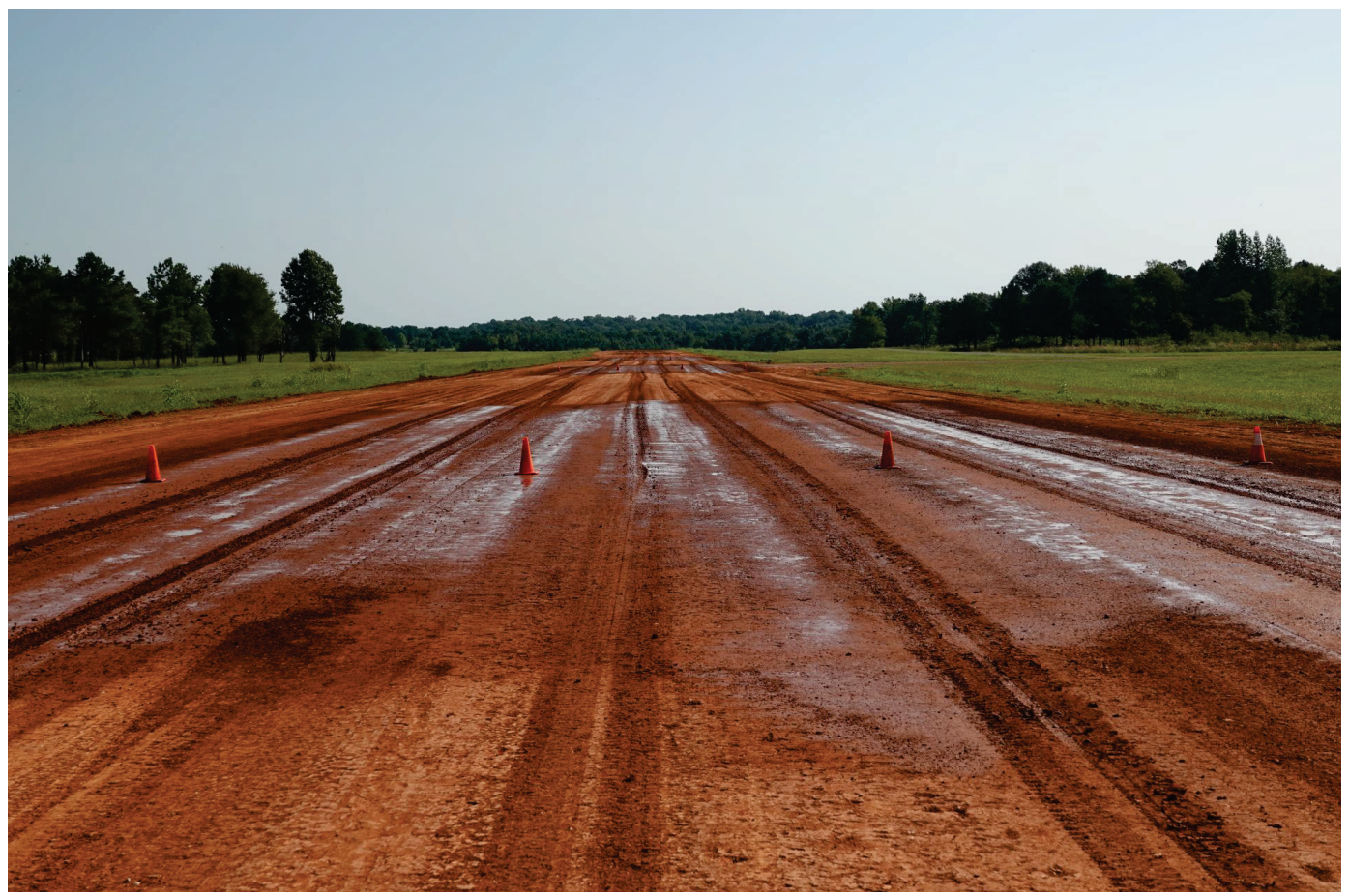

One way to modify the friction response from each semi-prepared surface was to change the moisture content of the soil surface layer. To accomplish this, water trucks were used to wet the soil surface on and around each brake site. Both front and rear sprayers were used during testing (see Figure $7 \mathrm{a}$ and b, respectively). The front sprayers were angled slightly more downward than the rear sprayers, leading to a significant plowing effect that removed loose dust and material from the test surface. One downside of using the front sprayers was that the water truck itself would traffic the wetted test surface and leave ruts. 
Figure 7. Water truck sprayers wetting a test site at Golden Eagle LZ.

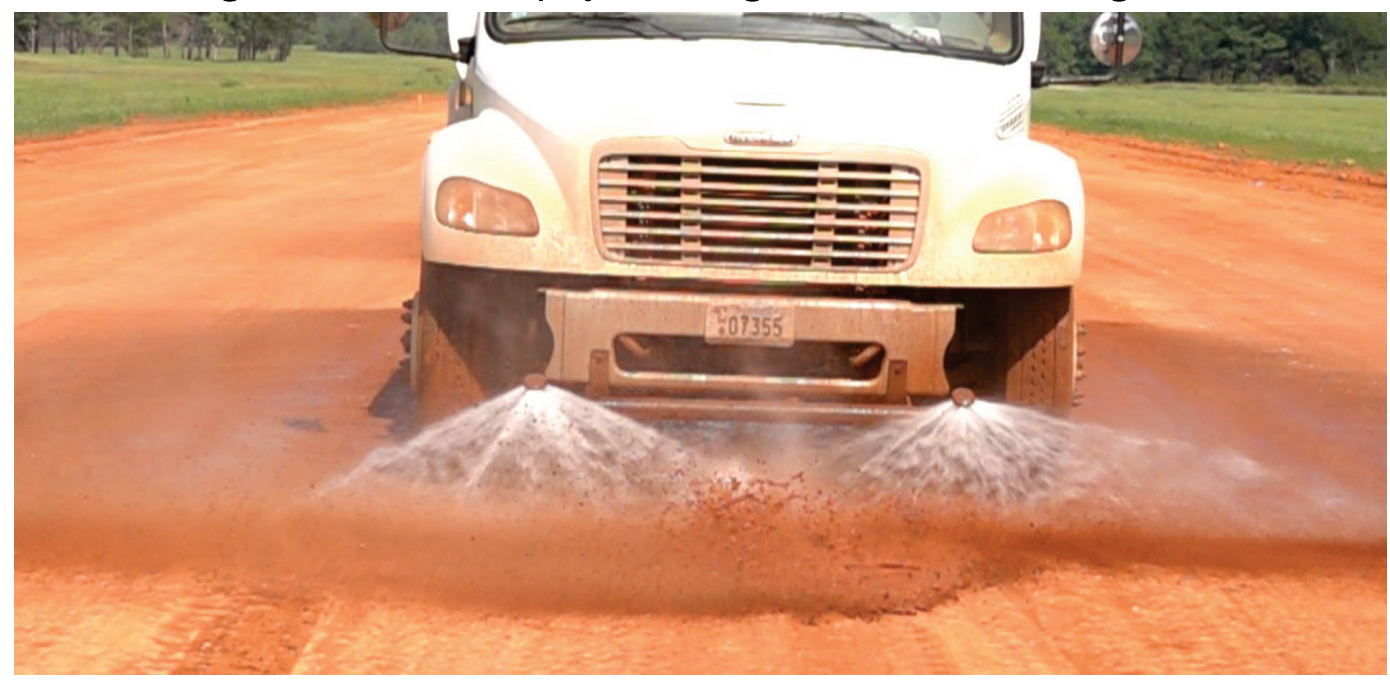

(a) Water truck front sprayer

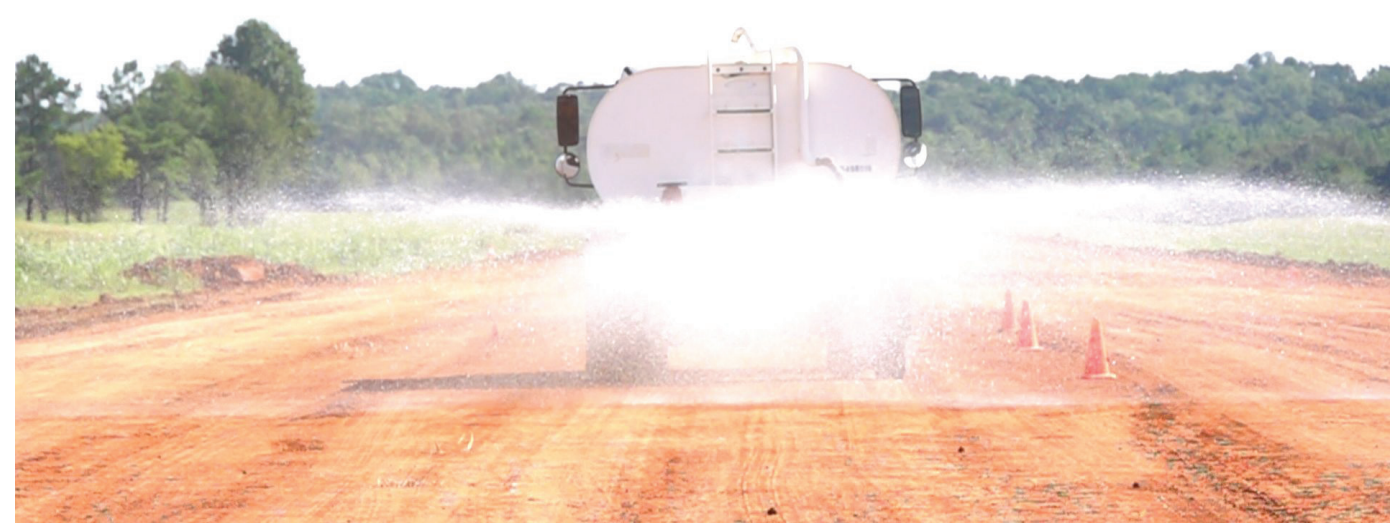

(b) Water truck rear sprayer

Given the above considerations, a typical series of brake tests took the following form:

1. Three test vehicles were lined up and evenly spaced on the test track.

2. The Mk2 GT tow vehicle lined up between a pair of test vehicles.

3. One or two water trucks operated by one technician each were aligned on the edges of the other vehicles (see Figure 8).

4. The water trucks wetted the test surface with a pre-determined volume of water and were positioned off the test track.

5. Water was allowed to penetrate the soil surface for a pre-determined amount of time, after which the Mk2 GT vehicle ran its course through the test track, collecting initial surface friction values. 
6. The three test ground vehicles then ran through their brake tests in a staggered formation (HMMWV first, 1/2-ton truck second, and SUV third).

7. Finally, when all test ground vehicles were done with their course, the Mk2 GT vehicle ran again to collect surface friction values.

Figure 8. Lineup of test vehicles during Golden Eagle LZ data collection.

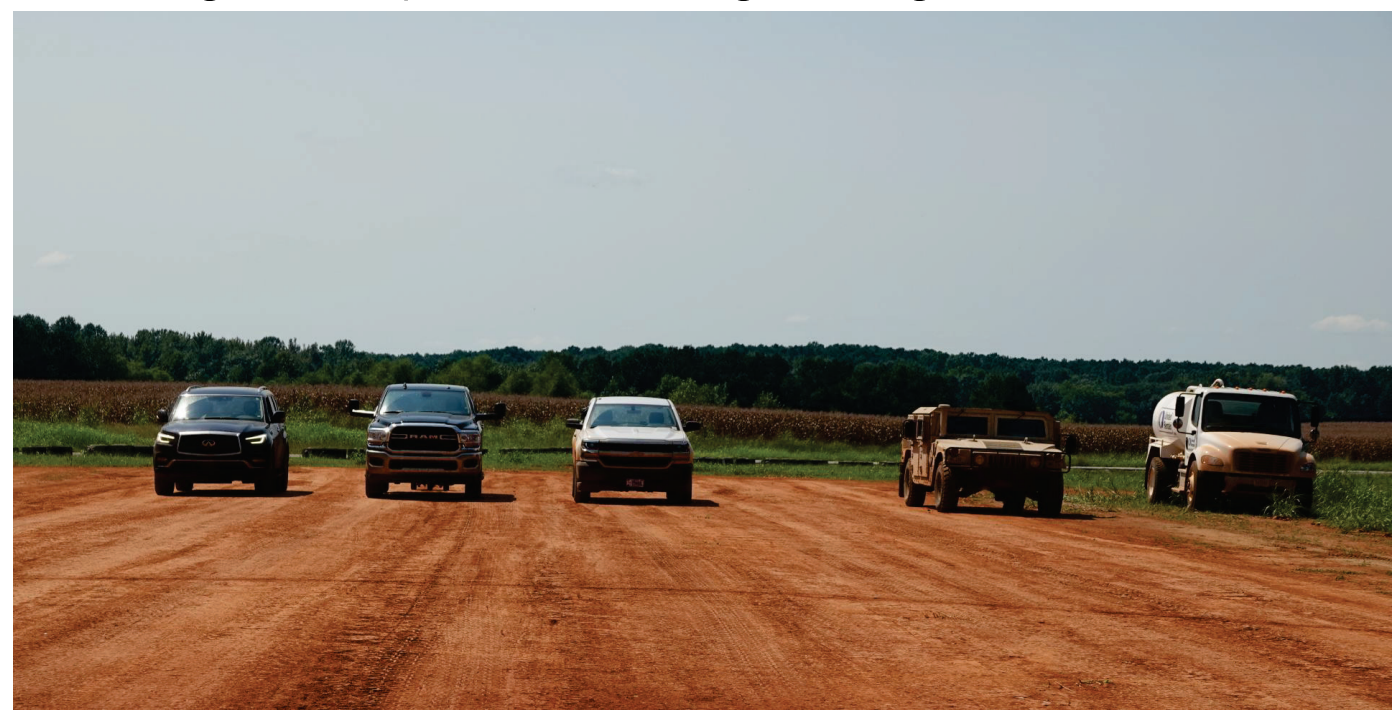

\subsection{CFME testing}

The military standard continuous friction measuring equipment, the Findlay Irvine Mk2 GripTester (Mk2 GT; see Figure 2), was selected to provide accurate surface friction measurement. The Mk2 GT was proven during the original SPRO effort to provide accurate and consistent measures of surface friction and was also shown to be robust to mud, water, and dust contamination (Tingle et al. 2017).

Prior to operation, the Mk2 GT was cleaned, in the event that mud from prior tests was still present, and field calibrated (see Figure 9). Field calibration ensured that the device's horizontal and vertical load cells were within factory tolerance. This was done by attaching a hanging scale to each load cell and checking the weight (or load) against factory specifications. 
Figure 9. Mk2 GT field calibration.

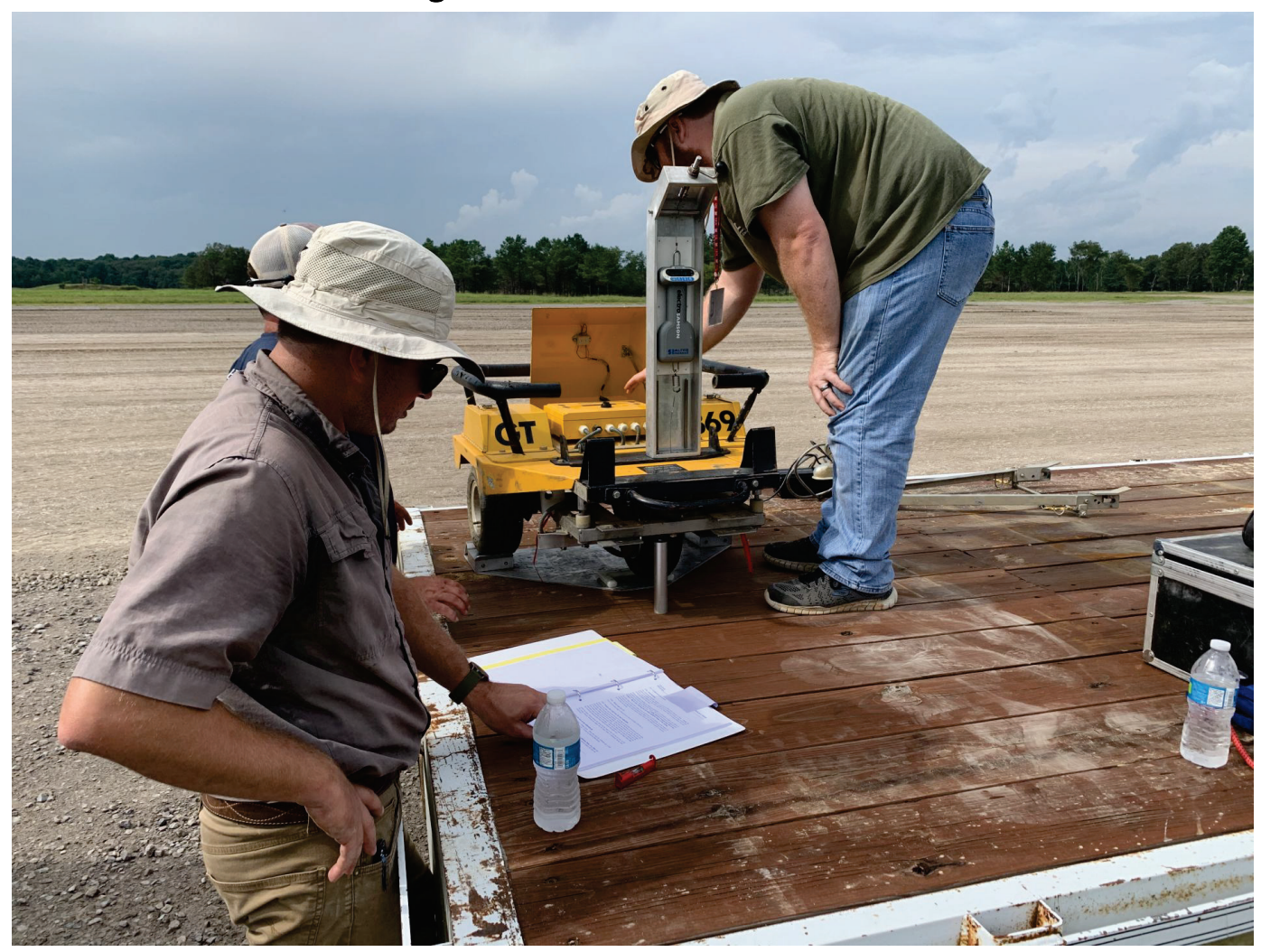

Standard test speeds on airfields for fixed-slip CFMEs are typically 40 and $60 \mathrm{mph}$ (ASTM 2021). Due to safety concerns regarding the use of brake testing on wetted, unpaved surfaces, the Mk2 GT operating speed for this effort was reduced to $25 \mathrm{mph}$. One other variation from standard methods regards the use of a water system to place a 1-mm film of water in front of the test tire. The SPRO effort relied on the use of water trucks to wet the entire testing surface such that the water system standard on the Mk2 GT was unnecessary. This greatly simplified operation of the Mk2 GT with effectively only one cable necessary for operations (see Figure 10). 
Figure 10. Mk2 GT attached to tow vehicle.

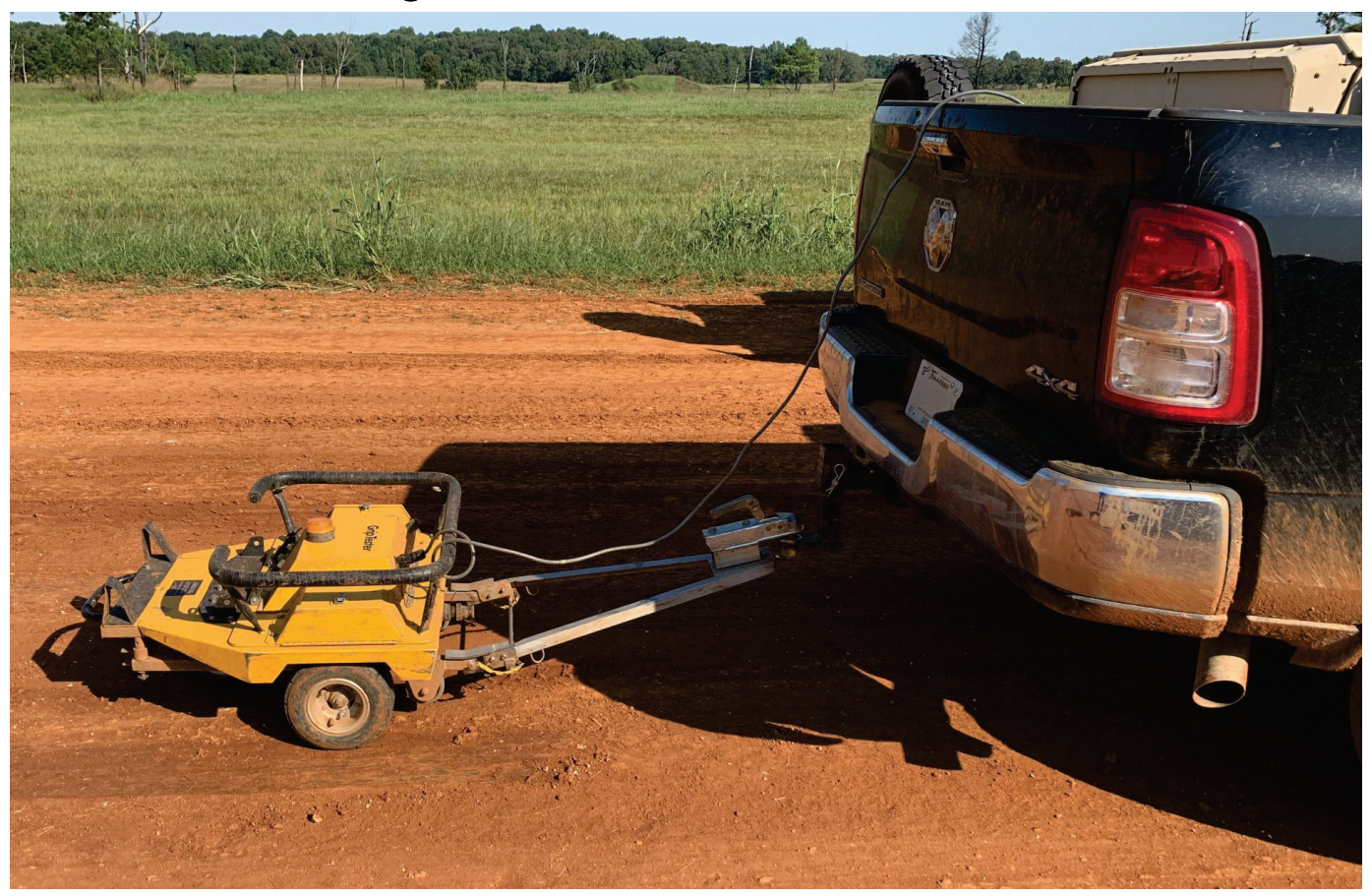

In this configuration, the Mk2 GT required two technicians for efficient operation. The first maintained a constant speed of $25 \mathrm{mph}$, based on the vehicle's speedometer, and the second controlled the Mk2 GT data collection via a Windows-based laptop.

Data collection with the Mk2 GT was done by use of the Findlay Irvine Air Base software. Each Mk2 GT run was initiated approximately $100 \mathrm{ft}$ before the start of the test area. This run-up allowed for the Mk2 GT tow vehicle to reach the test speed of $25 \mathrm{mph}$. At each brake site (usually denoted by cones or flags), the Mk2 GT software operator placed a marker in the continuous Mk2 GT data. This marker represented the exact point of each brake site and allowed for Mk2 GT data to be gathered before and after the marker during post-processing.

Each airfield presented its own unique spacing and weather restrictions; therefore, the standard testing procedure was modified as necessary to meet testing requirements. In particular, the Mk2 GT tow vehicle was typically placed in one of two areas for data collection: adjacent to or between the other test vehicles (positions 1a and 1b in Figure 5, respectively). In both cases, the intent was to collect surface friction data in areas representative of where the ground vehicles were performing brake tests. 
The result of repeated testing on wetted semi-prepared surfaces was the accumulation of water and mud on the topside and underside of the Mk2 GT (see Figure 11 and Figure 12, respectively). Following every day of testing, the Mk2 GT was thoroughly cleaned with pressured water, brushes, and scrapers. The chain drive was cleaned and oiled following repeated testing to ensure no external resistance occurred during testing.

Figure 11. Top side of muddy Mk2 GT post-test.

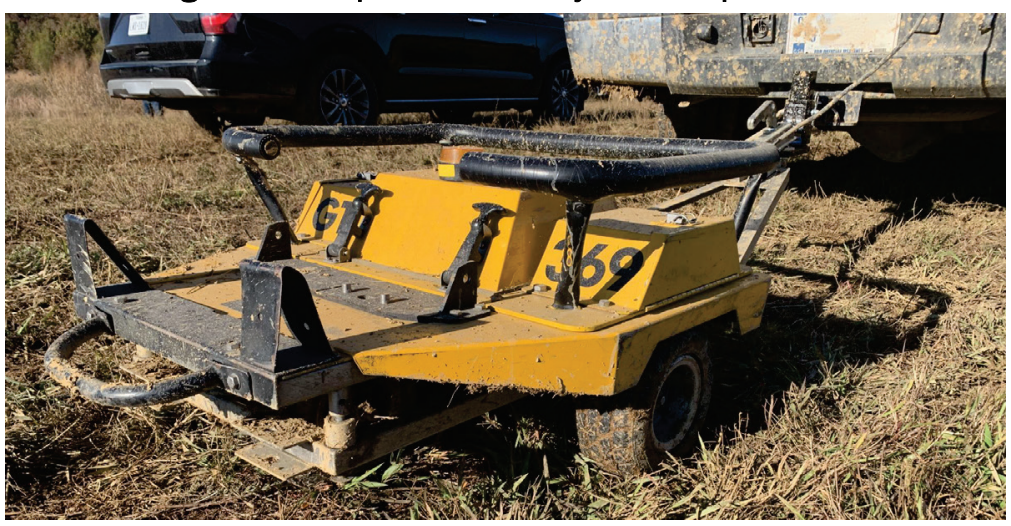

Figure 12. Underside of muddy Mk2 GT post-test.

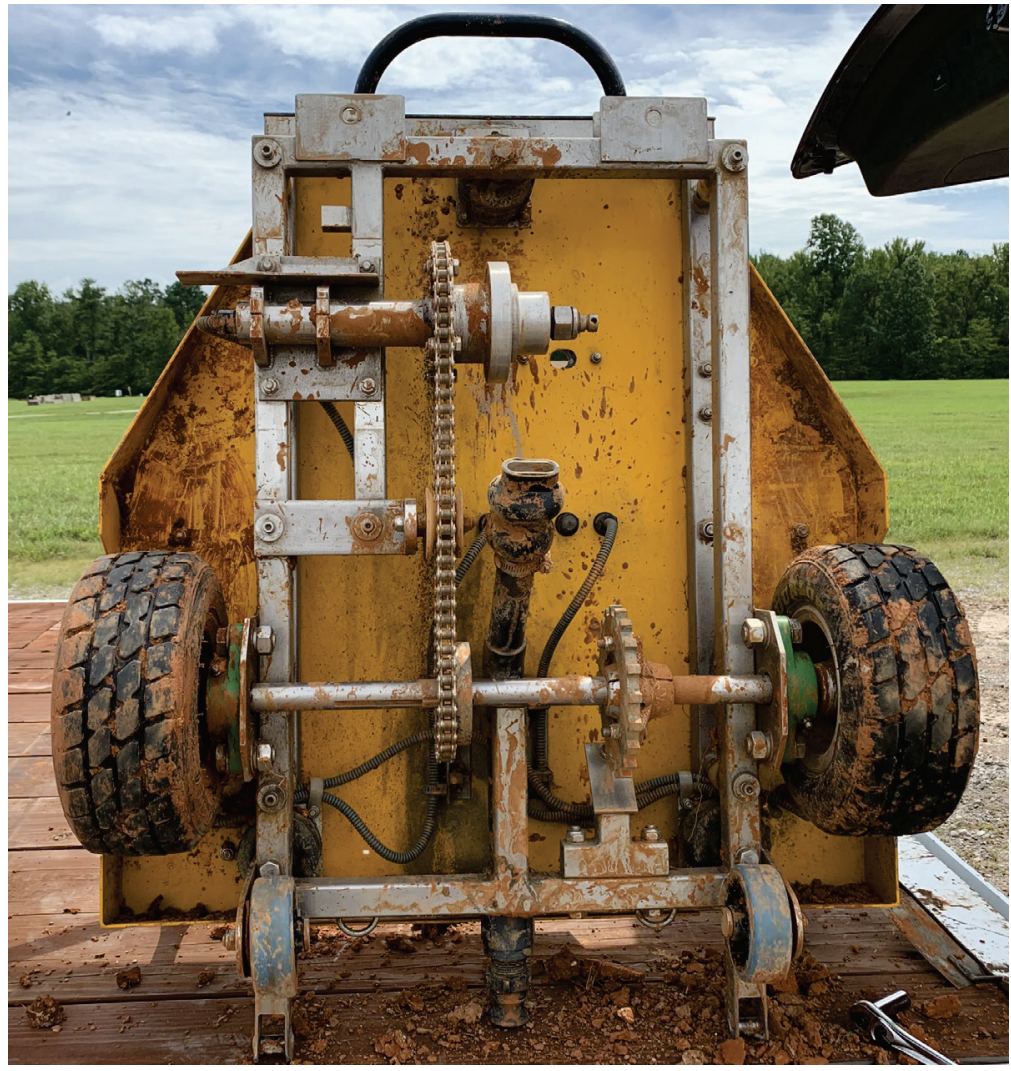




\subsection{Deceleration-based testing}

The deceleration-based data collection tools described here rely on the use of a three-axis accelerometer to measure changes in speed over time in three dimensions. It is proposed that these devices, when mounted securely to a ground vehicle, can provide a measure of surface friction through the act of braking heavily. This principle, as described in Section 2.2.2, has been in use for many decades. Details regarding the mounting and operation of each device are detailed in the following three sub-sections.

\subsubsection{Bowmonk AFM2 Mk3}

The Bowmonk AFM2 Mk3 (Bowmonk) is an industry standard deceleration-based friction measurement device (see Figure 13). It is operated by use of an internal computer and displays deceleration results on a small LCD screen or via a built-in dot matrix printer. The Bowmonk was used to validate the results from less-standard equipment such as the smartphones to be described below. Unlike smartphone accelerometers, the Bowmonk is designed for pavement deceleration measurements. This device employs a solid-state accelerometer (Bowmonk 2016) and has been shown to be highly accurate compared to other nonstandard equipment (Ward et al. 2019).

Figure 13. Bowmonk AFM2 Mk3 top-down view.

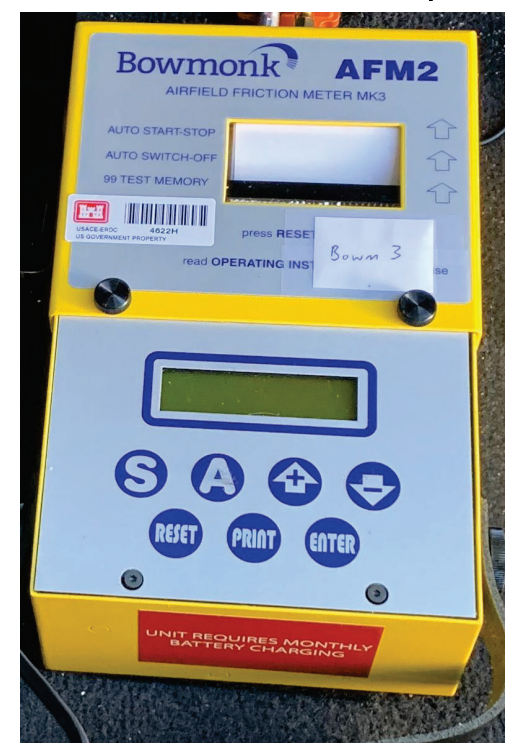

The standard mounting position of a Bowmonk is the passenger floorboard or some other flat, rigid surface within the ground vehicle. The device itself is affixed to the flat surface by use of hook-and-loop 
backing, such as Velcro. The front of the Bowmonk should be pointed towards the direction of travel of the ground vehicle. Vehicle-specific mounting details are described in Section 3.4.

At the beginning of a series of Bowmonk runs, a slope offset is calculated for the test surface. This offset allows the Bowmonk's internal computer to accurately filter the acceleration of gravity, $g$, from the linear acceleration data. The offset is calculated only once at the beginning of a series of runs and again only when a new test surface is utilized.

Following the slope offset calculation, Bowmonk data collection is manually started by the operator. Following a braking event, data collection is automatically stopped by the Bowmonk's internal computer. Peak deceleration readings are presented in units of $g$ with three significant figures. These readings are recorded on paper in terms of $\% g$.

The Bowmonk's internal battery allows for $12 \mathrm{hr}$ of continuous testing and printing without charging (Bowmonk 2016); however, poor seasoning and maintenance of the internal battery can require frequent charging. As a result, each device was equipped with a car charger for use during testing.

\subsubsection{Xsens MTi-G-710}

While the aforementioned Bowmonk is a standard measuring device for pavement surface friction, it is limited in its scope of capabilities. In comparison, a number of IMUs produced by the company Xsens provide similar accuracy in acceleration measurement at a lower or comparable cost with significantly higher flexibility in application. As such, a set of high-accuracy IMUs were acquired for the present effort to act as a standard, high accuracy, general purpose IMU, namely the Xsens MTi-G710 (Xsens IMU; see Figure 14). This IMU is small $(57 \times 42 \times 23.5 \mathrm{~mm})$ compared to the Bowmonk $(140 \times 220 \times 80 \mathrm{~mm})$ and also lighter $(55 \mathrm{~g}$ compared to $275 \mathrm{~g}$ for the Bowmonk). 
Figure 14. Xsens MTi-G-710 IMU top-down view.

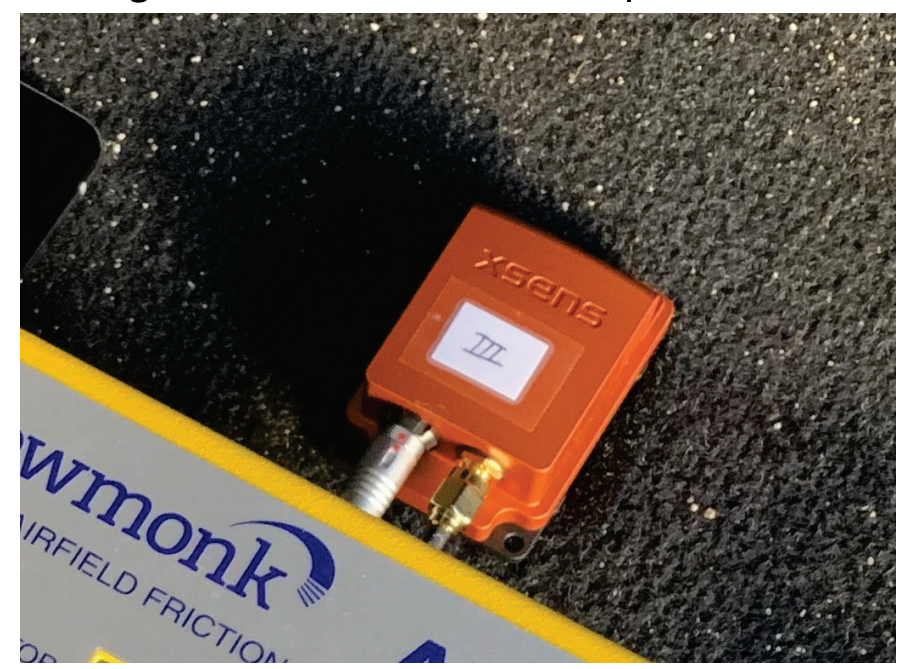

The Xsens IMU can be mounted in a variety of configurations inside or outside of a test vehicle. For the present effort, the Xsens IMU was mounted either in the passenger floorboard or on some other flat, rigid surface inside the vehicle (see Section 3.4). Unlike the Bowmonk, the Xsens IMU does not display deceleration results on a display or printout. Custom MATLAB software was developed, making use of an Xsens software development kit (SDK), to recover data from the Xsens IMU in real time. This software was installed on a Windows-based laptop computer that was also securely mounted to each test vehicle. Peak deceleration data are reported on the laptop screen in units of $\% g$. A unique feature of this particular Xsens IMU is that it utilizes global navigation satellite system (GNSS) technology to support navigation and stabilization output. While this output is not necessarily relevant to the acceleration data needed for the present effort, it does provide a useful tool for determining braking positions during testing.

Given the above considerations, two connections are necessary for operating the Xsens IMU: power/data and GNSS. Power and data are transmitted simultaneously through a proprietary connection at the sensor end (left-most connection in Figure 14) and a USB-A at the other. GNSS data are gathered through a small meter-accurate antenna mounted atop the testing vehicle and terminating, on the sensor end, in an SMA connector (right-most connection in Figure 14). 


\subsubsection{Smartphones}

Most modern smartphones are equipped with sufficient sensor technology to serve as deceleration-based friction assessment tools. That is, they generally are equipped with a three-axis accelerometer, gyroscope, and magnetometer. As part of a prior effort, Android (see Figure 15) and iOS (see Figure 16) software was developed in order to utilize smartphone sensor technology to develop surface friction assessment tools (Ward et al. 2019). The software developed for that effort was used during the present one as a method of measuring surface friction derived from ground vehicle deceleration.

Figure 15. ERDC DECEL Android app screenshots.
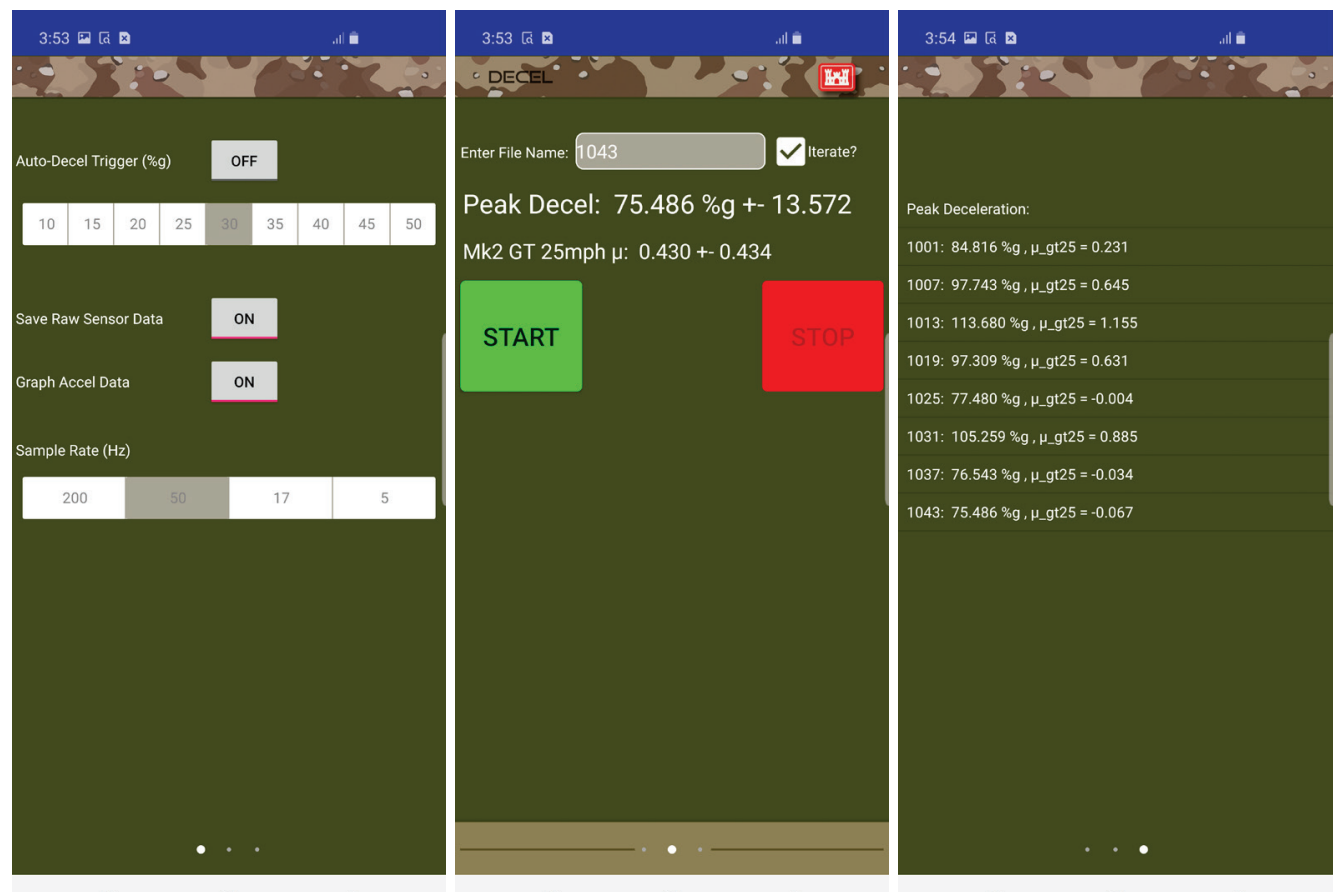

III

III

○

III

○ 
Figure 16. ERDC DECEL iOS app screenshots.
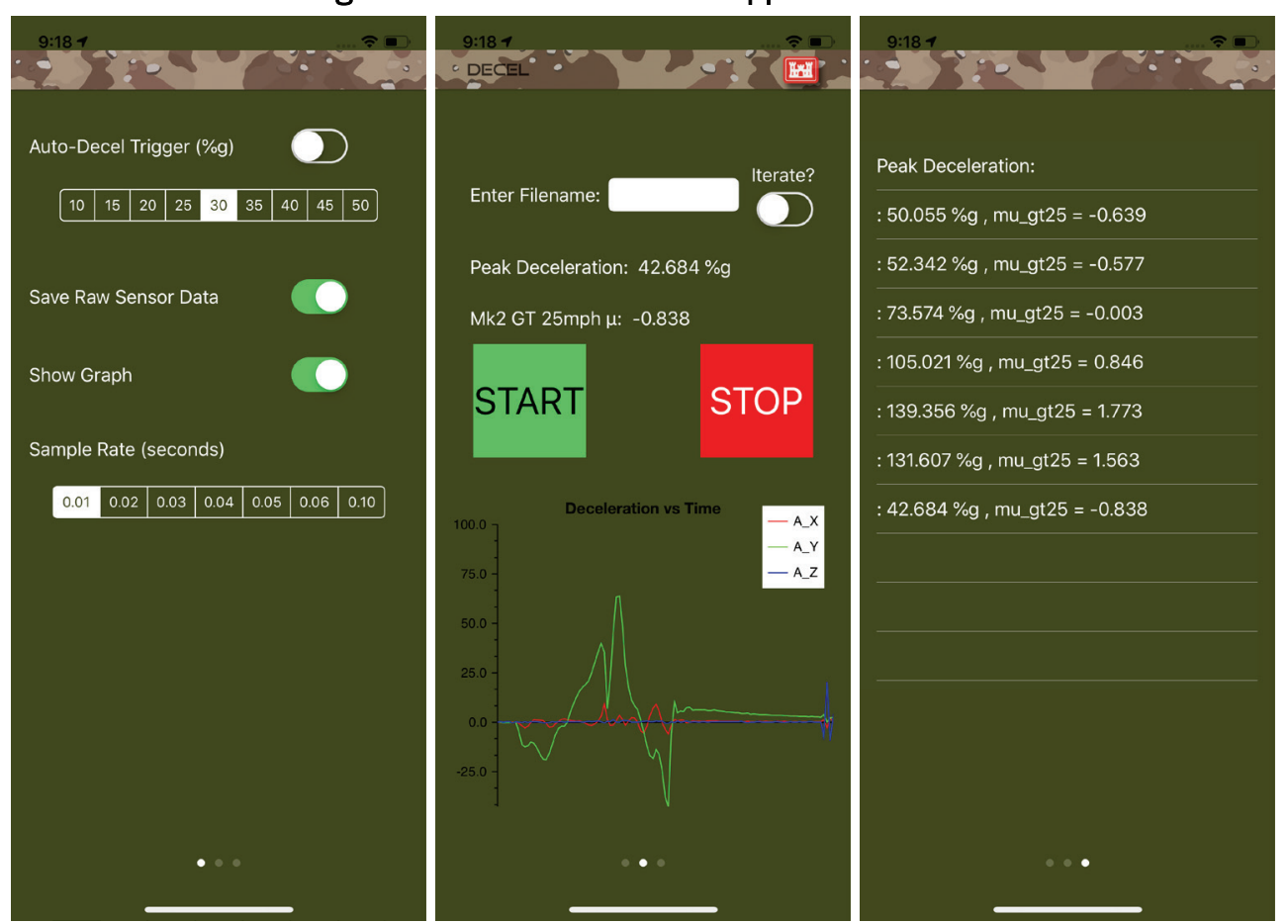

Four smartphones were tested during this effort (see Table 2). Unlike the aforementioned Bowmonk and Xsens IMU, the smartphones tested were not intended to serve as research or data collection tools and, thus, required meaningful repeatability testing.

Table 2. Smartphones used during brake testing.

\begin{tabular}{|l|l|l|l|}
\hline Phone Manuf. & Phone Model & \multicolumn{1}{c|}{ IMU Manuf. } & \multicolumn{1}{c|}{ IMU Model } \\
\hline LG & V20 & LGE,Bosch & LGE Custom \\
\hline Apple & iPhone 7 & Invensense & 773C \\
\hline Samsung & Galaxy S10 & STMicroelectronics & LSM6DSO \\
\hline Apple & iPhone 11 Pro & Unknown / Likely Bosch & $\begin{array}{l}\text { Unknown / Likely } \\
\text { BMI160 or BMI055 }\end{array}$ \\
\hline
\end{tabular}

Each smartphone was mounted to either the vehicle floorboard or some other flat, rigid surface inside the vehicle by use of hook-and-loop backing. Software onboard each smartphone required the user to input a run ID and to initiate run start. Data collection was automatically stopped at a user-defined value. Peak deceleration was displayed on the smartphone screen and also saved to the smartphone's internal storage. Data were transmitted, via USB, to a laptop computer for post-processing. 


\subsection{Ground vehicle configuration}

For this effort, three test vehicles were chosen that are likely to be available during actual semi-prepared runway operations: HMMWV (Humvee), a $1 / 2$-ton single cab pickup truck, and a full-size sport utility vehicle (SUV). All the selected test vehicles were capable of reaching the braking test speed of $25 \mathrm{mph}$ within a reasonable amount of time. Each vehicle presented its own unique mounting concerns. It should be noted that a standard configuration of the deceleration devices was maintained throughout all test vehicles (see Figure 17). While the placement of these devices within the vehicle changed based on spatial restrictions, this general scheme was maintained. Specific configuration details for each vehicle are described in the following three sub-sections.

Figure 17. Standard deceleration device configuration.

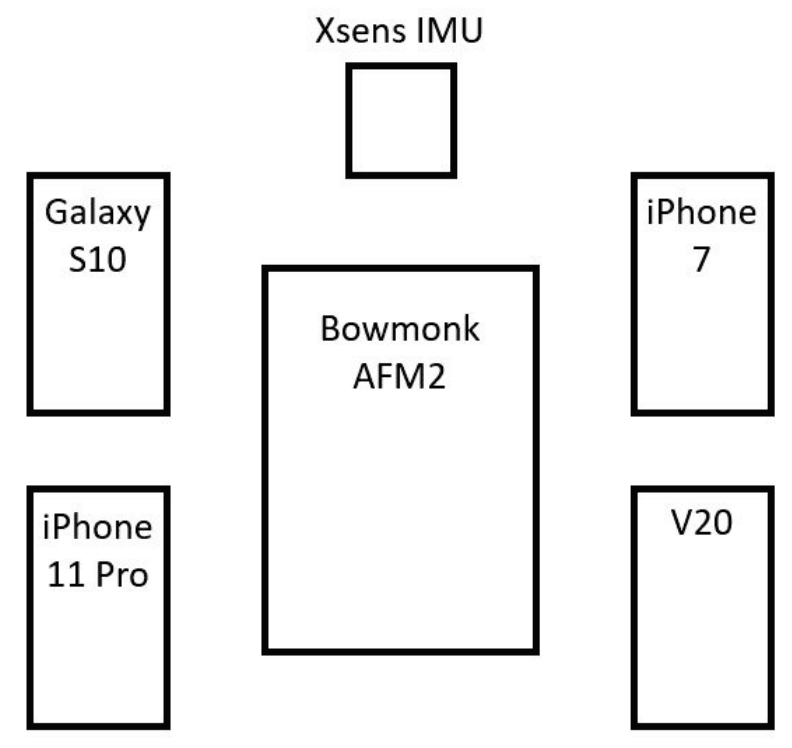

\subsubsection{HMMWV}

The HMMWV is a staple of light-armored, multi-purpose military vehicles. It is still used around the world today and is likely to be on or near many semi-prepared expeditionary airfields. It should be noted that the HMMWV is in the process of being replaced in favor of the more modern mine-resistant ambush protected (MRAP) vehicles and more recently the new joint light tactical vehicles (JLTVs). Two modern, up-armored HMMWVs were borrowed from the $412^{\text {th }}$ Theatre Engineer Command (TEC) in Vicksburg, MS. Specifically, the $412^{\text {th }}$ TEC loaned ERDC two M1165A1 HMMWVs (see Figure 18) for the purposes of SPRO testing. 
One vehicle was kept in reserve in the event that the first became inoperable. Other than minor electrical problems, the first HMMWV was used throughout testing and the second one was not utilized.

Figure 18. Two M1165A1 HMMWVs loaned by the $412^{\text {th }}$ TEC.

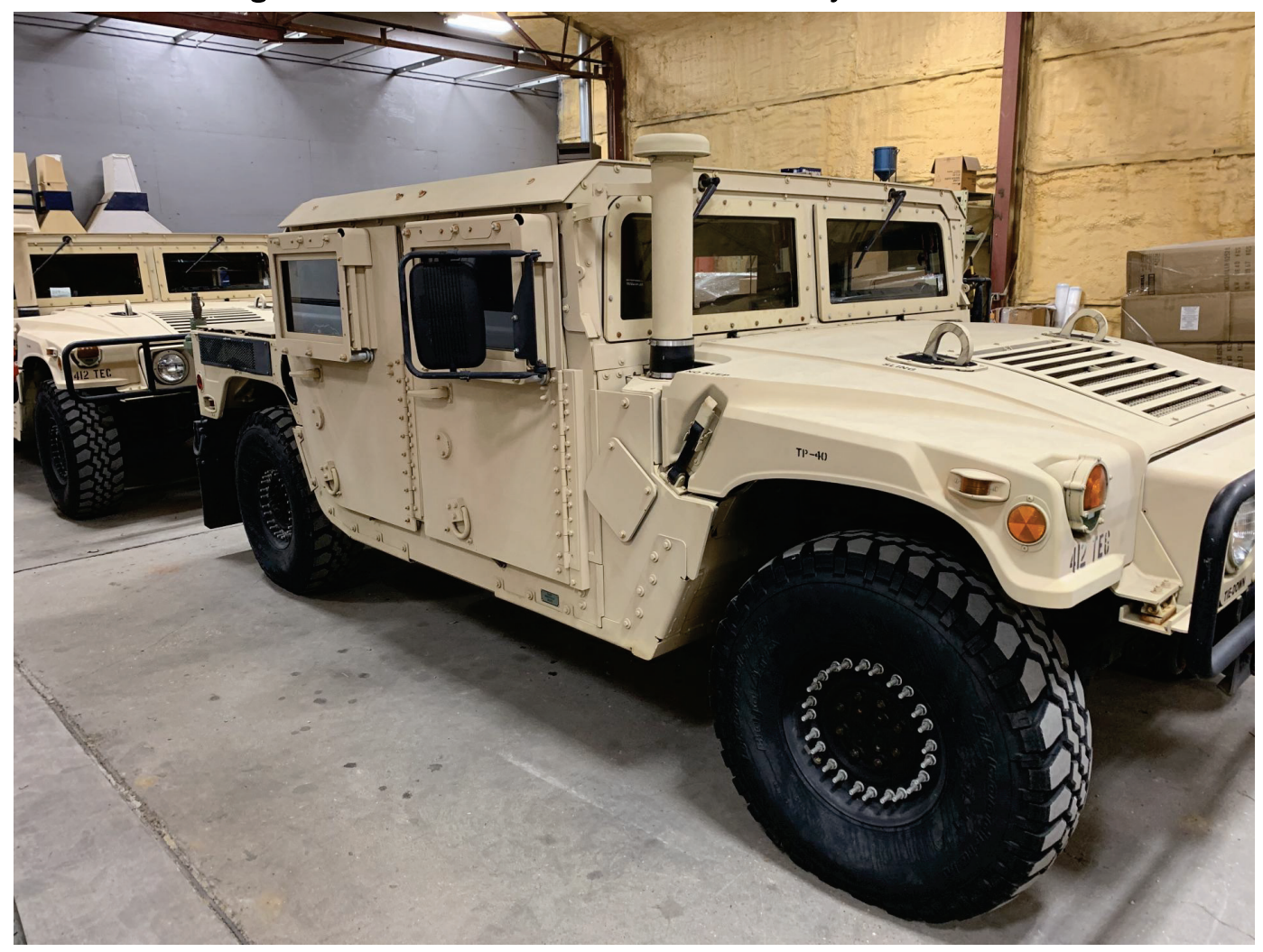

The passenger floorboard of the HMMWV was too small and inaccessible to mount all six deceleration-based devices. As such, these devices were fitted to the large center platform of the vehicle (see Figure 19). All devices were oriented such that they were pointing towards the direction of travel of the vehicle. In this configuration, readings of negative acceleration represented braking friction. 
Figure 19. HMMWV deceleration equipment mounting configuration.

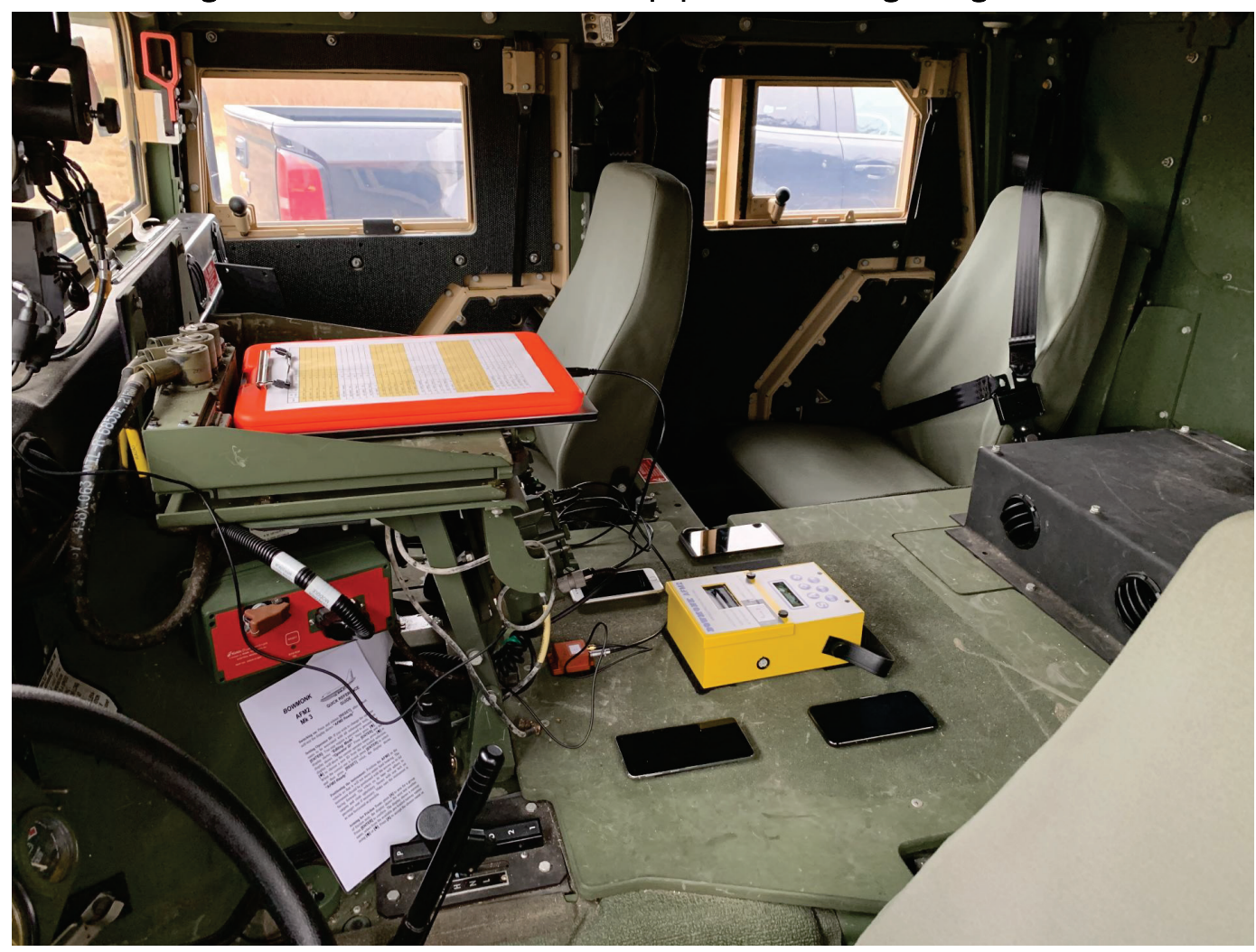

In order to support the GNSS functionality of the Xsens IMU, a GPS/GLONASS active patch antenna was attached by hook-and-loop backing to the outside of the HMMWV (see Figure 20). This antenna provided meteraccurate positioning data for all data collected by the Xsens IMU. A Windows-based laptop was used to operate the Xsens IMU. This laptop was held secure by a supporting technician in the rear passenger side seat. 
Figure 20. HMMWV GPS antenna mounting position.

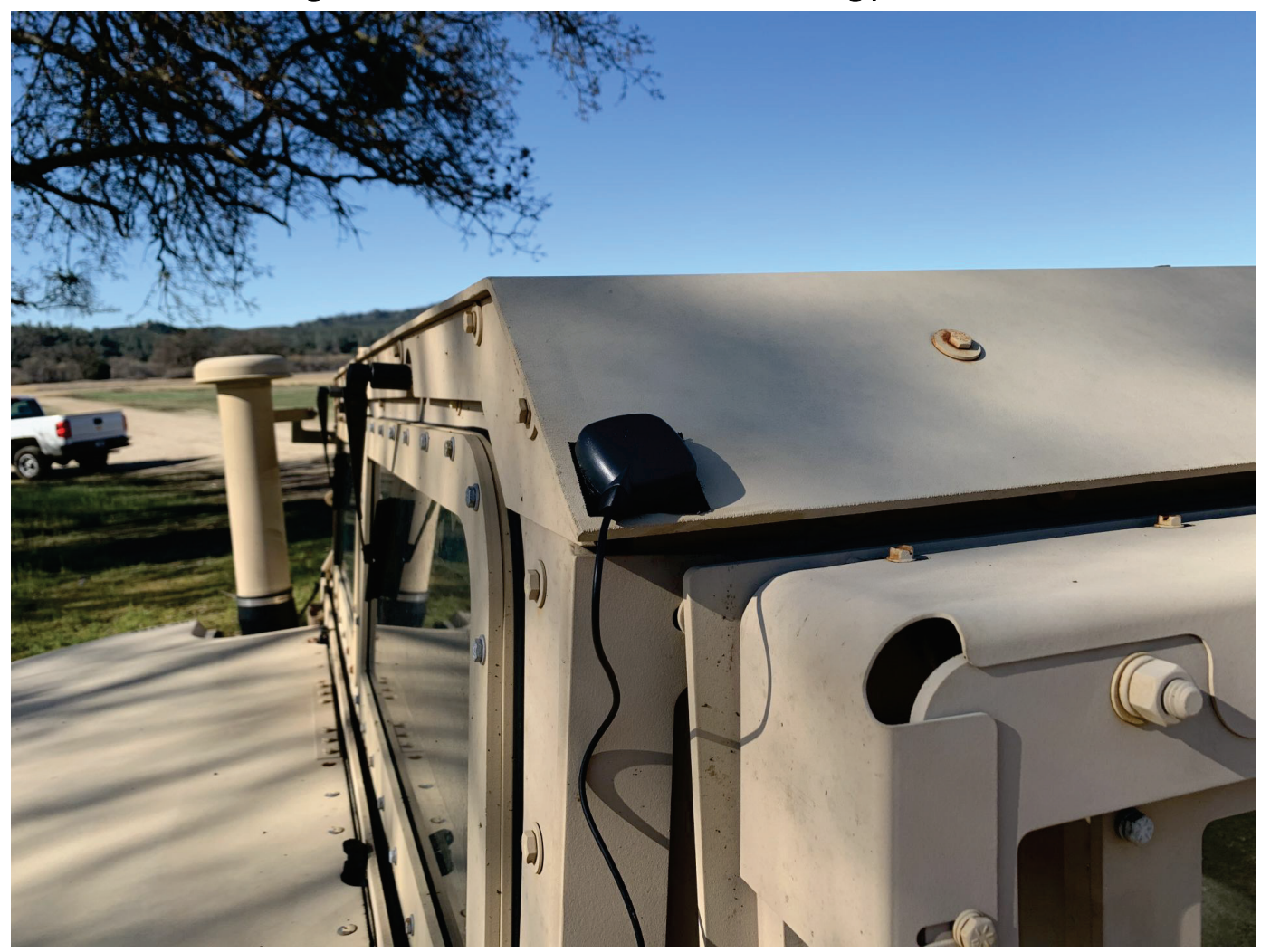

Finally, all HMMWV tires were maintained at the manufacturer recommended inflation pressures throughout the experiment as to eliminate them as an experimental control.

\subsubsection{Truck}

A 1/2-ton pickup truck is common on most airfields and otherwise around the world. For this effort, a branch general services administration (GSA) truck was used throughout testing: a 2017 Chevrolet Silverado 1500 4WD regular cab work truck (see Figure 21). 
Figure 21. 2017 Chevrolet Silverado 1500 4WD 1/2-ton pickup truck.

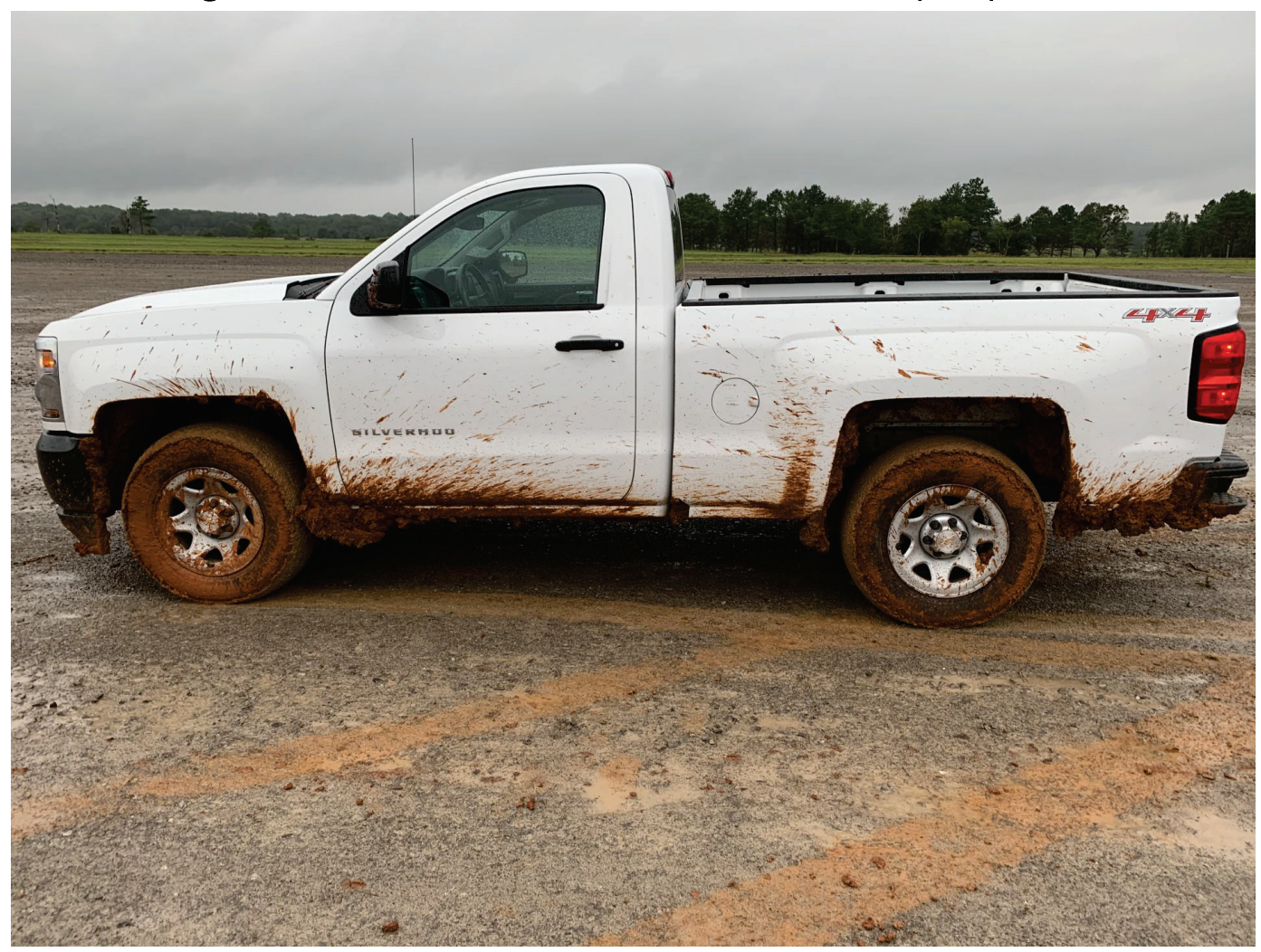

The 1/2-ton pickup truck tested had sufficient room in the passenger floorboard to mount all deceleration equipment (see Figure 22); however, it had little to no extra room for additional technician support in the vehicle. Therefore, only one operator was utilized for testing with the $1 / 2$ ton pickup truck. All devices were oriented such that they were pointing towards the direction of travel of the vehicle. In this configuration, readings of negative acceleration represented braking friction. 
Figure 22. Floorboard mounting configuration of $1 / 2$-ton truck deceleration equipment.

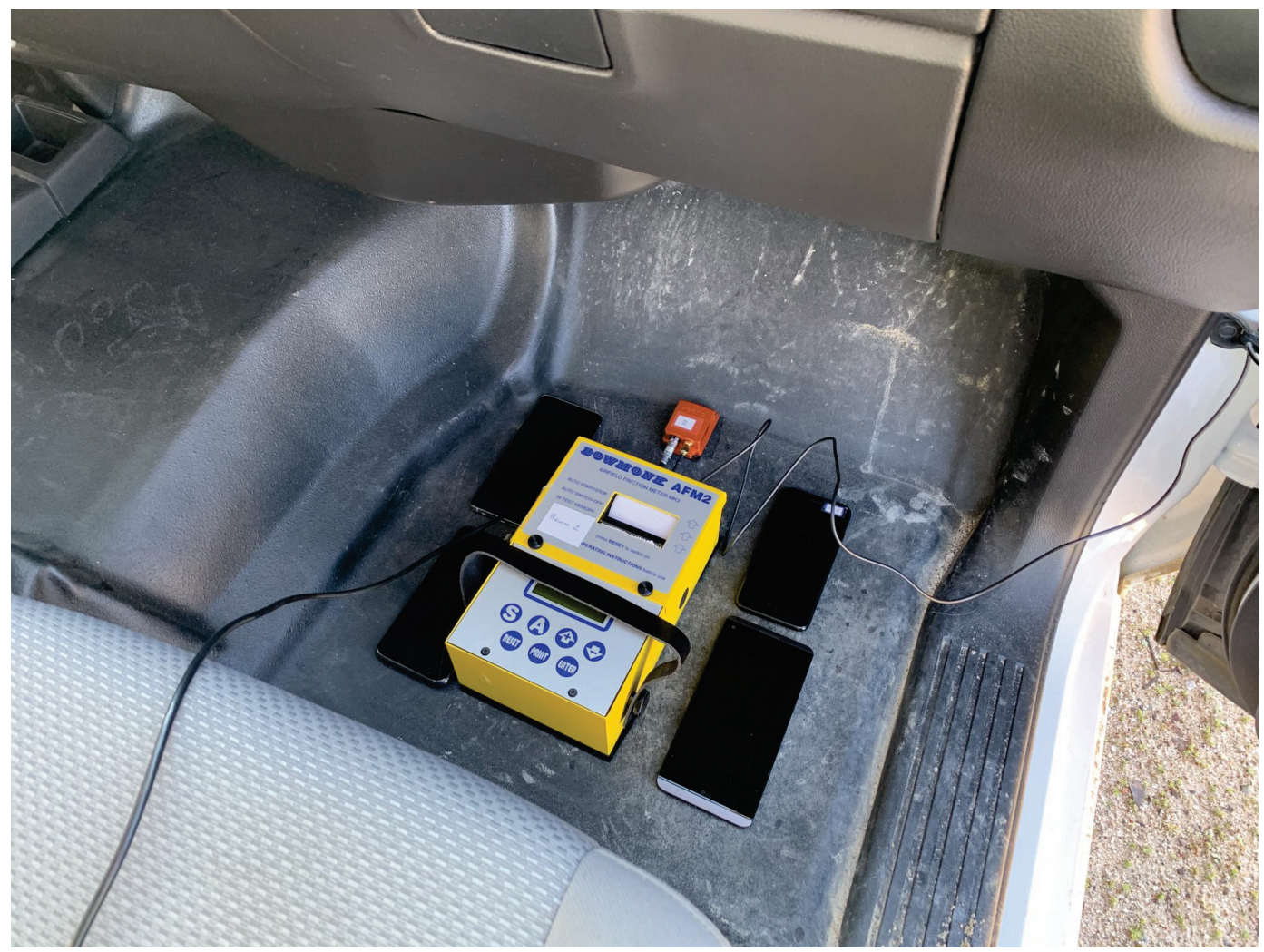

To support the GNSS functionality of the Xsens IMU, a GPS/GLONASS active patch antenna was attached by hook-and-loop backing just above the passenger door on the outside of the truck (see Figure 23).

Additionally, a Windows-based laptop was used to operate the Xsens IMU. As no additional supporting personnel could safely fit in this vehicle, the laptop was held in place by the driver on the center passenger seat.

Figure 23. Mounting position of $1 / 2$-ton truck antenna.

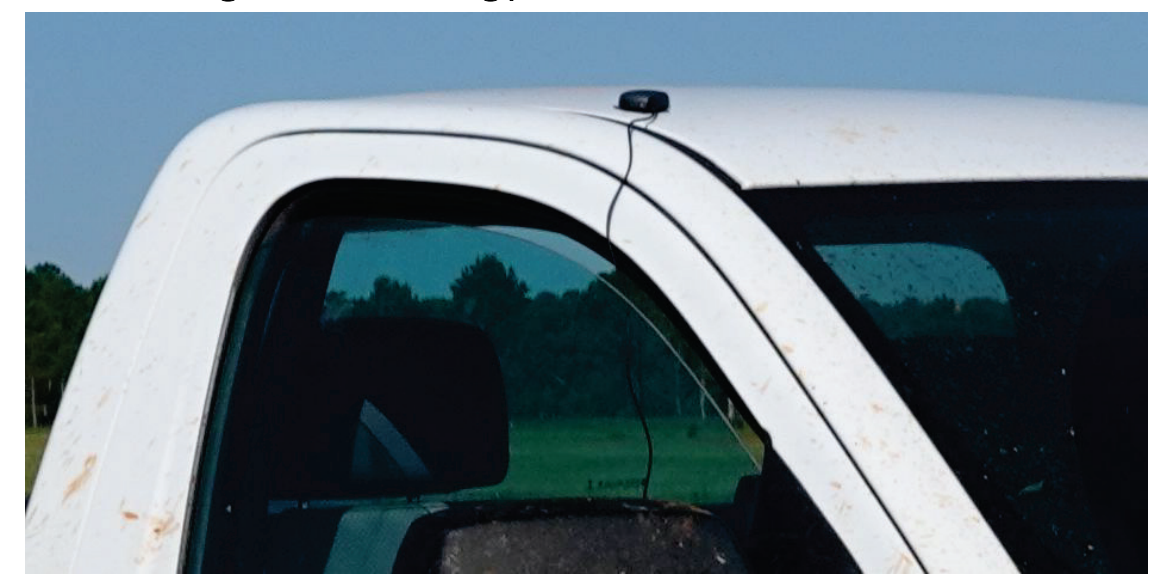


Finally, all truck tires were maintained at the manufacturer recommended inflation pressures throughout the experiment to eliminate them as an experimental control.

\subsubsection{SUV}

The third and final test vehicle selected for testing was the SUV. The SUV represented a large civilian vehicle that, while not common on airfields, was largely available around the world. Additionally, a different SUV was used at each testing site (three total). This occurred for two reasons: the inherent difficulty in maintaining the same rental vehicle over the course of a year of testing and the desire to estimate the effect of vehicle extrinsic properties as an experimental control. The first SUV, tested at Rattlesnake LZ, was a 2019 Ford Expedition 2WD (see Figure 24).

Figure 24. 2019 Ford Expedition SUV at Rattlesnake LZ.

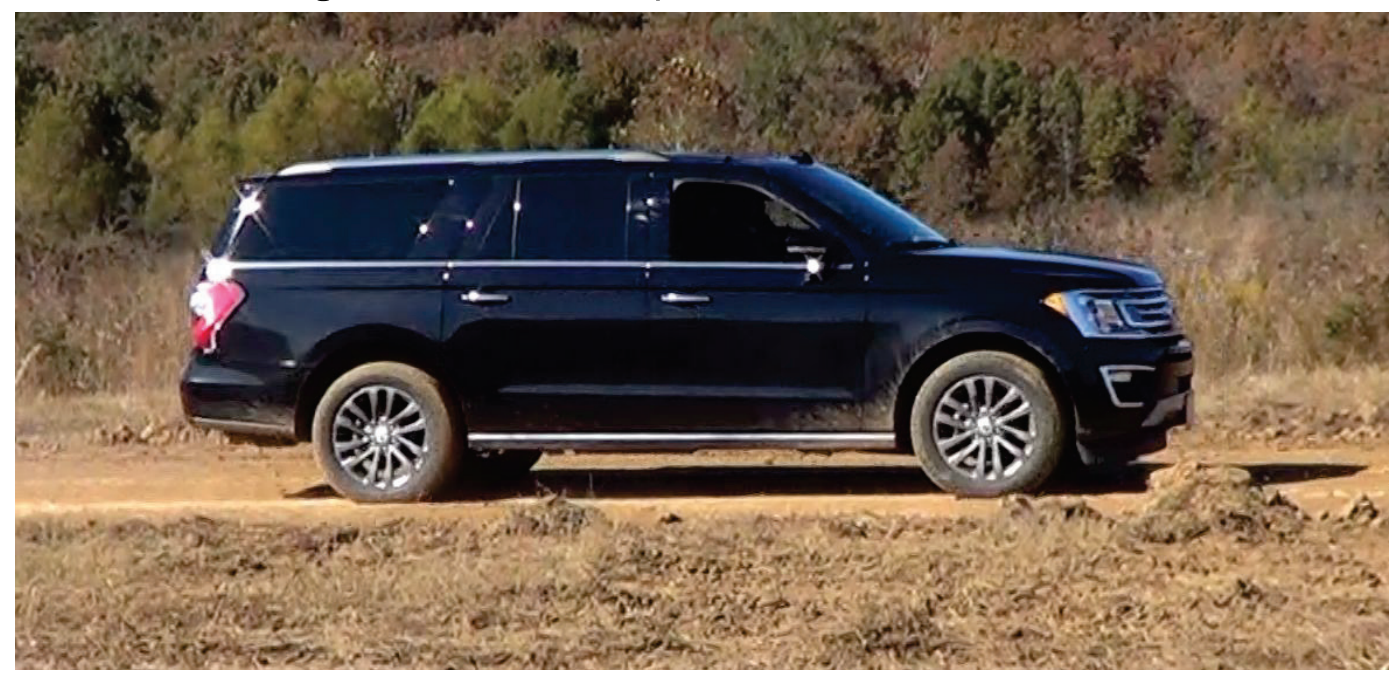

It was quickly learned that a large SUV without $4 \mathrm{WD}$ struggles in the muddy conditions typical on clay surfaces with high moisture content. Most tests were successful; however, the rear-wheel drive SUV had difficulty lining up for subsequent runs. The second SUV, tested at Schoonover LZ, was a 2019 Chevrolet Tahoe 2WD (see Figure 25). 
Figure 25. 2019 Chevrolet Tahoe SUV at Schoonover LZ.

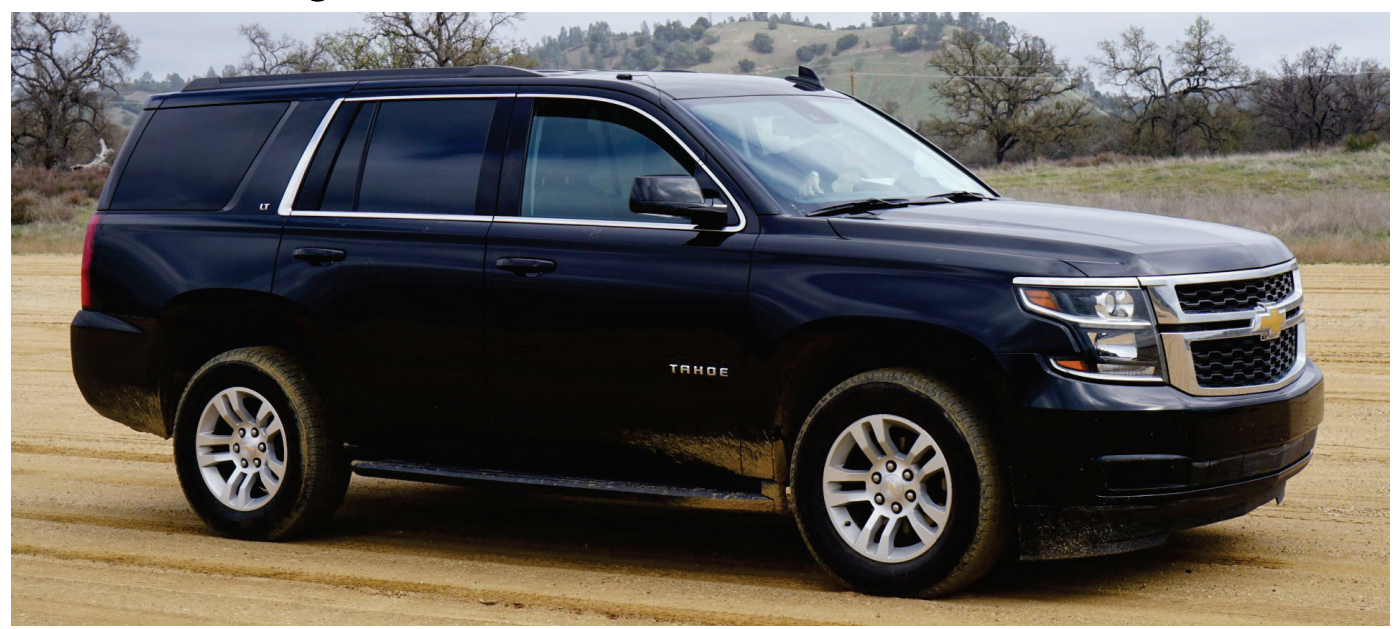

While this SUV was also rear-wheel drive, it navigated the sandy surface at Schoonover LZ without issue even at high moisture contents. The third SUV, tested at Golden Eagle LZ, was a 2019 Infiniti QX80 4WD (see Figure 26).

Figure 26. 2019 Infiniti QX80 SUV at Golden Eagle LZ.

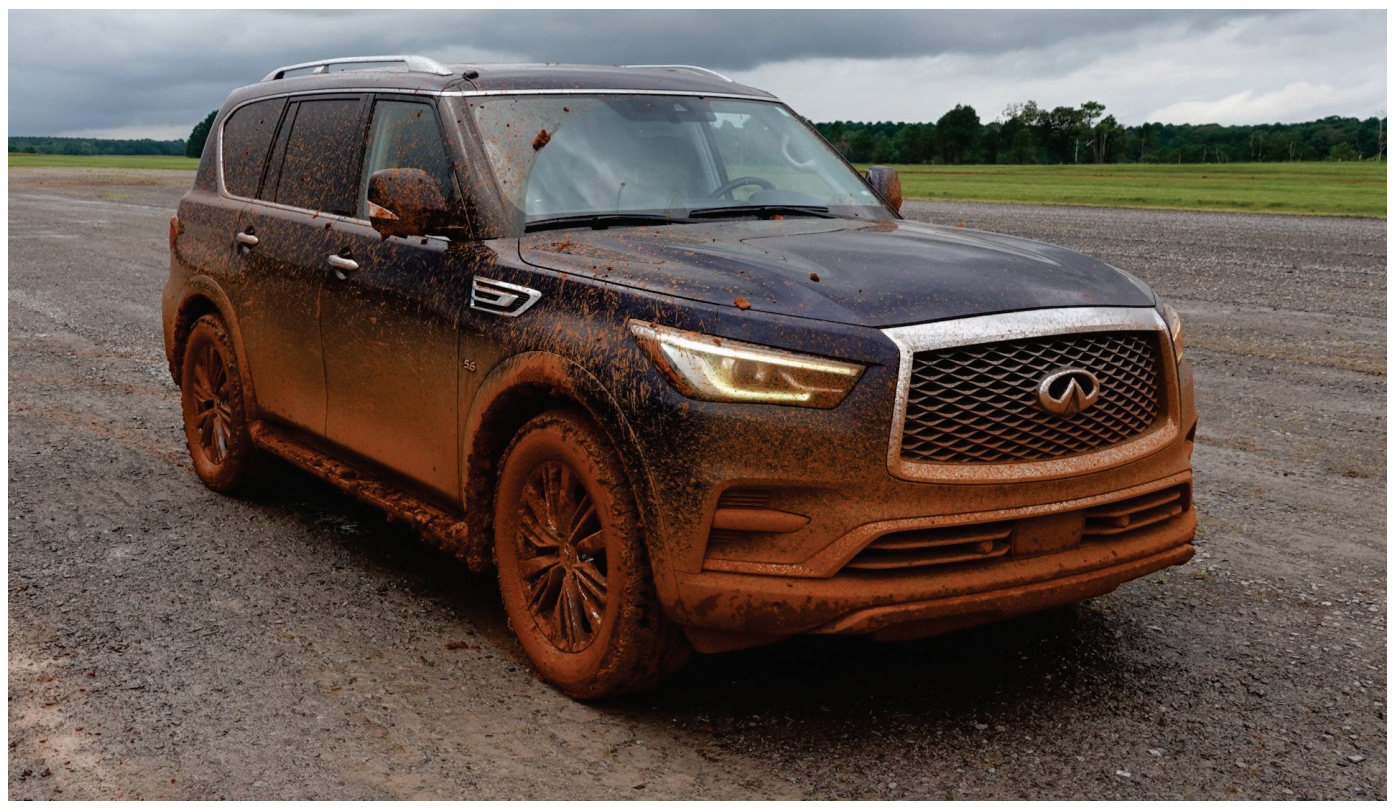

Based on findings from the earlier Rattlesnake LZ data collection, it was determined that a 4 WD SUV would be necessary to effectively navigate the muddy clay present at Golden Eagle LZ. The Infiniti QX8o handled the muddy clay surface well and had no issue managing multiple brake tests.

Each of the three SUVs had sufficient room in the passenger floorboard to mount all deceleration equipment. An example of this mounting 
configuration, achieved with hook-and-loop backing, for the Rattlesnake LZ data collection can be seen in Figure 27.

Figure 27. SUV deceleration equipment floorboard mounting configuration.

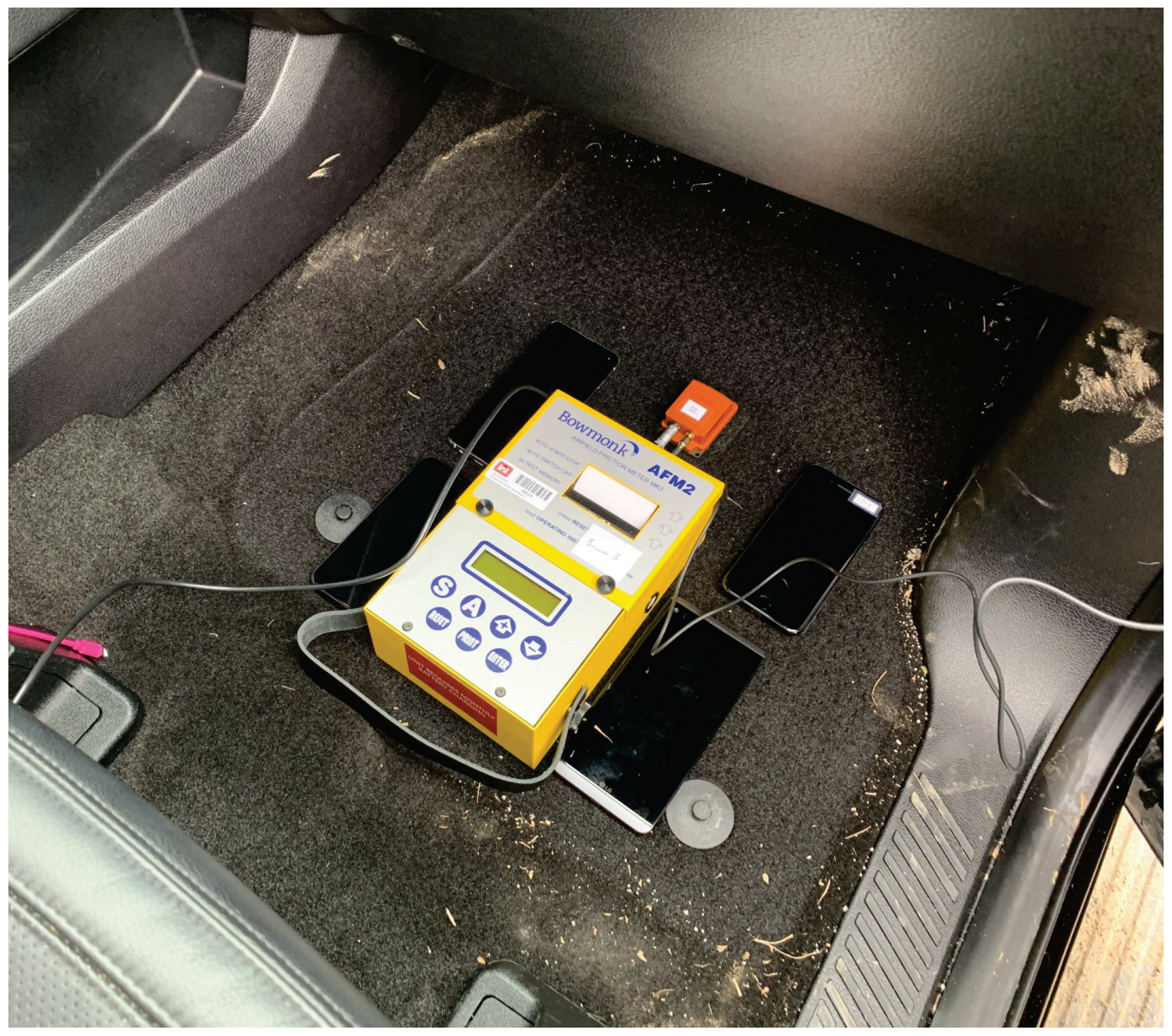

Each SUV also had sufficient room for supporting personnel. A supporting technician was seated in the rear passenger cabin behind the front passenger seat. The supporting technician operated and secured the Windows-based laptop necessary for Xsens operation during testing. All devices were oriented such that they were pointing towards the direction of travel of the vehicle. In this configuration, readings of negative acceleration represented braking friction. Furthermore, to support the GNSS functionality of the Xsens IMU, a GPS/GLONASS active patch antenna was attached, by hook-and-loop backing, just above the passenger door on the outside of each SUV (see Figure 28). 
Figure 28. SUV antenna mounting position.

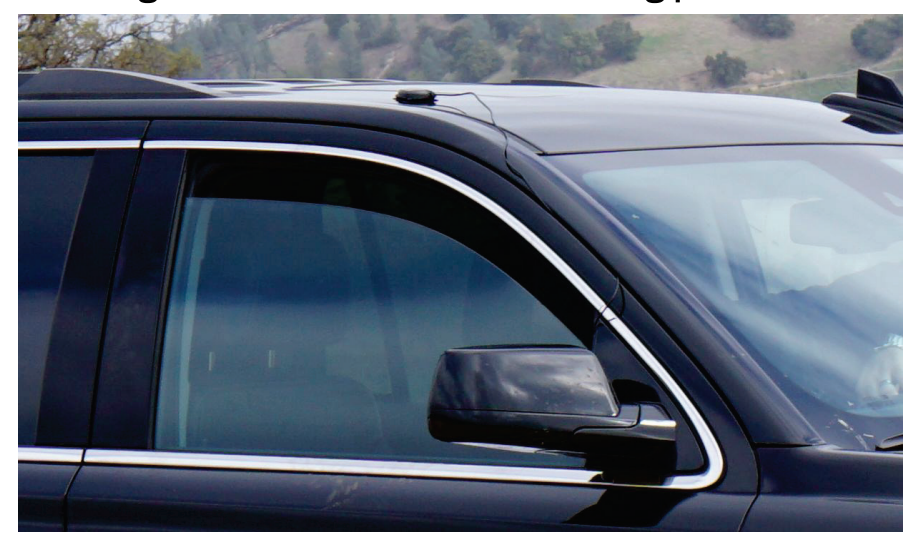

Finally, all SUV tires were maintained at the manufacturer recommended inflation pressures throughout the experiment to eliminate them as an experimental control.

\subsection{Soil testing and classification}

Various soil test methods were utilized at each test site in order to better understand and characterize the site's unique soil properties. These soil properties contribute to the runway surface's friction response and are therefore of considerable interest to this effort. Test procedures for each soil test utilized are described below.

\subsubsection{Standard soil classification}

Before proceeding to the specific soil classification techniques below, it is important to first describe the way in which these soils will be defined and classified on a broad scale. Broad soil classification, for engineering purposes, is done by separating different soil types into classes or groups based on engineering properties such as grain size distribution, liquid limit, or plastic limit (Zakikhani et al. 2017).

The present effort relied on the Unified Soil Classification System (USCS) for such classification (ASTM 2017a). The USCS divides soil types by use of a two-letter descriptor (see Table 3). It should be noted that, based on certain criteria enumerated in ASTM D2487-17 (2017a), some groups require dual symbols. For the sake of brevity, those will be excluded here. 
Table 3. USCS soil classification chart.

\begin{tabular}{|c|c|c|}
\hline $\begin{array}{c}\text { Group } \\
\text { Symbol }\end{array}$ & Group Name & Laboratory Classification \\
\hline GW & Well-graded gravel & \multirow{2}{*}{$\begin{array}{l}\text { Clean Gravels } \\
\text { (Less than 5\% fines) }\end{array}$} \\
\hline GP & Poorly graded gravel & \\
\hline GM & Silty gravel & \multirow{2}{*}{$\begin{array}{l}\text { Gravels with Fines } \\
\text { (More than } 12 \% \text { fines) }\end{array}$} \\
\hline $\mathrm{GC}$ & Clayey gravel & \\
\hline SW & Well-graded sand & \multirow{2}{*}{$\begin{array}{l}\text { Clean Sands } \\
\text { (Less than 5\% fines) }\end{array}$} \\
\hline SP & Poorly graded sand & \\
\hline SM & Silty sand & \multirow{2}{*}{$\begin{array}{l}\text { Sands with Fines } \\
\text { (More than } 12 \% \text { fines) }\end{array}$} \\
\hline SC & Clayey sand & \\
\hline $\mathrm{CL}$ & Lean clay & \multirow{2}{*}{$\begin{array}{l}\text { Inorganic } \\
\text { (Liquid limit less than 50) }\end{array}$} \\
\hline$M L$ & Silt & \\
\hline $\mathrm{OL}$ & $\begin{array}{l}\text { Organic } \\
\text { clay/Organic silt }\end{array}$ & $\begin{array}{l}\text { Organic } \\
\text { (Liquid limit less than 50) }\end{array}$ \\
\hline $\mathrm{CH}$ & Fat clay & \multirow{2}{*}{$\begin{array}{l}\text { Inorganic } \\
\text { (Liquid limit } 50 \text { or more) }\end{array}$} \\
\hline $\mathrm{MH}$ & Elastic clay & \\
\hline $\mathrm{OH}$ & $\begin{array}{l}\text { Organic } \\
\text { clay/Organic silt }\end{array}$ & $\begin{array}{l}\text { Organic } \\
\text { (Liquid limit } 50 \text { or more) }\end{array}$ \\
\hline PT & Peat & -- \\
\hline
\end{tabular}

\subsubsection{Dynamic cone penetrometer}

A dual-mass dynamic cone penetrometer (DCP) was used to obtain the in-situ strength of each soil structure. In general, the DCP tests consisted of a uniform weight being dropped along a metal shaft, which had a small penetrating cone at its end. The number of uniform applications of the dropped weight and the penetration depth of the cone yielded surface and subsurface soil properties. The penetrating cone was constructed of steel, and the uniform weight was either 10.1 or 17.6 lb. For this effort, only the 17.6-lb hammer was utilized. Generally, a DCP consists of seven components (see Figure 29). 
Figure 29. Generic DCP component diagram.

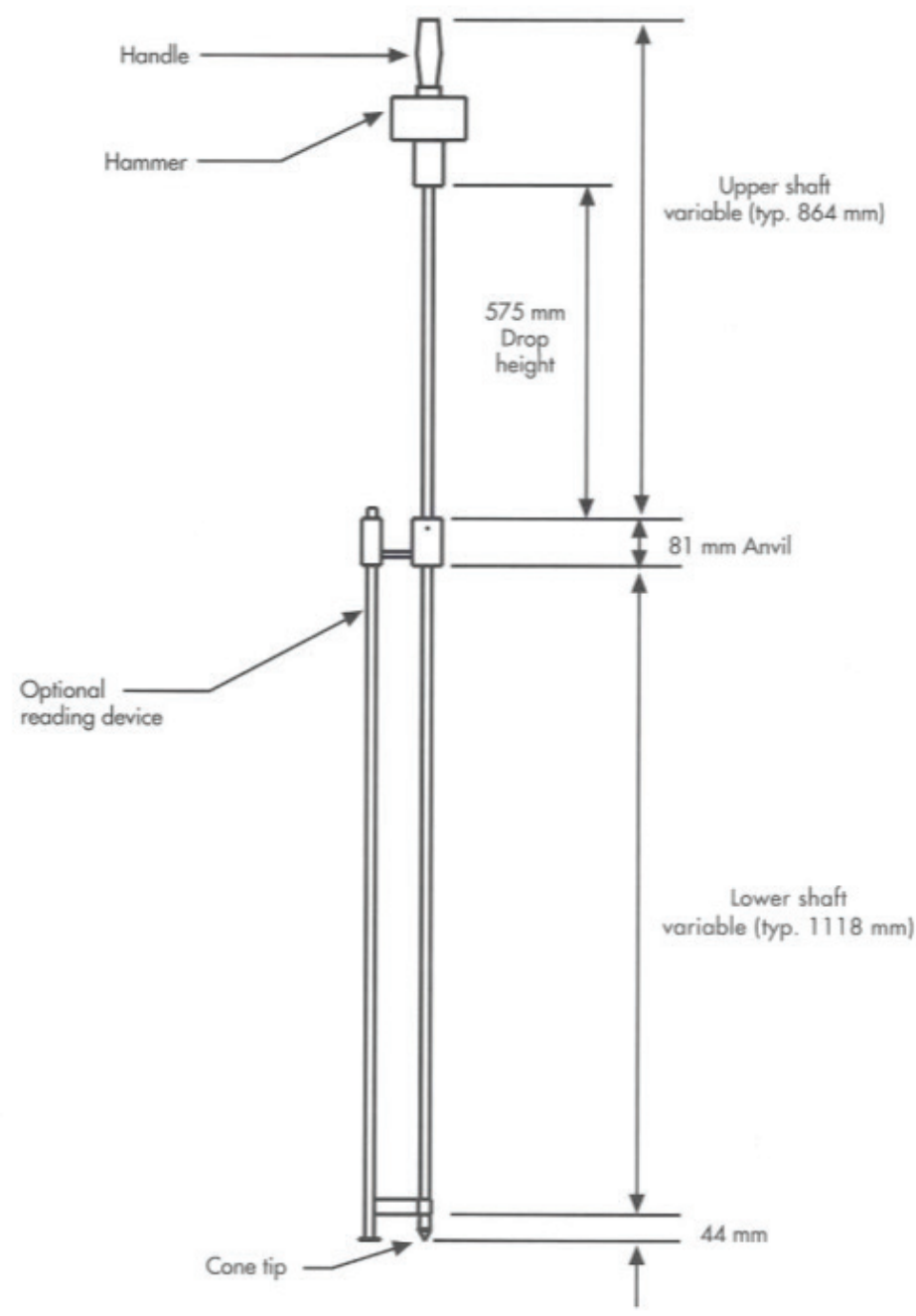

The bulk of the DCP itself consists of a metal upper and lower shaft (often separable) that acts as a falling guide for the uniform weight, known as a hammer. At the top of the metal shaft is a handle for added stability and user safety during testing. Between the upper and lower shafts is a metal anvil that acts as a stopping mechanism for the hammer. At the bottom of the lower shaft is a steel cone that penetrates the soil structure. The penetrating cone is typically left in the soil when the DCP is removed following a test. Finally, there is an optional ruler along the lower shaft that is used to measure penetration depth.

During this effort, penetration depth measurements were taken approximately every $1 \mathrm{in}$. as the material allowed. The number of successive hammer drops between measurements was adjusted to maintain a consistent penetration rate. The test soil's resistance to penetration was 
recorded as millimeters penetrated per hammer blow. Three personnel were used to conduct each DCP experiment: one to document results, one to measure penetration depth, and one to lift and release the hammer (see Figure 30). As the lifting task quickly induced fatigue, that position was shared among all personnel evenly throughout the evaluation.

Figure 30. DCP test being performed at Rattlesnake LZ, Fort Chaffee, AR.

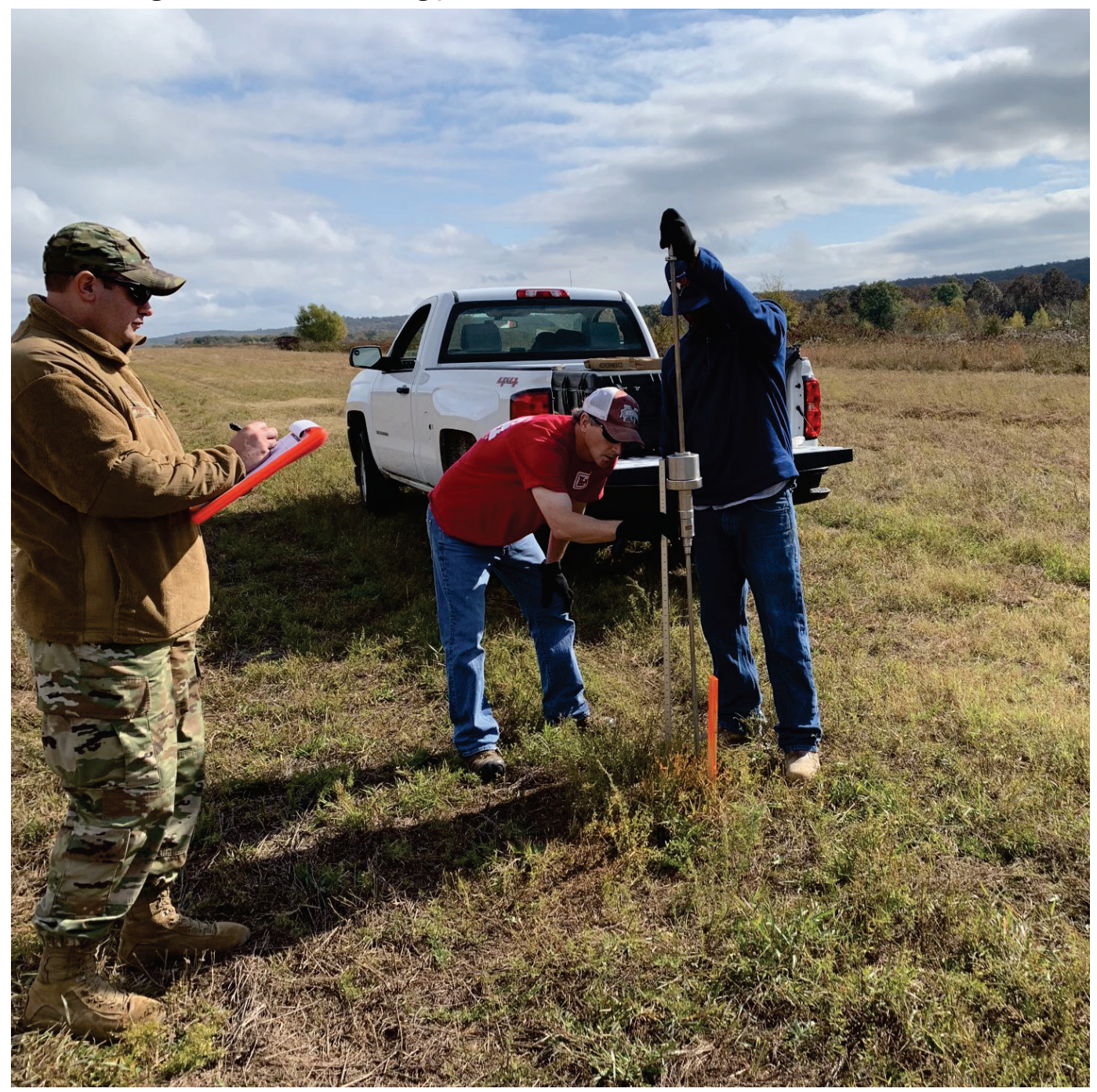

\subsubsection{Soil moisture content}

Soil samples were collected from the surface of each test site in order to determine average moisture content prior to data collection. A number of test methods are available to perform such a task; however, the microwave oven-heating technique was implemented during this study (ASTM 2017b). In general, this test is performed by collecting a small sample of soil and iteratively drying it until the weight change is approximately 
constant. This process begins by weighing the specimen container prior to soil collection. This value is colloquially known as the tare weight. Once the tare weight is documented, the soil specimen is collected and immediately placed into the container, sealed, and weighed.

The sealed specimen container is placed in a microwave oven for $3 \mathrm{~min}$. Once the first drying process is complete, the specimen container is removed and weighed. Following the first drying cycle, a measure of percent weight change is made (see Equation 19). The drying process is continued in 1-min intervals until the percent weight change is $1 \%$ or less. Once this condition is met, a measure of moisture content percentage is made (see Equation 20).

$$
\begin{gathered}
m_{\%}=100 \times \frac{\left(m_{i-1}-m_{i}\right)}{m_{i-1}} \\
w=100 \times \frac{\left(m_{0}-m_{i}\right)}{m_{i}}
\end{gathered}
$$

where $m_{\%}$ is the percent mass change between successive drying cycles, $m_{i-1}$ is the previous dry mass,

$m_{i}$ is the current dry mass,

$m_{0}$ is the pre-dried mass, and

$w$ is the moisture content.

\subsubsection{Atterberg limits}

The Atterberg limits are a series of delineating limits based on the moisture content of fine-grained soil. They include the shrinkage limit (SL), plastic limit (PL), and liquid limit (LL). As a dry, fine-grained soil takes on increasing amounts of water, it undergoes distinct changes in behavior and consistency entering four basic states: solid, semisolid, plastic, and liquid (Das 2010). The limits described above define the barriers between these basic states (see Figure 31). 
Figure 31. Graphical representation of the Atterberg limits (Das 2010).

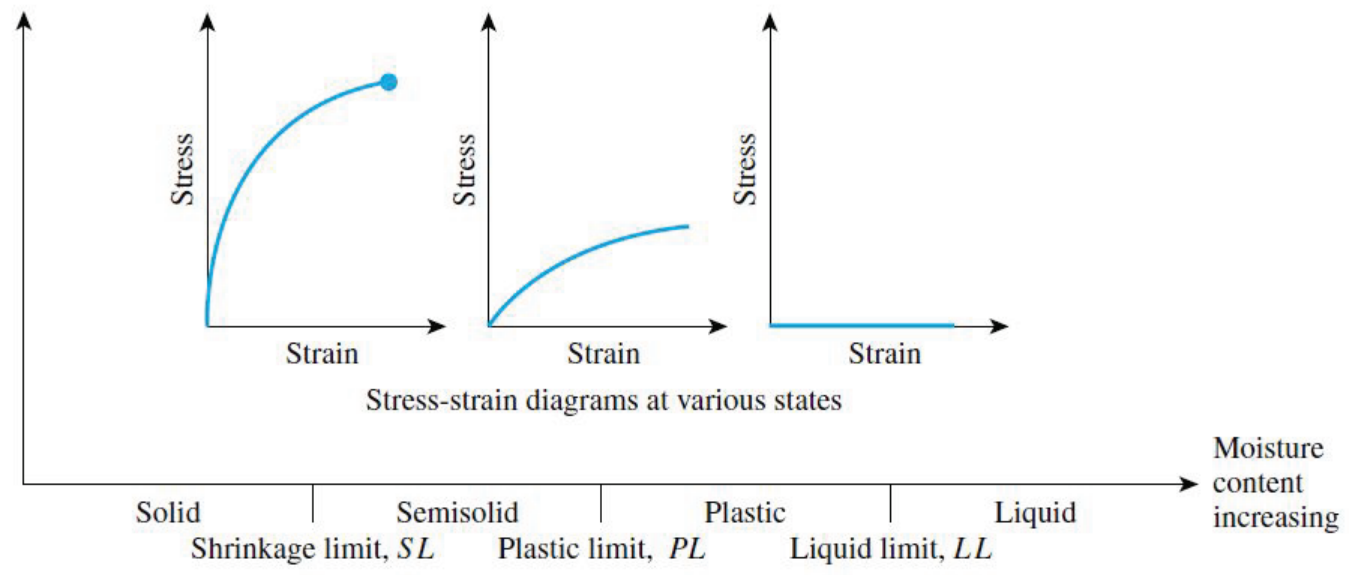

Of particular interest to the present study are the plastic and liquid limits and their difference, the plasticity index. These values, along with gradation testing, help to classify the soil present at the various SPRO test sites accurately. General test procedures for each are described in the following subsections.

\subsubsection{Liquid Limit (LL)}

First of the Atterberg limits is the liquid limit (LL). The LL, in general, represents the water content, as a percentage, of a soil between its semiliquid and plastic states. Standard test methods for conducting a liquid limit test are enumerated in ASTM D4318-17 (ASTM 2017c).

\subsubsection{Plastic Limit (PL)}

Second of the Atterberg limits is the plastic limit (PL). The PL, in general, represents the water content, as a percentage, of a soil between its plastic and semi-solid states. Standard test methods for conducting a plastic limit test are enumerated in ASTM D4318-17 (ASTM 2017c).

\subsubsection{Plasticity Index (PI)}

The plasticity index is based on the aforementioned liquid and plastic Atterberg limits. Theoretically, the PI represents the change in water content as a soil begins and ends to act plastically. Empirically, the PI is the difference between the liquid limit and the plastic limit. Standard methods for the calculation of the PI are enumerated in ASTM D4318-17 (ASTM 2017c). 


\subsubsection{Soil gradation}

The aforementioned Atterberg limits reveal the liquid and plastic properties of a material but do not indicate the breakdown of coarse and fine particles in the material. To better understand the breakdown of particle size in a soil sample, gradation and hydrometer studies are conducted.

Gradation testing details the breakdown of fine and coarse particles in a soil sample. In this type of testing, the barriers between gravels and sands are determined by how many particles are finer or coarser than the No. 4 sieve $(4.76 \mathrm{~mm})$. If $50 \%$ or more of particles are finer than the No. 4 sieve, then the soil is classified as a sand; and if more than $50 \%$ of particles are coarser than the No. 4 sieve, then the soil is classified as a gravel.

Another delineating measure for soils is the No. 200 sieve $(0.075 \mathrm{~mm})$. If $50 \%$ or more of a soil sample is finer than the No. 200 sieve, then the soil is classified as a fine-grained soil (also called fines), which is broken into two categories: silts and clays. Standard methods for determining a soil's particle distribution down to the No. 200 sieve are detailed in ASTM D6913/D6913M-17 (ASTM 2017d). In order to test a material at delineations smaller than the No. 200 sieve, hydrometer tests are conducted. A hydrometer test reveals the breakdown of a fine-grained soil into silts and clays. Standard methods for conducting hydrometer studies are detailed in ASTM D7928-17 (ASTM 2017e). The specific breakdown used in this study between silts and clays is $0.005 \mathrm{~mm}$. That is, fines greater than $0.005 \mathrm{~mm}$ are classified as silts, and those less than $0.005 \mathrm{~mm}$ are classified as clays. 


\section{Site Preparation}

Each of the three SPRO test sites was prepared with heavy equipment prior to any brake testing. Furthermore, every SPRO site required unique site preparation, the specifics for each of which are provided below.

\subsection{Rattlesnake Landing Zone}

Rattlesnake Landing Zone (Rattlesnake LZ) is located approximately 15 miles southwest of Headquarters, Fort Chaffee Joint Maneuver Training Facility (FCJMTF). The Rattlesnake LZ main runway is approximately 6,000 ft long and $90 \mathrm{ft}$ wide. The $\mathrm{LZ}$ is located near Washburn, $\mathrm{AR}$, and is accessed from McCartney Camp Road off of Highway AR 10 East (see Figure 32).

Figure 32. Directions to Rattlesnake $L Z$ from Highway AR 10 East.

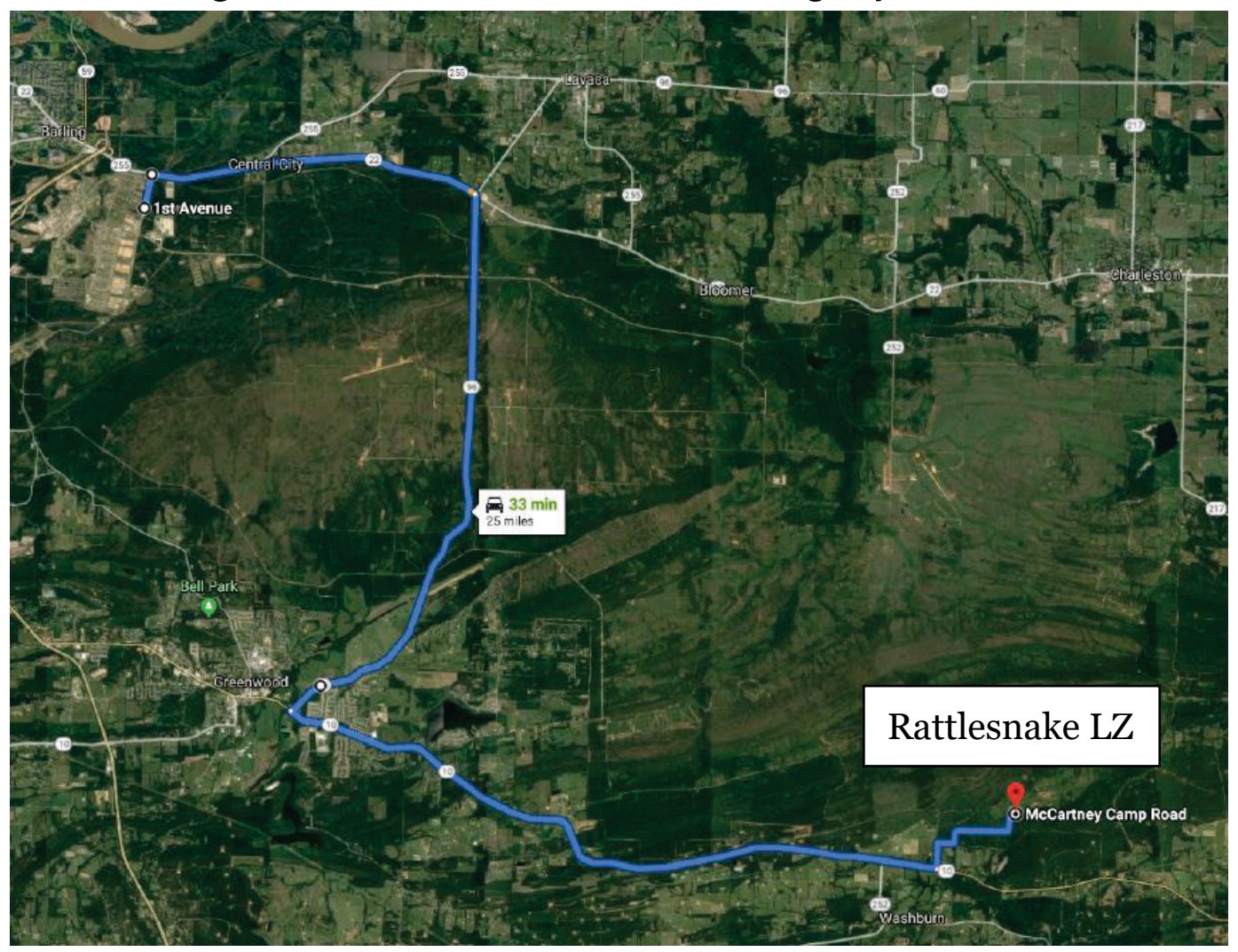

\subsubsection{Original condition}

The road leading into Rattlesnake LZ, McCartney Camp Road, was made of dirt and aggregate with significant rutting and low-severity washouts. 
The main runway on Rattlesnake LZ was completely covered in vegetation (see Figure 33). The vegetation was grown up to approximately 3-4 ft and made up primarily of lespedeza weeds. Prior to the main SPRO data collection, personnel at FCJMTC cut down the vegetation on site and nearby with a tractor-mounted rotary cutter (see Figure 34). Based on reports from personnel on site, the LZ had not been used since the previous SPRO effort approximately $10 \mathrm{yr}$ prior.

Figure 33. Rattlesnake LZ with significant vegetative growth.

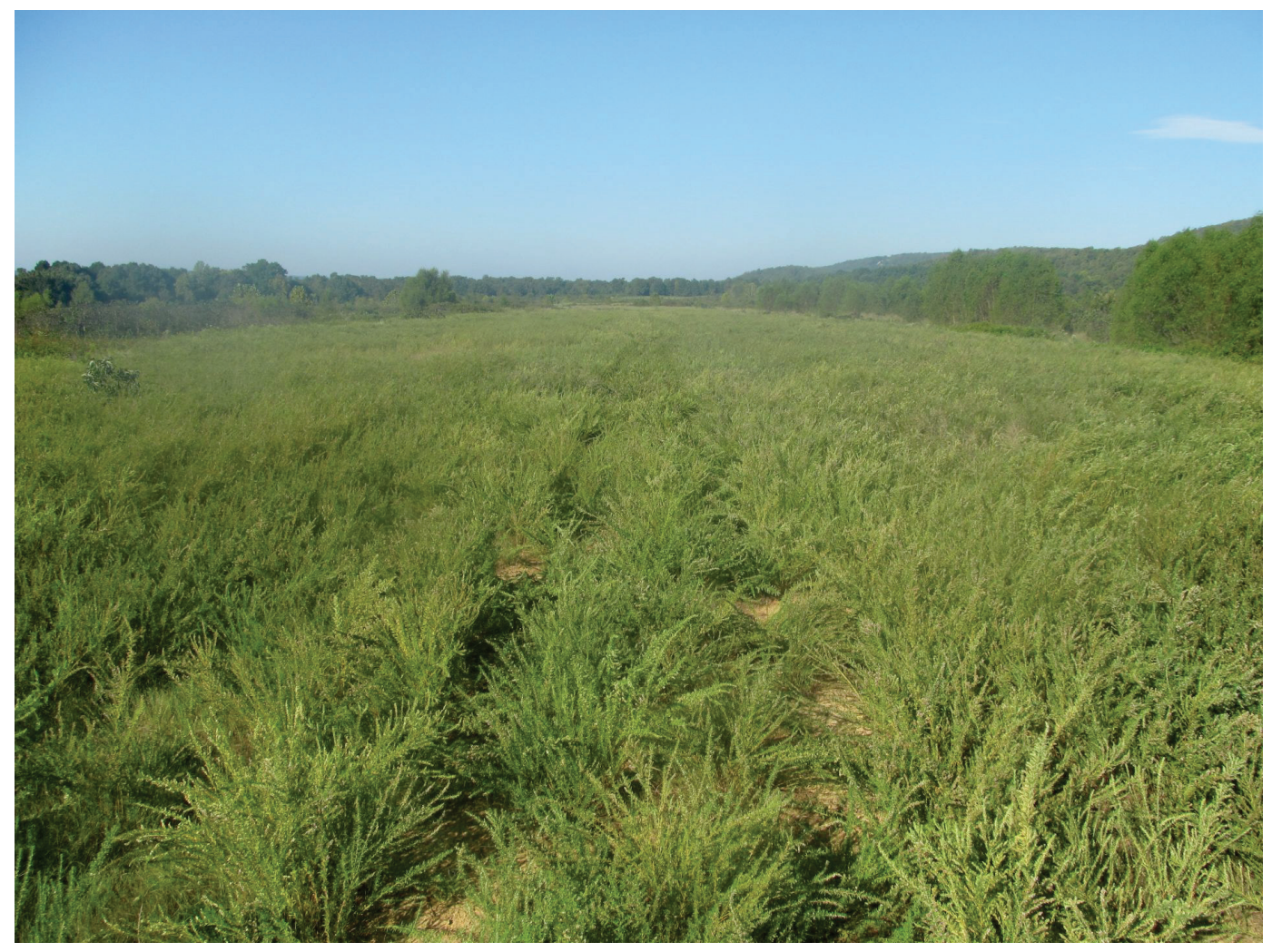


Figure 34. Rattlesnake LZ with cut-down vegetation.

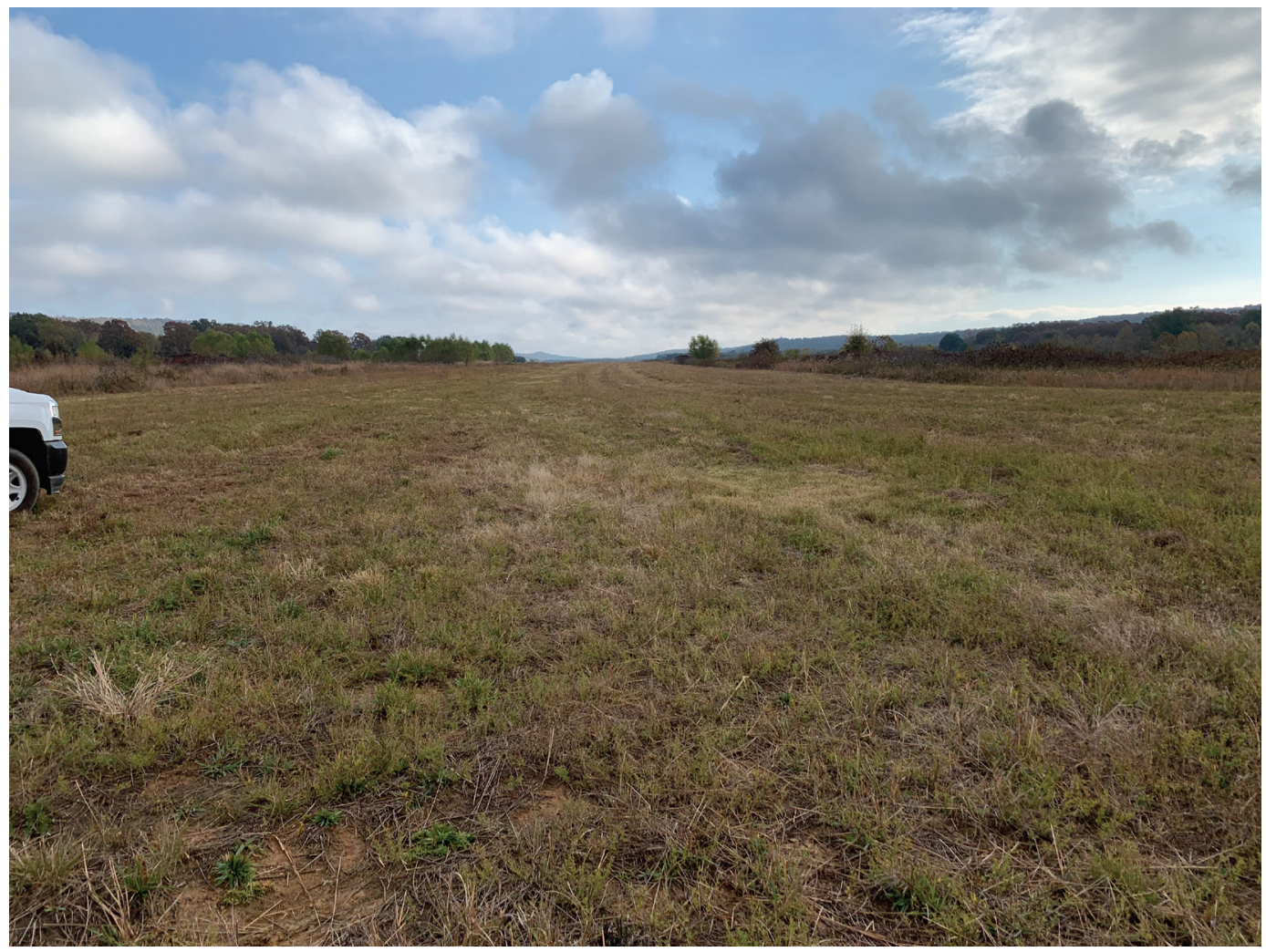

\subsubsection{Heavy equipment}

As the main runway at Rattlesnake LZ had been in disuse for many years prior to the present SPRO data collection, it was necessary to recover part of the surface for testing purposes. This recovery process required the use of various pieces of heavy equipment (see Table 4).

Table 4. Heavy equipment used during Rattlesnake $L Z$ data collection.

\begin{tabular}{|c|c|c|}
\hline $\begin{array}{c}\text { Equipment } \\
\text { Make }\end{array}$ & $\begin{array}{c}\text { Equipment } \\
\text { Model }\end{array}$ & Description \\
\hline John Deere & $554 \mathrm{~K}$ & Front-end loader with front bucket attachment. \\
\hline John Deere & $670 \mathrm{G}$ & $\begin{array}{c}\text { Motor grader, 12 ft moldboard with 34,000-lb blade } \\
\text { pull }\end{array}$ \\
\hline HAMM & H12i & $\begin{array}{c}\text { Smooth steel drum, vibratory roller compactor; } \\
50,000 \text { min centrifugal force }\end{array}$ \\
\hline Ford & F-650 SD & $\begin{array}{c}\text { Water truck, 2,000-gal tier 4; front, rear, and side } \\
\text { spray heads }\end{array}$ \\
\hline
\end{tabular}

First, a large front-end loader with a front bucket attachment (see Figure 35) was necessary to assist in moving excess soil from the test site. As the 
site had been in disuse for an extended time, it was estimated beforehand that a skid steer would be inadequate for our purposes.

Figure 35. John Deere 554K front-end loader.

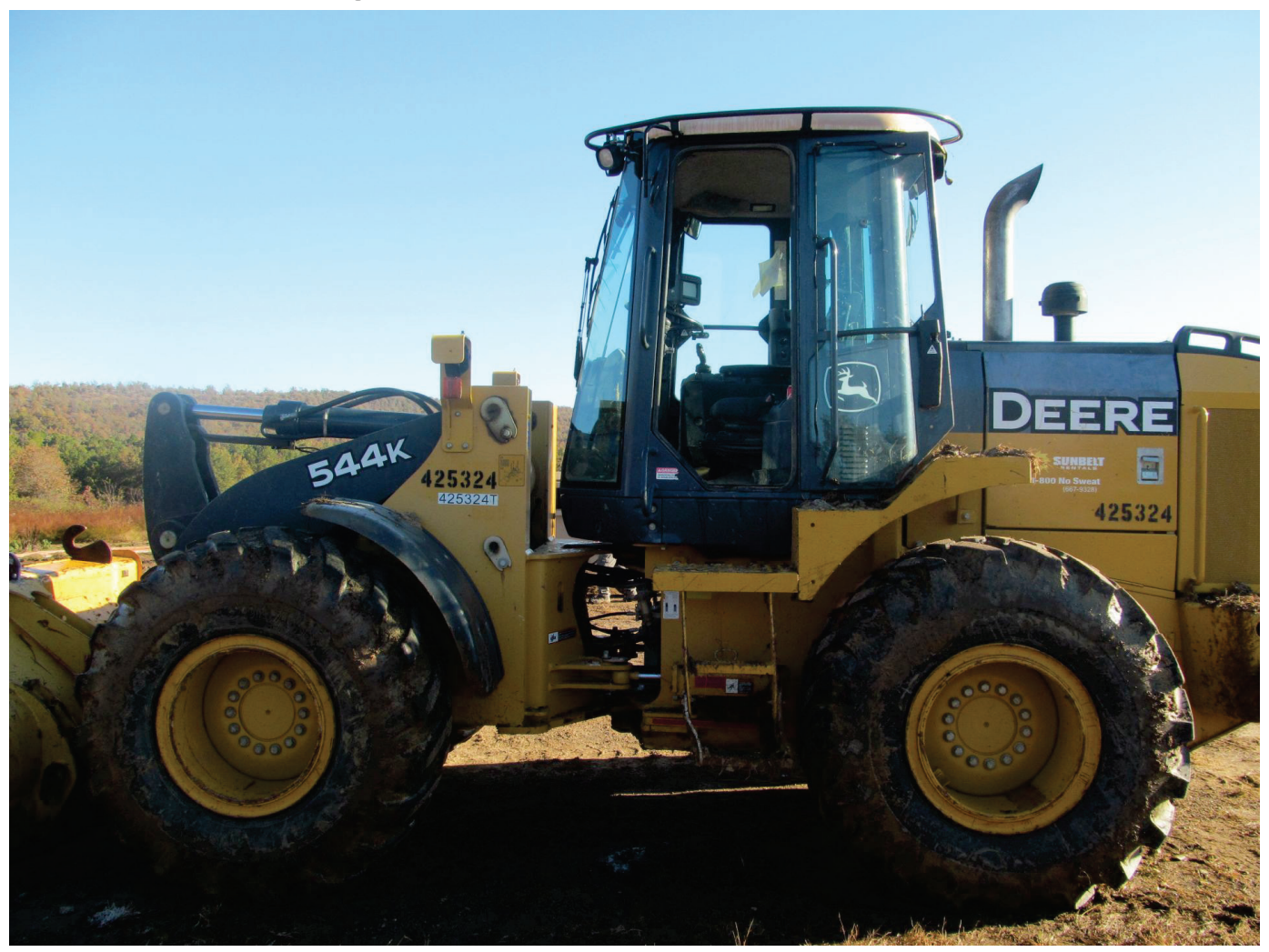

The single most important piece of equipment at the Rattlesnake LZ site was a motor grader with a 12 -ft blade (see Figure 36). The large motor grader allowed for large quantities of surface vegetation to be removed efficiently. This piece of equipment also allowed experienced heavyequipment operators to precisely control the grade of the recovered Rattlesnake LZ runway. 
Figure 36. John Deere 670G motor grader.

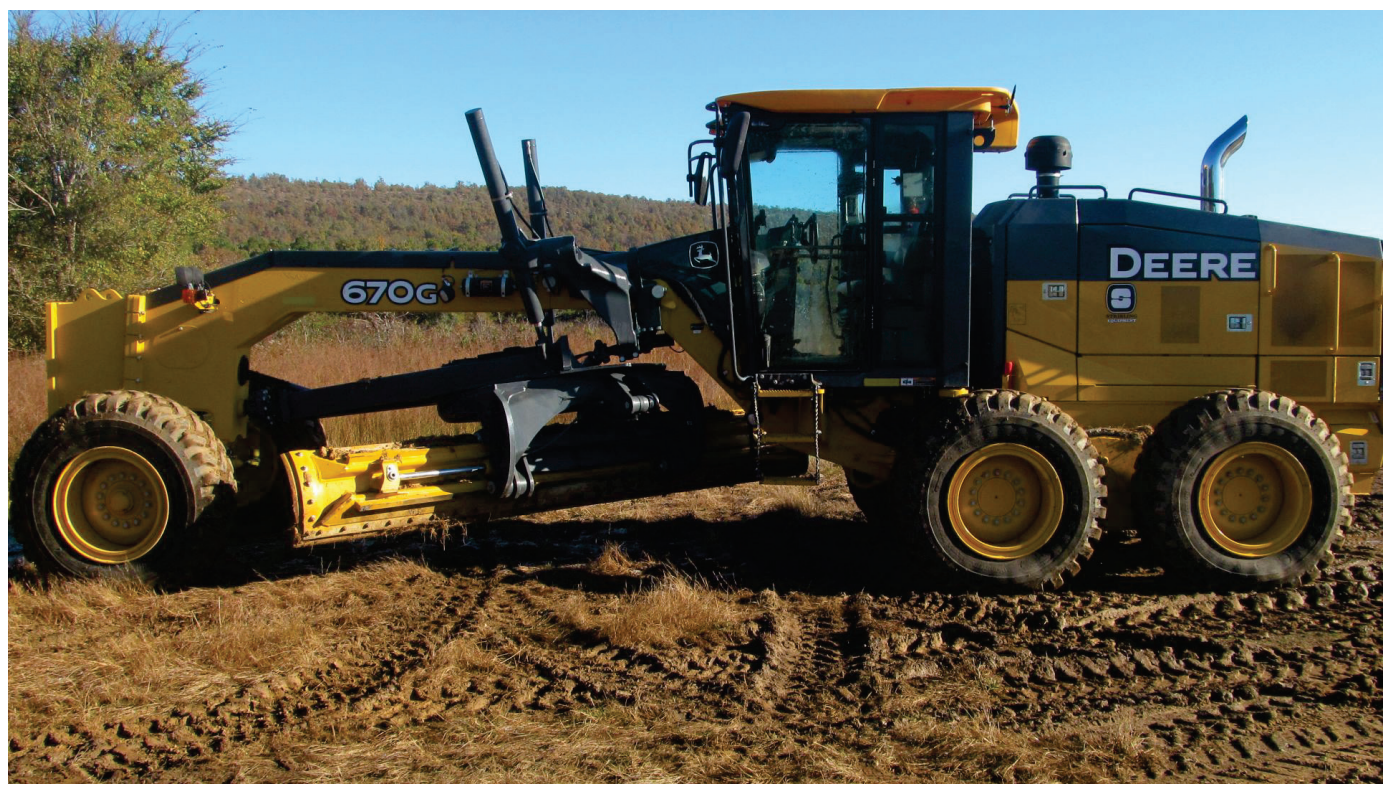

Once the surface had been flattened and grade-controlled and the excess soil had been removed from the area, it was necessary to compact the surface using a vibratory roller compactor (see Figure 37). This piece of equipment allowed for the compaction of surface and near-surface soil for the purposes of heavy brake testing.

Figure 37. HAMM H12i vibratory roller compactor.

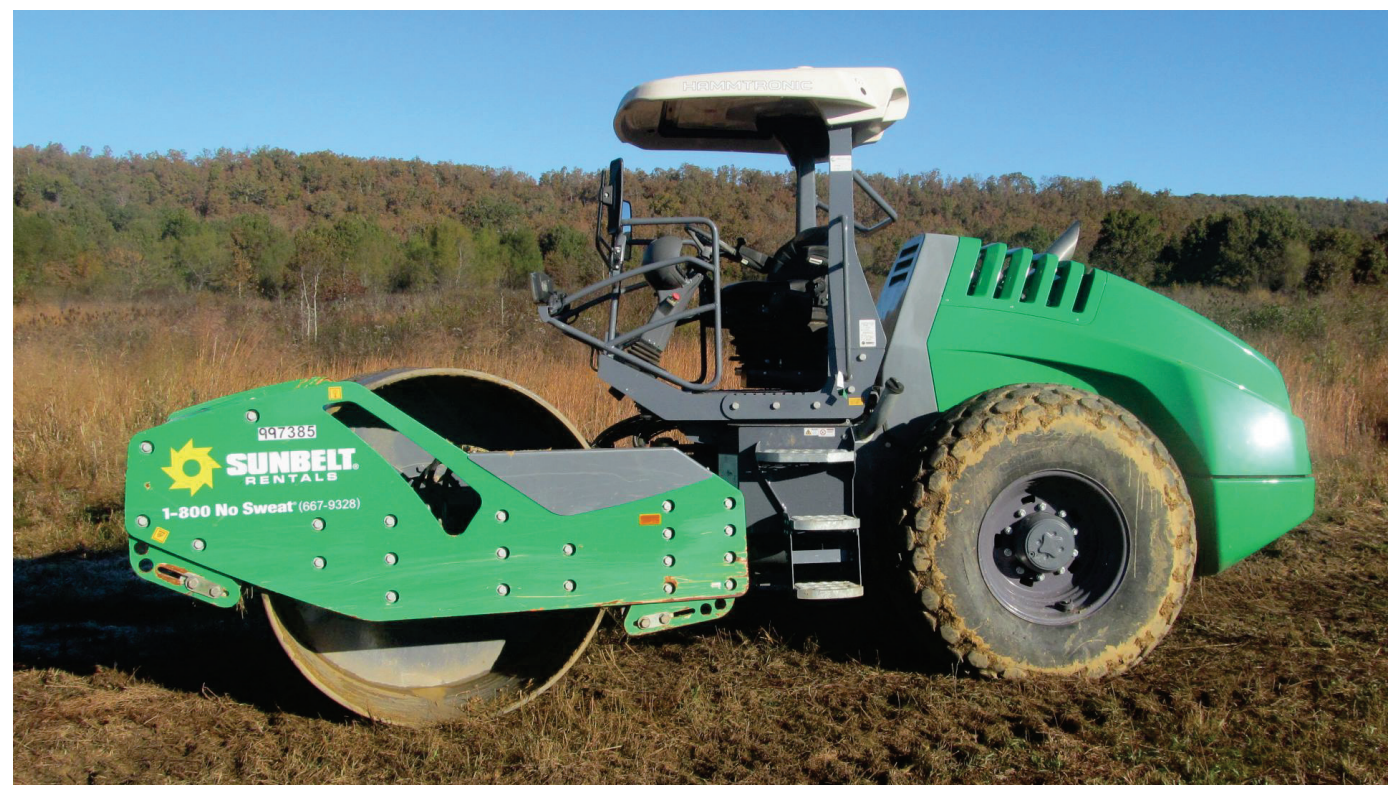

Finally, in order to control the moisture content of the newly exposed soil surface, a water truck was needed. A 2,000-gal front, side, and rear spray 
water truck (see Figure 38) was acquired to perform this task. A single water truck was needed to fully wet the recovered Rattlesnake LZ surface.

Figure 38. Fort F-650 SD 2,000-gal water truck.

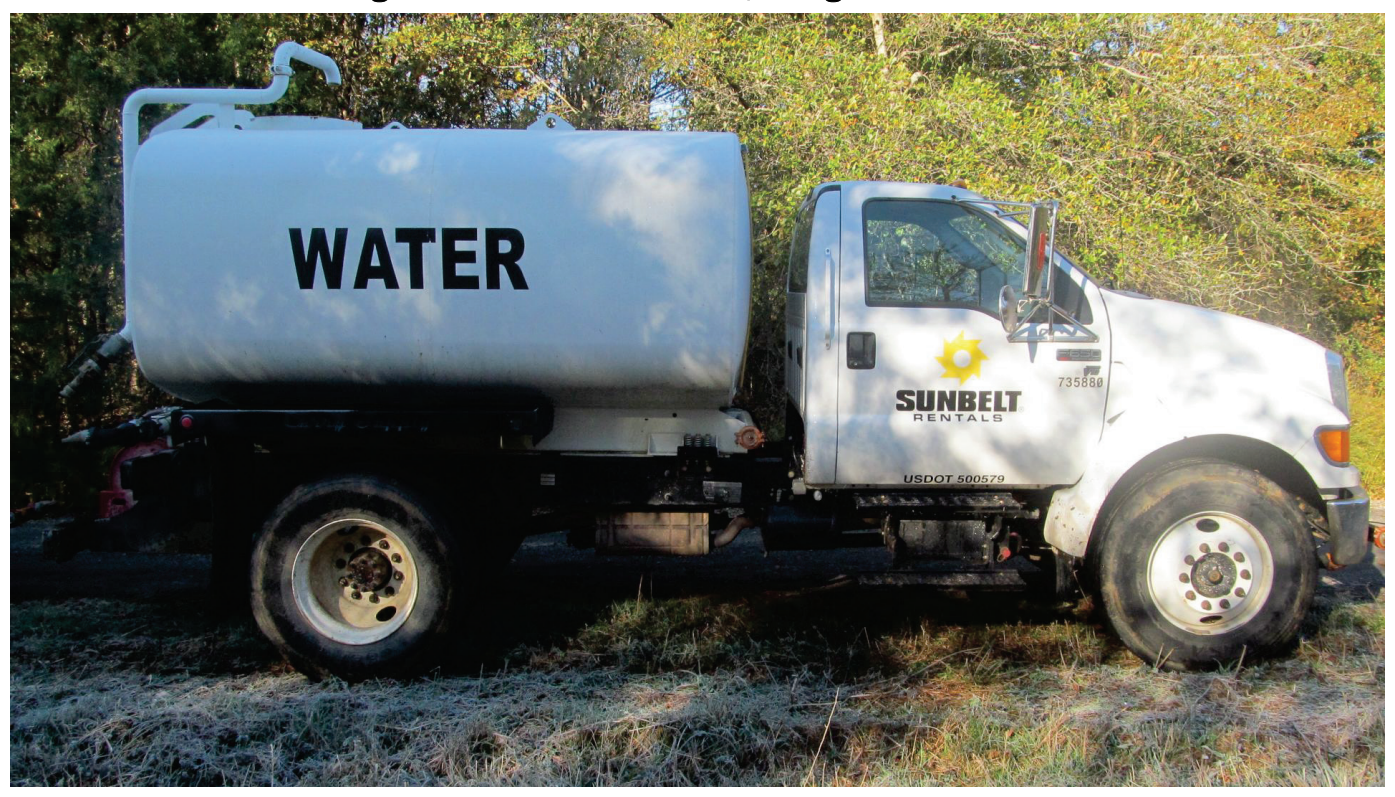

\subsubsection{Recovery efforts}

Following a round of exploratory DCP measurements, to be discussed in the Site Characterization section, a single 1,000-ft long by $30-\mathrm{ft}$ wide strip of runway was chosen as the only test site. This site presented the strongest soil characteristics of the entire runway and allowed for suitable soil compaction. First, a motor grader was used to cut and remove the top layer of vegetation and loose soil while a front-end loader was used to relocate the removed soil (see Figure 39). 
Figure 39. Motor grader and front-end loader on Rattlesnake LZ.

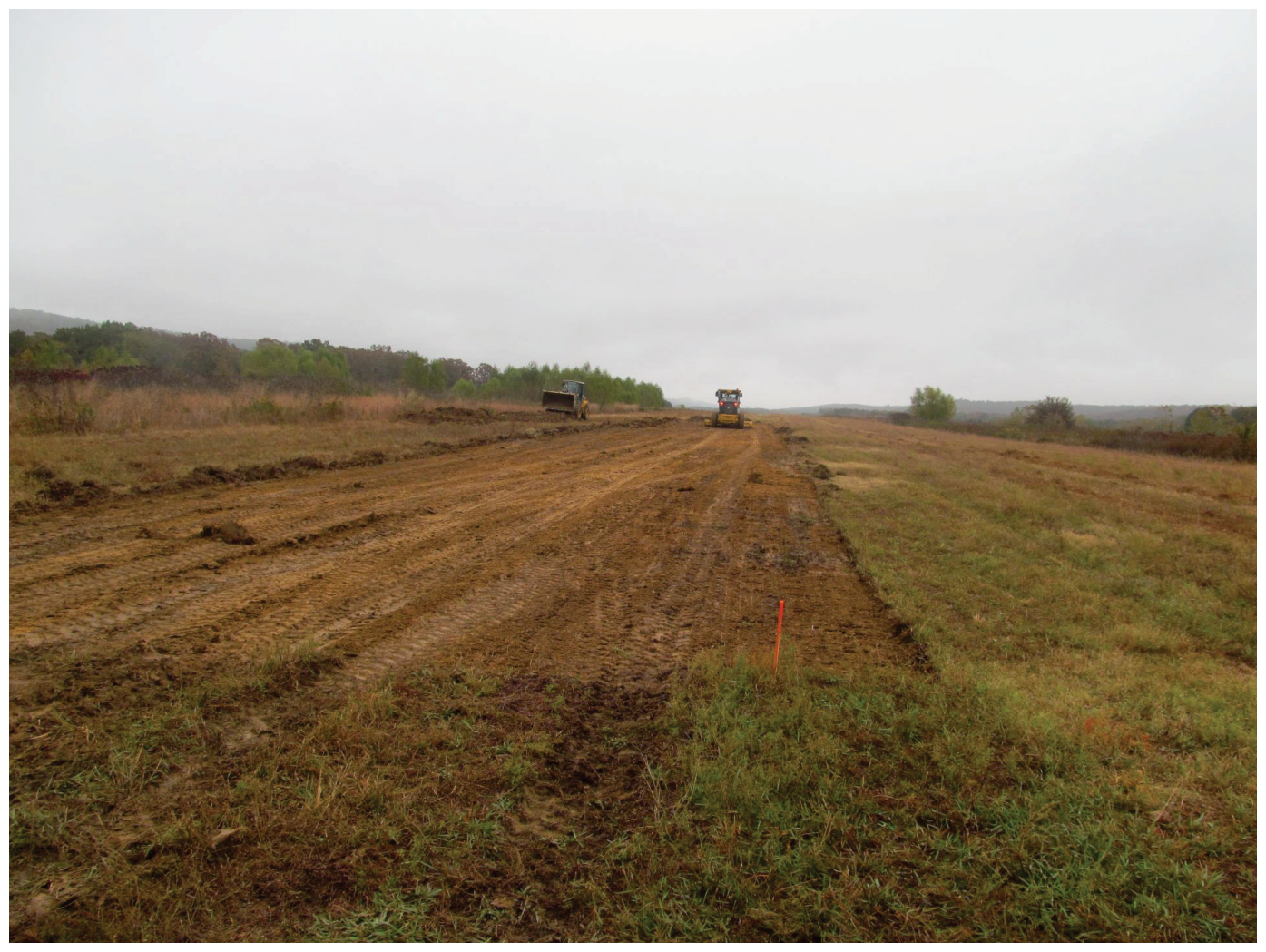

Once the underlying soil was exposed, a smooth-wheeled vibratory compactor was used to compact the test surface (see Figure 40). Following two full coverages with the compactor, the final surface construction was complete (see Figure 41). 
Figure 40. Vibratory roller compactor on Rattlesnake LZ.

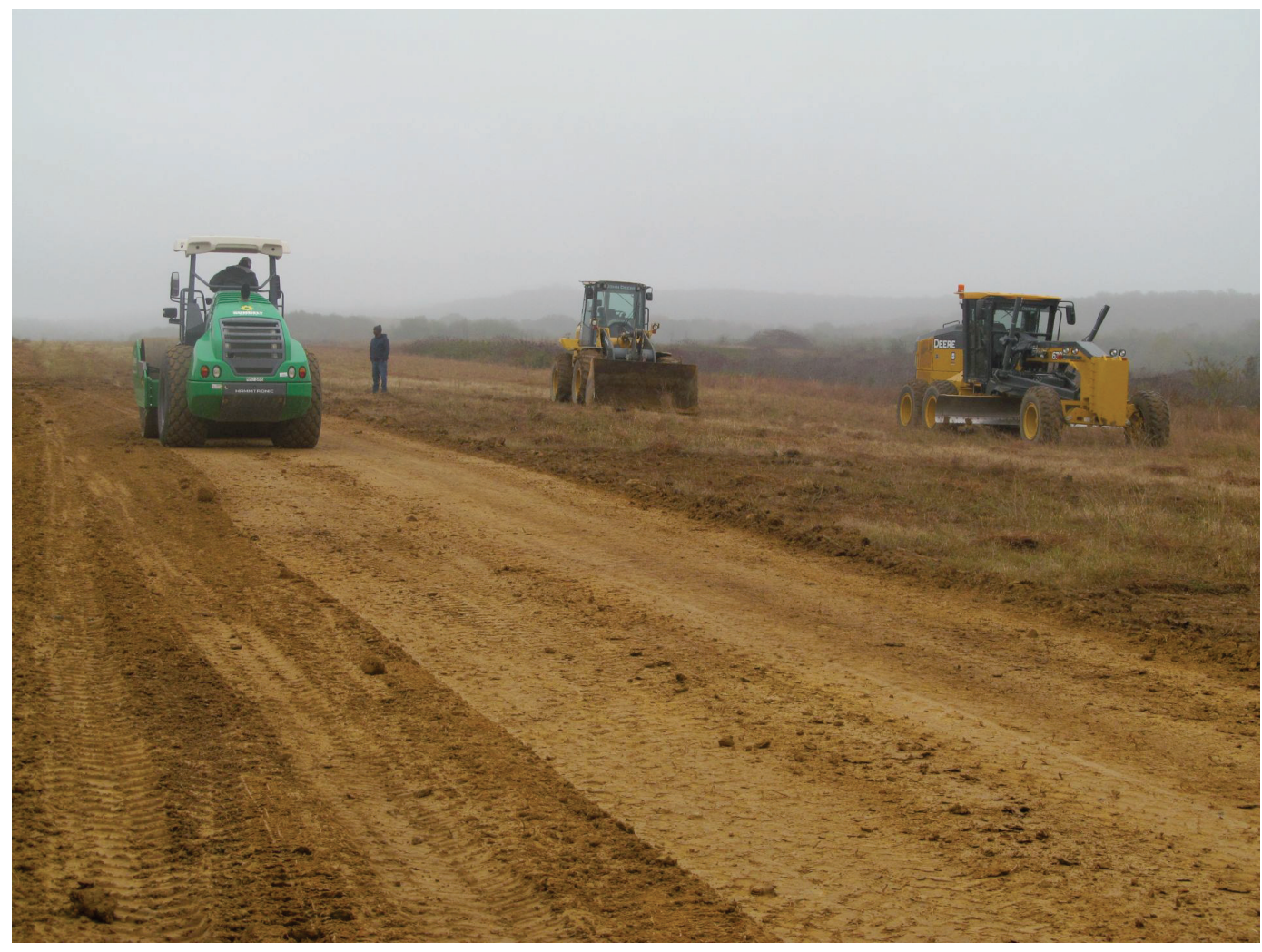

Figure 41. Completed Rattlesnake LZ test surface.

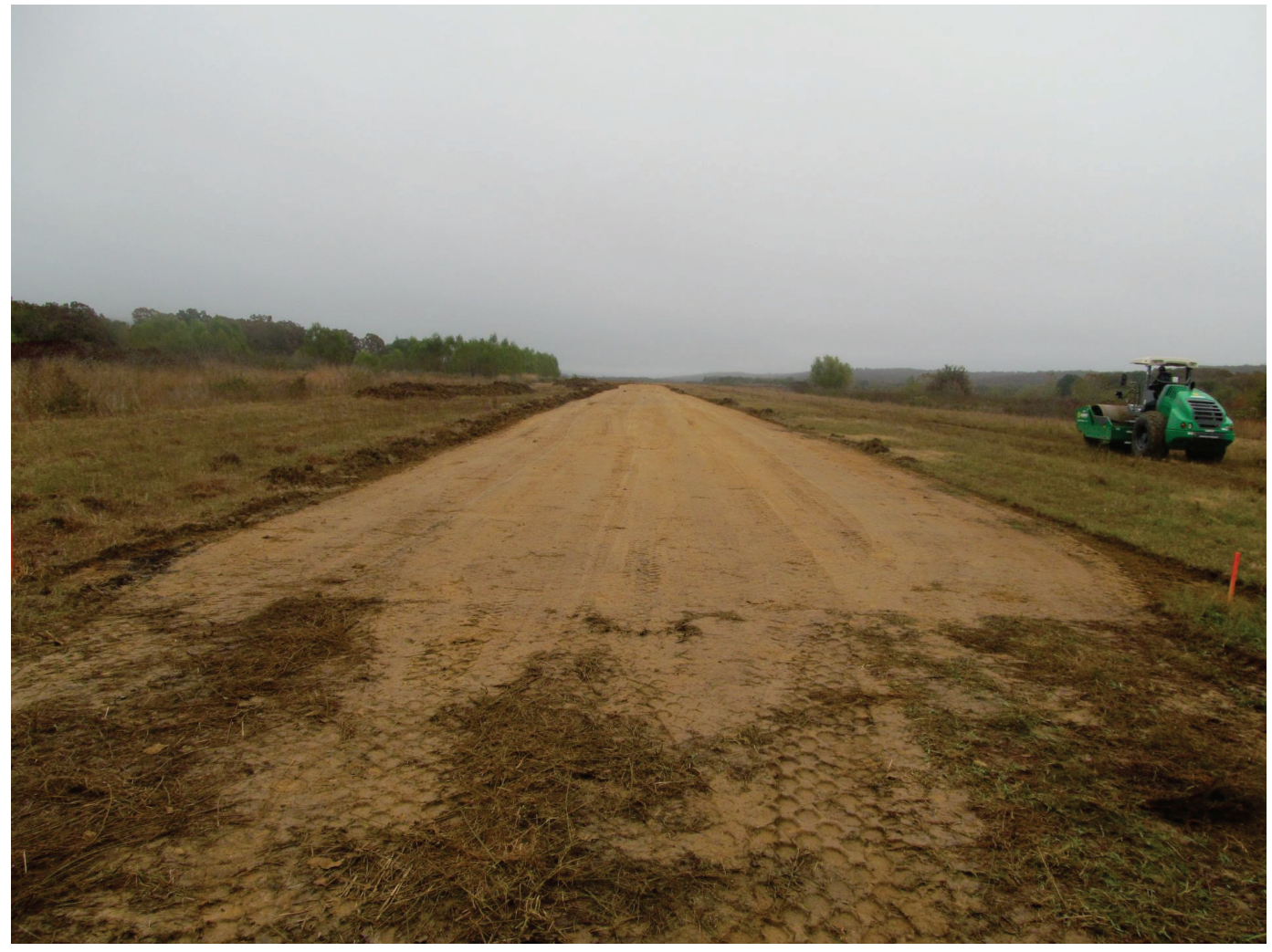




\subsubsection{Aerial survey}

Following test site construction and all rounds of brake testing, a series of roughness tests was performed in support of another effort. While these tests were being conducted, an aerial survey was performed with a small unmanned aerial system (sUAS). The sUAS chosen to perform this survey was the BirdsEyeView Aerobotics FireFLY 6 PRO (see Figure 42).

Figure 42. BirdsEyeView Aerobotics FireFLY 6 PRO.

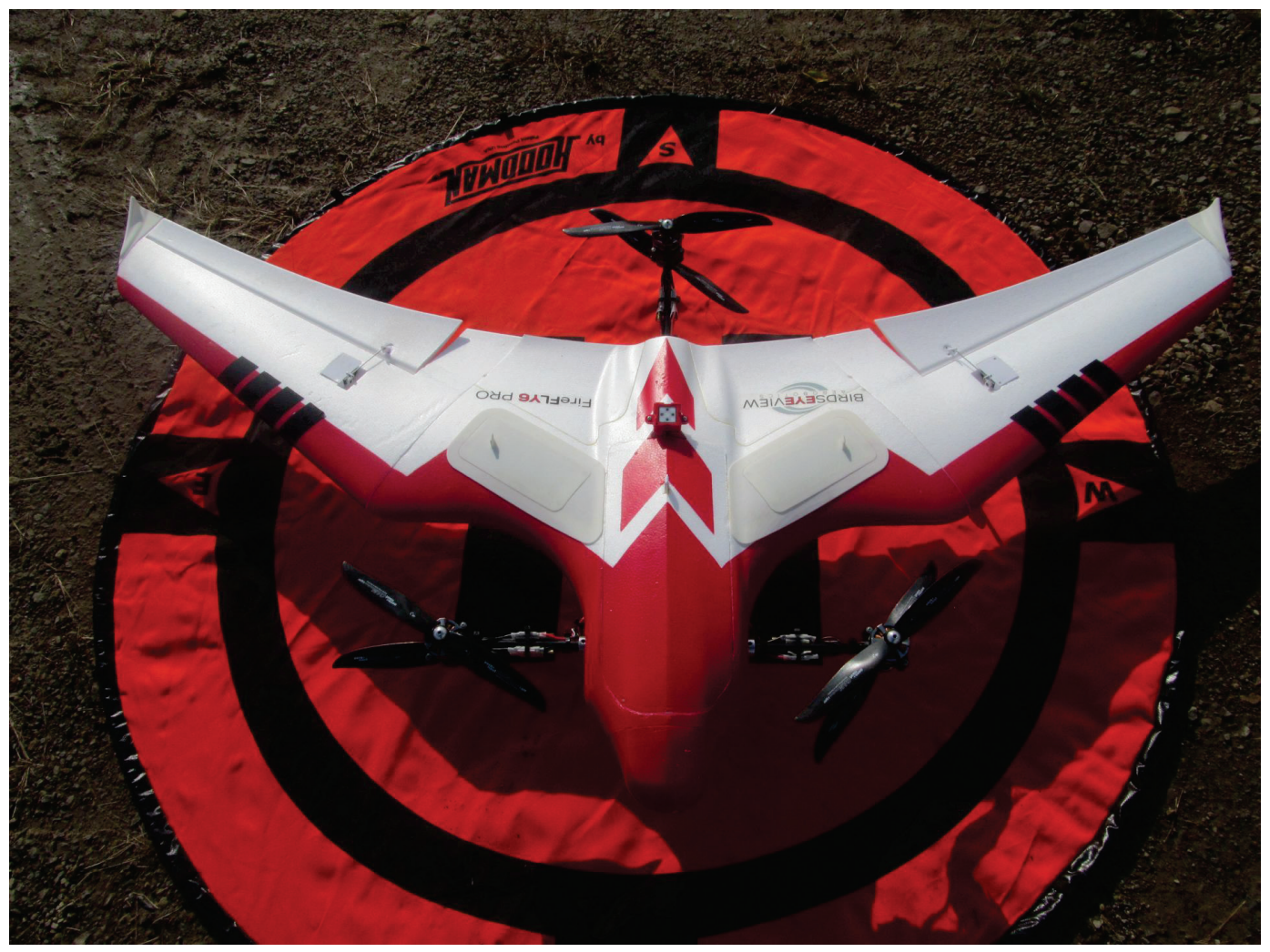

The FireFLY 6 PRO is a fixed-wing, vertical takeoff and landing (VTOL) sUAS capable of surface-to-400-ft electro-optical (EO) survey flights. This sUAS can also be equipped with a variety of commercial-off-the-shelf (COTS) EO sensors. Of interest to the present study is a single survey mission at an altitude of $400 \mathrm{ft}$ with a Sony RX1R EO camera. This mission resulted in a georeferenced $\mathrm{EO}$ mosaic of the test site and surrounding area (see Figure 43 and Figure 44). The resulting mosaic and three-dimensional (3-D) reconstructions give a sense of scale for the test area as well as the relative damage caused to the test area following extensive brake testing. 
Figure 43. Rattlesnake LZ full runway mosaic.

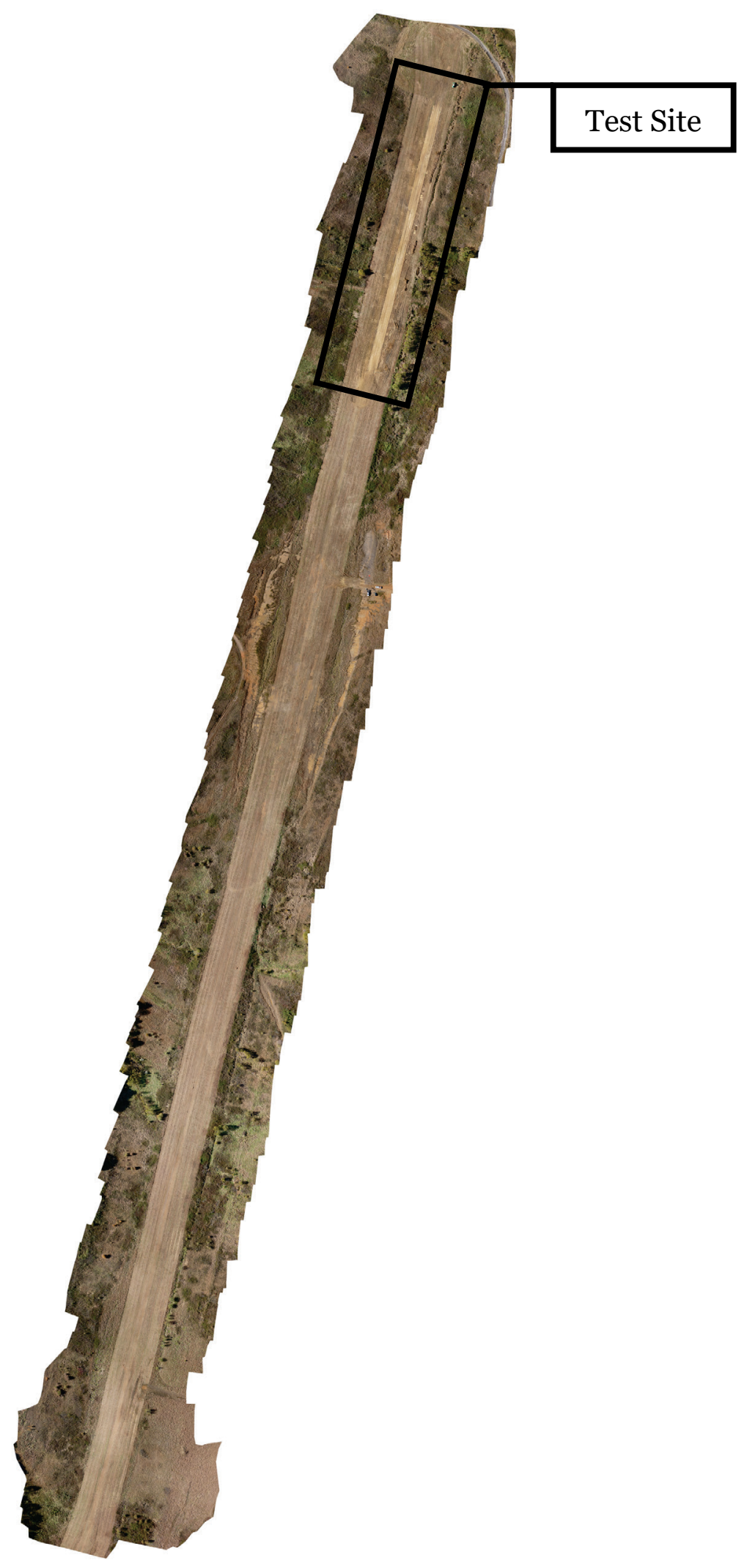


Figure 44. Rattlesnake $L Z$ test site mosaic.

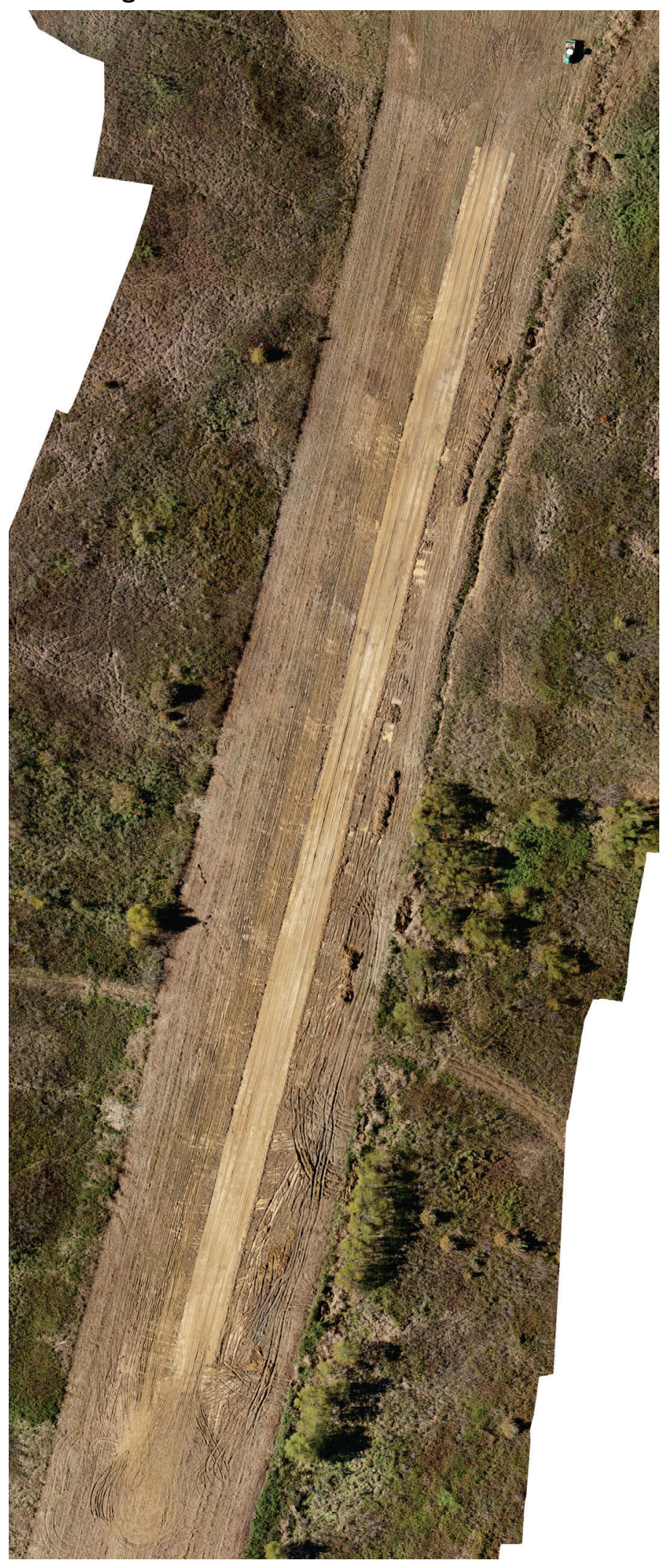




\subsection{Schoonover Landing Zone}

Schoonover Landing Zone (Schoonover LZ) is owned, maintained, and operated by U.S. Army Garrison (USAG) Fort Hunter Liggett, CA. Schoonover LZ is located approximately 18 miles south of King City, CA, in Monterey County. The LZ is accessed by traveling approximately 1.5 miles west from the intersection of Jolon Road and Mission Road in Jolon, CA (see Figure 45).

Figure 45. Satellite imagery of the Schoonover LZ and access road location.

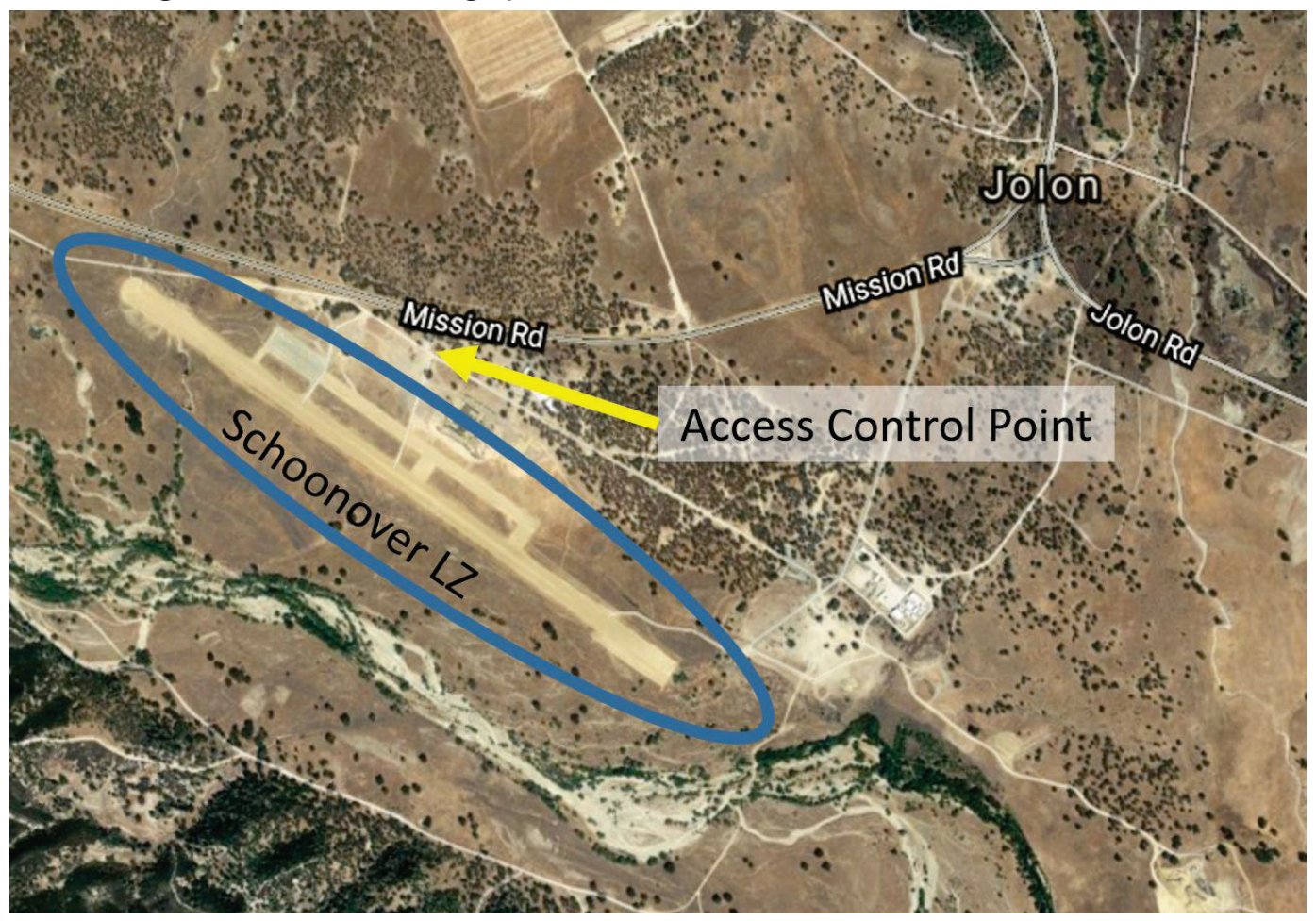

Schoonover LZ consists of a 500-ft-long by $90-\mathrm{ft}$-wide main runway (12-30) that runs northwest to southeast with hammerhead turnarounds at each end. The LZ also contains a parallel taxiway connected to the main runway by smaller perpendicular taxiways.

\subsubsection{Original condition}

Upon arrival, Schoonover LZ was in great condition with little to no vegetation on or around the main runway (see Figure 46). Schoonover LZ has been maintained as an active $\mathrm{C}-17$ capable semi-prepared runway and was more than suitable for successive brake testing without any surface-recovery efforts. 
Figure 46. Overview of Schoonover LZ main runway.

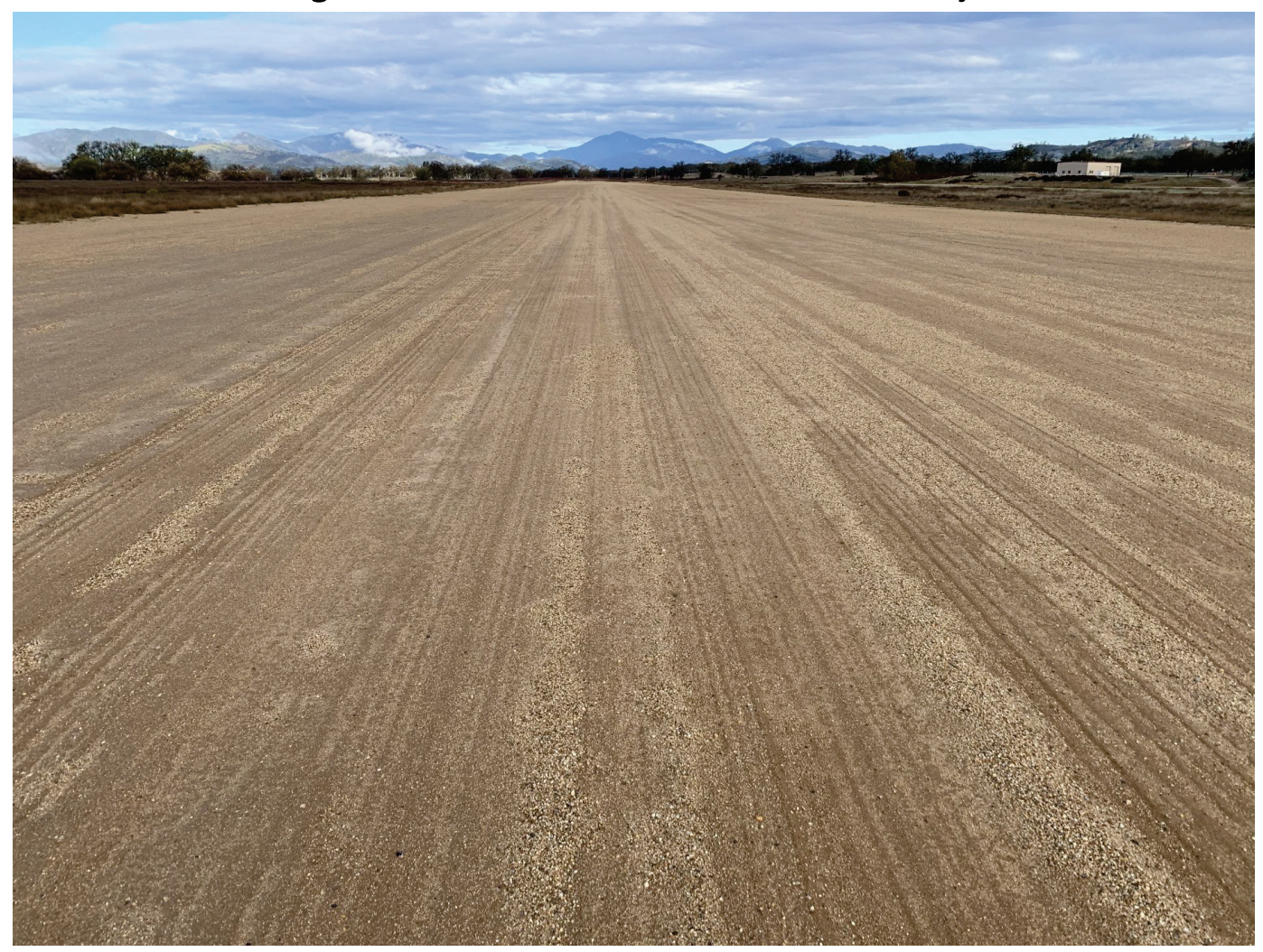

\subsubsection{Heavy equipment}

As Schoonover LZ was very well-maintained, a surface-recovery effort was not necessary prior to testing. Following all brake tests, however, significant rutting damage had been done to the surface of the main runway such that a post-test surface-recovery effort took place. The equipment necessary to remediate damage done to the main runway following testing is listed in Table 5 .

Table 5. Heavy equipment used during the Schoonover LZ data collection.

\begin{tabular}{|l|l|l|}
\hline \multicolumn{1}{|c|}{$\begin{array}{c}\text { Equipment } \\
\text { Make }\end{array}$} & \multicolumn{1}{|c|}{$\begin{array}{c}\text { Equipment } \\
\text { Model }\end{array}$} & \multicolumn{1}{c|}{ Description } \\
\hline CAT & 12M3 AWD & $\begin{array}{l}\text { Motor grader, 12-ft moldboard with } \\
\text { 49,630-Ib blade pull }\end{array}$ \\
\hline CAT & 289D & $\begin{array}{l}\text { Compact track loader with front } \\
\text { bucket attachment }\end{array}$ \\
\hline CAT & CS56B & $\begin{array}{l}\text { Smooth steel drum, vibratory roller; } \\
67,600-l b \text { max centrifugal force }\end{array}$ \\
\hline FREIGHTLINER & Water Truck & $\begin{array}{l}\text { Water truck, 2,000-gal; front, rear, } \\
\text { and side spray heads }\end{array}$ \\
\hline
\end{tabular}


First, it was determined that a large front-end loader would be unnecessary for this effort, as very little soil would need to be displaced. Therefore, a compact track loader with a front bucket attachment (see Figure 47) was acquired instead. This piece of equipment, also known as a skid steer, was suitable for moving small amounts of soil and was more maneuverable and efficient.

Figure 47. CAT 289D skid steer.

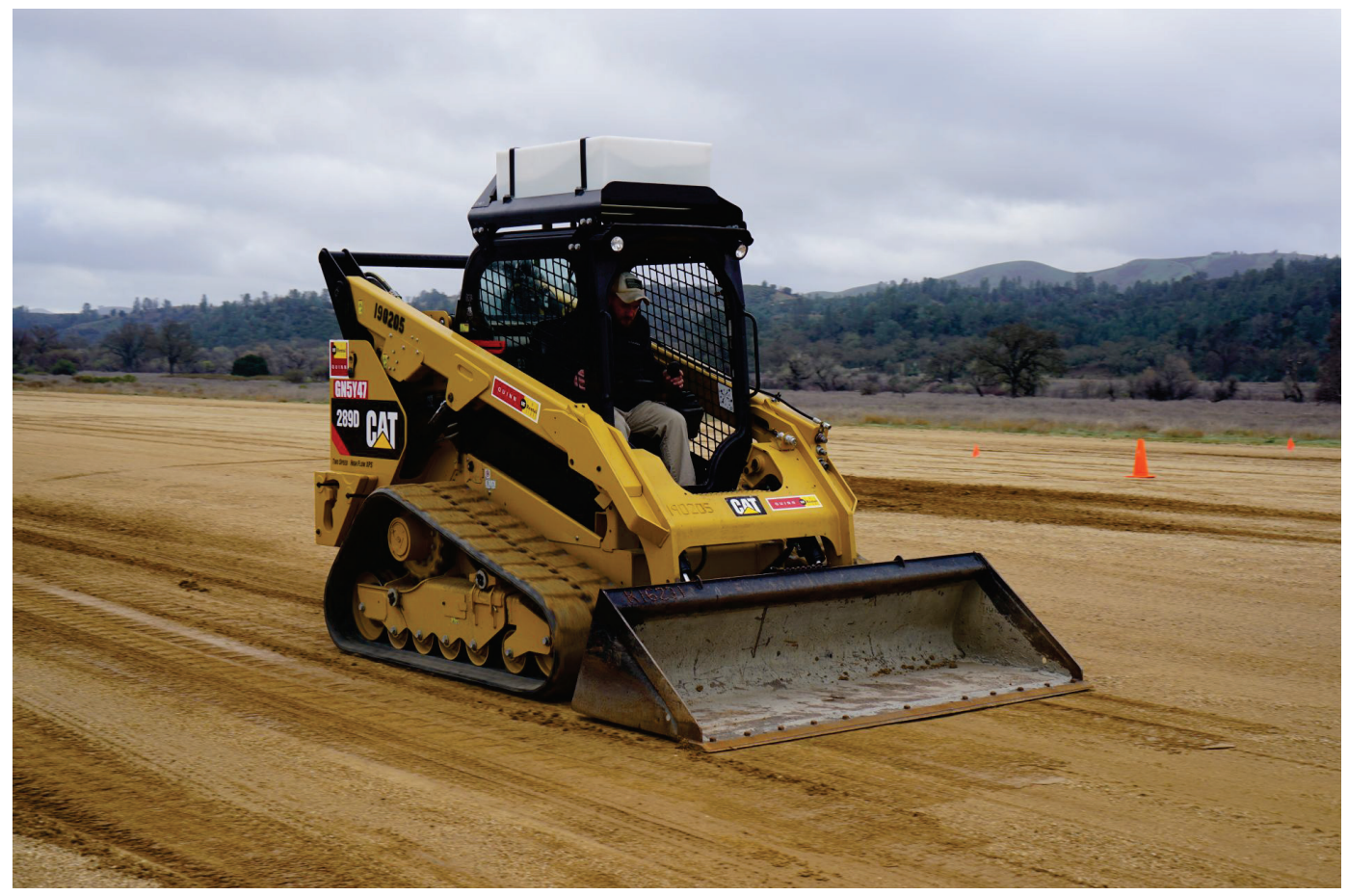

Much like the previous data collection at Rattlesnake LZ, this effort required the use of a motor grader with a 12-ft blade (see Figure 48). The motor grader, as the name implies, was used to control the grade of the runway surface and to cut and remove excess soil. This piece of equipment was crucial in returning the main runway surface to its wellmaintained, pre-test condition. 
Figure 48. CAT 12M3 AWD motor grader.

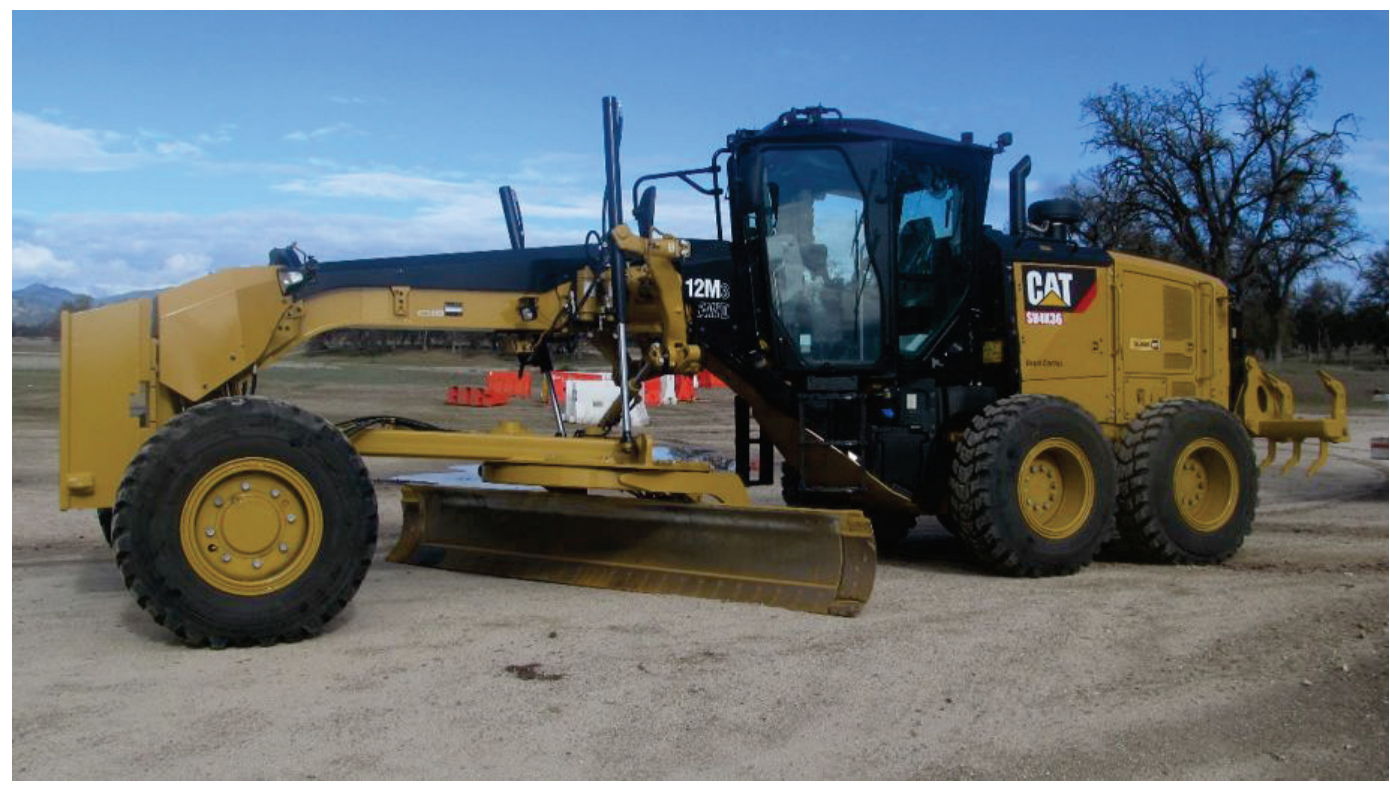

Once the soil surface was grade-controlled, it became necessary to compact the loose surface and near-surface soil. For this purpose, a vibratory roller compactor was used (see Figure 49).

Figure 49. CAT CS56B vibratory roller compactor.

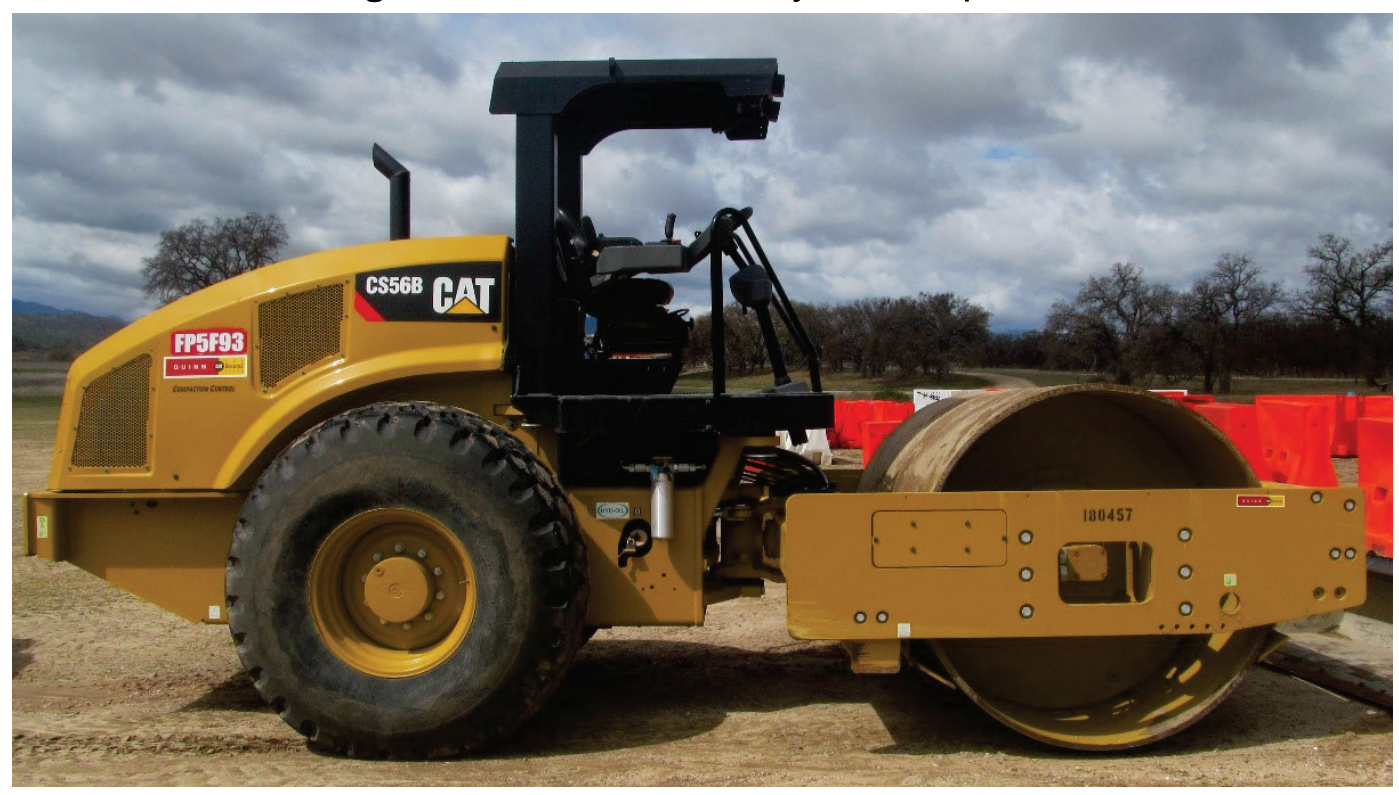

Finally, to control the moisture content of the main runway soil surface, a water truck was needed. A 2,000-gal front, side, and rear spray water truck (see Figure 50) was acquired to perform this task. Two water trucks were acquired to allow for efficient wetting of the entire test area in one pass. 
Figure 50. FREIGHTLINER 2,000-gal water truck.

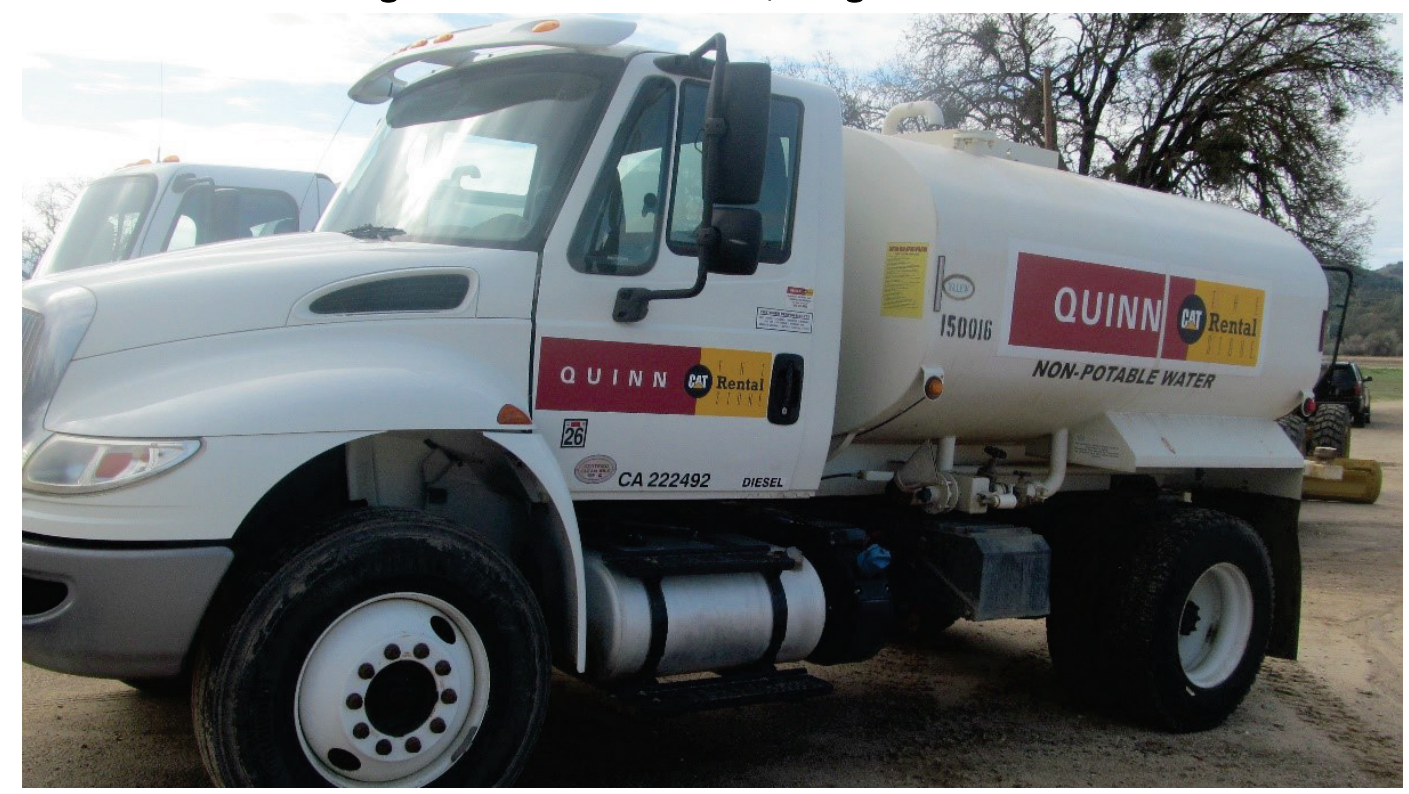

\subsubsection{Recovery efforts}

Unlike the data collection at Rattlesnake LZ, soil recovery efforts prior to testing were unnecessary at Schoonover LZ. It was necessary, however, to remediate rutting damage from the surface following heavy brake testing. To achieve this, first the entire test-affected surface was grade-controlled (see Figure 51). The blade was set to cut approximately $0.5^{-0.75}$ in. from the top of the runway surface.

Figure 51. Grade control operations at Schoonover LZ following testing.

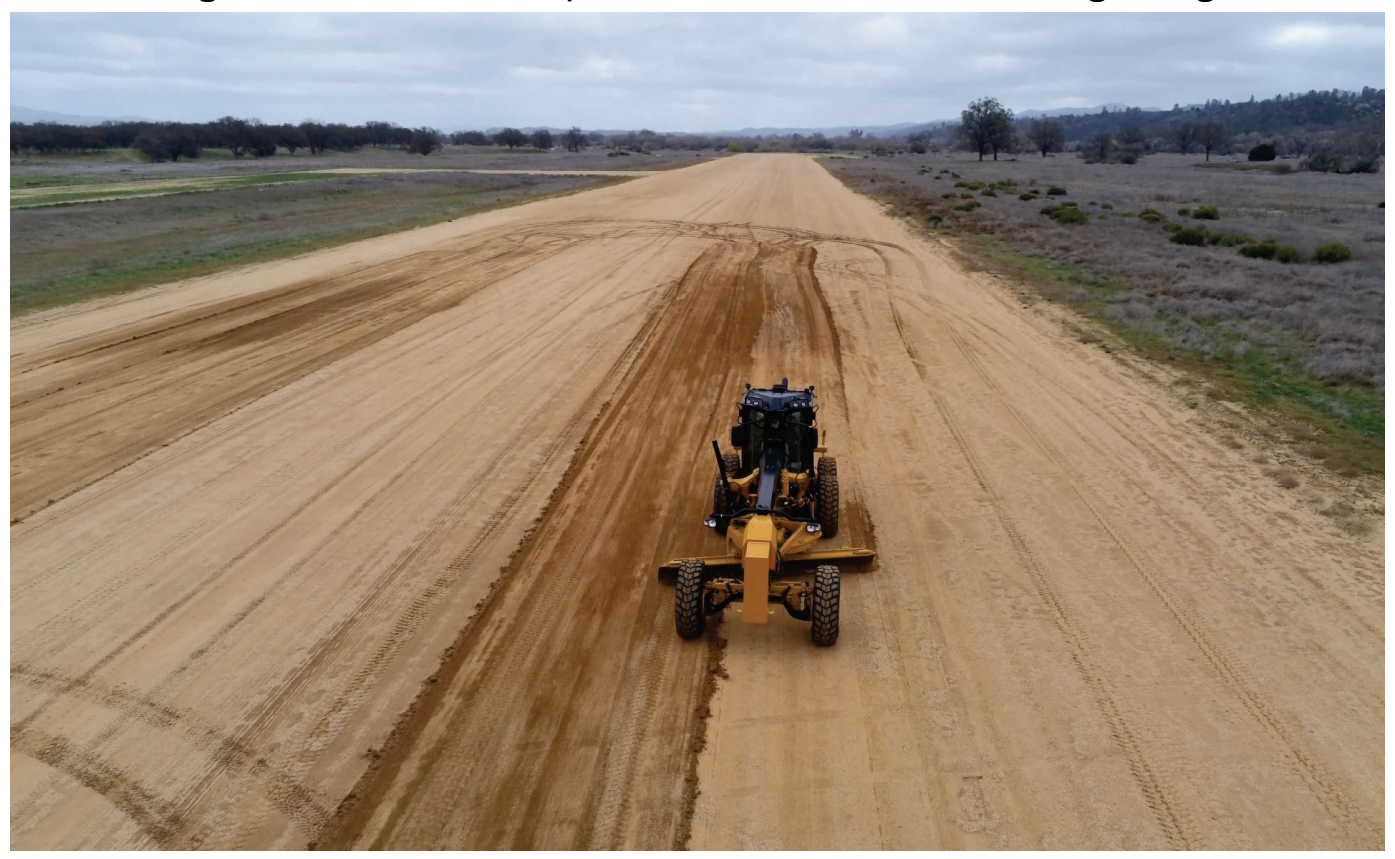


During the grade-control process, it was found that very near the surface of the main runway were various sizes of rock and aggregate (see Figure $52 \mathrm{a}$ and $\mathrm{b}$ ). Base operations were notified of the exposed rocks, and excess soil from other parts of the runway was used to cover them.

Figure 52. Near-surface rocks on the Schoonover LZ main runway.

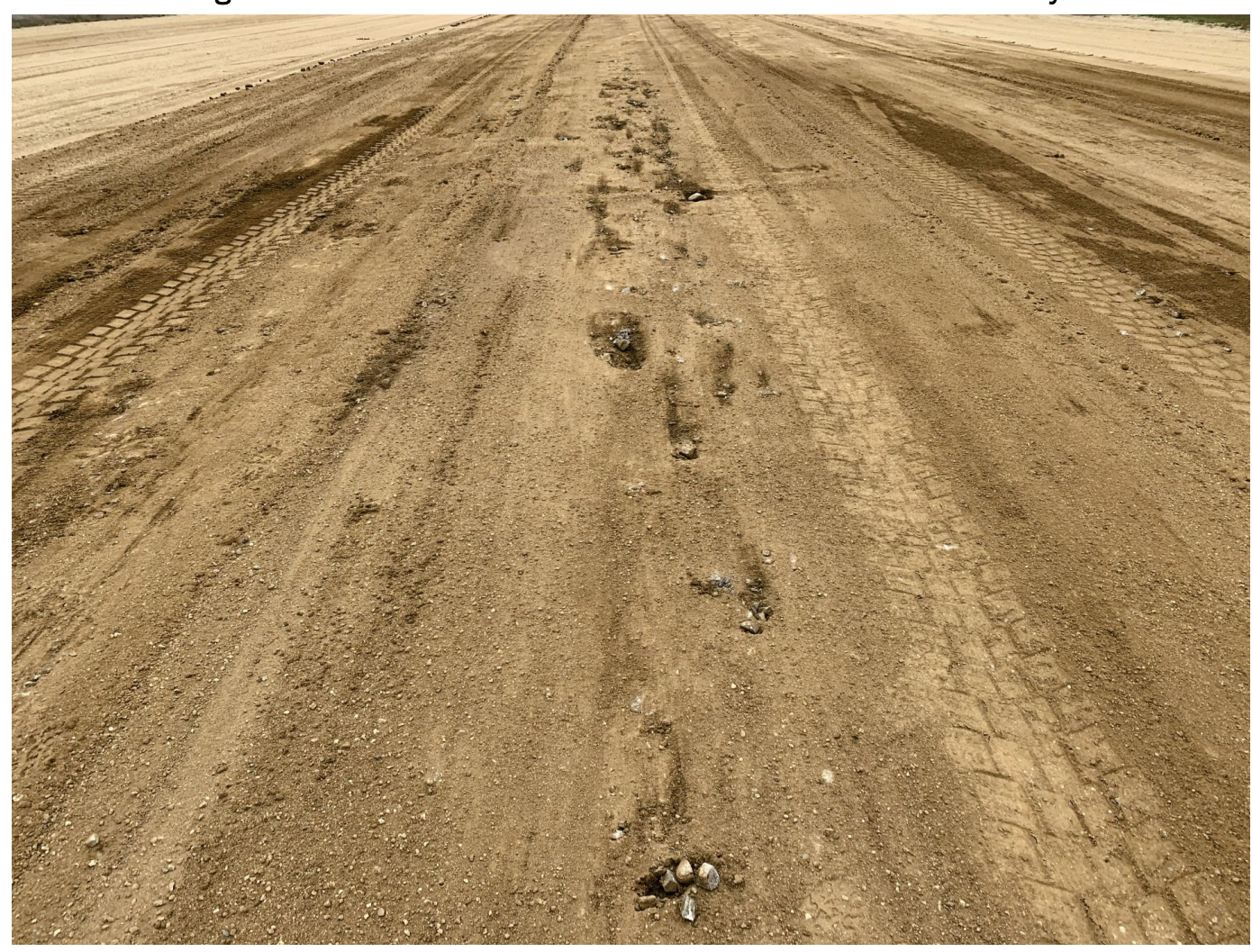

(a) Overview of rocks near the center of the main runway

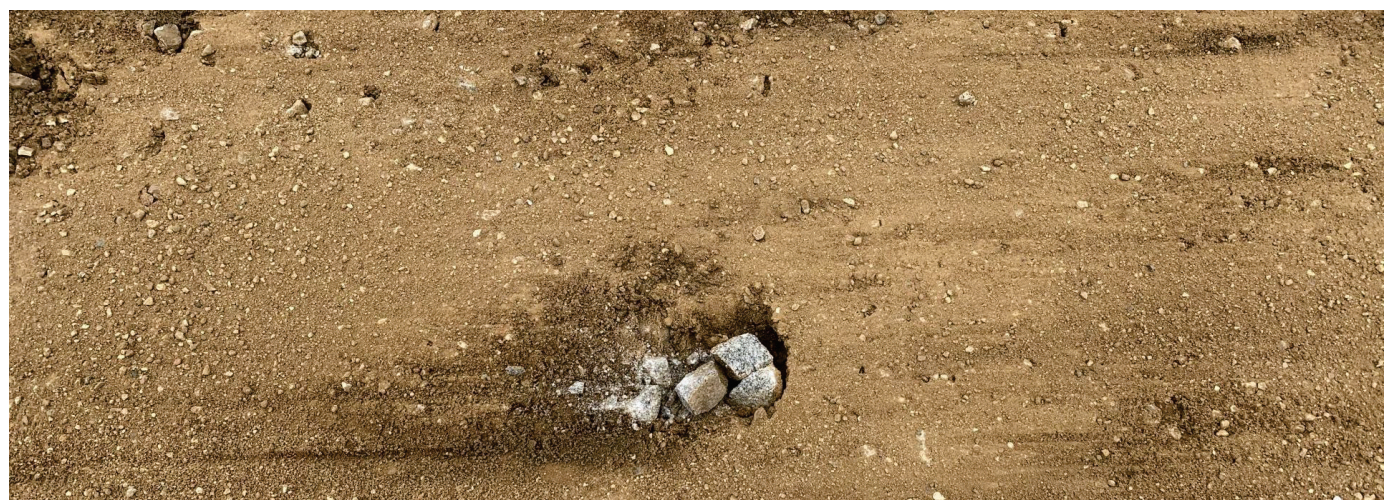

(b) Close-up of rocks near the center of the main runway.

Following grade-control, two pieces of equipment were used to compact the surface. First, the front bucket of the skid steer was used to lightly compact soil at and near the surface (see Figure 53), and the vibratory 
roller compactor was used afterwards to complete compaction of the top soil layer (see Figure 54). Damage remediation was finalized by completing two coverages with the vibratory roller compactor.

Figure 53. Skid steer compaction on the Schoonover $L Z$ main runway.

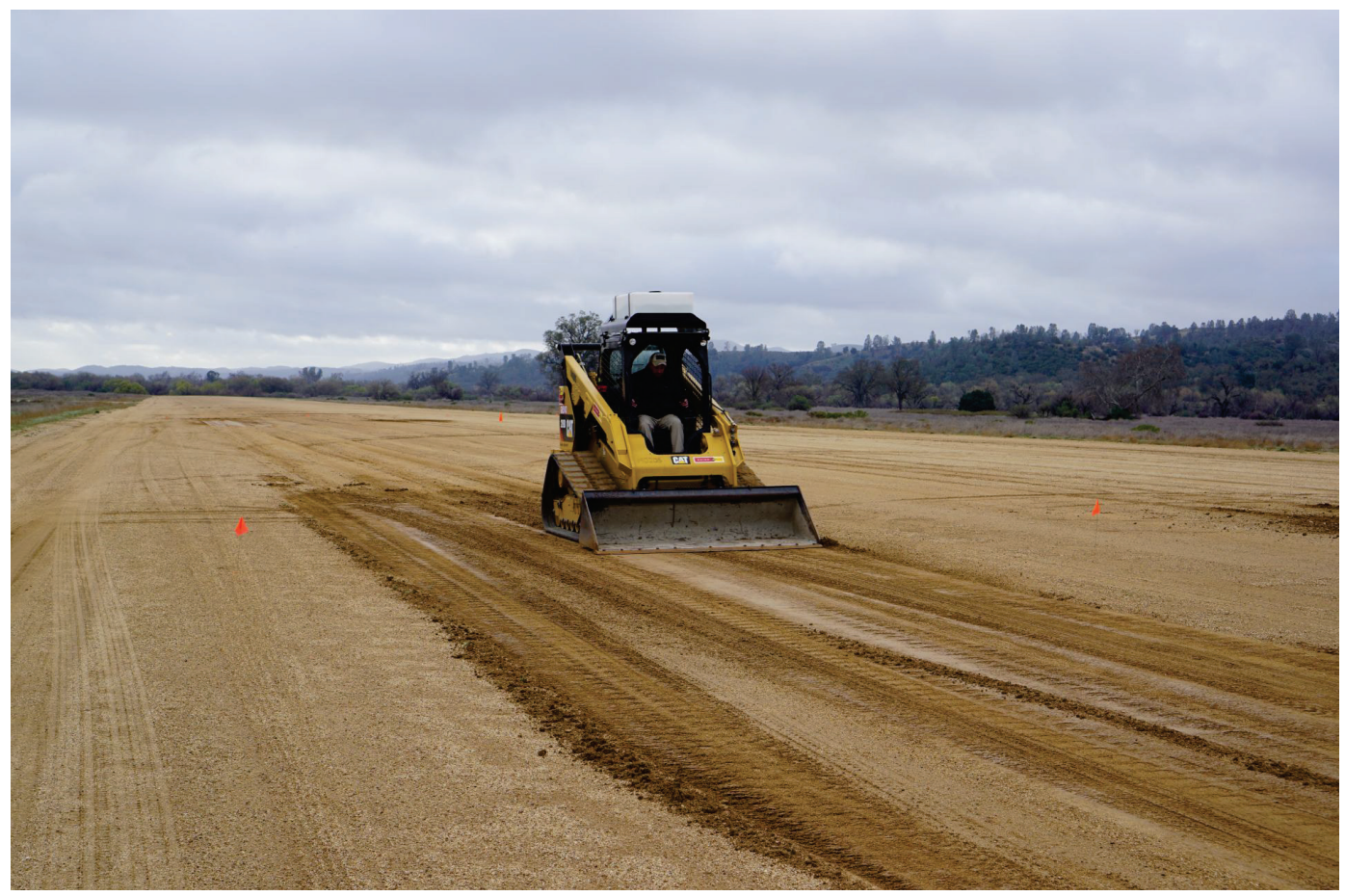

Figure 54. Vibratory roller compaction on the Schoonover LZ main runway.

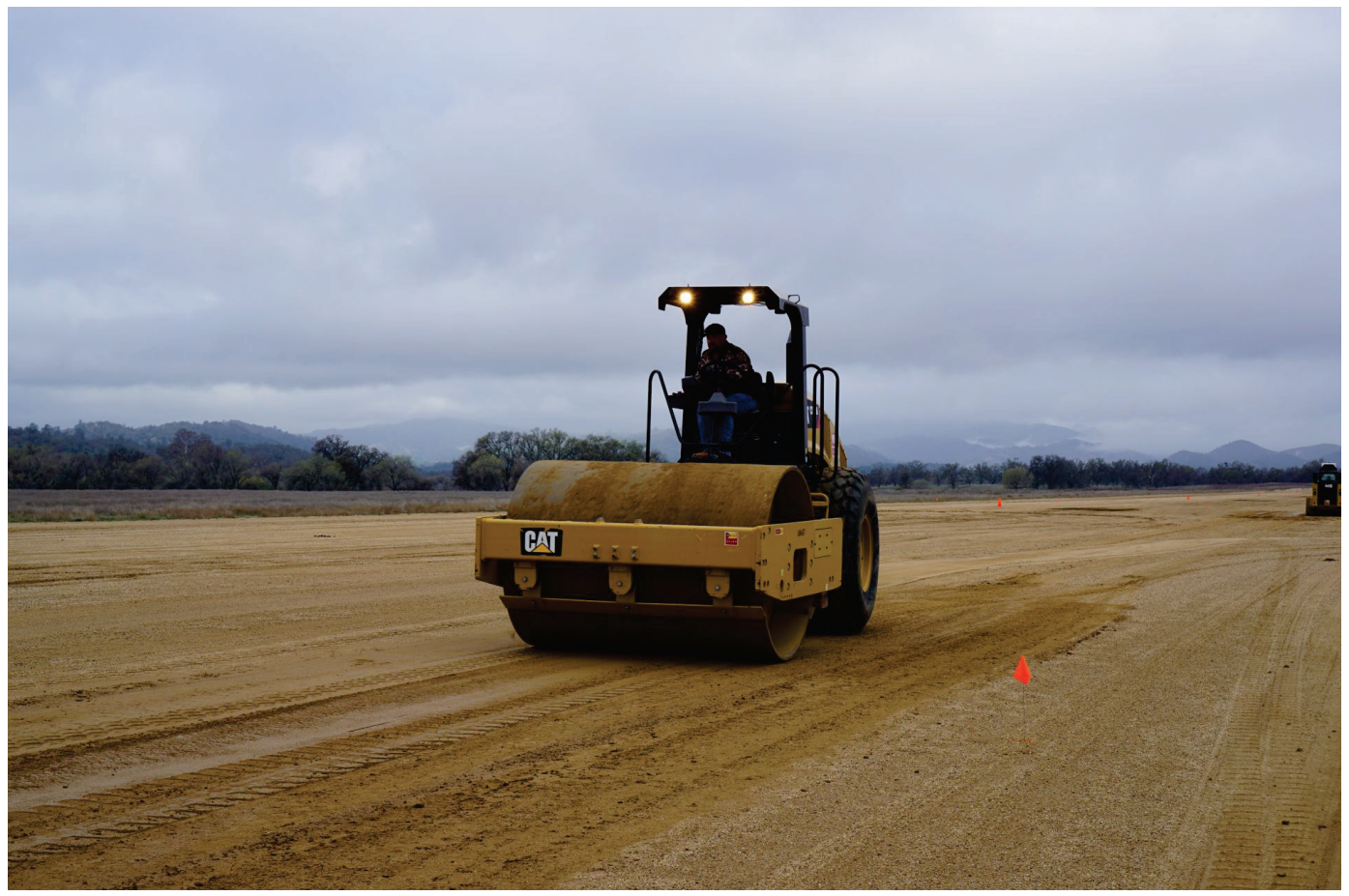




\subsection{Golden Eagle Landing Zone}

Golden Eagle Landing Zone (Golden Eagle LZ) is owned, maintained, and operated by USAG Fort Campbell, KY. The LZ is located approximately 1.5 miles northwest of Woodlawn, TN, in Montgomery County. The LZ is accessed by $101^{\text {st }}$ Airborne Division Road (see Figure 55). The main runway on Golden Eagle LZ was approximately 4,000 ft long with a variable width ranging from 60 to $75 \mathrm{ft}$.

Figure 55. Satellite imagery of Golden Eagle $\measuredangle Z$ and access road location.

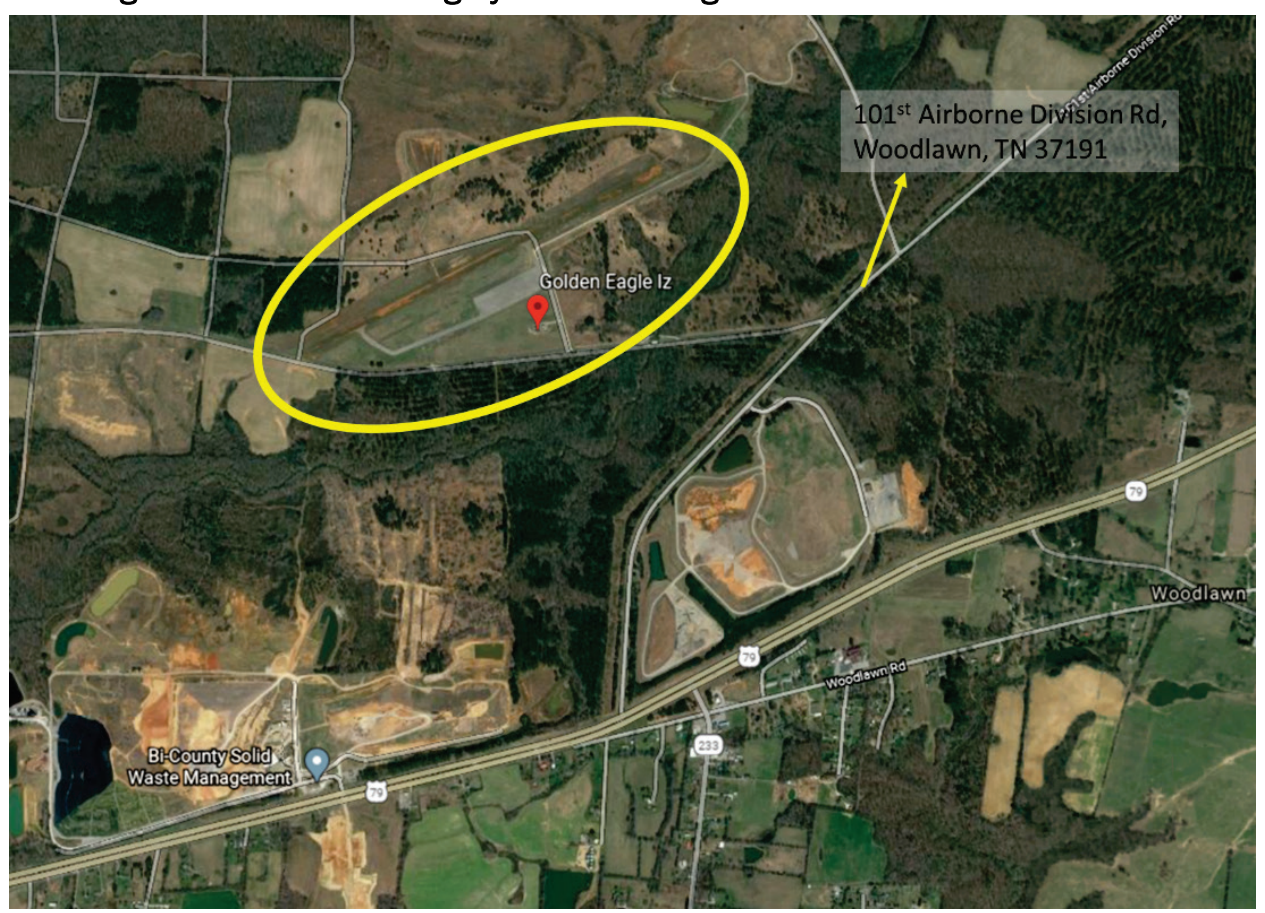

\subsubsection{Original condition}

Access roads leading into Golden Eagle LZ were a mixture of paved and gravel, all well-maintained. The main runway on Golden Eagle LZ was completely covered in vegetation (see Figure 56 ). The vegetation was grown up approximately 3 to $5 \mathrm{in}$. and covered most of the main runway with intermittent spots of bare soil (see Figure 57). 
Figure 56. Golden Eagle LZ main runway covered with short vegetation.

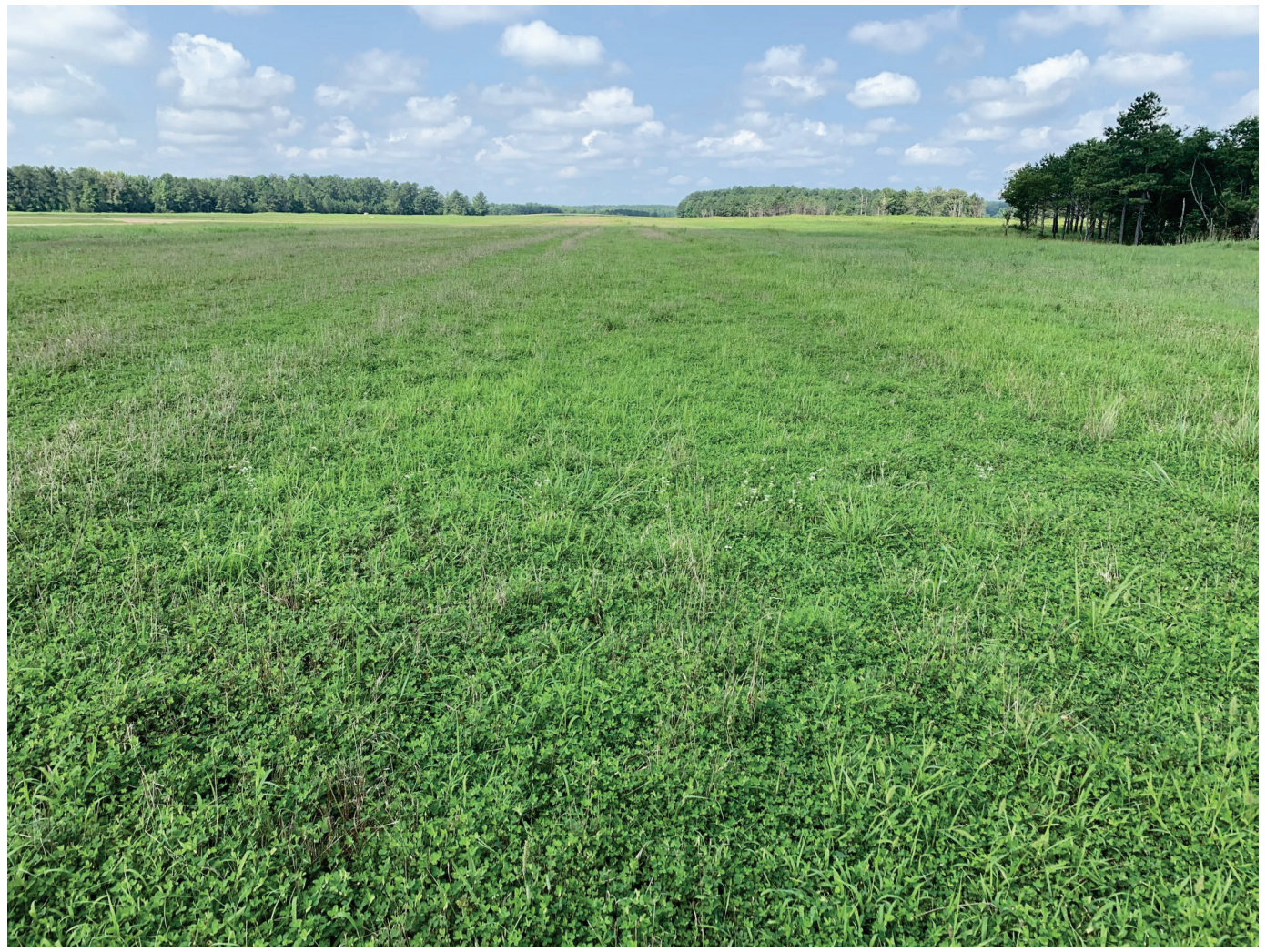

Figure 57. Golden Eagle LZ main runway with intermittent bare soil.

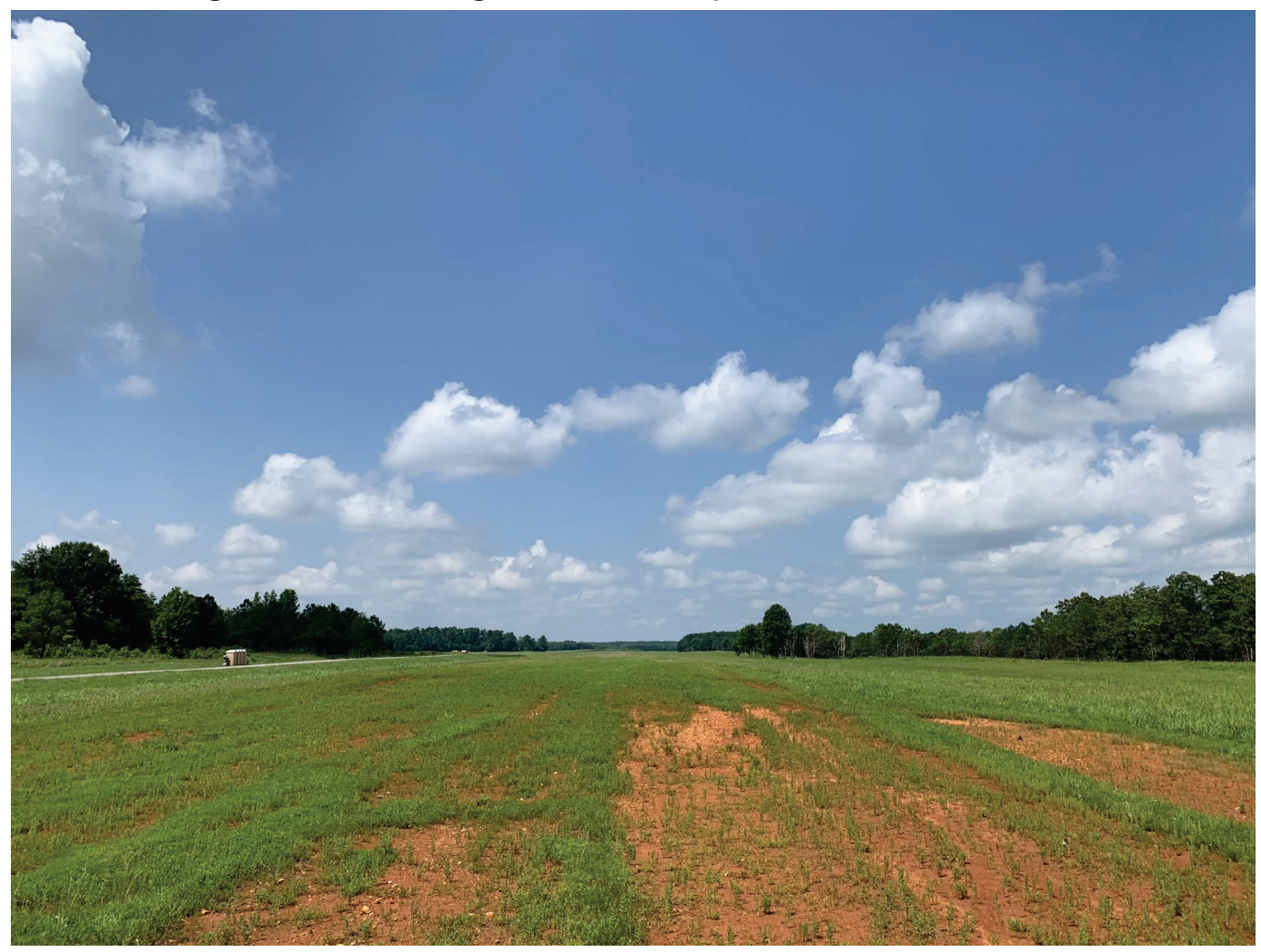


While the Golden Eagle LZ runway and surrounding taxiways appeared to have been in disuse for at least a few years, preliminary DCP measurements, to be discussed in the Site Characterization section, indicated that the underlying soil structure was strong enough to support heavy brake testing. Prior to the main SPRO data collection, personnel from Fort Campbell's Land Rehabilitation and Maintenance (LRAM) team bladed the top few inches of the main runway surface, removing most of the vegetation and exposing the underlying soil structure (see Figure 58).

Figure 58. Golden Eagle LZ main runway after preliminary blading by LRAM.

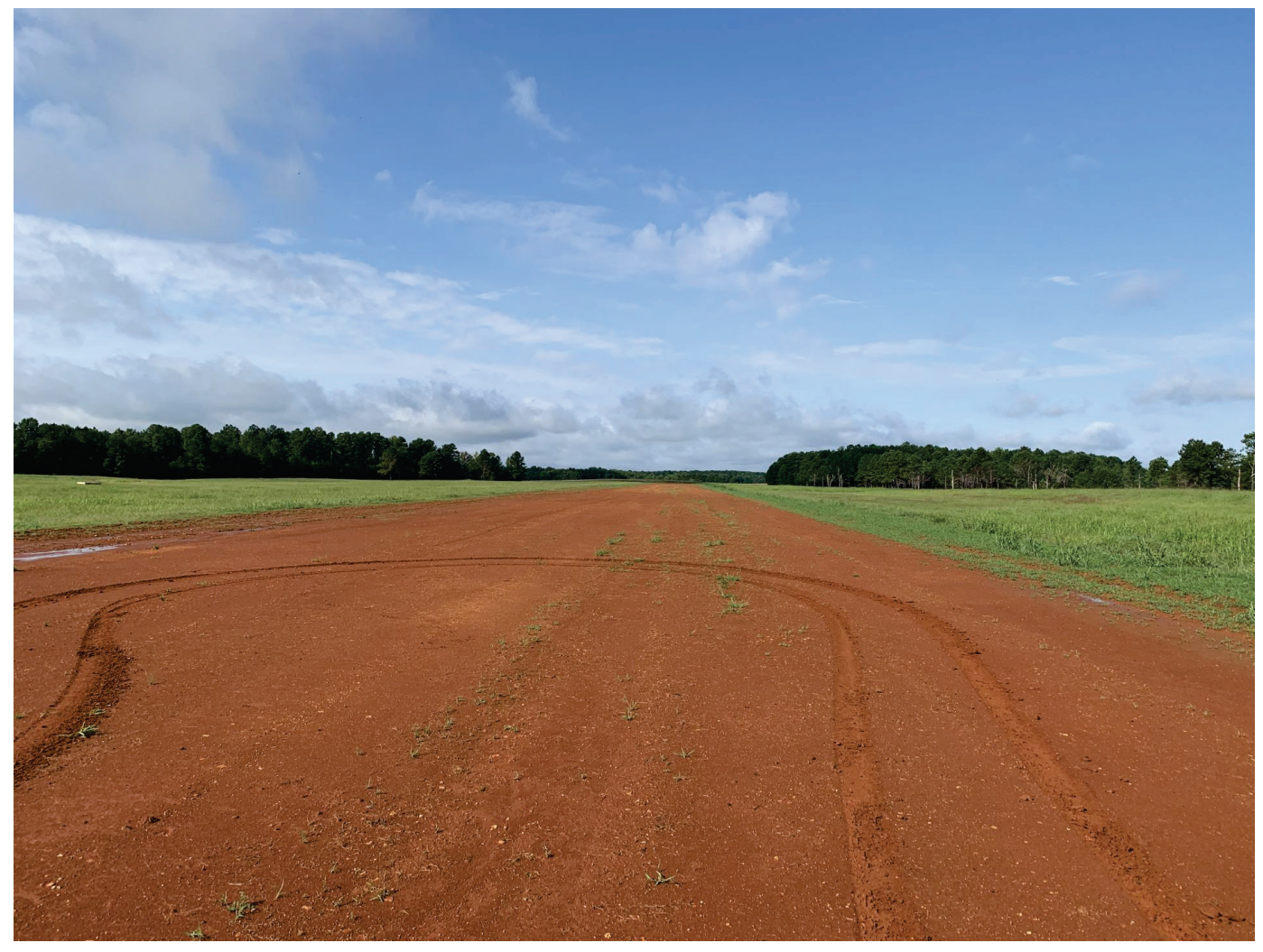

\subsubsection{Heavy equipment}

The main runway, adjacent taxiways, and parking aprons at Golden Eagle LZ exhibited signs of disuse and required surface-recovery efforts before and after data collection. As such, a variety of heavy equipment was procured to perform these tasks (see Table 6). Descriptions of each piece of equipment are provided below. 
Table 6. Heavy equipment used during the Golden Eagle LZ data collection.

\begin{tabular}{|l|l|l|}
\hline \multicolumn{1}{|c|}{$\begin{array}{c}\text { Equipment } \\
\text { Make }\end{array}$} & \multicolumn{1}{|c|}{$\begin{array}{c}\text { Equipment } \\
\text { Model }\end{array}$} & \multicolumn{1}{c|}{ Description } \\
\hline CAT & $120 \mathrm{M} 2$ & $\begin{array}{l}\text { Motor grader, 12-ft moldboard with } \\
\text { 30,000-lb blade pull }\end{array}$ \\
\hline CAT & $918 \mathrm{M}$ & $\begin{array}{l}\text { Front-end loader with front bucket } \\
\text { attachment, operating weight } \\
21,082 \mathrm{lb}\end{array}$ \\
\hline CAT & CS56B & $\begin{array}{l}\text { Smooth steel drum, vibratory roller; } \\
67,600-l b \text { max centrifugal force }\end{array}$ \\
\hline FREIGHTLINER & Ledwell Model & $\begin{array}{l}\text { Water truck, 2,000-gal tier 4; front, } \\
\text { rear, and side spray heads }\end{array}$ \\
\hline
\end{tabular}

As the main runway surface was in disuse, it was determined that a large front-end loader with a front bucket attachment (see Figure 59) was necessary. The front-end loader was used to move large amounts of excess soil from the runway surface during recovery efforts. This piece of equipment was also used to place soil in areas where significant erosion had taken place.

Figure 59. CAT 918M front-end loader.

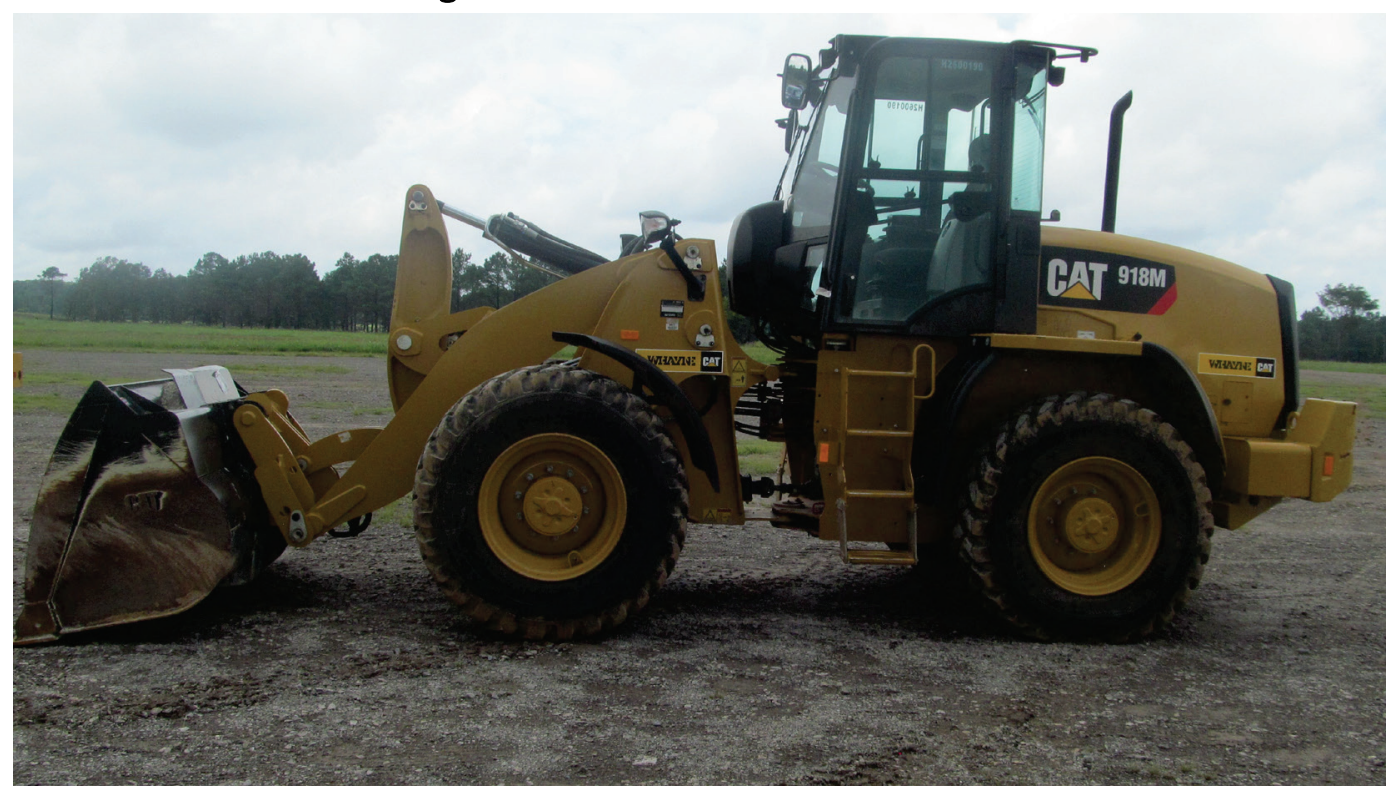

A motor grader with a 12-ft blade (see Figure 60) was necessary to gradecontrol the main runway surface. As with the previous efforts, the motor grader was key in returning the runway surface to a pre-damaged state. 
Figure 60. CAT 120M2 motor grader.

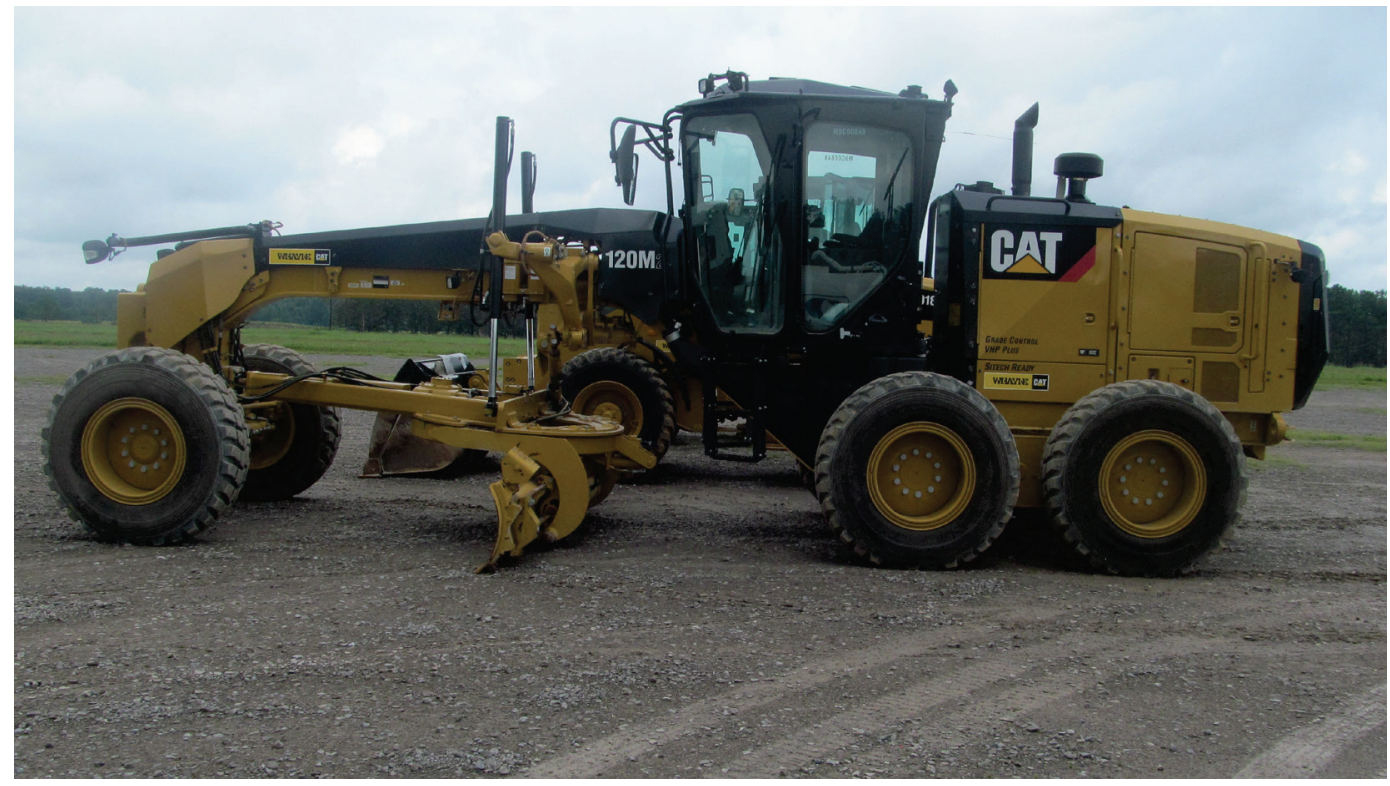

Once the surface had been flattened and grade-controlled and the excess soil had been removed from the area, it was necessary to compact the surface using a vibratory roller compactor (see Figure 61). This piece of equipment allowed for the compaction of surface and near-surface soil for the purposes of heavy brake testing.

Figure 61. CAT CS56B vibratory roller compactor.

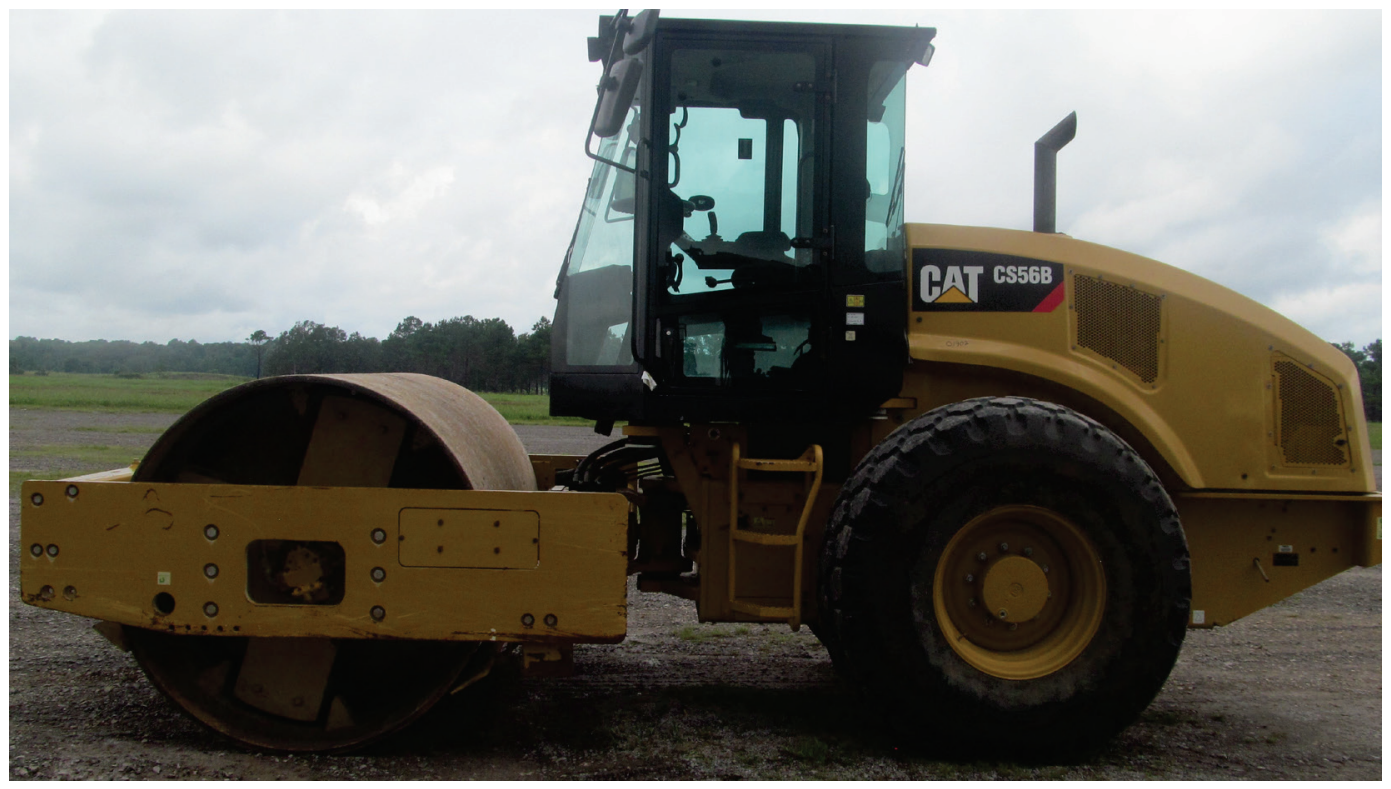

Finally, a pair of 2,000-gal water trucks (see Figure 62) was necessary to control the moisture content of the surface during testing. The pair of water trucks allowed for more efficient wetting of the runway surface. 
Figure 62. FREIGHTLINER 2,000-gal water truck.

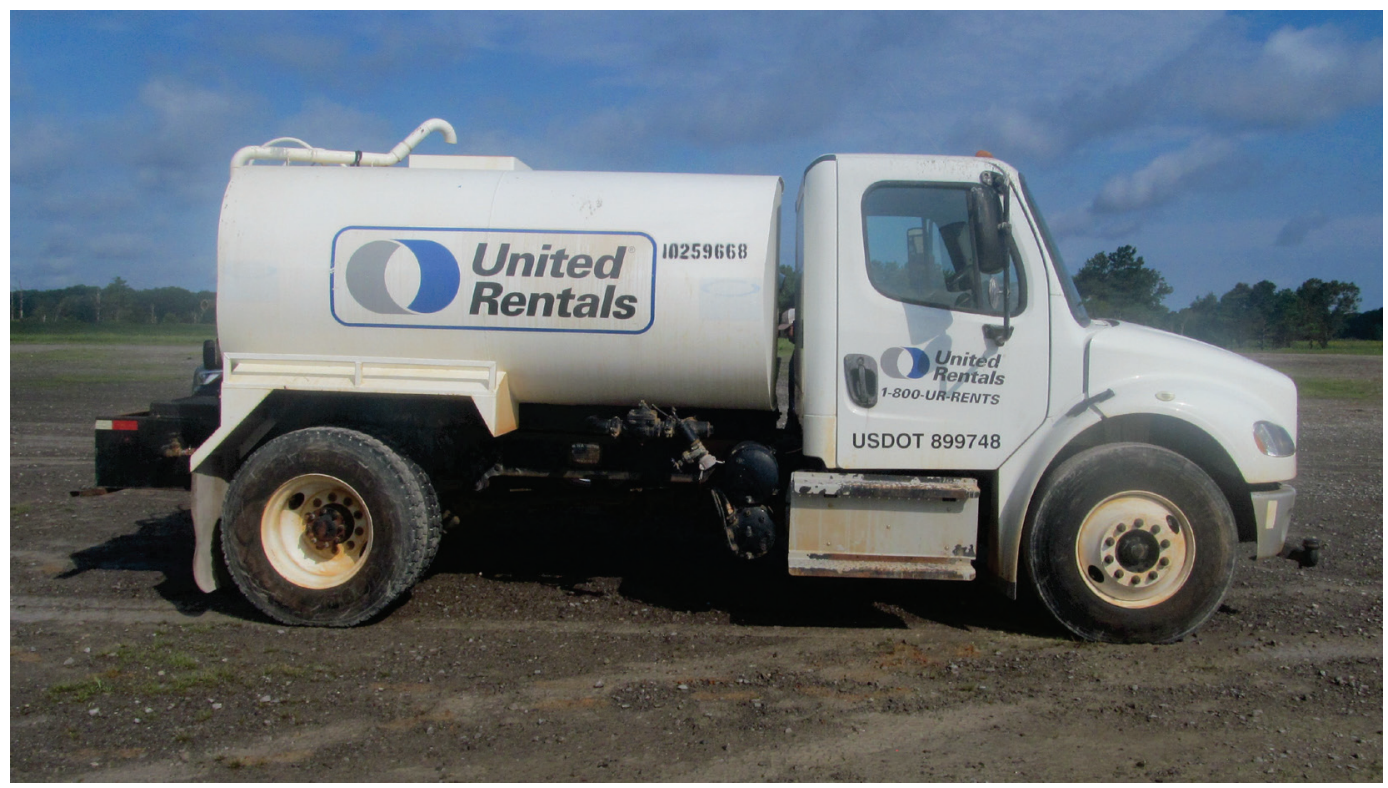

\subsubsection{Recovery efforts}

As mentioned above, the Fort Campbell LRAM team graciously bladed the runway surface prior to the SPRO team's arrival. This allowed for a more expedient surface-recovery effort. Due to inclement weather before and after the team's arrival to Golden Eagle LZ, the SPRO team was unable to operate on the main runway initially, as it was far too saturated to perform controlled testing. As a result, work first began on the adjacent gravel parking apron. The parking apron was approximately $600 \mathrm{ft}$ long by $226 \mathrm{ft}$ wide and appeared to be in good shape. The motor grader and vibratory roller compactor were used to clear off two test areas that ran the length of the apron (see Figure 63a and b). 
Figure 63. Motor grader and compactor on Golden Eagle LZ parking apron.

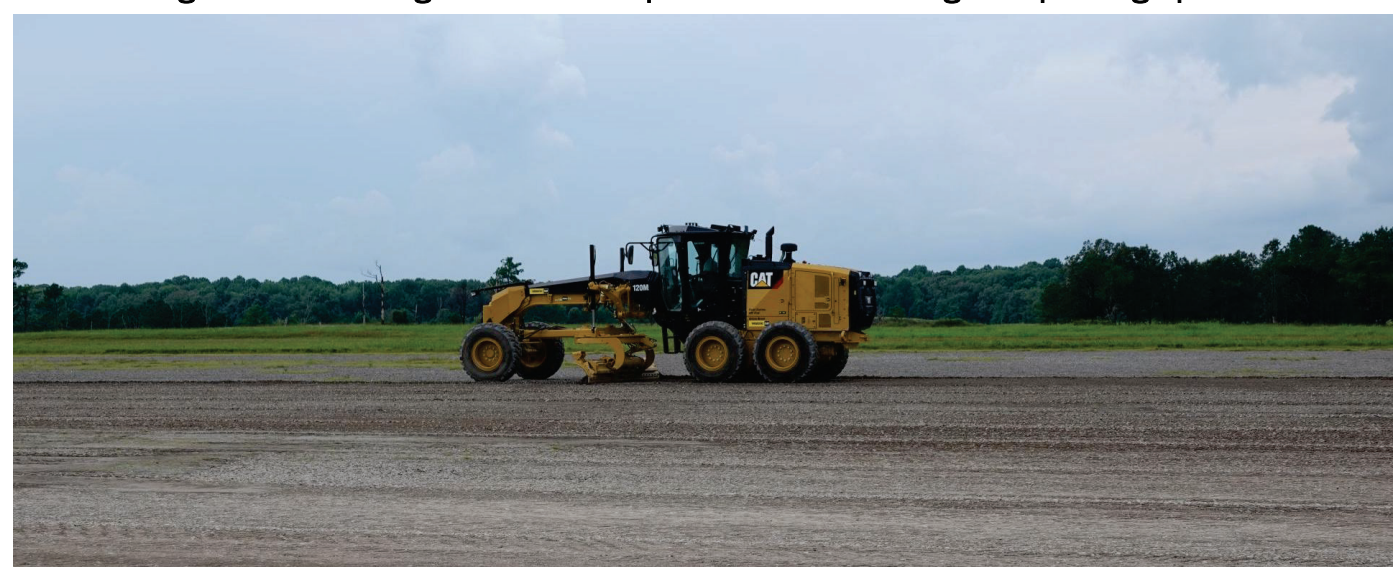

(a) Grade control on the parking apron

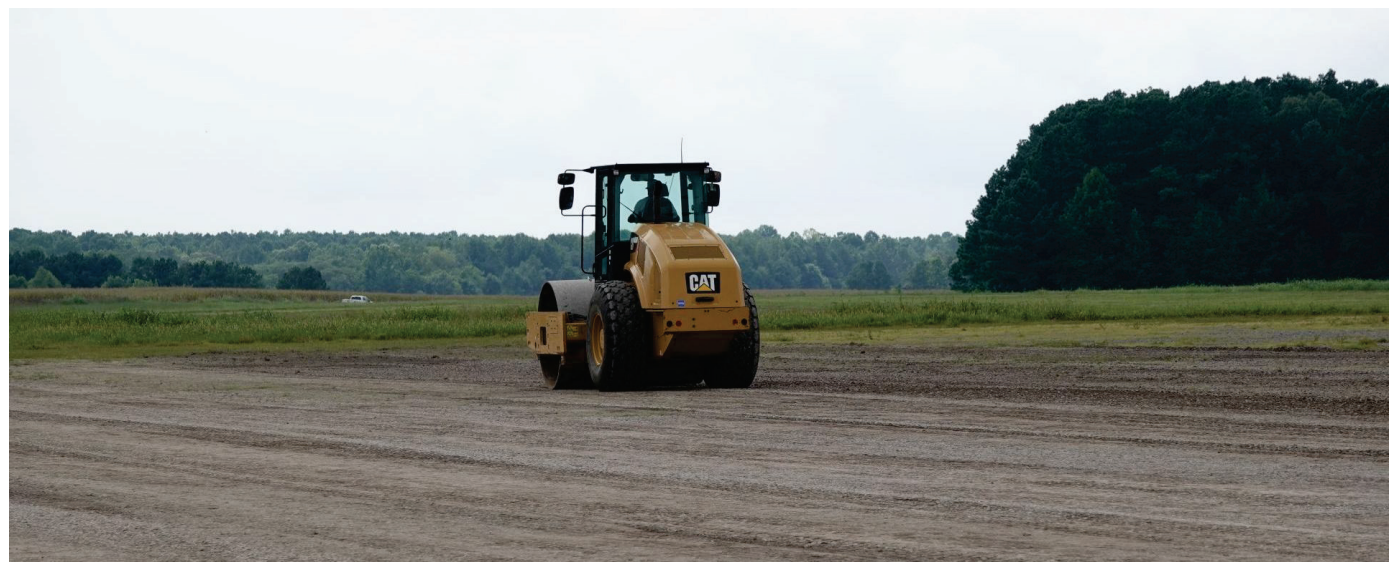

(b) Surface compaction on the parking apron

Following brake tests on the parking apron, weather permitted heavyequipment use on the main runway. The southwest end of the main runway dried the quickest and was the first target for main runway recovery. Work on the southwest end began by first blading the surface with the motor grader (see Figure 64) and then compacting with the vibratory roller (see Figure 65). 
Figure 64. Initial grade control on the southwest end of Golden Eagle LZ.

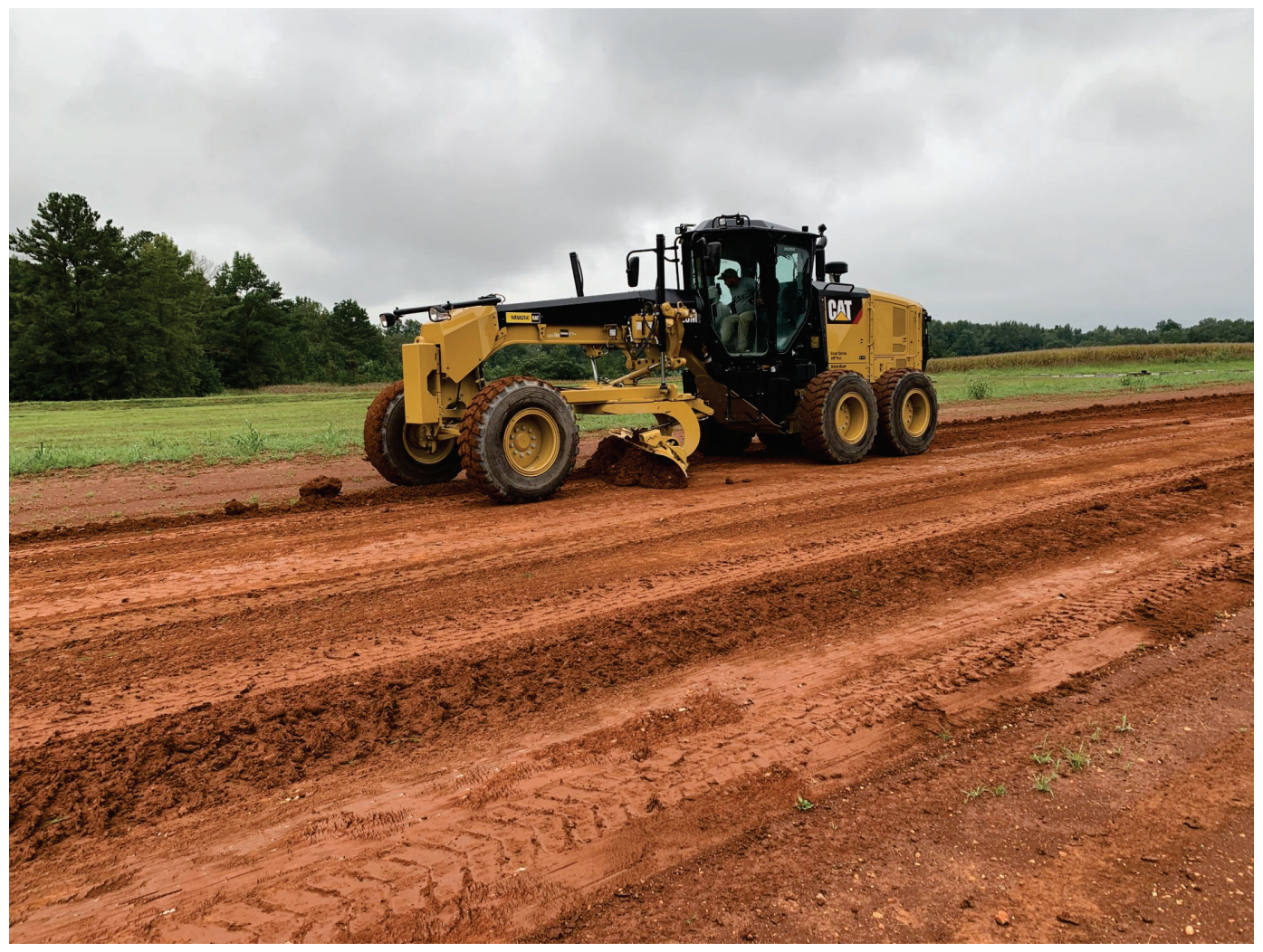

Figure 65. Initial compaction on the southwest end of Golden Eagle $L 7$.

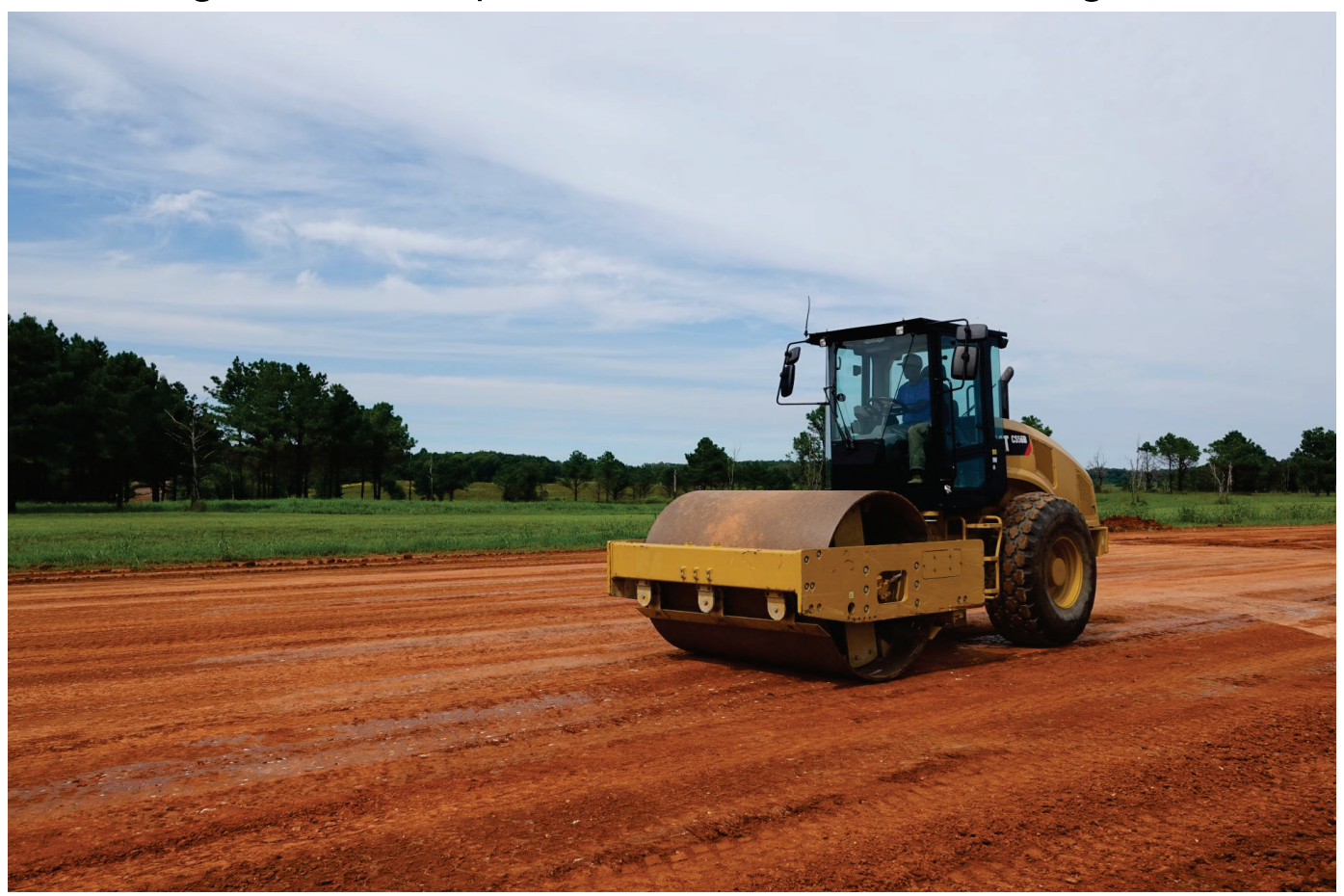


As work continued on the southwest end, the remainder of the main runway began to dry, and recovery efforts moved farther northeast until the full runway was recovered (see Figure 66). It was important here to recover as much of the main runway as possible as repeated testing required the designated brake test site to move.

Figure 66. Blading and compaction continue the length of the runway.

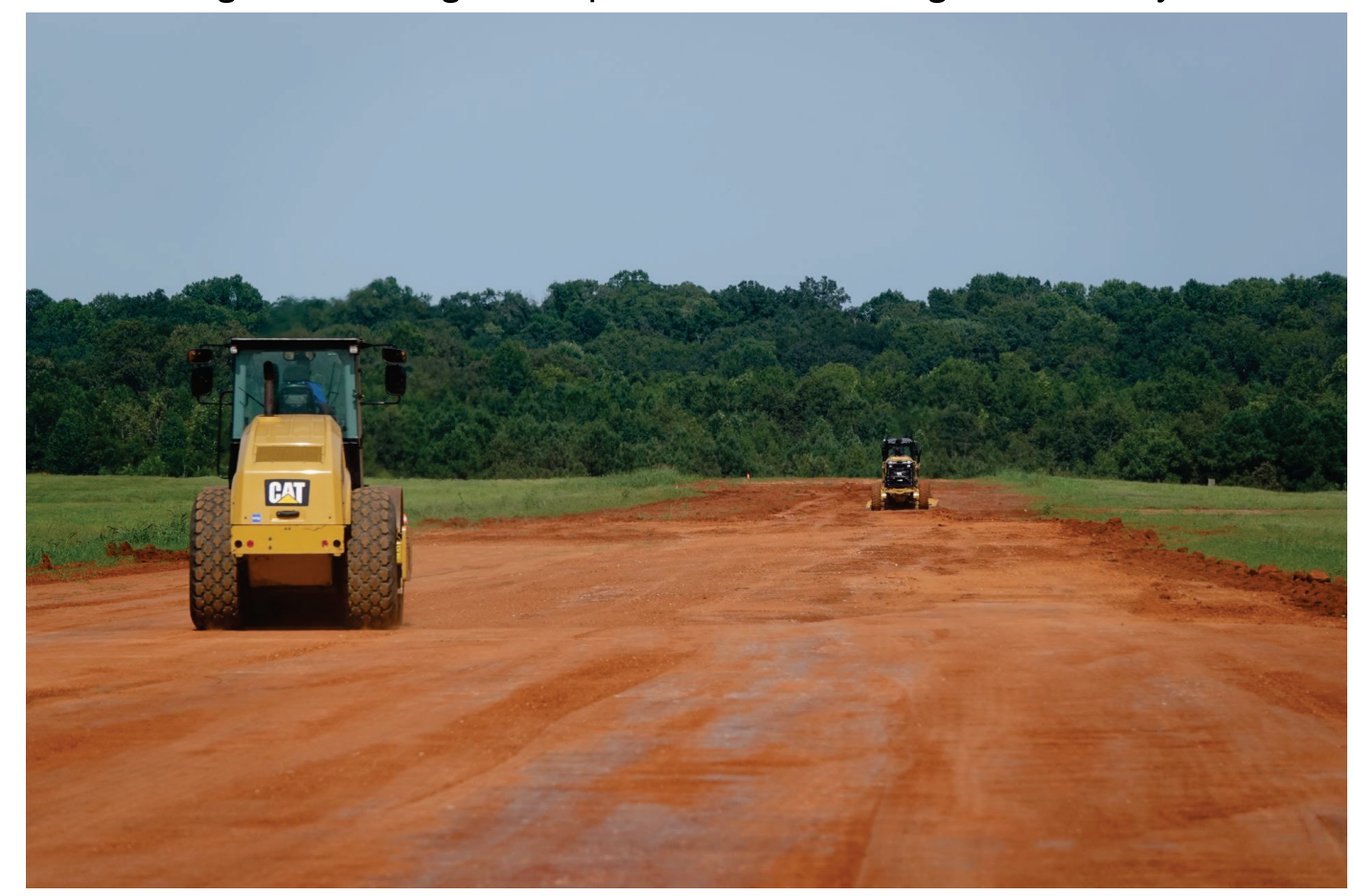

Following the initial surface-recovery process, heavy brake testing began. The recovery mission then became more intermittent. Finally, after all brake tests were completed, a wrap-up surface-recovery mission began by cleaning up all damage done to the surface during testing. As with previous runway recovery work, the motor grader was used to gradecontrol the surface, the compactor was used to compact the surface and near-surface soil, and finally the front-end loader was used to remove large amounts of excess soil from the runway surface (see Figure 67). 
Figure 67. Heavy-equipment wrap-up work on Golden Eagle LZ main runway.

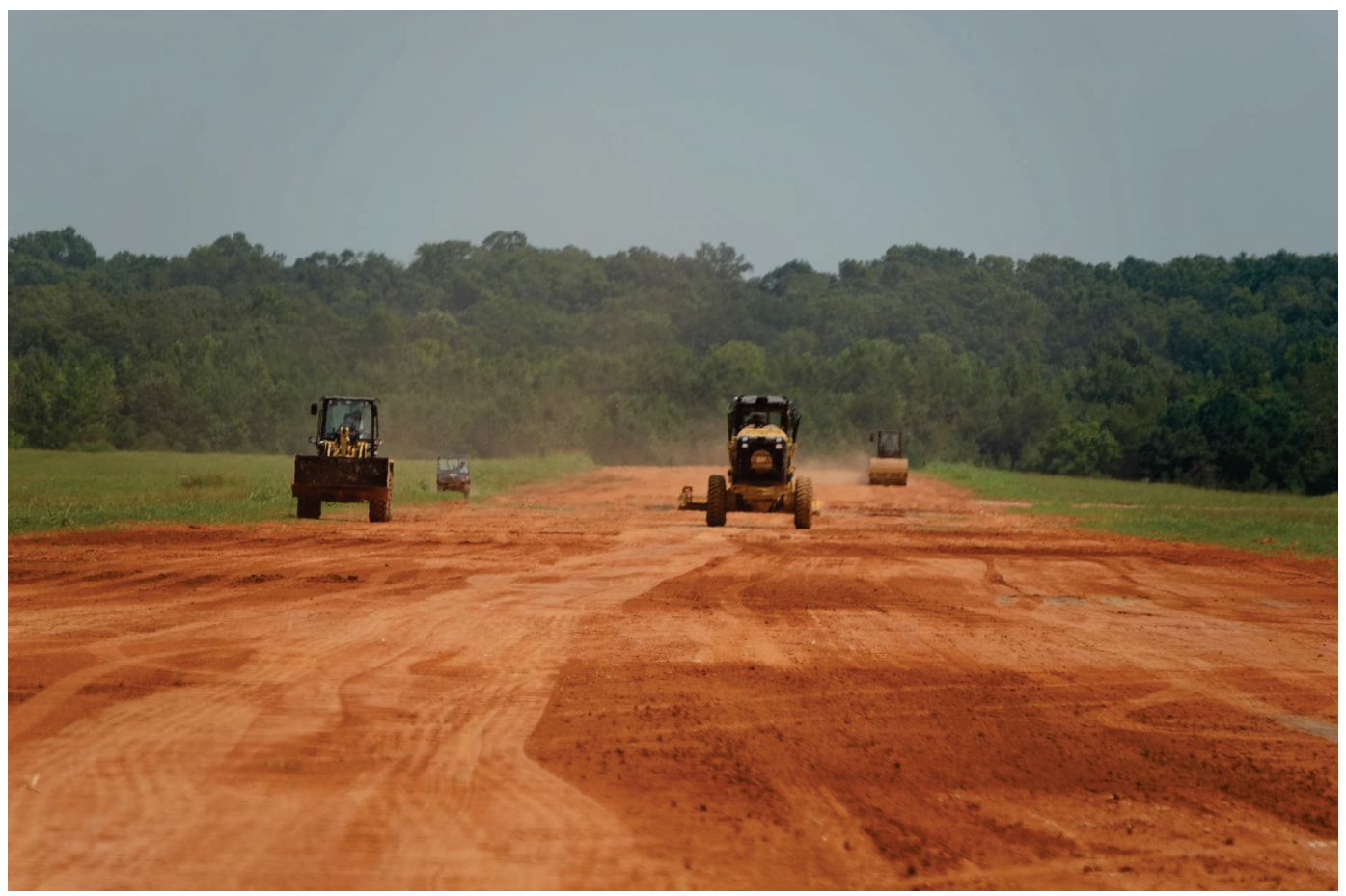

Final DCP measurements, to be discussed in the Site Characterization section, confirmed that the surface had been recovered to a better condition than when the SPRO team first arrived. All excess soil had been removed past the shoulder of the runway, and soil compaction had been completed the length and width of the main runway (see Figure 68a and b). 
Figure 68. Final state of Golden Eagle LZ main runway following all testing.

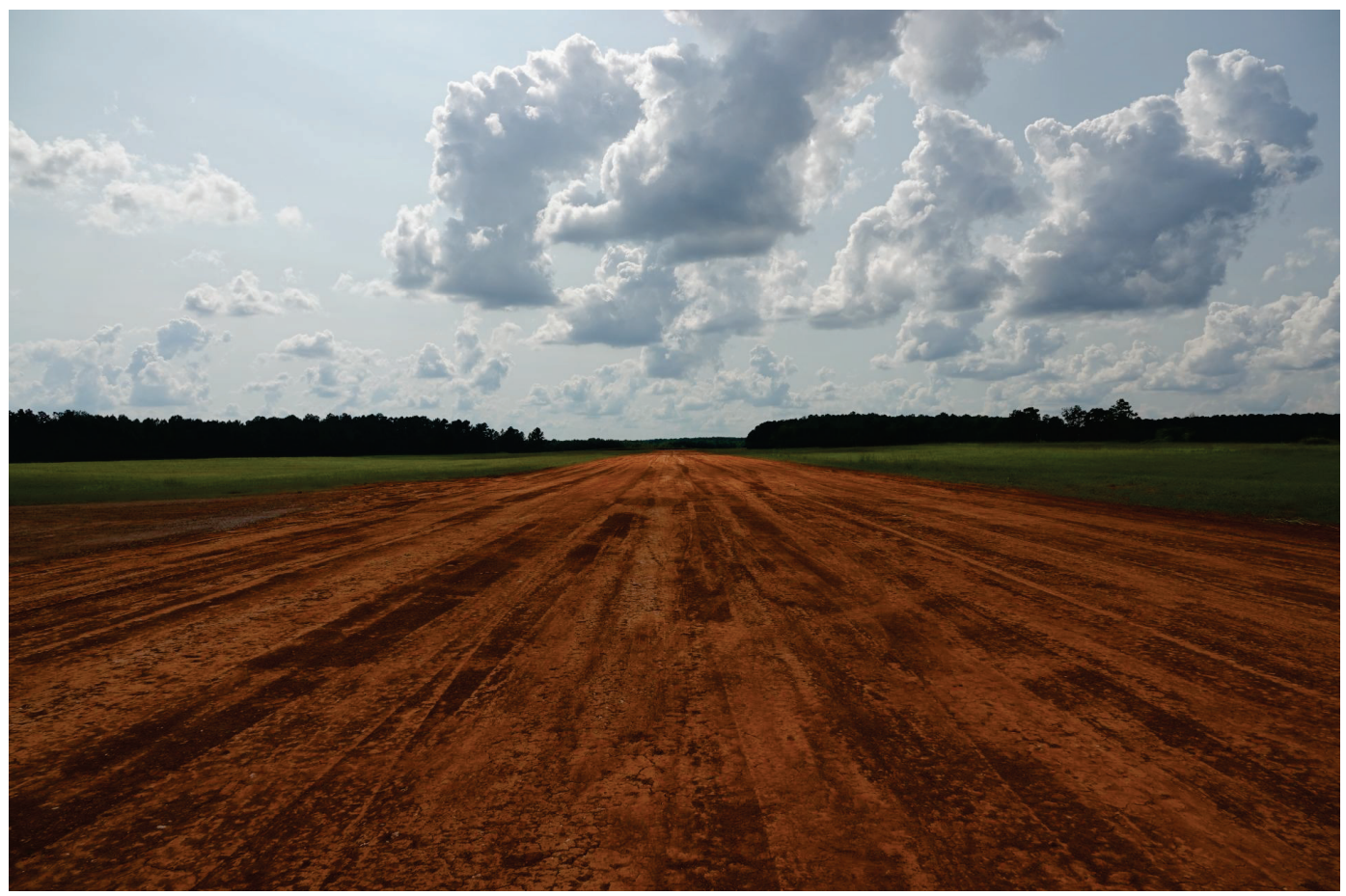

(a) Final main runway surface facing southwest

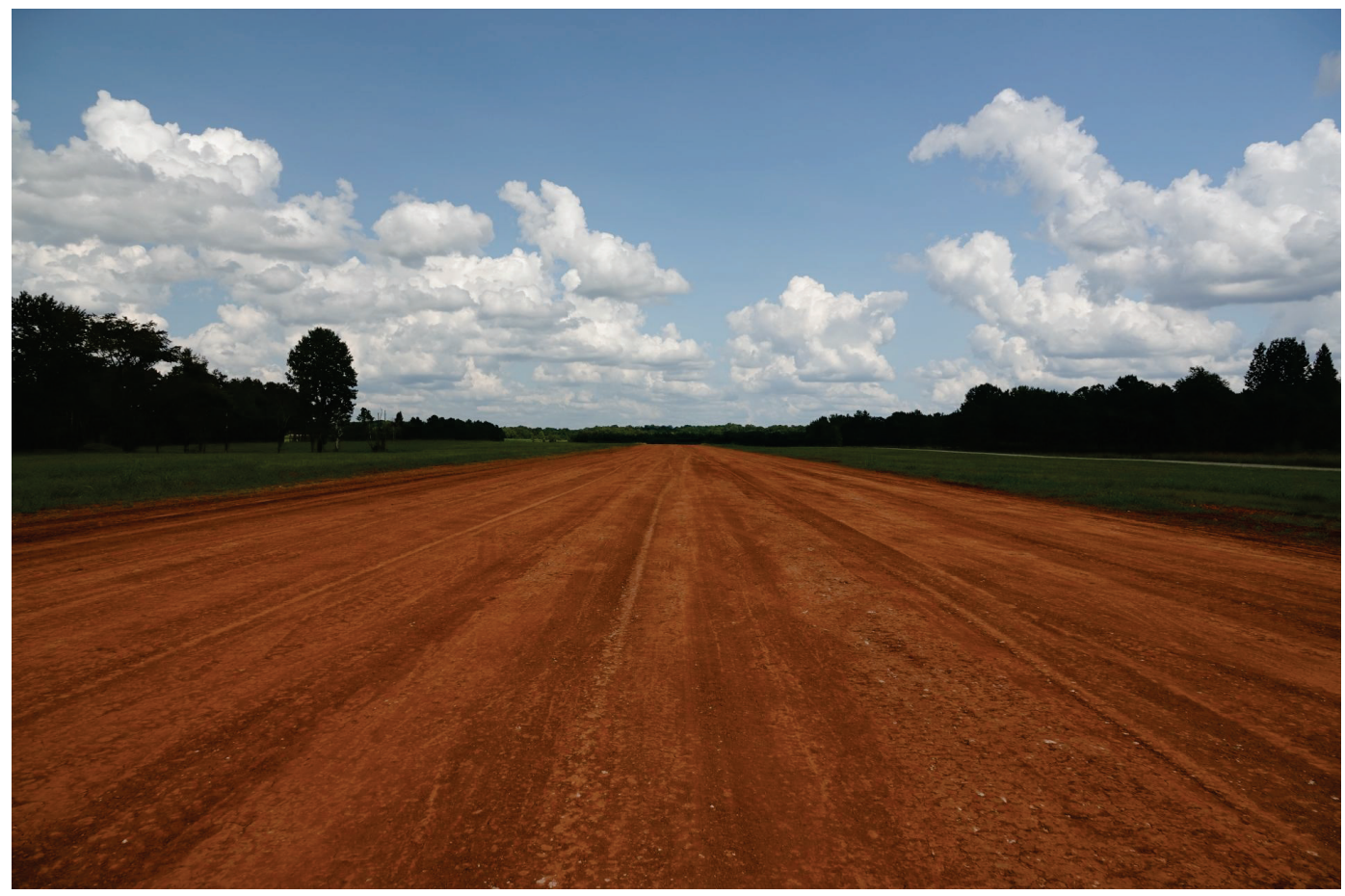

(b) Final main runway surface facing northeast 


\section{Site Characterization}

In order to choose an appropriate test site within each airfield, a site characterization study was conducted. These studies consisted of determining in-situ soil strength by use of the DCP test and soil classification by use of lab-based gradation and plasticity testing. Aerial surveys were also conducted when permitted by local range operations and weather conditions. Details regarding this range of testing for each airfield are discussed below.

\subsection{Rattlesnake Landing Zone}

As referenced in Section 4.1.1, Rattlesnake LZ was in a disused, poor condition upon arrival. This condition necessitated the use of DCP tests to determine what part, if any, of the underlying surface was suitable for repeated brake testing. Further tests were conducted in a lab setting to determine soil classification. Lastly, sUAS flights were conducted on the entire runway surface in order to accurately map all test areas. Details regarding these tests are discussed in the following three sub-sections.

\subsubsection{Soil strength}

The in-situ strength of Rattlesnake LZ's underlying soil structure was obtained prior to testing by use of the DCP test. A rough centerline was determined, and tests were conducted every 1,000 ft. Adjacent DCP tests were also conducted $50 \mathrm{ft}$ north and south of the center line, also at 1,000$\mathrm{ft}$ intervals. The soil structure results from these tests can be seen in Table 7 to Table 9. The pre-test soil surface was dry. 
Table 7. CBR values on the Rattlesnake LZ centerline.

\begin{tabular}{|c|c|c|c|c|c|c|}
\hline \multirow{3}{*}{$\begin{array}{l}\text { Depth } \\
\text { (inches) }\end{array}$} & \multicolumn{6}{|c|}{ CBR } \\
\hline & \multicolumn{6}{|c|}{ Centerline } \\
\hline & $00+00$ & $10+00$ & $20+00$ & $30+00$ & $40+00$ & $50+00$ \\
\hline 0 & \multirow{10}{*}{7} & \multirow{5}{*}{6} & \multirow{15}{*}{12} & \multirow{10}{*}{5} & \multirow{16}{*}{3} & \multirow{20}{*}{7} \\
\hline 1 & & & & & & \\
\hline 2 & & & & & & \\
\hline 3 & & & & & & \\
\hline 4 & & & & & & \\
\hline 5 & & \multirow{20}{*}{48} & & & & \\
\hline 6 & & & & & & \\
\hline 7 & & & & & & \\
\hline 8 & & & & & & \\
\hline 9 & & & & & & \\
\hline 10 & \multirow{11}{*}{18} & & & \multirow{10}{*}{8} & & \\
\hline 11 & & & & & & \\
\hline 12 & & & & & & \\
\hline 13 & & & & & & \\
\hline 14 & & & & & & \\
\hline 15 & & & \multirow{7}{*}{34} & & & \\
\hline 16 & & & & & \multirow{5}{*}{16} & \\
\hline 17 & & & & & & \\
\hline 18 & & & & & & \\
\hline 19 & & & & & & \\
\hline 20 & & & & \multirow{12}{*}{79} & & \multirow{12}{*}{52} \\
\hline 21 & \multirow{11}{*}{85} & & & & \multirow{11}{*}{34} & \\
\hline 22 & & & \multirow{10}{*}{89} & & & \\
\hline 23 & & & & & & \\
\hline 24 & & & & & & \\
\hline 25 & & \multirow{7}{*}{57} & & & & \\
\hline 26 & & & & & & \\
\hline 27 & & & & & & \\
\hline 28 & & & & & & \\
\hline 29 & & & & & & \\
\hline 30 & & & & & & \\
\hline 31 & & & & & & \\
\hline
\end{tabular}


Table 8. CBR values $50 \mathrm{ft}$ north of the Rattlesnake $L Z$ centerline.

\begin{tabular}{|c|c|c|c|c|c|c|}
\hline \multirow{3}{*}{$\begin{array}{l}\text { Depth } \\
\text { (inches) }\end{array}$} & \multicolumn{6}{|c|}{ CBR } \\
\hline & \multicolumn{6}{|c|}{$50-\mathrm{ft}$ North of Centerline } \\
\hline & $00+00$ & $10+00$ & $20+00$ & $30+00$ & $40+00$ & $50+00$ \\
\hline 0 & \multirow{7}{*}{13} & \multirow{8}{*}{12} & \multirow{20}{*}{8} & \multirow{14}{*}{1} & \multirow{11}{*}{2} & \multirow{10}{*}{2} \\
\hline 1 & & & & & & \\
\hline 2 & & & & & & \\
\hline 3 & & & & & & \\
\hline 4 & & & & & & \\
\hline 5 & & & & & & \\
\hline 6 & & & & & & \\
\hline 7 & \multirow{9}{*}{34} & & & & & \\
\hline 8 & & \multirow{24}{*}{57} & & & & \\
\hline 9 & & & & & & \\
\hline 10 & & & & & & \multirow{10}{*}{35} \\
\hline 11 & & & & & \multirow{11}{*}{9} & \\
\hline 12 & & & & & & \\
\hline 13 & & & & & & \\
\hline 14 & & & & \multirow{8}{*}{7} & & \\
\hline 15 & & & & & & \\
\hline 16 & \multirow{16}{*}{83} & & & & & \\
\hline 17 & & & & & & \\
\hline 18 & & & & & & \\
\hline 19 & & & & & & \\
\hline 20 & & & \multirow{12}{*}{99} & & & \multirow{12}{*}{85} \\
\hline 21 & & & & & & \\
\hline 22 & & & & \multirow{10}{*}{24} & \multirow{10}{*}{30} & \\
\hline 23 & & & & & & \\
\hline 24 & & & & & & \\
\hline 25 & & & & & & \\
\hline 26 & & & & & & \\
\hline 27 & & & & & & \\
\hline 28 & & & & & & \\
\hline 29 & & & & & & \\
\hline 30 & & & & & & \\
\hline 31 & & & & & & \\
\hline
\end{tabular}


Table 9. CBR values $50 \mathrm{ft}$ south of the Rattlesnake $L Z$ centerline.

\begin{tabular}{|c|c|c|c|c|c|c|}
\hline \multirow{3}{*}{$\begin{array}{l}\text { Depth } \\
\text { (inches) }\end{array}$} & \multicolumn{6}{|c|}{ CBR } \\
\hline & \multicolumn{6}{|c|}{ 50-ft South of Centerline } \\
\hline & $00+00$ & $10+00$ & $20+00$ & $30+00$ & $40+00$ & $50+00$ \\
\hline 0 & \multirow{9}{*}{2} & \multirow{14}{*}{2} & \multirow{16}{*}{5} & \multirow{19}{*}{1} & \multirow{18}{*}{4} & \multirow{16}{*}{3} \\
\hline 1 & & & & & & \\
\hline 2 & & & & & & \\
\hline 3 & & & & & & \\
\hline 4 & & & & & & \\
\hline 5 & & & & & & \\
\hline 6 & & & & & & \\
\hline 7 & & & & & & \\
\hline 8 & & & & & & \\
\hline 9 & \multirow{10}{*}{19} & & & & & \\
\hline 10 & & & & & & \\
\hline 11 & & & & & & \\
\hline 12 & & & & & & \\
\hline 13 & & & & & & \\
\hline 14 & & \multirow{18}{*}{44} & & & & \\
\hline 15 & & & & & & \\
\hline 16 & & & \multirow{16}{*}{18} & & & \\
\hline 17 & & & & & & \\
\hline 18 & & & & & & \\
\hline 19 & \multirow{13}{*}{96} & & & & & 24 \\
\hline 20 & & & & & & \\
\hline 21 & & & & & & \\
\hline 22 & & & & & & \\
\hline 23 & & & & & & \multirow{9}{*}{15} \\
\hline 24 & & & & & 13 & \\
\hline 25 & & & & 60 & D & \\
\hline 26 & & & & & & \\
\hline 27 & & & & & & \\
\hline 28 & & & & & & \\
\hline 29 & & & & & & \\
\hline 30 & & & & & & \\
\hline 31 & & & & & & \\
\hline
\end{tabular}

As expected, based on the disused nature of the landing zone, much of the runway surface had degraded and exhibited very poor strength characteristics. As can be seen in Table 9, the entire southern portion of the runway exhibited CBR values at or less than 5 down as far as the first 18 in. Only the first $1,000 \mathrm{ft}$ of the runway north of the centerline was suitable for repeated brake testing (i.e., had CBR values greater than 10 for the first 6 to 7 in.). The remainder of the runway surface was largely unusable with an 
average CBR value of 5 for the first layer. Further DCP tests were conducted on the test surface following recovery operations and brake testing (see Table 10). These tests were conducted only on the recovered test surface at each of the three brake sites. It should be noted that significant rainfall took place two days prior to the post-test DCP collection.

Table 10. CBR values from the recovered test site on Rattlesnake LZ.

\begin{tabular}{|c|c|c|c|c|c|c|}
\hline \multirow{3}{*}{$\begin{array}{c}\text { Depth } \\
\text { (inches) }\end{array}$} & \multicolumn{6}{|c|}{ CBR } \\
\hline & \multicolumn{6}{|c|}{ Site A } \\
\hline & $\begin{array}{c}\text { Brake } 1 \\
\text { Left }\end{array}$ & $\begin{array}{c}\text { Brake 1 } \\
\text { Right }\end{array}$ & $\begin{array}{c}\text { Brake 2 } \\
\text { Left }\end{array}$ & $\begin{array}{c}\text { Brake } 2 \\
\text { Right }\end{array}$ & $\begin{array}{c}\text { Brake } 3 \\
\text { Left }\end{array}$ & $\begin{array}{c}\text { Brake } 3 \\
\text { Right }\end{array}$ \\
\hline 0 & \multirow{14}{*}{6} & \multirow{18}{*}{5} & \multirow{15}{*}{2} & \multirow{18}{*}{2} & \multirow{16}{*}{3} & \multirow{16}{*}{1} \\
\hline 1 & & & & & & \\
\hline 2 & & & & & & \\
\hline 3 & & & & & & \\
\hline 4 & & & & & & \\
\hline 5 & & & & & & \\
\hline 6 & & & & & & \\
\hline 7 & & & & & & \\
\hline 8 & & & & & & \\
\hline 9 & & & & & & \\
\hline 10 & & & & & & \\
\hline 11 & & & & & & \\
\hline 12 & & & & & & \\
\hline 13 & & & & & & \\
\hline 14 & \multirow{18}{*}{14} & & & & & \\
\hline 15 & & & \multirow{17}{*}{3} & & & \\
\hline 16 & & & & & \multirow{16}{*}{7} & \multirow{16}{*}{5} \\
\hline 17 & & & & & & \\
\hline 18 & & \multirow{14}{*}{13} & & \multirow{14}{*}{5} & & \\
\hline 19 & & & & & & \\
\hline 20 & & & & & & \\
\hline 21 & & & & & & \\
\hline 22 & & & & & & \\
\hline 23 & & & & & & \\
\hline 24 & & & & & & \\
\hline 25 & & & & & & \\
\hline 26 & & & & & & \\
\hline 27 & & & & & & \\
\hline 28 & & & & & & \\
\hline 29 & & & & & & \\
\hline 30 & & & & & & \\
\hline 31 & & & & & & \\
\hline
\end{tabular}


The post-test DCP results are largely ambiguous as heavy rainfall took place immediately following surface-recovery efforts. It is notable that even following multiple passes with a vibratory steel-wheel roller compactor, the rain-soaked surface exhibited poor CBR values (less than 10) down as far as the first $17 \mathrm{in}$. This is an expected result, given the surface's largely clay composition, as will be discussed in the following sub-section.

\subsubsection{Soil classification}

In order to accurately classify the soil tested at Rattlesnake LZ, a representative sample was taken from the recovered runway surface and processed at a third-party laboratory. Classification of the collected soil sample was determined by use of two general analyses: Atterberg limits and gradation. A summary of soil analysis results for Rattlesnake LZ can be found in Table 11 .

Table 11. Soil analysis data for SPRO sites.

\begin{tabular}{|l|l|l|l|l|l|l|l|l|l|l|l|}
\hline \multirow{2}{*}{\multicolumn{1}{|c}{ Site }} & \multicolumn{3}{|c|}{$\begin{array}{c}\text { Atterberg } \\
\text { Limits }\end{array}$} & \multicolumn{3}{c|}{$\begin{array}{c}\text { Percent } \\
\text { Gravel }\end{array}$} & \multicolumn{4}{c|}{$\begin{array}{c}\text { Percent } \\
\text { Sand }\end{array}$} & \multicolumn{2}{c|}{$\begin{array}{c}\text { Percent } \\
\text { Fines }\end{array}$} \\
\cline { 2 - 13 } & PL & LL & PI & Coarse & Fine & Coarse & Medium & Fine & Silt & Clay \\
\hline Rattlesnake LZ & 19 & 51 & 32 & 0.0 & 0.0 & 0.0 & 2.4 & 5.8 & 47.2 & 44.6 \\
\hline Schoonover LZ & 16 & 22 & 6 & 0.0 & 8.9 & 16.4 & 38.4 & 19.9 & 16.4 \\
\hline Golden Eagle LZ & 16 & 38 & 22 & 0.0 & 2.6 & 1.4 & 2.8 & 7.9 & 38.9 & 46.4 \\
\hline
\end{tabular}

A plasticity chart, based on ASTM D2487-17 (2017a), for the Rattlesnake LZ soil sample revealed that the surface material was likely a high plasticity clay (see Figure 69). 
Figure 69. Plasticity chart for SPRO sites.

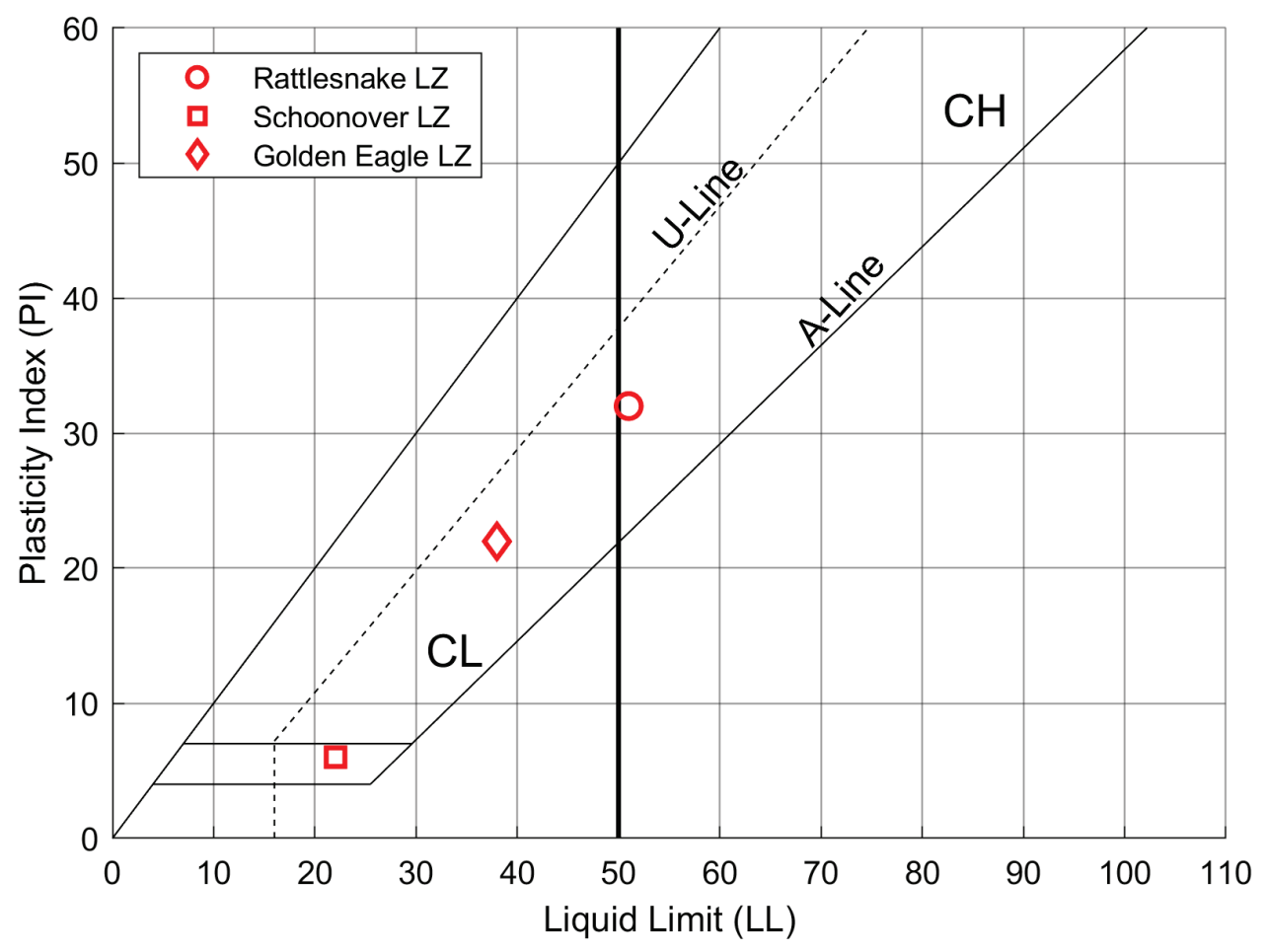

Furthermore, gradation testing revealed a large portion of the sample passed the No. 200 sieve (see Figure 70). The USCS classification for a soil of this type is $\mathrm{CH}$, or a high plasticity clay. Combined with a visual analysis, the soil can be further classified as a tan clay $(\mathrm{CH})$, slightly sandy with silty clay pockets. 
Figure 70. Gradation chart for Rattlesnake LZ soil sample.

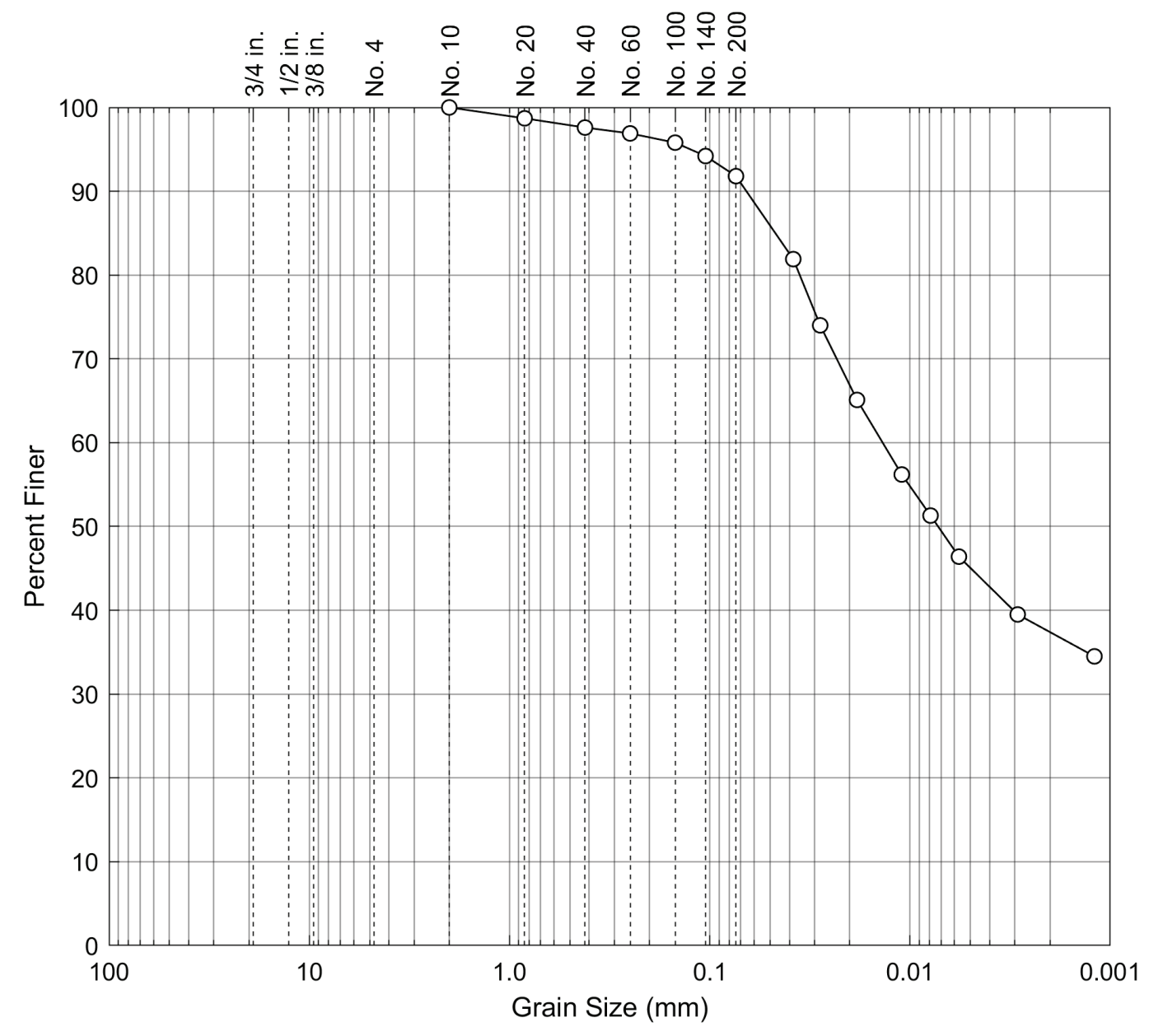

\subsubsection{Aerial survey}

Two aerial surveys were conducted on Rattlesnake LZ. The first was a 200-ft altitude survey mission using the FireFLY 6 PRO sUAS and Sony A600o EO camera. The second was a 400-ft altitude survey mission with the same sUAS and a Sony RX1R EO camera. The airfield was inside restricted Class G airspace (see Figure 71) under the control of Fort Chaffee and, as a result, signed approval from Fort Chaffee Range Control was obtained prior to flight operations. 
Figure 71. Rattlesnake LZ sectional chart.

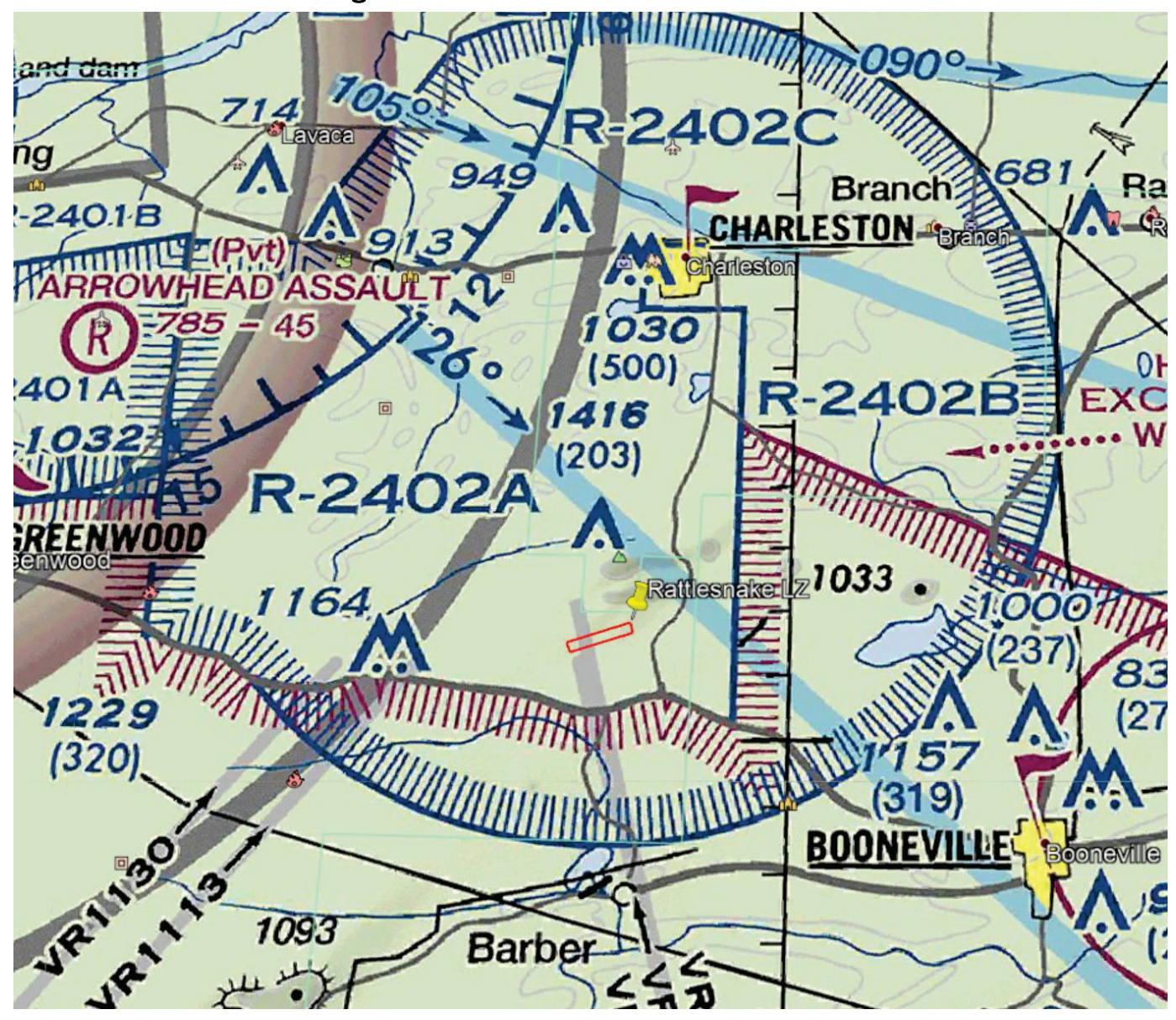

Photogrammetric reconstructions resulting from the $400-\mathrm{ft}$ altitude survey can be seen in Figure 43 and Figure 44. The 200-ft altitude survey allowed for a very high-resolution survey of just the recovered test site. Examples of surface degradation following brake testing can be seen in Figure 72a and b. 
Figure 72. Brake site sUAS imagery on Rattlesnake LZ.

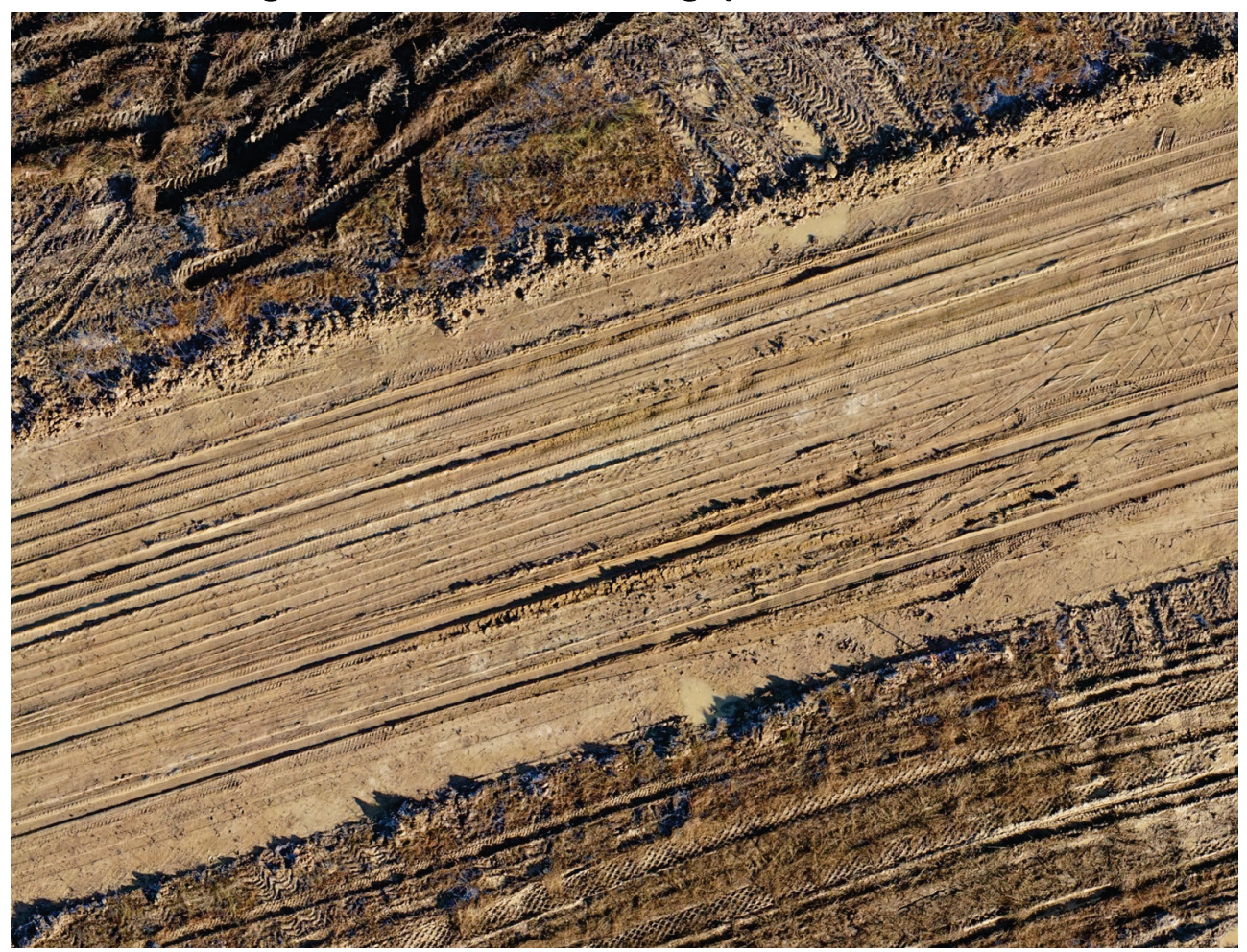

(a) Brake site 2

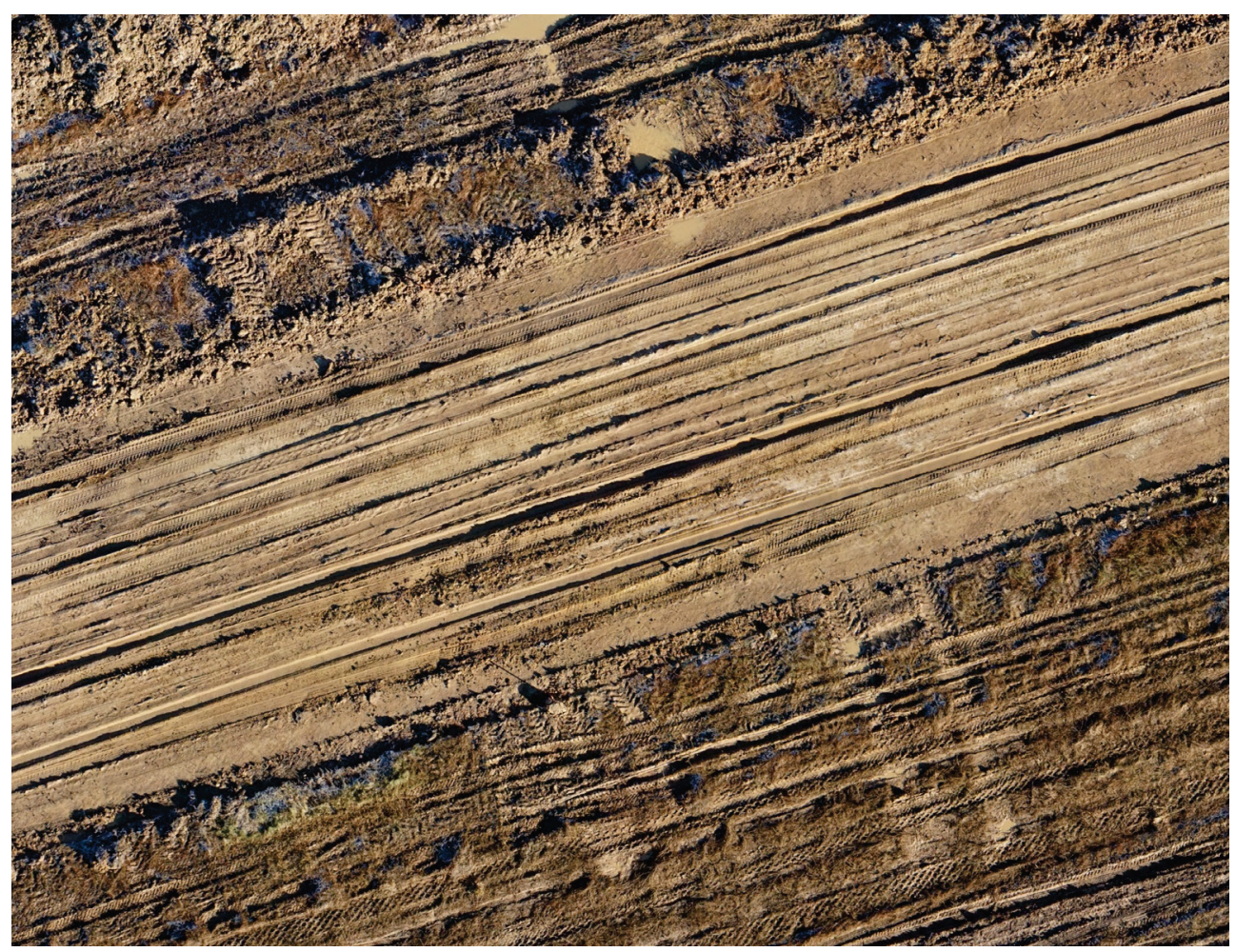

(b) Brake site 3 
Finally, the sUAS surveys combined with existing Google Earth satellite imagery allowed for a direct comparison of the historical condition of Rattlesnake LZ with the condition upon completion of all SPRO activities on site. This comparison, seen in Figure 73a and b, reveals the degraded and disused condition of the LZ prior to arrival.

Figure 73. Before and after of Rattlesnake LZ main runway.

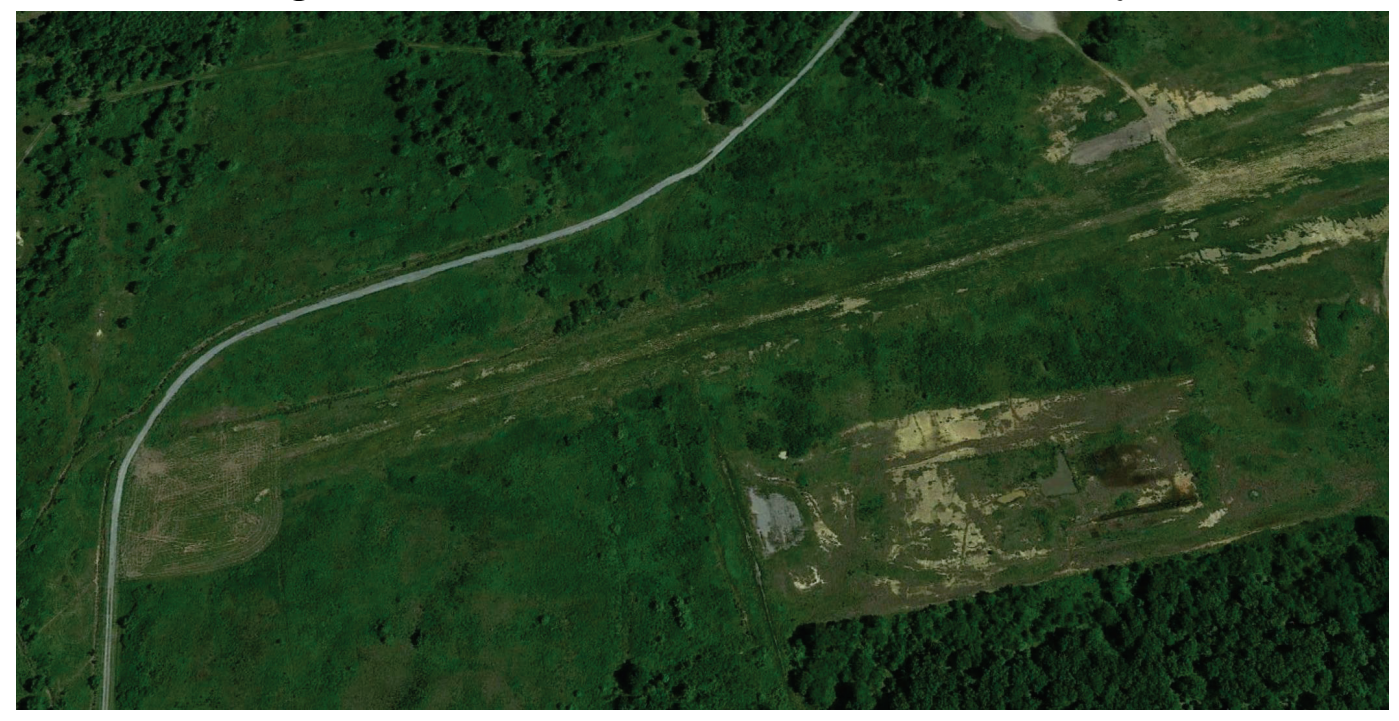

(a) Before state of Rattlesnake LZ, based on Google Earth imagery

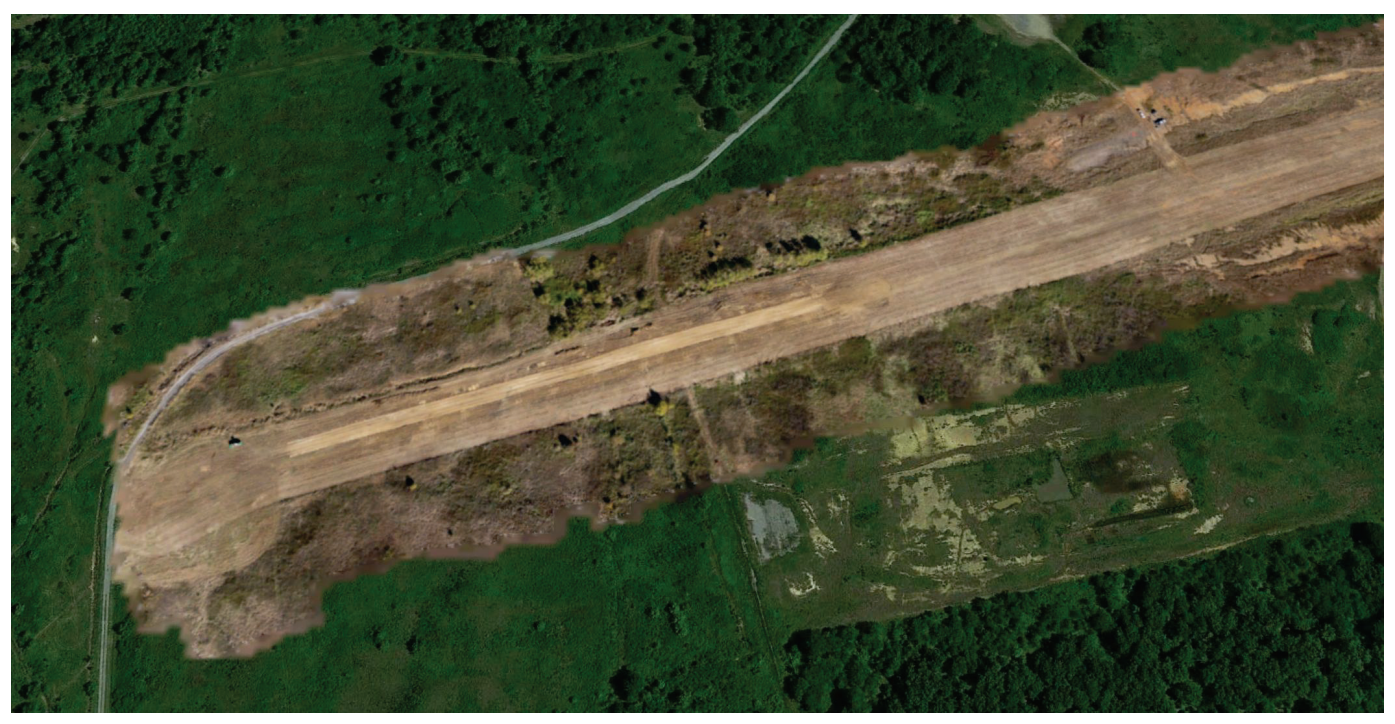

(b) After state of Rattlesnake LZ, based on sUAS survey flights

\subsection{Schoonover Landing Zone}

As referenced in Section 4.2.1, Schoonover LZ was in excellent condition upon arrival. Furthermore, a recent airfield condition survey had been conducted on the LZ by the ERDC airfield inspection team. This condition 
survey revealed a number of soil characteristics and helped inform site preparation tasks. Lastly, sUAS flights were conducted on a limited basis. Details regarding these tests are discussed in the following three sub-sections.

\subsubsection{Soil strength}

Analysis of a previously conducted airfield condition survey completed in 2018 revealed very high CBR values along the main runway at Schoonover LZ (Bly 2018). DCP refusals (instances where no cone penetration was recorded following multiple hammer drops) were reported along the main runway, and the corresponding CBR values were approximated to be 100 (see Figure 74).

Figure 74. CBR vs. depth along the main runway at Schoonover LZ (Bly 2018).

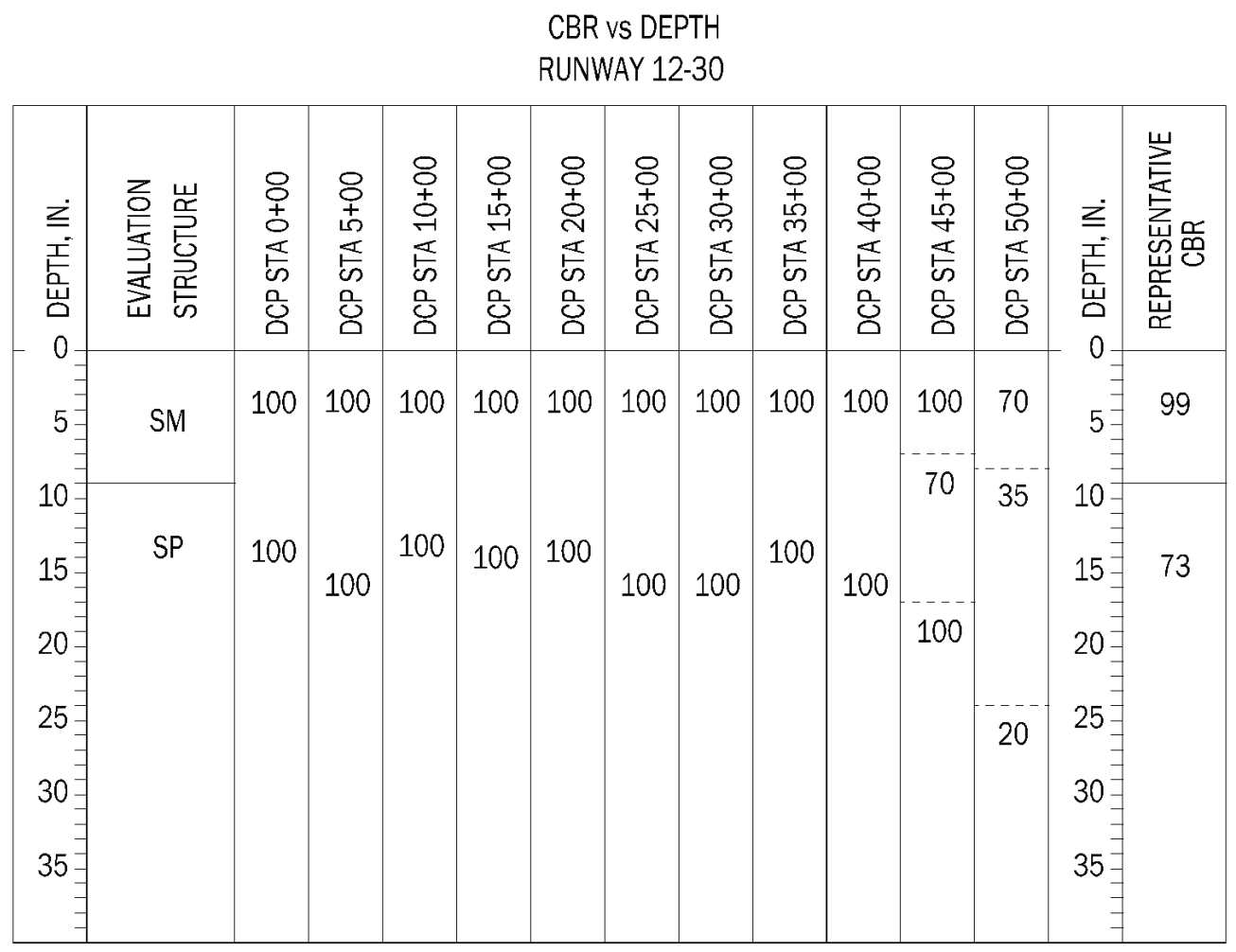

It was determined that, based on the 2018 condition survey, updated DCP tests would be unnecessary to accurately categorize the surface's soil strength. No significant change was reported for the surface between the time of the condition survey, June 2018, and the SPRO field tests, March 2020. As a result, no further DCP data were gathered during the SPRO data collection at Schoonover LZ. 


\subsubsection{Soil classification}

A representative sample of the Schoonover LZ surface soil was collected from the main runway. The soil sample was processed at a third-party laboratory for the purpose of determining soil classification properties. Classification of the collected soil sample was determined by two general analyses: Atterberg limits and gradation. A summary of soil analysis results for Schoonover LZ can be found in Table 11.

A plasticity chart, based on ASTM D2487-17 (2017a), for the Schoonover LZ soil sample revealed that the surface material was likely a silty or clayey sand (see Figure 69).

Furthermore, gradation testing revealed that a small percentage of the sample passed the No. 200 sieve (see Figure 75). The USCS classification for a soil of this type is SC-SM, or a mixture of silty and clayey sand. Combined with a visual analysis, the soil was further classified as a tan silty fine to coarse sand (SC-SM), slightly clayey with gravel. 
Figure 75. Gradation chart for Schoonover LZ soil sample.

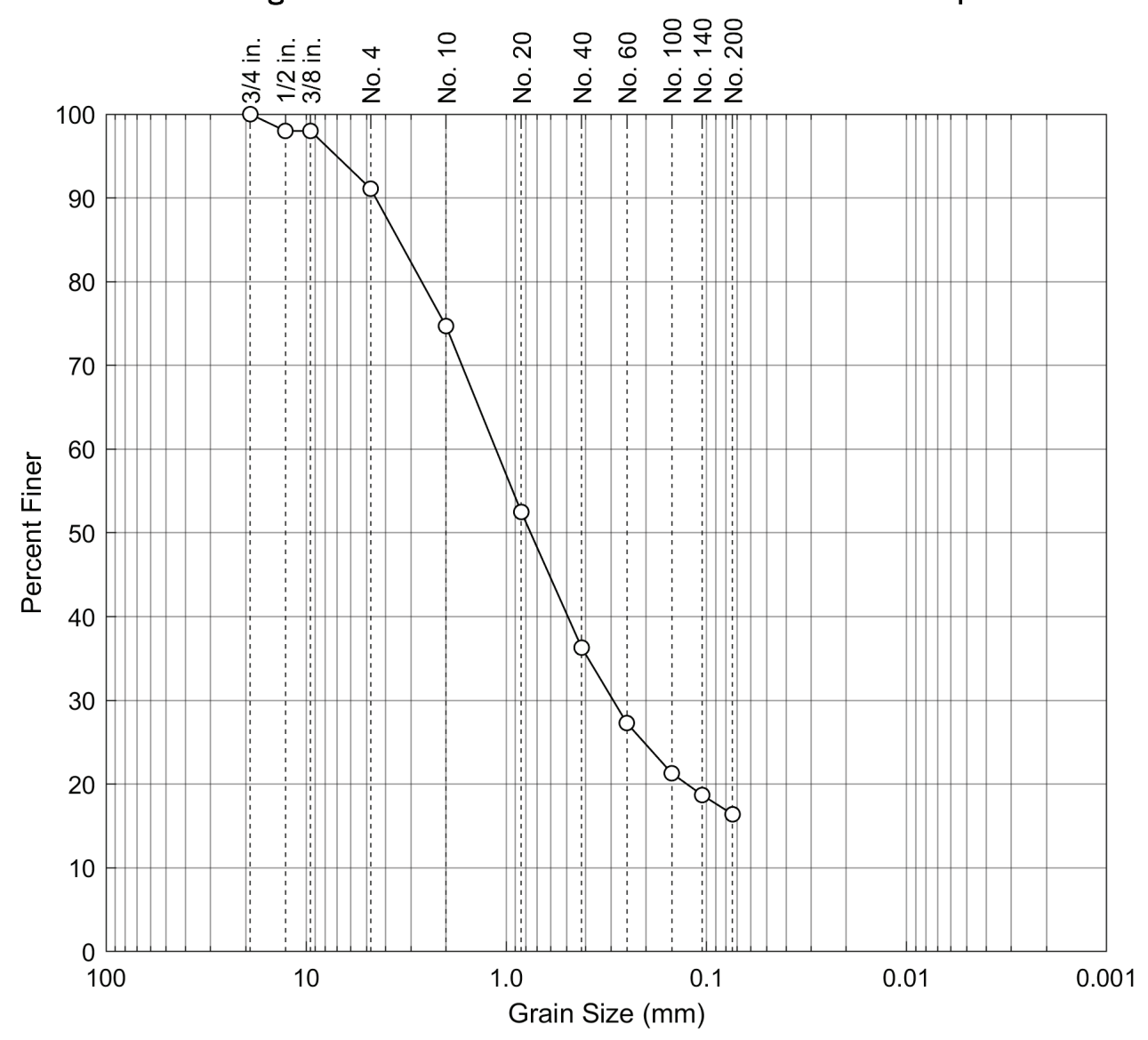

\subsubsection{Aerial survey}

Flights conducted using sUAS were limited due to regulatory and weatherbased restrictions. As such, a full survey of the airfield was not completed, and only a small portion of the LZ was surveyed. The lone survey mission was conducted using a Parrot Anafi Thermal sUAS with a proprietary $4 \mathrm{~K}$ $\mathrm{EO} / \mathrm{IR}$ camera at an altitude of approximately $50 \mathrm{ft}$. The airfield was inside restricted Class $\mathrm{G}$ airspace (see Figure 76) under the control of Fort Hunter Liggett; as a result, signed approval from Fort Hunter Liggett Range Control was obtained prior to flight operations. 
Figure 76. Schoonover LZ sectional chart.

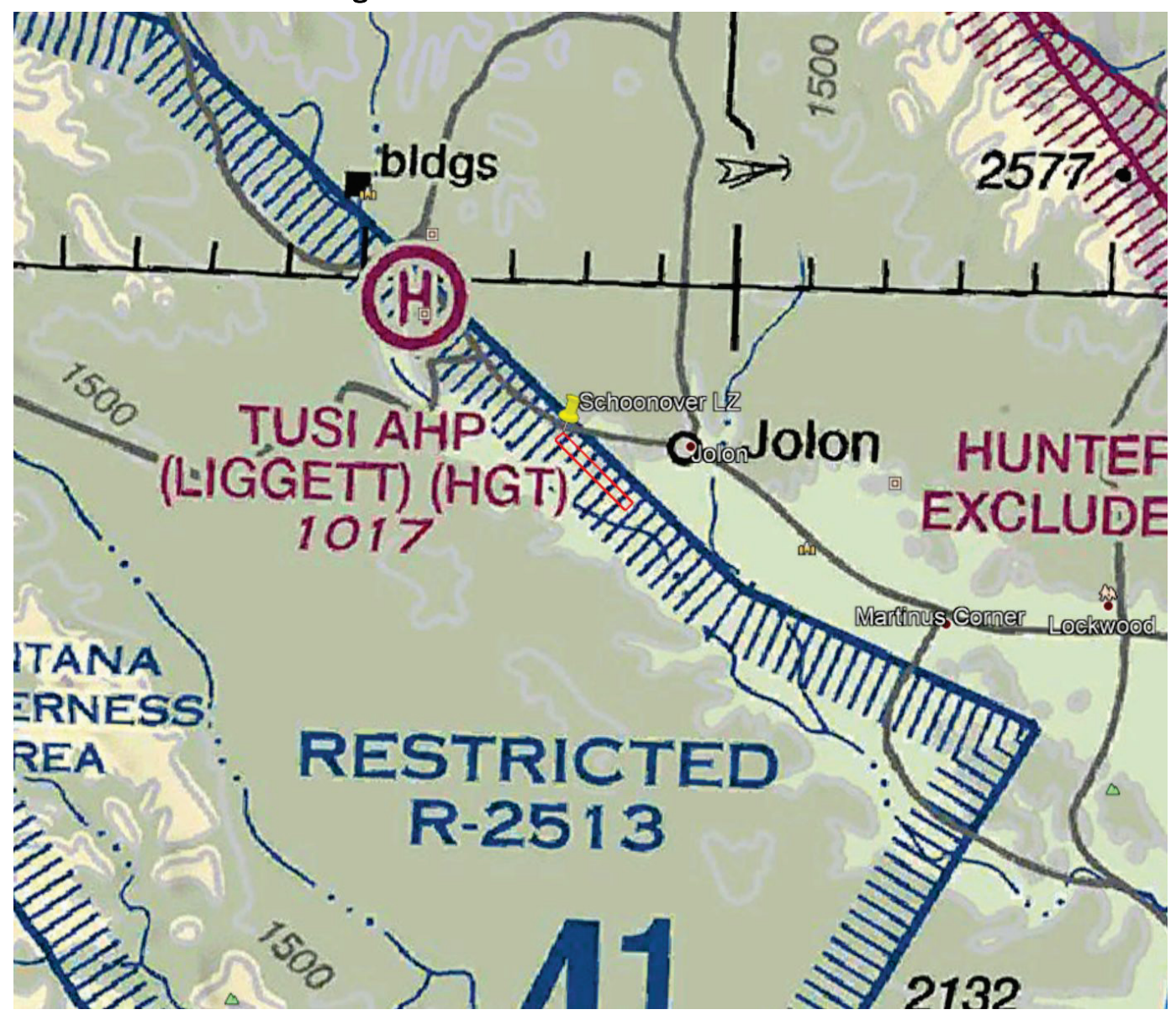

A single photogrammetric reconstruction was performed on the limited site survey and can be seen in Figure 77. The survey does not provide much information regarding the data collection; however, it does give a general idea of the surface's condition during testing. 
Figure 77. Schoonover LZ partial runway mosaic.

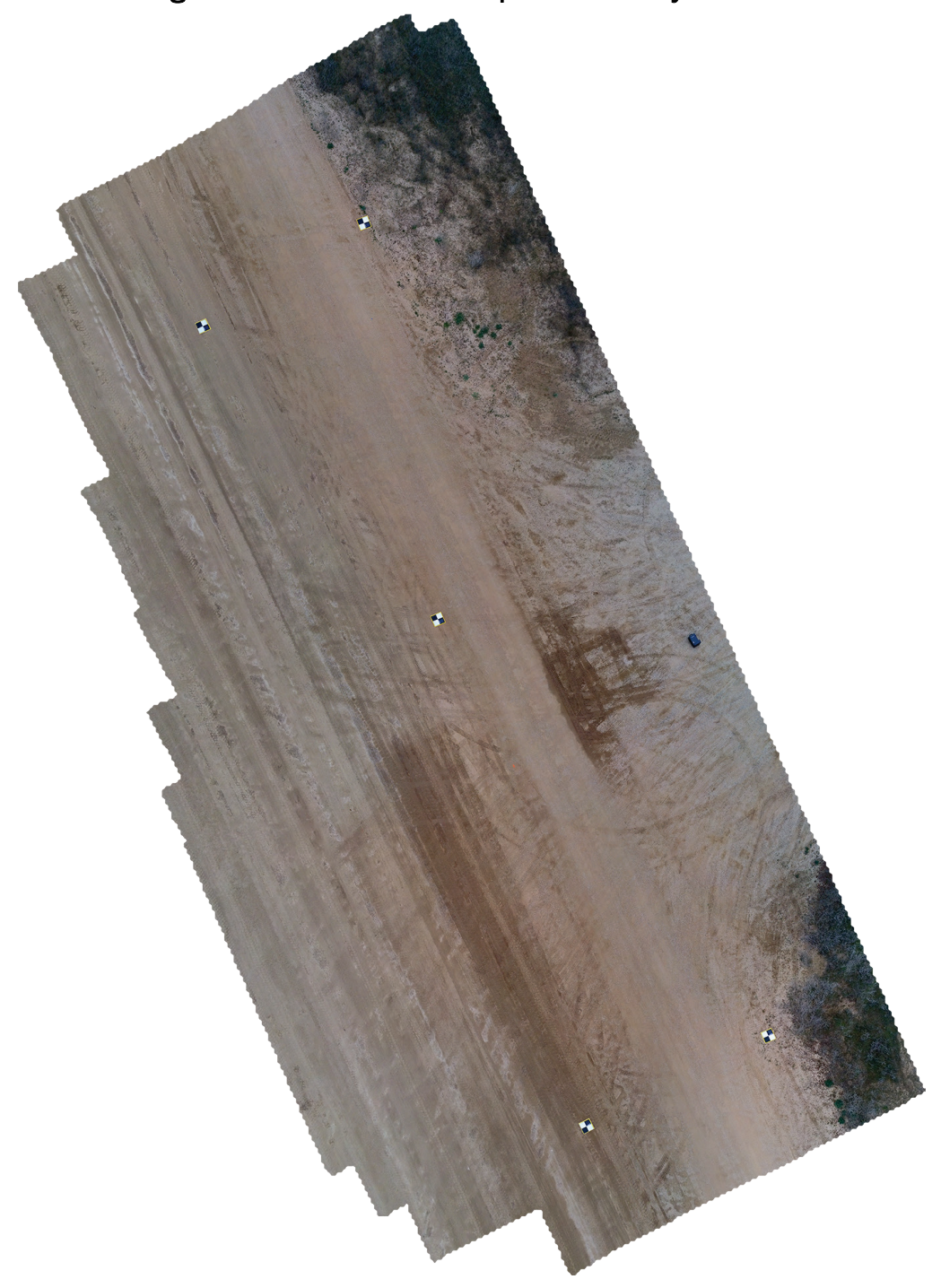

\subsection{Golden Eagle Landing Zone}

As referenced in Section 4.3.1, Golden Eagle LZ was in a degraded and disused but recoverable state. Much like Rattlesnake LZ, the disused condition of the main runway surface necessitated the use of DCP tests to determine what part, if any, of the underlying surface was suitable for repeated brake testing. Further tests were conducted in a lab setting to determine soil classification. Lastly, sUAS flights were not attempted during this data collection due to logistical and weather-based restrictions. Details regarding these tests are discussed in the following three sub-sections. 


\subsubsection{Soil strength}

The in-situ strength of Golden Eagle LZ's underlying soil structure was obtained prior to testing by use of the DCP test. A rough centerline was determined, and tests were conducted every $500 \mathrm{ft}$. Adjacent DCP tests were also conducted $20 \mathrm{ft}$ north and south of the centerline, and at 500$\mathrm{ft}$ intervals. Soil structure results from these tests can be seen in Table 12 to Table 14 . The pre-test surface was damp.

Table 12. CBR values on the Golden Eagle LZ centerline.

\begin{tabular}{|c|c|c|c|c|c|c|c|c|c|}
\hline \multirow{3}{*}{$\begin{array}{c}\text { Depth } \\
\text { (inches) }\end{array}$} & \multicolumn{9}{|c|}{ CBR } \\
\hline & \multicolumn{9}{|c|}{ Centerline } \\
\hline & $05-00$ & $00+00$ & $05+00$ & $10+00$ & $15+00$ & $20+00$ & $25+00$ & $30+00$ & $35+00$ \\
\hline 0 & \multirow{11}{*}{7} & \multirow{11}{*}{6} & \multirow{12}{*}{4} & \multirow{10}{*}{3} & \multirow{14}{*}{6} & \multirow{6}{*}{5} & \multirow{9}{*}{7} & \multirow{13}{*}{7} & \multirow{7}{*}{4} \\
\hline 1 & & & & & & & & & \\
\hline 2 & & & & & & & & & \\
\hline 3 & & & & & & & & & \\
\hline 4 & & & & & & & & & \\
\hline 5 & & & & & & & & & \\
\hline 6 & & & & & & \multirow{26}{*}{9} & & & \\
\hline 7 & & & & & & & & & \multirow{9}{*}{10} \\
\hline 8 & & & & & & & & & \\
\hline 9 & & & & & & & \multirow{8}{*}{13} & & \\
\hline 10 & & & & \multirow{6}{*}{12} & & & & & \\
\hline 11 & \multirow{21}{*}{16} & \multirow{12}{*}{11} & & & & & & & \\
\hline 12 & & & \multirow{7}{*}{33} & & & & & & \\
\hline 13 & & & & & & & & \multirow{9}{*}{42} & \\
\hline 14 & & & & & \multirow{9}{*}{12} & & & & \\
\hline 15 & & & & & & & & & \\
\hline 16 & & & & \multirow{16}{*}{36} & & & & & \\
\hline 17 & & & & & & & \multirow{6}{*}{62} & & \\
\hline 18 & & & & & & & & & \\
\hline 19 & & & \multirow{13}{*}{16} & & & & & & \\
\hline 20 & & & & & & & & & \\
\hline 21 & & & & & & & & & \\
\hline 22 & & & & & & & & & \\
\hline 23 & & \multirow{9}{*}{14} & & & \multirow{9}{*}{24} & & \multirow{9}{*}{20} & & 12 \\
\hline 24 & & & & & & & & & 12 \\
\hline 25 & & & & & & & & & \\
\hline 26 & & & & & & & & 50 & \\
\hline 27 & & & & & & & & 50 & \\
\hline 28 & & & & & & & & & \\
\hline 29 & & & & & & & & & \\
\hline 30 & & & & & & & & & \\
\hline 31 & & & & & & & & & \\
\hline
\end{tabular}


Table 13. CBR values $20 \mathrm{ft}$ north of the Golden Eagle $L Z$ centerline.

\begin{tabular}{|c|c|c|c|c|c|c|c|c|c|}
\hline \multirow{3}{*}{$\begin{array}{l}\text { Depth } \\
\text { (inches) }\end{array}$} & \multicolumn{9}{|c|}{ CBR } \\
\hline & \multicolumn{9}{|c|}{ 20-ft North of Centerline } \\
\hline & $05-00$ & $00+00$ & $05+00$ & $10+00$ & $15+00$ & $20+00$ & $25+00$ & $30+00$ & $35+00$ \\
\hline 0 & \multirow{12}{*}{8} & \multirow{11}{*}{6} & \multirow{17}{*}{6} & \multirow{12}{*}{4} & \multirow{8}{*}{4} & \multirow{7}{*}{6} & \multirow{15}{*}{5} & \multirow{10}{*}{5} & \multirow{7}{*}{4} \\
\hline 1 & & & & & & & & & \\
\hline 2 & & & & & & & & & \\
\hline 3 & & & & & & & & & \\
\hline 4 & & & & & & & & & \\
\hline 5 & & & & & & & & & \\
\hline 6 & & & & & & & & & \\
\hline 7 & & & & & & \multirow{9}{*}{6} & & & \\
\hline 8 & & & & & \multirow{8}{*}{17} & & & & \\
\hline 9 & & & & & & & & & \\
\hline 10 & & & & & & & & \multirow{9}{*}{51} & \\
\hline 11 & & \multirow{12}{*}{5} & & & & & & & \\
\hline 12 & \multirow{11}{*}{10} & & & \multirow{8}{*}{12} & & & & & \\
\hline 13 & & & & & & & & & \\
\hline 14 & & & & & & & & & \\
\hline 15 & & & & & & & & & 8 \\
\hline 16 & & & & & \multirow{16}{*}{9} & \multirow{7}{*}{7} & & & \\
\hline 17 & & & \multirow{10}{*}{10} & & & & & & \\
\hline 18 & & & & & & & & & \\
\hline 19 & & & & & & & & & \\
\hline 20 & & & & & & & & & \\
\hline 21 & & & & & & & & & \\
\hline 22 & & & & & & & & & \\
\hline 23 & \multirow{9}{*}{9} & \multirow{9}{*}{12} & & & & \multirow{9}{*}{19} & Rej. & & \\
\hline 24 & & & & & & & & & \\
\hline 25 & & & & 10 & & & & 24 & \\
\hline 26 & & & & 17 & & & & & \\
\hline 27 & & & \multirow{5}{*}{24} & & & & & & 11 \\
\hline 28 & & & & & & & & & 11 \\
\hline 29 & & & & & & & & & \\
\hline 30 & & & & & & & & & \\
\hline 31 & & & & & & & & & \\
\hline
\end{tabular}


Table 14. CBR values $20 \mathrm{ft}$ south of the Golden Eagle $L Z$ centerline.

\begin{tabular}{|c|c|c|c|c|c|c|c|c|c|}
\hline \multirow{3}{*}{$\begin{array}{c}\text { Depth } \\
\text { (inches) }\end{array}$} & \multicolumn{9}{|c|}{ CBR } \\
\hline & \multicolumn{9}{|c|}{ 20-ft South of Centerline } \\
\hline & 05-00 & $00+00$ & $05+00$ & $10+00$ & $15+00$ & $20+00$ & $25+00$ & $30+00$ & $35+00$ \\
\hline 0 & \multirow{12}{*}{6} & \multirow{6}{*}{7} & \multirow{6}{*}{8} & & \multirow{8}{*}{5} & \multirow{8}{*}{6} & \multirow{7}{*}{4} & \multirow{13}{*}{2} & \multirow{12}{*}{5} \\
\hline 1 & & & & & & & & & \\
\hline 2 & & & & & & & & & \\
\hline 3 & & & & & & & & & \\
\hline 4 & & & & & & & & & \\
\hline 5 & & & & 4 & & & & & \\
\hline 6 & & \multirow{16}{*}{7} & \multirow{6}{*}{8} & & & & & & \\
\hline 7 & & & & & & & \multirow{17}{*}{6} & & \\
\hline 8 & & & & & \multirow{13}{*}{15} & \multirow{7}{*}{5} & & & \\
\hline 9 & & & & & & & & & \\
\hline 10 & & & & & & & & & \\
\hline 11 & & & & & & & & & \\
\hline 12 & \multirow{4}{*}{6} & & \multirow{20}{*}{16} & \multirow{6}{*}{15} & & & & & \multirow{10}{*}{7} \\
\hline 13 & & & & & & & & \multirow{5}{*}{6} & \\
\hline 14 & & & & & & & & & \\
\hline 15 & & & & & & \multirow{17}{*}{16} & & & \\
\hline 16 & \multirow{16}{*}{20} & & & & & & & & \\
\hline 17 & & & & & & & & & \\
\hline 18 & & & & \multirow{14}{*}{20} & & & & & \\
\hline 19 & & & & & & & & & \\
\hline 20 & & & & & & & & & \\
\hline 21 & & & & & & & & & \\
\hline 22 & & \multirow{10}{*}{13} & & & & & & & \\
\hline 23 & & & & & & & & & \\
\hline 24 & & & & & & & & 9 & \\
\hline 25 & & & & & & & & J & \\
\hline 26 & & & & & 58 & & & & 6 \\
\hline 27 & & & & & & & 15 & & \\
\hline 28 & & & & & & & J & & \\
\hline 29 & & & & & & & & & \\
\hline 30 & & & & & & & & & \\
\hline 31 & & & & & & & & & \\
\hline
\end{tabular}

As expected, based on the disused nature of the landing zone, much of the runway surface had degraded and exhibited poor strength characteristics (< $10 \mathrm{CBR}$ in the surface layer). These tests also revealed that the surface layer was in roughly the same condition as that of the pre-test Rattlesnake LZ surface with an average surface layer CBR of 5.33, compared to 5.28 at Rattlesnake LZ. DCP results did show strong sub-surface layers indicating that the entire surface may be recoverable and made suitable for repeated 
brake testing. Further DCP tests were conducted on the runway surface following recovery operations and brake testing (see Table 15 to Table 17). The post-test DCP evaluation took place at the same tests sites as the pre-test DCP evaluation. It should be noted that while significant rainfall did take place prior to recovery efforts, the post-test DCPs were conducted in completely dry conditions.

Table 15. CBR values from the recovered runway on Golden Eagle LZ at the centerline.

\begin{tabular}{|c|c|c|c|c|c|c|c|c|c|}
\hline \multirow{3}{*}{$\begin{array}{l}\text { Depth } \\
\text { (inches) }\end{array}$} & \multicolumn{9}{|c|}{ CBR } \\
\hline & \multicolumn{9}{|c|}{ Centerline } \\
\hline & $05-00$ & $00+00$ & $05+00$ & $10+00$ & $15+00$ & $20+00$ & $25+00$ & $30+00$ & $35+00$ \\
\hline 0 & \multirow{13}{*}{55} & \multirow{11}{*}{36} & \multirow{11}{*}{31} & \multirow{12}{*}{45} & \multirow{13}{*}{47} & \multirow{12}{*}{49} & \multirow{10}{*}{33} & \multirow{10}{*}{27} & \multirow{12}{*}{21} \\
\hline 1 & & & & & & & & & \\
\hline 2 & & & & & & & & & \\
\hline 3 & & & & & & & & & \\
\hline 4 & & & & & & & & & \\
\hline 5 & & & & & & & & & \\
\hline 6 & & & & & & & & & \\
\hline 7 & & & & & & & & & \\
\hline 8 & & & & & & & & & \\
\hline 9 & & & & & & & & & \\
\hline 10 & & & & & & & & & \\
\hline 11 & & \multirow{5}{*}{13} & \multirow{6}{*}{17} & & & & & & \\
\hline 12 & & & & \multirow{6}{*}{15} & & & & & \\
\hline 13 & & & & & \multirow{12}{*}{57} & & 42 & & \\
\hline 14 & & & & & & & & 7 & \\
\hline 15 & & & & & & 20 & & & \\
\hline 16 & 61 & \multirow{8}{*}{7} & & & & & & & 9 \\
\hline 17 & & & \multirow{9}{*}{15} & & & & & & \\
\hline 18 & & & & \multirow{14}{*}{21} & & & & & \\
\hline 19 & & & & & & \multirow{13}{*}{12} & \multirow{13}{*}{ Rej. } & & \\
\hline 20 & \multirow{8}{*}{19} & & & & & & & & \\
\hline 21 & & & & & & & & 2? & \\
\hline 22 & & & & & & & & 22 & \multirow{4}{*}{7} \\
\hline 23 & & & & & & & & & \\
\hline 24 & & \multirow{8}{*}{12} & & & & & & & \\
\hline 25 & & & & & \multirow{7}{*}{13} & & & & \\
\hline 26 & & & \multirow{6}{*}{18} & & & & & & \\
\hline 27 & & & & & & & & & \\
\hline 28 & \multirow{4}{*}{34} & & & & & & & 25 & 8 \\
\hline 29 & & & & & & & & & \\
\hline 30 & & & & & & & & & \\
\hline 31 & & & & & & & & & \\
\hline
\end{tabular}


Table 16. CBR values from the recovered runway on Golden Eagle $L Z 20 \mathrm{ft}$ north of the centerline.

\begin{tabular}{|c|c|c|c|c|c|c|c|c|c|}
\hline \multirow{3}{*}{$\begin{array}{l}\text { Depth } \\
\text { (inches) }\end{array}$} & \multicolumn{9}{|c|}{ CBR } \\
\hline & \multicolumn{9}{|c|}{ 20-ft North of Centerline } \\
\hline & $05-00$ & $00+00$ & $05+00$ & $10+00$ & $15+00$ & $20+00$ & $25+00$ & $30+00$ & $35+00$ \\
\hline 0 & \multirow{11}{*}{46} & \multirow{11}{*}{31} & \multirow{10}{*}{34} & \multirow{14}{*}{20} & \multirow{11}{*}{23} & \multirow{11}{*}{36} & \multirow{10}{*}{40} & \multirow{13}{*}{34} & \multirow{15}{*}{26} \\
\hline 1 & & & & & & & & & \\
\hline 2 & & & & & & & & & \\
\hline 3 & & & & & & & & & \\
\hline 4 & & & & & & & & & \\
\hline 5 & & & & & & & & & \\
\hline 6 & & & & & & & & & \\
\hline 7 & & & & & & & & & \\
\hline 8 & & & & & & & & & \\
\hline 9 & & & & & & & & & \\
\hline 10 & & & \multirow{12}{*}{9} & & & & \multirow{9}{*}{12} & & \\
\hline 11 & \multirow{9}{*}{12} & \multirow{16}{*}{10} & & & \multirow{9}{*}{9} & \multirow{21}{*}{10} & & & \\
\hline 12 & & & & & & & & & \\
\hline 13 & & & & & & & & \multirow{12}{*}{14} & \\
\hline 14 & & & & \multirow{8}{*}{9} & & & & & \\
\hline 15 & & & & & & & & & \\
\hline 16 & & & & & & & & & \\
\hline 17 & & & & & & & & & \\
\hline 18 & & & & & & & & & \\
\hline 19 & & & & & & & \multirow{8}{*}{12} & & 14 \\
\hline 20 & \multirow{7}{*}{58} & & & & \multirow{12}{*}{10} & & & & 14 \\
\hline 21 & & & & & & & & & \\
\hline 22 & & & & \multirow{10}{*}{22} & & & & & \\
\hline 23 & & & 20 & & & & & & \\
\hline 24 & & & & & & & & & \\
\hline 25 & & & \multirow{7}{*}{10} & & & & & & \\
\hline 26 & & & & & & & & & \\
\hline 27 & \multirow{5}{*}{32} & \multirow{5}{*}{7} & & & & & & & \\
\hline 28 & & & & & & & & 7 & 13 \\
\hline 29 & & & & & & & 18 & & \\
\hline 30 & & & & & & & & & \\
\hline 31 & & & & & & & & & \\
\hline
\end{tabular}


Table 17. CBR values from the recovered runway on Golden Eagle LZ $20 \mathrm{ft}$ south of the centerline.

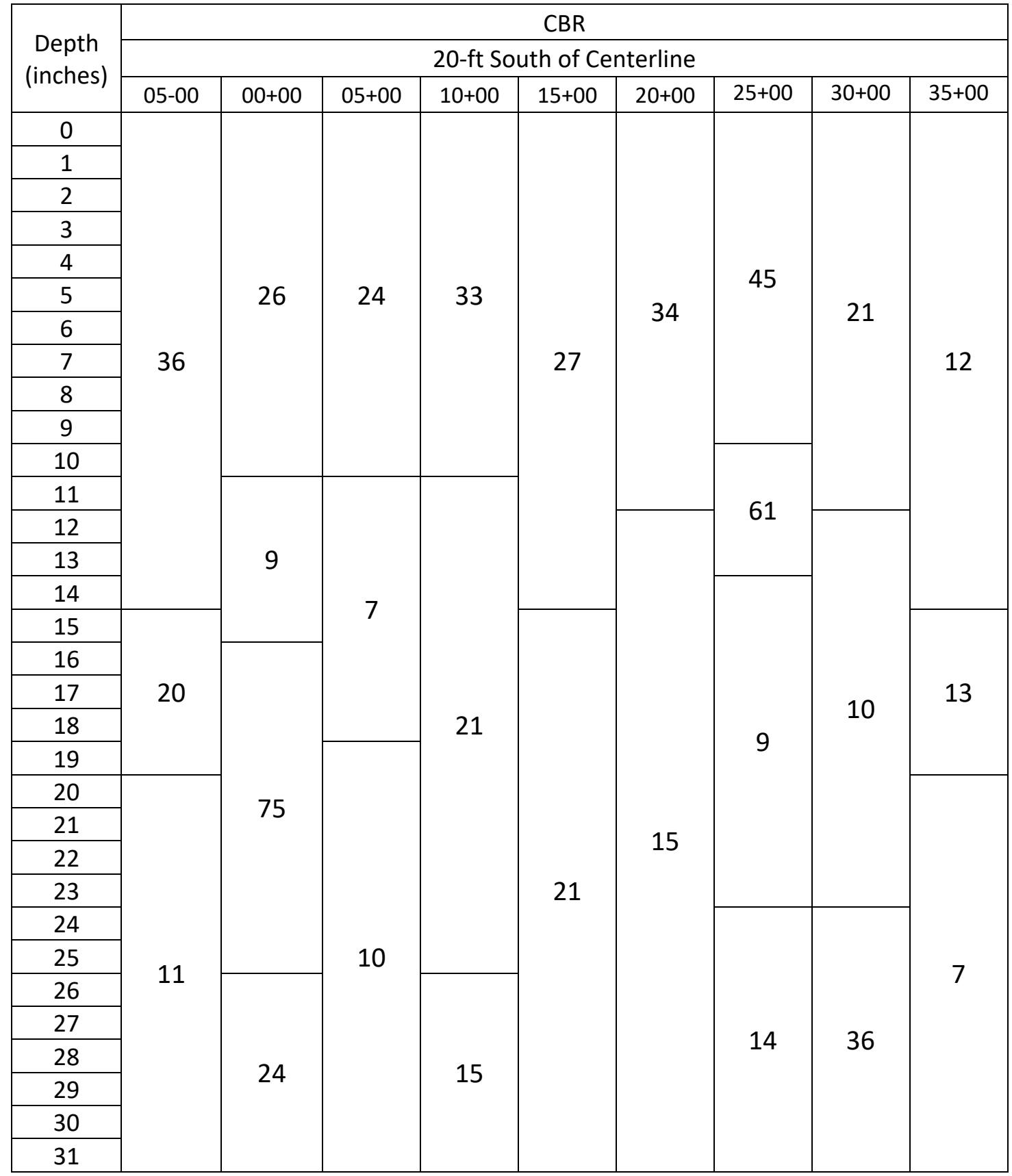

The post-test DCP results revealed a very strong surface layer with an average CBR of 38.22 at the centerline, 32.22 north of the centerline, and 28.67 south of the centerline. The sub-surface layers were also strengthened by the team's recovery efforts, but not as much as the surface layer with an average CBR of 26.78 at the centerline, 11 north of the centerline, and 13.89 south of the centerline. The resulting layer 
structure is more ambiguous after the first two layers with two-, three-, and four-layer structures throughout the runway.

\subsubsection{Soil classification}

In order to accurately classify the soil tested at Golden Eagle LZ, a representative sample was taken from the recovered runway surface and processed at a third-party laboratory. Classification of the collected soil sample was determined by use of two general analyses: Atterberg limits and gradation. A summary of soil analysis results for Golden Eagle LZ can be found in Table 11. A plasticity chart, based on ASTM D2487-17 (2017a), for the Golden Eagle LZ soil sample revealed that the surface was likely a low plasticity clay (see Figure 69). Furthermore, gradation testing revealed a large portion of the sample passed the No. 200 sieve (see Figure 78). The USCS classification for a soil of this type is CL, or a low plasticity clay. Combined with a visual analysis, the soil can be further classified as a red silty clay (CL), slightly sandy with gravel.

Figure 78. Gradation chart for Golden Eagle LZ soil sample.

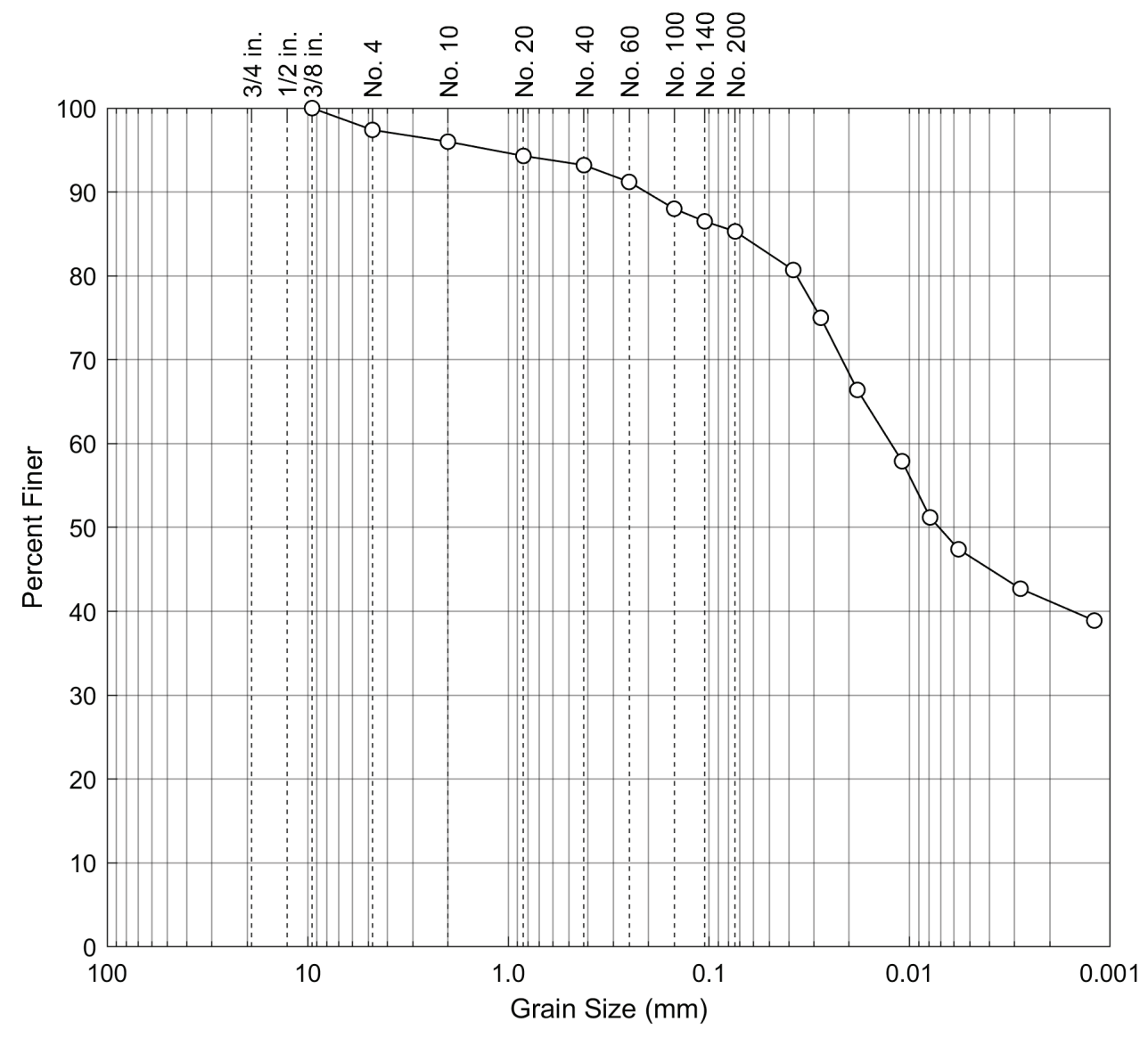




\subsubsection{Aerial survey}

There were no aerial surveys of Golden Eagle LZ conducted during or after SPRO testing. The landing zone itself sits in between a restricted Class $\mathrm{G}$ airspace and a military operations area (MOA) Class $\mathrm{G}$ airspace (see Figure 79).

Figure 79. Golden Eagle LZ sectional chart

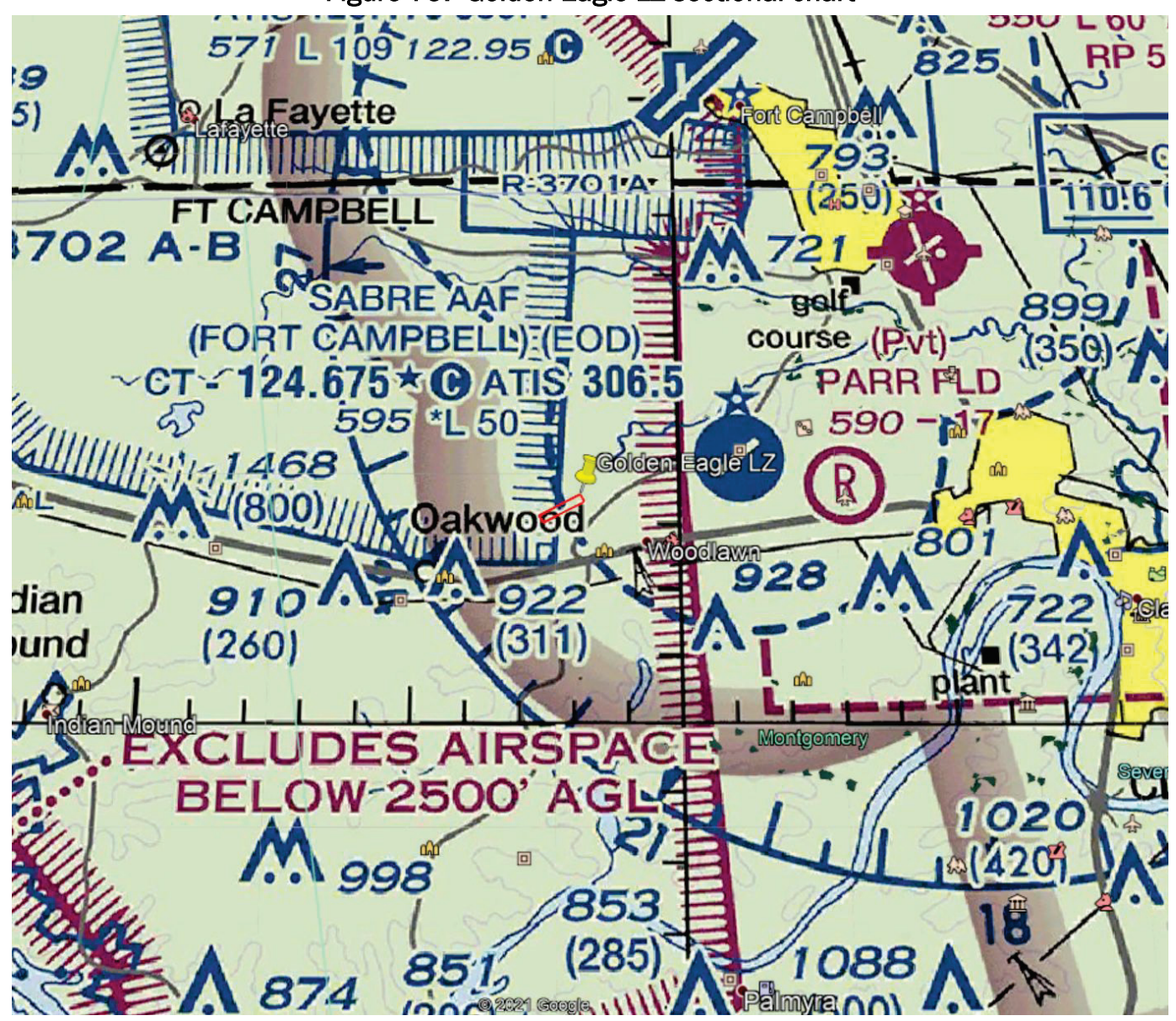




\section{Results}

The following results were derived from friction and deceleration surveys conducted on three test sites with three test vehicles, utilizing seven measurement devices (see Table 18).

Table 18. SPRO test sites, vehicles, and devices.

\begin{tabular}{|c|c|c|}
\hline $\begin{array}{l}\text { Test } \\
\text { Sites }\end{array}$ & $\begin{array}{c}\text { Test } \\
\text { Vehicles }\end{array}$ & $\begin{array}{c}\text { Test } \\
\text { Devices }\end{array}$ \\
\hline \multirow[t]{7}{*}{$\begin{array}{l}\text { Rattlesnake } \\
\text { LZ }\end{array}$} & N/A & $\begin{array}{l}\text { Findlay Irvine Mk2 } \\
\text { GripTester }\end{array}$ \\
\hline & \multirow{2}{*}{$\begin{array}{l}\text { HMMWV } \\
\text { M1165A1 }\end{array}$} & Bowmonk AFM2 Mk3 \\
\hline & & Xsens MTi-G-710 \\
\hline & \multirow{2}{*}{$\begin{array}{l}2017 \text { Chevrolet } \\
\text { Silverado } 1500 \\
4 \times 4\end{array}$} & Apple iPhone 7 \\
\hline & & LG V20 \\
\hline & \multirow{2}{*}{$\begin{array}{l}2019 \text { Ford } \\
\text { Expedition }\end{array}$} & Apple iPhone 11 Pro \\
\hline & & Samsung Galaxy S10 \\
\hline \multirow[t]{7}{*}{$\begin{array}{l}\text { Schoonover } \\
\text { LZ }\end{array}$} & N/A & $\begin{array}{l}\text { Findlay Irvine Mk2 } \\
\text { GripTester }\end{array}$ \\
\hline & \multirow{2}{*}{$\begin{array}{l}\text { HMMWV } \\
\text { M1165A1 }\end{array}$} & Bowmonk AFM2 Mk3 \\
\hline & & Xsens MTi-G-710 \\
\hline & \multirow{2}{*}{$\begin{array}{l}2017 \text { Chevrolet } \\
\text { Silverado } 1500 \\
4 \times 4\end{array}$} & Apple iPhone 7 \\
\hline & & LG V20 \\
\hline & \multirow{2}{*}{$\begin{array}{l}2019 \\
\text { Chevrolet } \\
\text { Tahoe } \\
\end{array}$} & Apple iPhone 11 Pro \\
\hline & & Samsung Galaxy S10 \\
\hline \multirow[t]{7}{*}{$\begin{array}{l}\text { Golden Eagle } \\
\text { LZ }\end{array}$} & N/A & $\begin{array}{l}\text { Findlay Irvine Mk2 } \\
\text { GripTester }\end{array}$ \\
\hline & \multirow{2}{*}{$\begin{array}{l}\text { HMMWV } \\
\text { M1165A1 }\end{array}$} & Bowmonk AFM2 Mk3 \\
\hline & & Xsens MTi-G-710 \\
\hline & \multirow{2}{*}{$\begin{array}{l}2017 \text { Chevrolet } \\
\text { Silverado } 1500 \\
4 \times 4\end{array}$} & Apple iPhone 7 \\
\hline & & LG V20 \\
\hline & \multirow{2}{*}{$\begin{array}{l}2019 \text { Lexus } \\
\text { QX80 }\end{array}$} & Apple iPhone 11 Pro \\
\hline & & Samsung Galaxy S10 \\
\hline
\end{tabular}




\subsection{Outlier analysis}

Before presenting the friction and deceleration data collected during the SPRO effort, it is necessary to first cover the outlier analyses utilized for data reduction. Deceleration data, specifically those collected by smartphones, exhibits high experimental error and low inter-model repeatability (Ward et al. 2019). Furthermore, environmental conditions present on most semi-prepared surfaces induce high experimental error in fixed-slip surface friction measurement equipment (discussed in greater detail in the following section). As a result, it was necessary to utilize a data reduction technique that is robust to numerous outliers. To suit the unique problems resulting from friction and deceleration data collection, a median absolute deviation (MAD) outlier analysis was chosen. In this type of outlier analysis, the statistical variation of a data set is defined by how many absolute deviations exist between each point of data and the median of the entire set (see Equation 21 below).

$$
M A D_{i}=\operatorname{median}\left(\left|y_{i}-\tilde{y}\right|\right)
$$

where $y_{i}$ is the $i^{t h}$ point of data in the set of $n$ data points, $y \in\left\{y_{0} \cdots y_{n}\right\}$, $\tilde{y}$ is the median of the data set, $y$, and

$\mid$ quantity $\mid$ is the absolute value of the quantity.

Such an analysis, unlike those reliant on the mean of a data set, is largely insensitive to outliers. Furthermore, the MAD analysis has the benefit, over those analyses based on the mean, of being invariant to sample size (Huber 2004). This is useful, as friction and deceleration data collected here vary greatly in sample size. All data points, frictionand deceleration-based, further than two absolute deviations from the median were rejected from further analysis.

\subsection{GripTester results}

The purpose of testing on varied surfaces with varied moisture contents was to collect a wide range of GripTester friction response data. In particular, it was important to cover, at minimum, the same range of GripTester values collected in the original SPRO effort. The original SPRO effort collected 144 unique GT values ranging from 0.13 to 0.65 (see Figure 4). The current SPRO effort collected 43 unique GT values ranging from 0.06 to 0.71 (see Figure 80). 
Figure 80. Current SPRO GT values in ascending order.

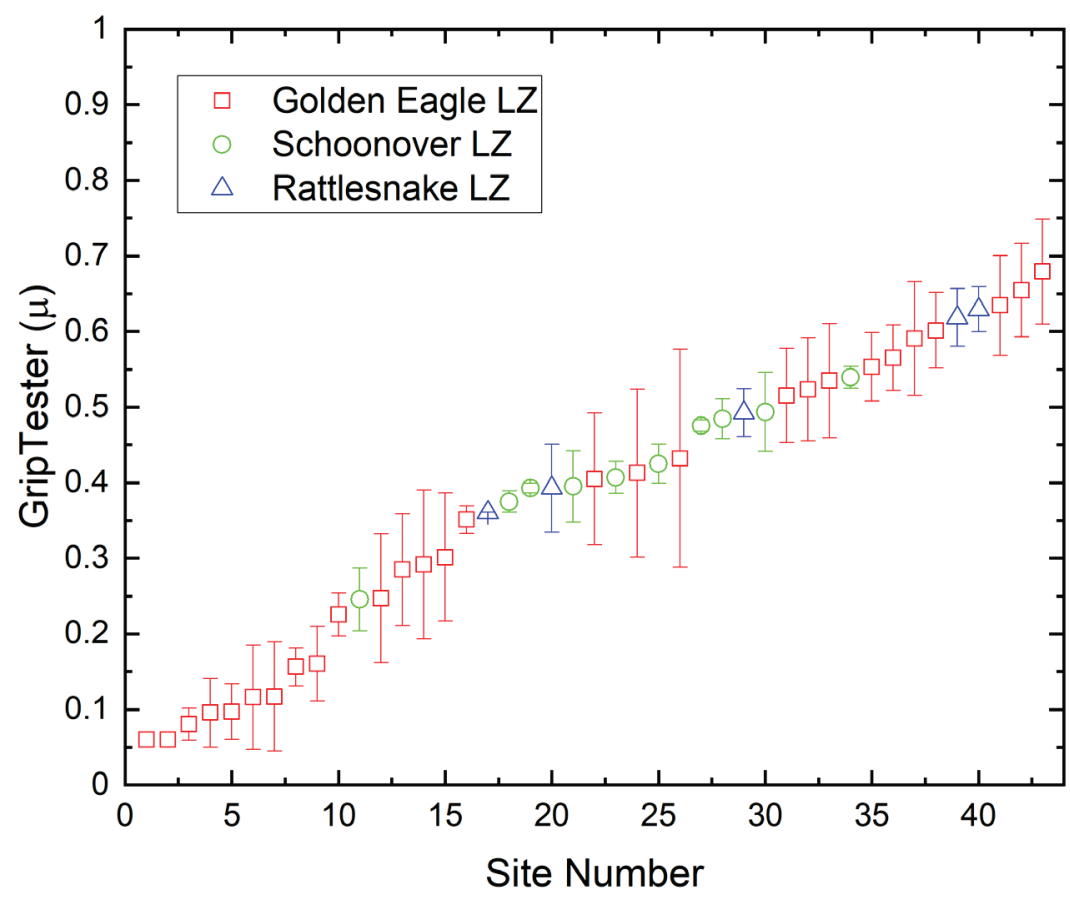

Due to weather and scheduling-related restrictions, data collections at Schoonover LZ and Rattlesnake LZ were limited in scope. The data collection at Golden Eagle LZ, however, allowed for a full range of friction and deceleration tests to be conducted, resulting in a wide variety of friction response data. It should be noted that while the GT typically provides high repeatability in its measurements, the rough semiprepared surfaces tested during the SPRO effort introduced a significant amount of experimental error in the GT data. Increased experimental error generally occurred for two reasons: mud contamination on and around the test tire, preventing it from rolling (100\% slip or locked-wheel condition), and bouncing of the test tire on the test surface. A fully locked test tire registers high horizontal load, resulting in minimum friction values not representative of the test surface. A bouncing test tire results in two extremes of friction response. First, while the tire is airborne, the vertical load cell registers zero force (outside that applied by the acceleration of gravity), resulting in a maximum friction response. Second, when the tire makes contact with the ground, the vertical load cell registers high load resulting in a minimum friction response. Given this behavior, it is relatively easy to remove outliers from the GT data as 
long as the surface friction response is not near the maximum or minimum value for the device (0.06 to 1.20 ).

\subsection{Synthesized vehicle-specific deceleration results}

Each of the three test vehicles utilized in this effort provided unique driving and braking characteristics. It was expected, then, that deceleration-based friction output would be highly vehicle dependent. As such, vehicle-specific results synthesized from all three data collections are presented in the following three subsections. It should be noted that the Bowmonk is a highly repeatable, dedicated deceleration-based friction measurement device. As such, it exhibits a low amount of data scatter. For this reason, graphical representations of deceleration data in this section are made in ascending order of Bowmonk values.

\subsubsection{HMMWV}

Deceleration data collected in the HMMWV for all three data collections can be found in Figure 81 .

Figure 81. Deceleration data from the HMMWV in ascending order.

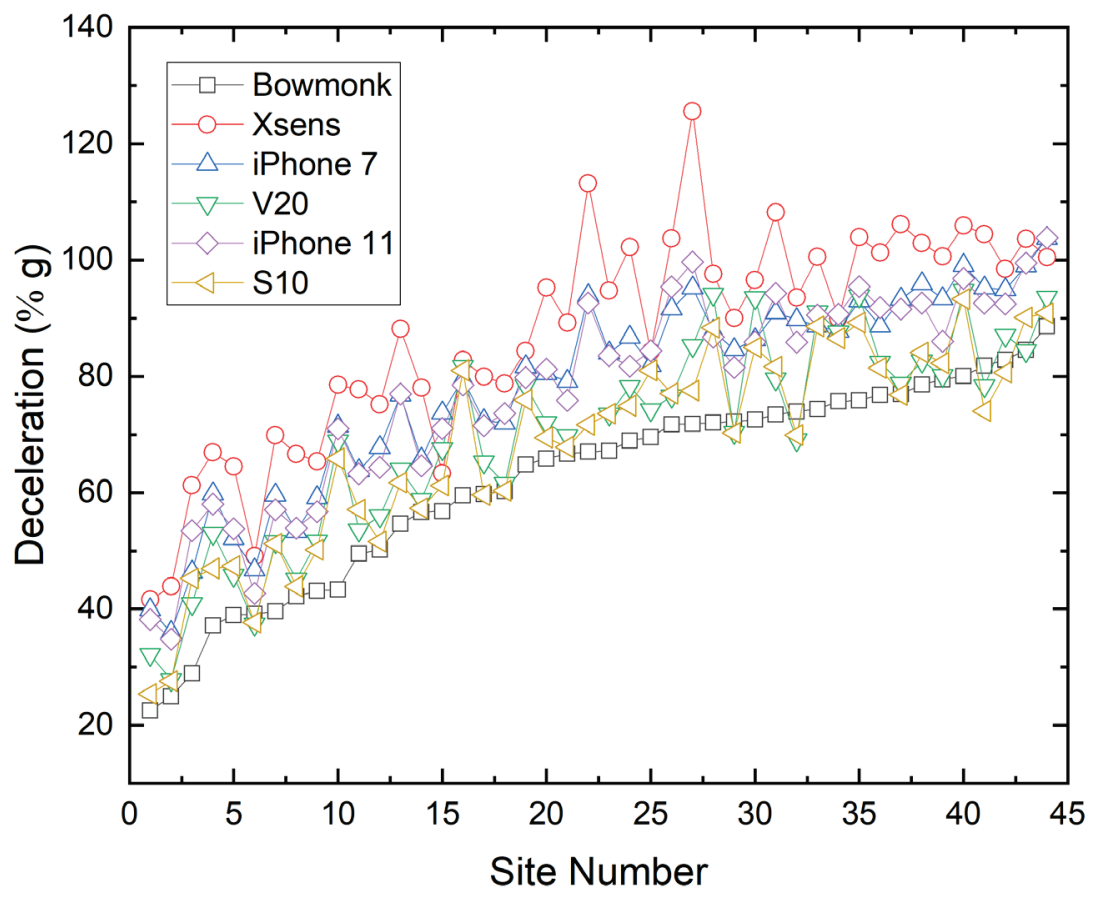


It is clear from the data in Figure 81 that while the smartphone-based deceleration data roughly follow the trend of Bowmonk data, they still vary widely. It is also clear that the Xsens deceleration data scatters as much or more than the data provided by the various smartphones. It does appear, however, that the variations in smartphone results represent a fixed trend rather than some type of stochastic behavior. This is further realized by a scatter matrix plot, seen in Figure 82.

Figure 82. Scatter matrix plot for HMMWV deceleration data.

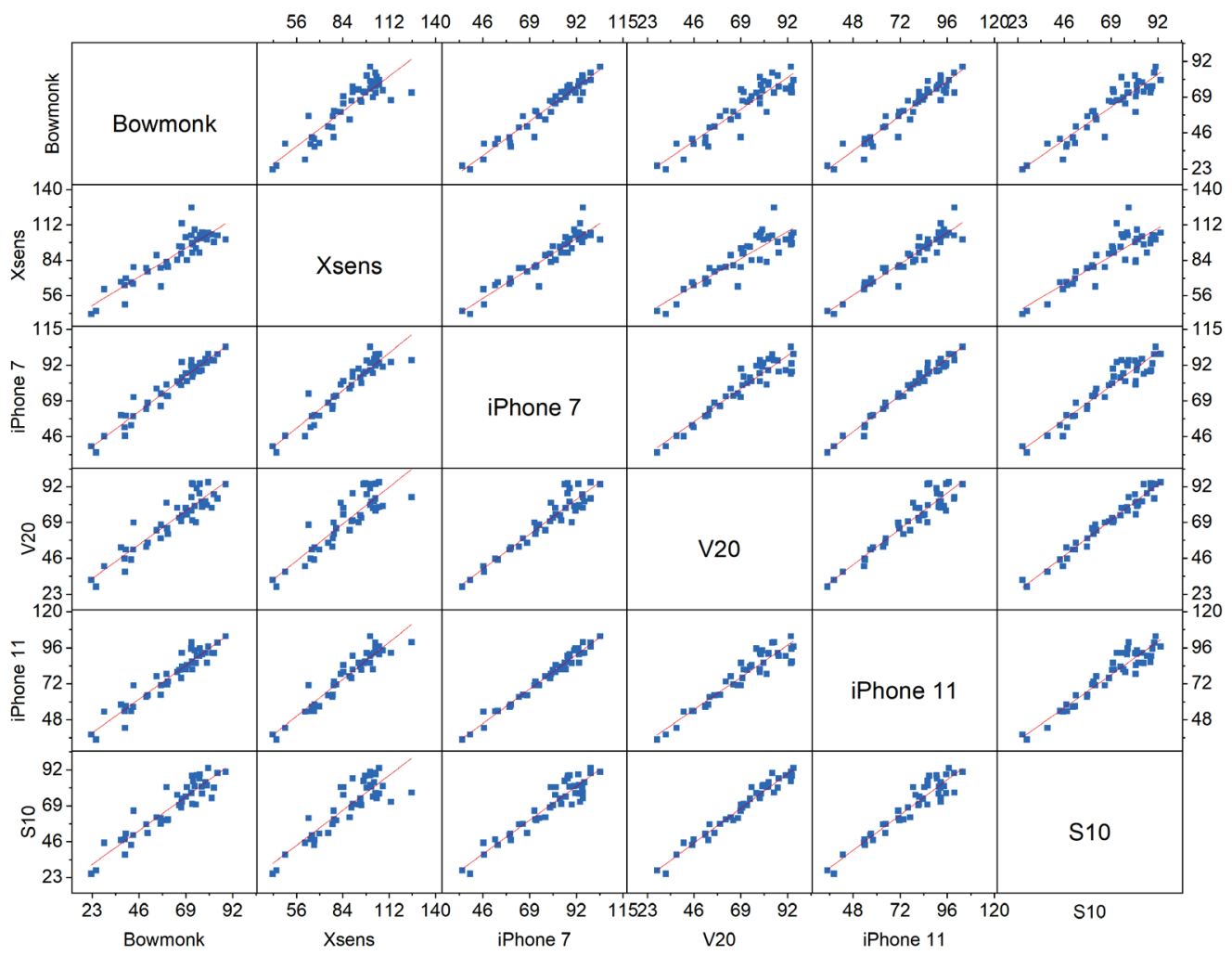

As seen in Figure 82, the various smartphones exhibit better intra-model than extra-model linear correlation than with the Bowmonk and Xsens IMUs. Such a result is reasonable given that the Bowmonk and Xsens devices are likely equipped with similar solid-state IMUs while the various smartphones have lower power and accuracy MEMS-based IMUs. Furthermore, weight characteristics also affect deceleration measurement during the braking action. The various smartphones are of very similar weight and weight distribution whereas the Bowmonk is much larger and heavier than the other devices, and the Xsens IMU is much smaller and lighter than all other devices. While it is the desired result of this effort to develop a predictive model for GripTester values with deceleration as 
input, it is also of great interest to learn how well the various decelerationbased devices correlate to each other. A table of linear model goodness-offit parameters measured for the HMMWV deceleration data can be seen in Table 19 below. Goodness-of-fit is quantified here by using the coefficient of determination (COD; square of Pearson's $r$ ).

Table 19. Linear model COD values for HMMWV deceleration equipment.

\begin{tabular}{|l|l|l|l|l|l|l|}
\hline & Bowmonk & Xsens & iPhone 7 & V20 & $\begin{array}{l}\text { iPhone } \\
11\end{array}$ & S10 \\
\hline Bowmonk & 1.000 & 0.792 & 0.939 & 0.840 & 0.909 & 0.863 \\
\hline Xsens & 0.792 & 1.000 & 0.886 & 0.787 & 0.901 & 0.766 \\
\hline iPhone 7 & 0.939 & 0.866 & 1.000 & 0.895 & 0.975 & 0.890 \\
\hline $\begin{array}{l}\text { V20 } \\
\text { 11 }\end{array}$ & 0.840 & 0.787 & 0.895 & 1.000 & 0.896 & 0.963 \\
\hline S10 & 0.863 & 0.766 & 0.890 & 0.963 & 0.903 & 1.000 \\
\hline Mean* & 0.869 & 0.822 & 0.917 & 0.876 & 0.917 & 0.877 \\
\hline STDEV* & 0.058 & 0.058 & 0.039 & 0.066 & 0.033 & 0.072 \\
\hline
\end{tabular}

* Mean and standard deviation calculations exclude 1.000 COD correlations.

Mean COD values displayed in the above table reiterate the higher scatter present in the Xsens deceleration data. It is also obvious from the mean COD values that the two iPhone models tested exhibit higher linear correlation than any of the other deceleration devices.

Furthermore, it is obvious that the two iPhone models tested are more consistently correlated to the other devices based on sample standard deviation values seen in Table 19. 


\subsubsection{Truck}

Deceleration data collected in the 1/2-ton pickup truck for all three data collections can be found in Figure 83 .

Figure 83. Deceleration data from the 1/2-ton pickup truck in ascending order.

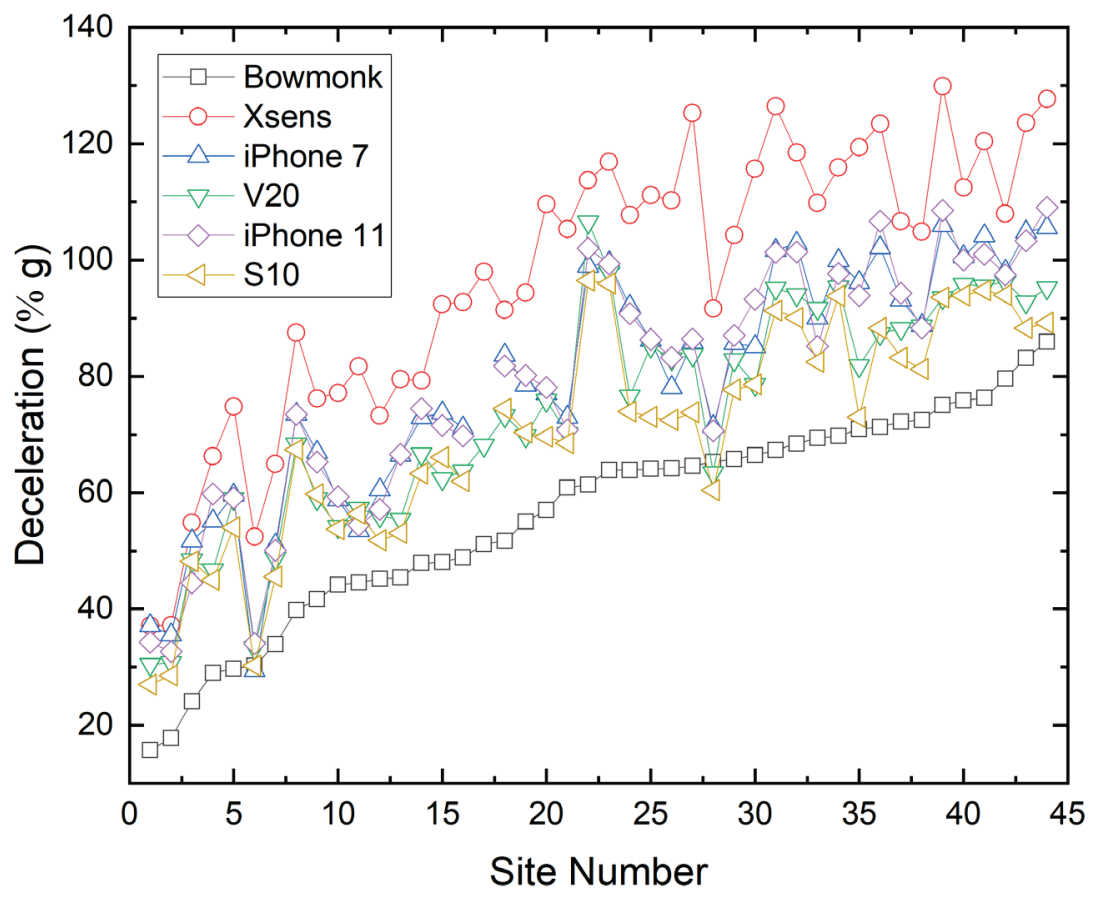

Once again, it is clear from the data in Figure 83 that a rough trend is visible between Bowmonk and smartphone data. It is also clear that there is a trend in deceleration-based friction-response unique to the smartphone and Xsens IMUs that is not visible in the Bowmonk results. It is unclear whether this added "smoothness" in the Bowmonk data is based on hardware or software properties unique to the device itself. These trends are further realized by a scatter matrix plot, seen in Figure 84. 
Figure 84. Scatter matrix plot for truck deceleration data.

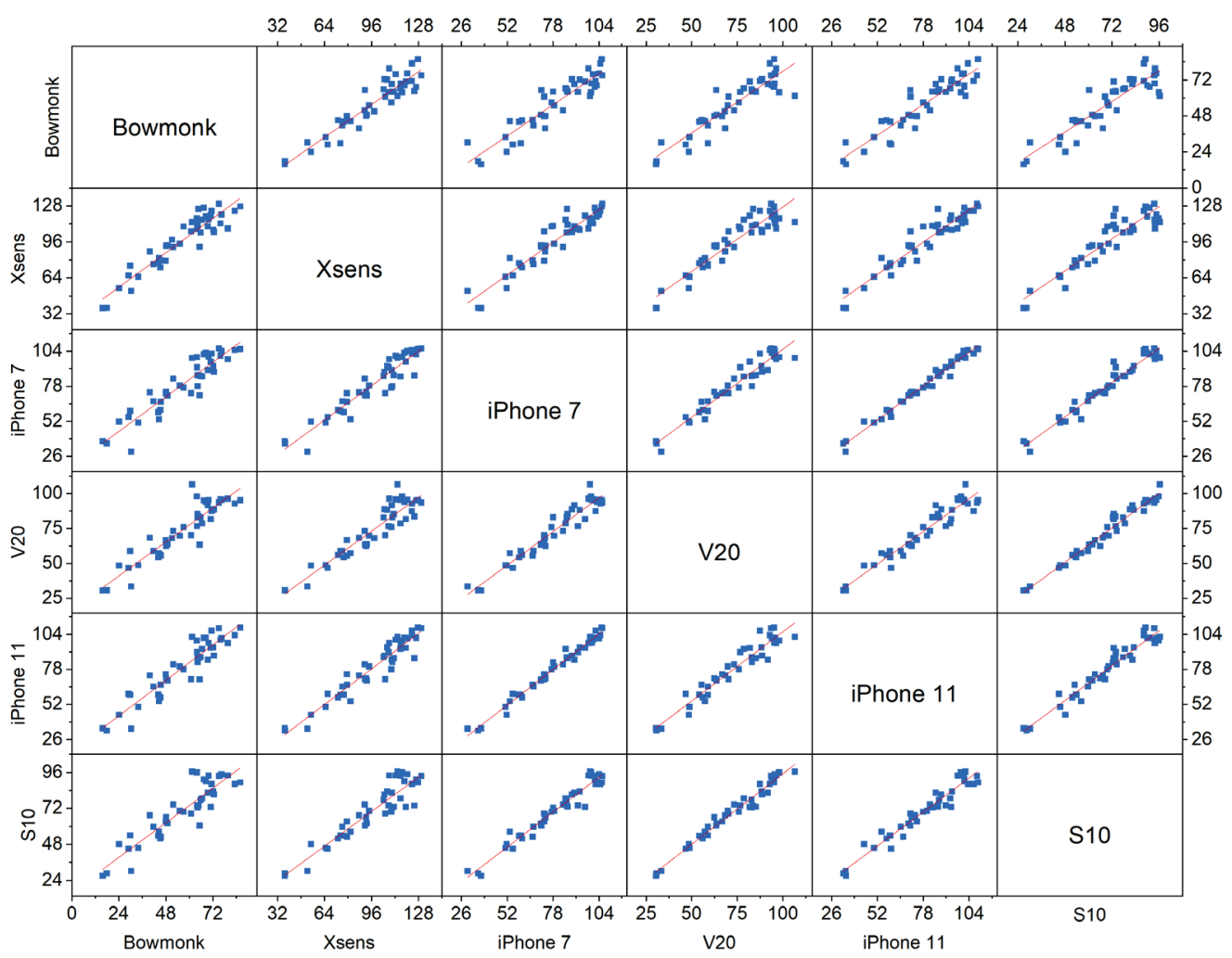

As seen in Figure 84, the various smartphones tested exhibit better intra-model than extra-model linear correlation than with the Bowmonk and Xsens IMUs. This is a reasonable result, given that the Bowmonk and Xsens IMUs are likely equipped with unique or proprietary solid-state IMUs whereas the various smartphones have lower power and accuracy MEMS-based IMUs. Also, as mentioned above, the weight characteristics of each device likely play an important role in deceleration output. A table of linear model goodness-of-fit parameters measured for the truck test vehicle deceleration data can be seen in Table 20. Goodness-of-fit is quantified here by using the COD. 
Table 20. Linear model COD values for truck deceleration equipment.

\begin{tabular}{|l|l|l|l|l|l|l|}
\hline & Bowmonk & Xsens & iPhone 7 & V20 & $\begin{array}{l}\text { iPhone } \\
11\end{array}$ & S10 \\
\hline Bowmonk & 1.000 & 0.873 & 0.852 & 0.834 & 0.858 & 0.817 \\
\hline Xsens & 0.873 & 1.000 & 0.891 & 0.875 & 0.91 & 0.859 \\
\hline iPhone 7 & 0.852 & 0.891 & 1.000 & 0.934 & 0.982 & 0.949 \\
\hline V20 & 0.834 & 0.875 & 0.934 & 1.000 & 0.926 & 0.969 \\
\hline $\begin{array}{l}\text { 11 } \\
\text { Mhone }\end{array}$ & 0.858 & 0.910 & 0.982 & 0.926 & 1.000 & 0.939 \\
\hline STDEV* & 0.022 & 0.020 & 0.051 & 0.053 & 0.045 & 0.065 \\
\hline
\end{tabular}

* Mean and standard deviation calculations exclude 1.000 COD correlations.

Mean COD values displayed in the above table further reiterate the higher scatter present in the Xsens deceleration data. Much like the HMMWV data, the two Apple iPhone models tested in the truck exhibit superior linear correlation to all devices. High linear correlation, however, does exist between all devices tested in the truck.

\subsubsection{SUV}

Deceleration data collected in the SUV for all three data collections can be found in Figure 85 . 
Figure 85. Deceleration data from the SUV in ascending order.

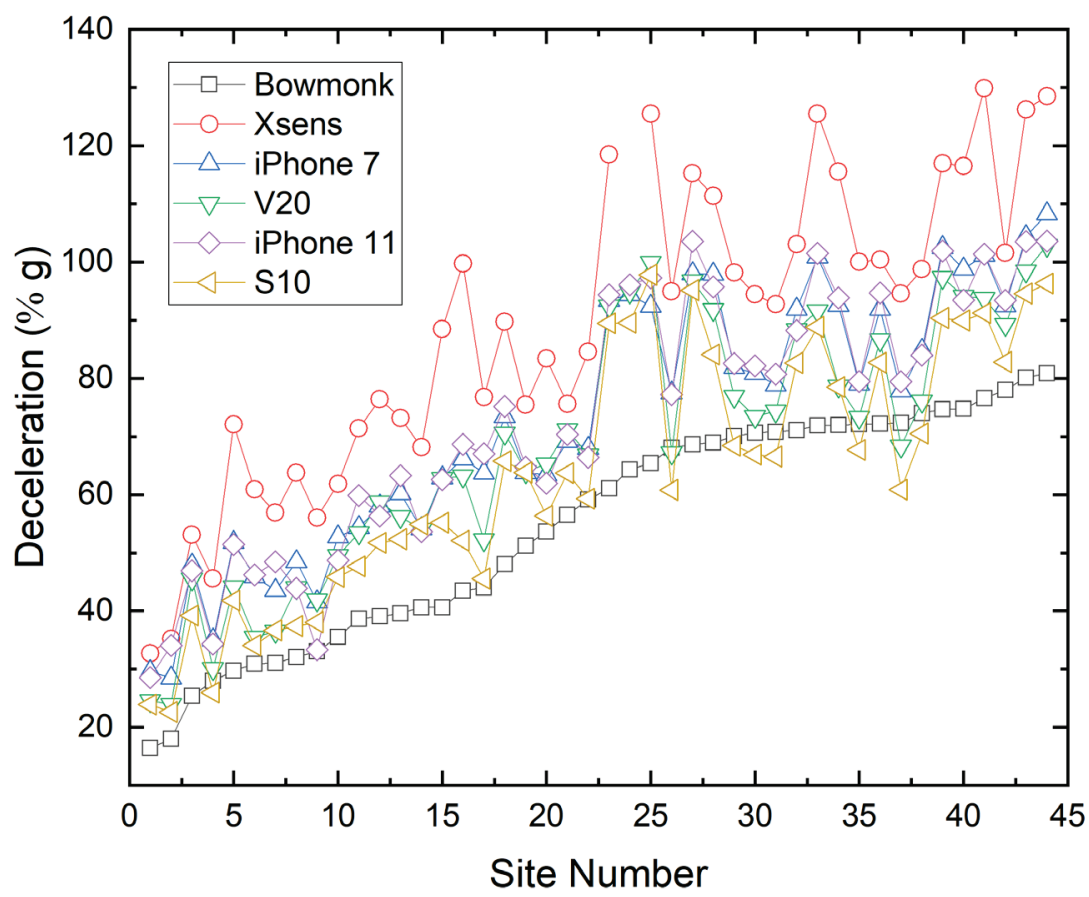

The SUV deceleration data (Figure 85) show clearly that the Bowmonk device continues the smooth trend seen in the other two test vehicles. Once again, the smartphones and Xsens IMU follow the same rough trend as the Bowmonk data with a unique variation. This is further realized by a scatter matrix plot, seen in Figure 86. 
Figure 86. Scatter matrix plot for SUV deceleration data.

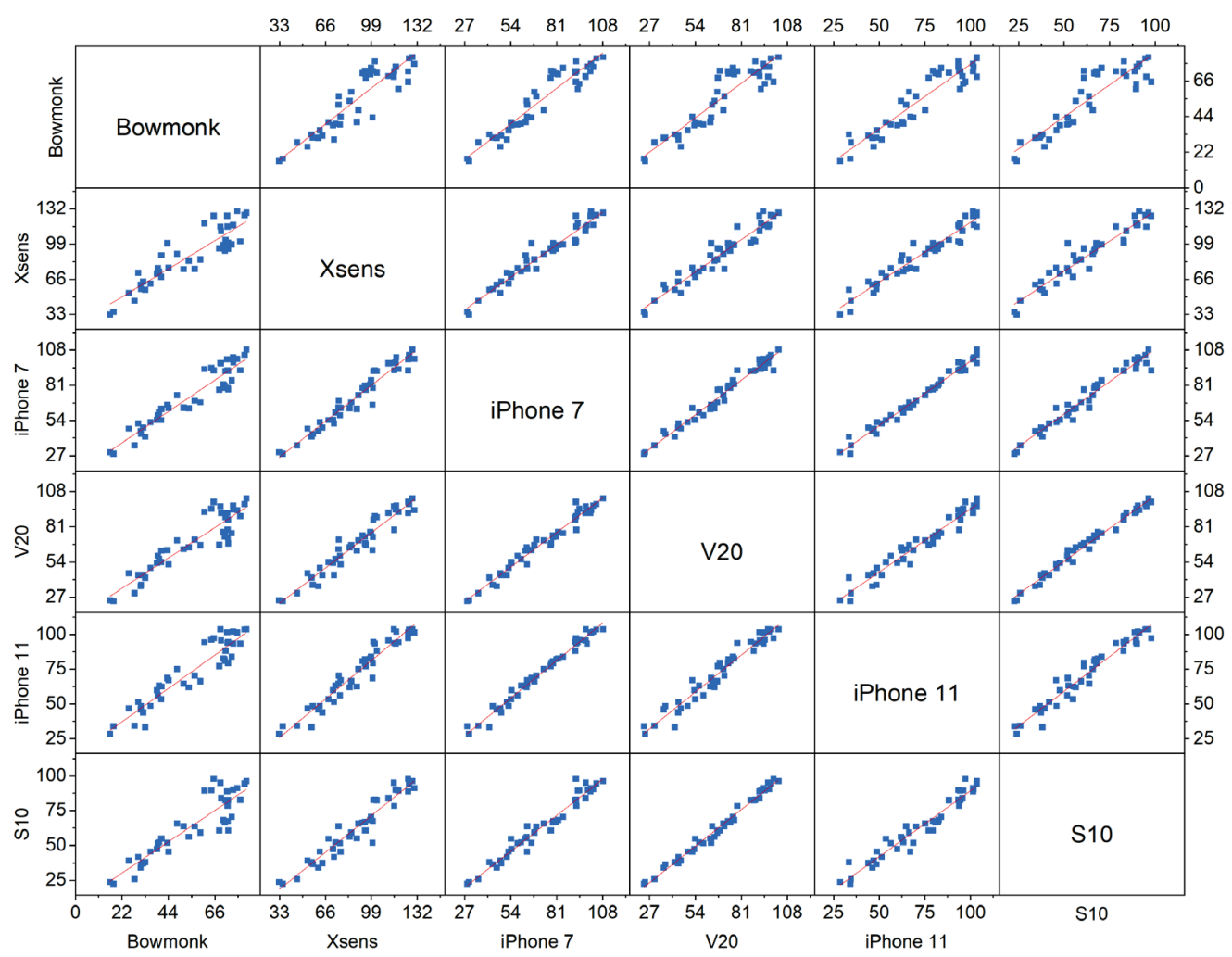

As seen in Figure 86, the various smartphones exhibit better intra-model than extra-model linear correlation than with the Bowmonk. Unlike the other two test vehicles' data, however, the SUV data appear to show a greater correlation between the Xsens IMU and the various smartphones. This further emphasizes the difference between the Bowmonk's unique weight and IMU characteristics and the MEMS-based smartphone IMUs. This is further emphasized by the linear model CODs displayed in Table 21. 
Table 21. Linear model COD values for SUV deceleration equipment.

\begin{tabular}{|l|l|l|l|l|l|l|}
\hline & Bowmonk & Xsens & iPhone 7 & V20 & $\begin{array}{l}\text { iPhone } \\
11\end{array}$ & S10 \\
\hline Bowmonk & 1.000 & 0.811 & 0.891 & 0.839 & 0.870 & 0.810 \\
\hline Xsens & 0.811 & 1.000 & 0.944 & 0.925 & 0.934 & 0.911 \\
\hline iPhone 7 & 0.891 & 0.944 & 1.000 & 0.966 & 0.982 & 0.954 \\
\hline $\begin{array}{l}\text { V20 } \\
11\end{array}$ & 0.839 & 0.925 & 0.966 & 1.000 & 0.949 & 0.984 \\
\hline S10 & 0.810 & 0.911 & 0.954 & 0.984 & 0.943 & 1.000 \\
\hline Mean* & 0.844 & 0.905 & 0.947 & 0.933 & 0.936 & 0.920 \\
\hline STDEV* & 0.036 & 0.054 & 0.035 & 0.057 & 0.041 & 0.067 \\
\hline
\end{tabular}

* Mean and standard deviation calculations exclude 1.000 COD correlations.

Mean COD values displayed in the above table reiterate the higher scatter present in the Xsens deceleration data. Much like data collected with the HMMWV and truck, deceleration data collected using the SUV exhibits highest linear correlation with the two Apple iPhone models tested. The Bowmonk, however, does exhibit more consistent measurement, evidenced by the low-sample standard deviation.

\subsection{Smartphone repeatability analysis}

A previous study (Ward et al. 2019) has shown, with limited datasets, that smartphone intra-model repeatability is high. In order to reinforce this conclusion, a larger repeatability study was conducted at Golden Eagle Landing Zone. Four smartphones with three replicates each were mounted 
in the HMMWV test vehicle (see Figure 87), and brake tests were conducted on three brake sites with varying moisture content.

Figure 87. Smartphone mounting configuration during replicate testing at Golden Eagle LZ.

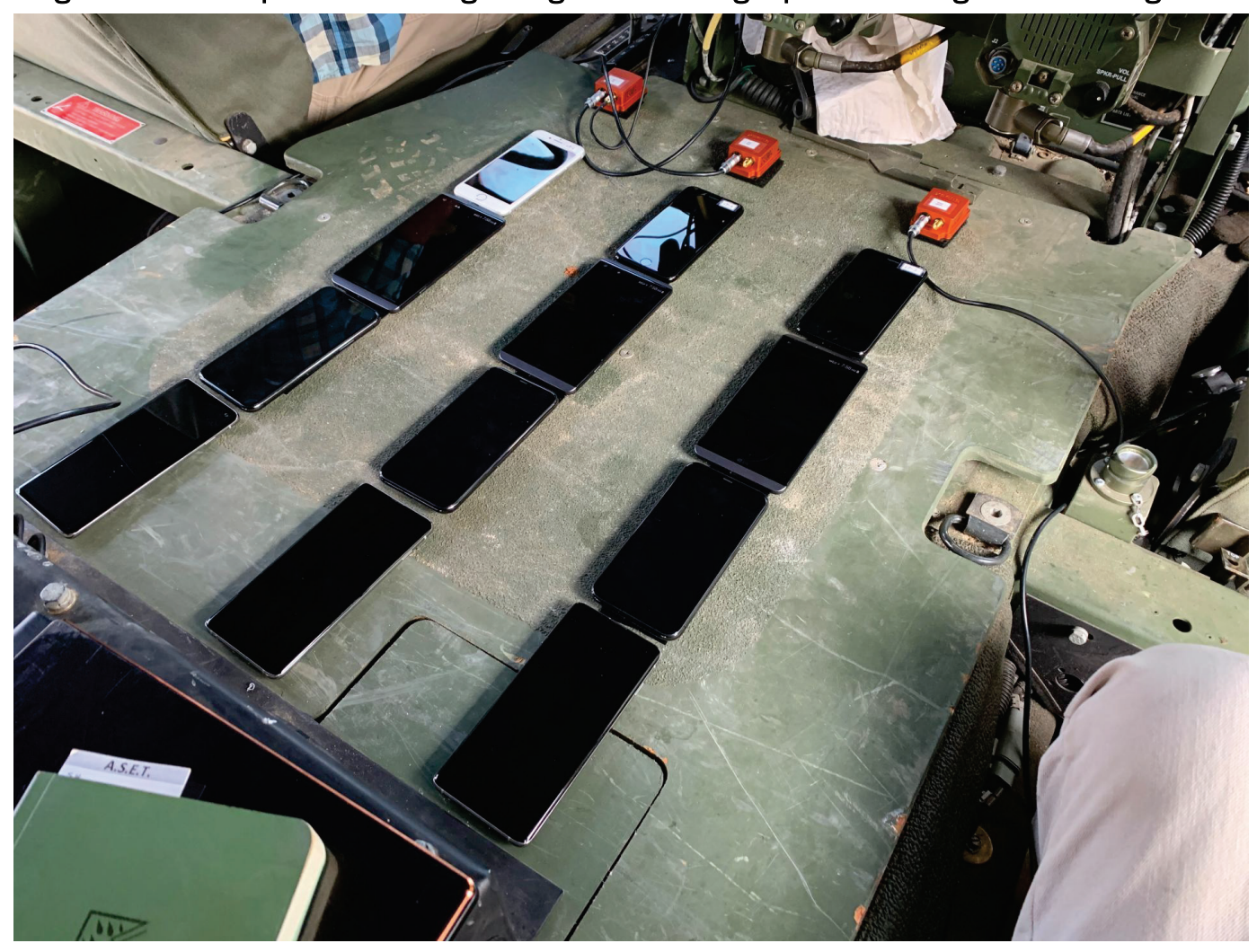

Roughly 22-24 replicate data sets were collected from each device (variability due to loss of data or device malfunction). In order to better visualize intra-model scatter in deceleration output, data were organized in ascending order according to the first device (see Figure 88). It is observable from the graph itself that variance in the smartphone data ranges from roughly 2 to 5 percent acceleration of gravity. This visual result is further evidenced by looking at some repeatability measures such as mean absolute error (MAE), pooled standard deviation, and mean COD (see Table 22). As seen in Table 22, the smartphones highly correlate with each other (based on mean COD), have roughly 2-5\%g (based on MAE), and exhibit low scatter (based on low pooled standard deviation values). 
Figure 88. Replicate smartphone deceleration data from the HMMWV at Golden Eagle LZ.
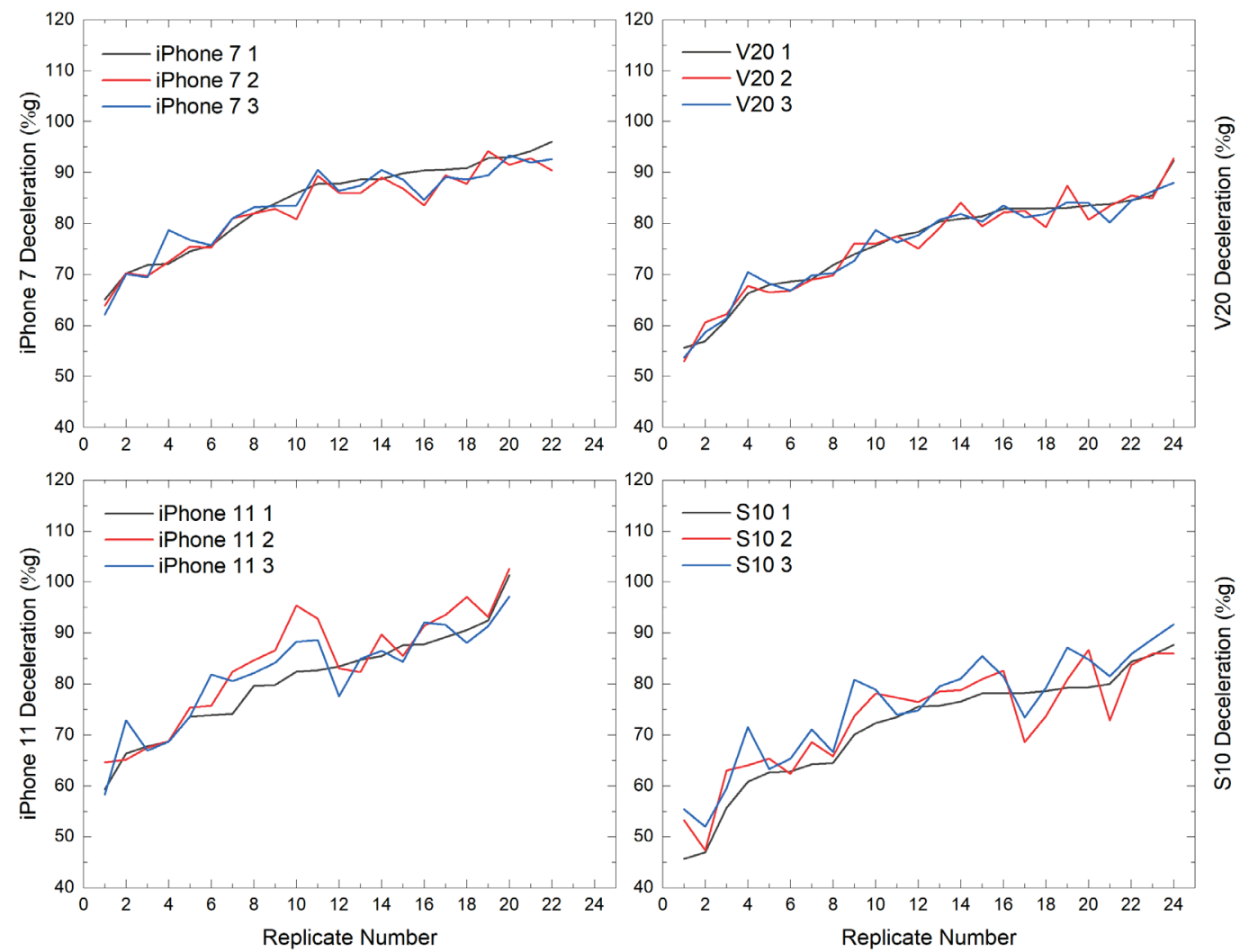

Table 22. Repeatability factors for replicate smartphone data.

\begin{tabular}{|l|l|l|l|}
\hline Device & MAE & $\begin{array}{l}\text { Pooled } \\
\text { Standard } \\
\text { Deviation }\end{array}$ & $\begin{array}{l}\text { Mean } \\
\text { COD }\end{array}$ \\
\hline iPhone 7 & 2.808 & 1.431 & 0.909 \\
\hline V20 & 2.532 & 1.201 & 0.949 \\
\hline $\begin{array}{l}\text { iPhone } \\
11\end{array}$ & 5.430 & 2.662 & 0.843 \\
\hline S10 & 5.864 & 2.744 & 0.856 \\
\hline
\end{tabular}

\subsection{Final predictive models}

While it is important to draw correlations among the various deceleration-based devices, it is of the utmost importance to draw sufficient correlations between the deceleration-based devices and the 
GripTester. Following the regression methods detailed by the original SPRO team (Tingle et al. 2017), two types of model regression were evaluated: linear and power. The purpose of these regressions was not only to accurately model deceleration-based surface friction predictions, but also to provide enough model conservatism for safe use during actual $\mathrm{C}-17$ operations. As such, regressions drawn in this section include actual GT measurements as well as GT minus one sample standard deviation (GT-10), GT minus one and a half sample standard deviations

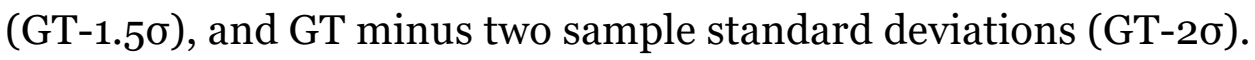
Model reliability in this section is measured as the probability that a measurement is higher than the model prediction.

\subsubsection{HMMWV}

First, an examination of non-smartphone deceleration measurements (Bowmonk and Xsens) and their correlation to GT surface frictions measurements is conducted. Linear surface friction prediction models for the Bowmonk and Xsens IMUs are presented in Figure 89. Power model surface friction predictions for the same devices are presented in Figure 90. Associated model parameters for each are presented in Table 23.

Base GT linear and power model predictions for the Bowmonk and Xsens have CODs greater than 0.6 ; however, a significant percentage $(\sim 50 \%)$ of data exist below the prediction line. Reliability for the Bowmonk tends to scale better with the power model predictions (86\% for GT-1 $\sigma$ and $95 \%$

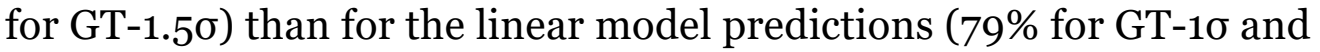
97\% for GT-1.5\%). Scatter present in the Xsens device measurements provides worse predictions than that in the Bowmonk. As a result, linear model reliability (70\% for GT- $1 \sigma$ and $84 \%$ for GT-1.5 $\sigma$ ) scales better than the power model predictions ( $59 \%$ for GT- $1 \sigma$ and $81 \%$ for GT-1.5\%); however, their GT-1.5 $\sigma$ predictions are roughly the same. 
Figure 89. Bowmonk and Xsens linear model predictions in the HMMWV.
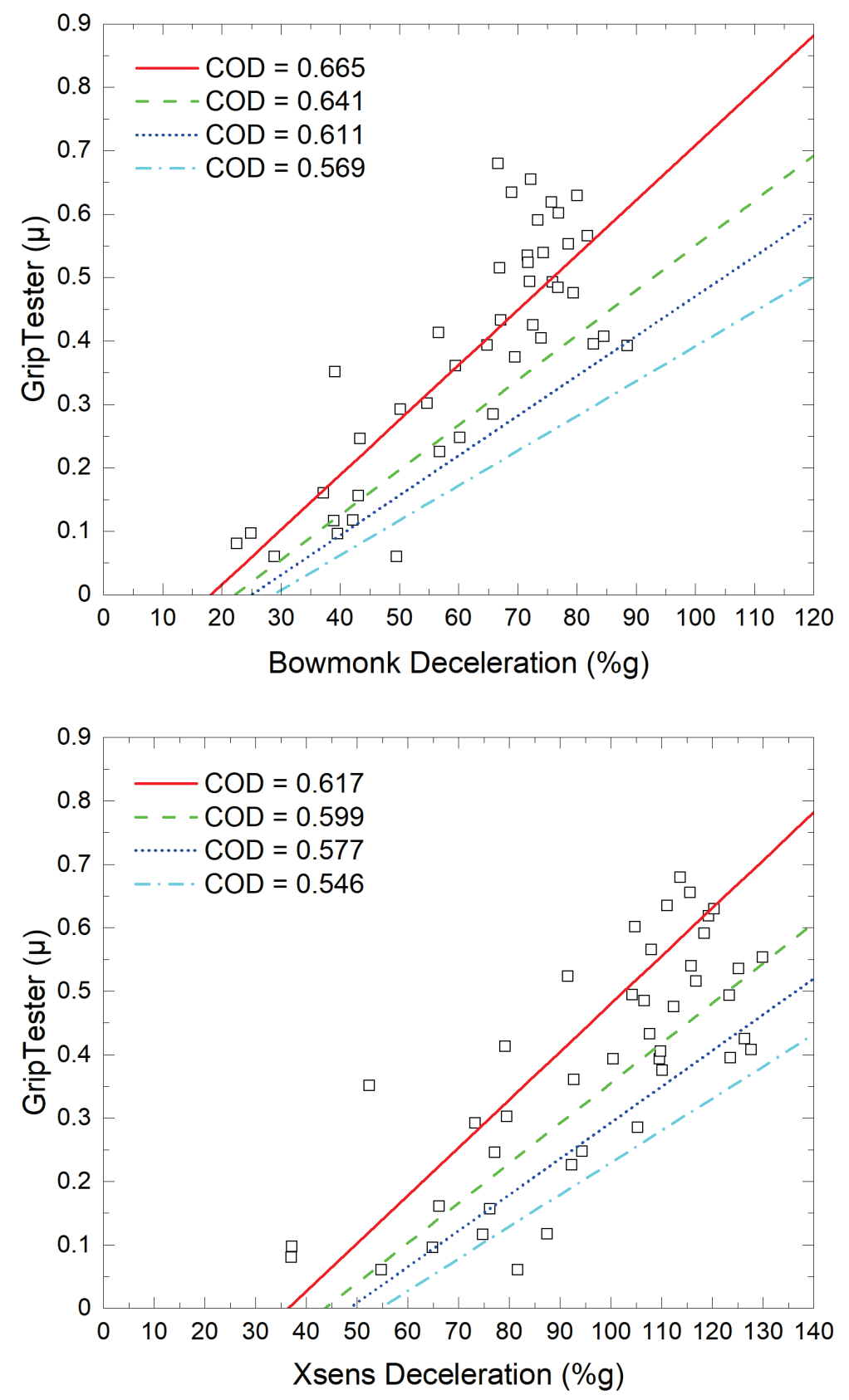

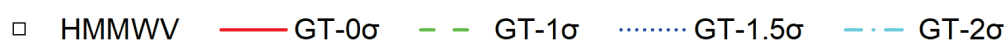


Figure 90. Bowmonk and Xsens power model predictions in the HMMWV.
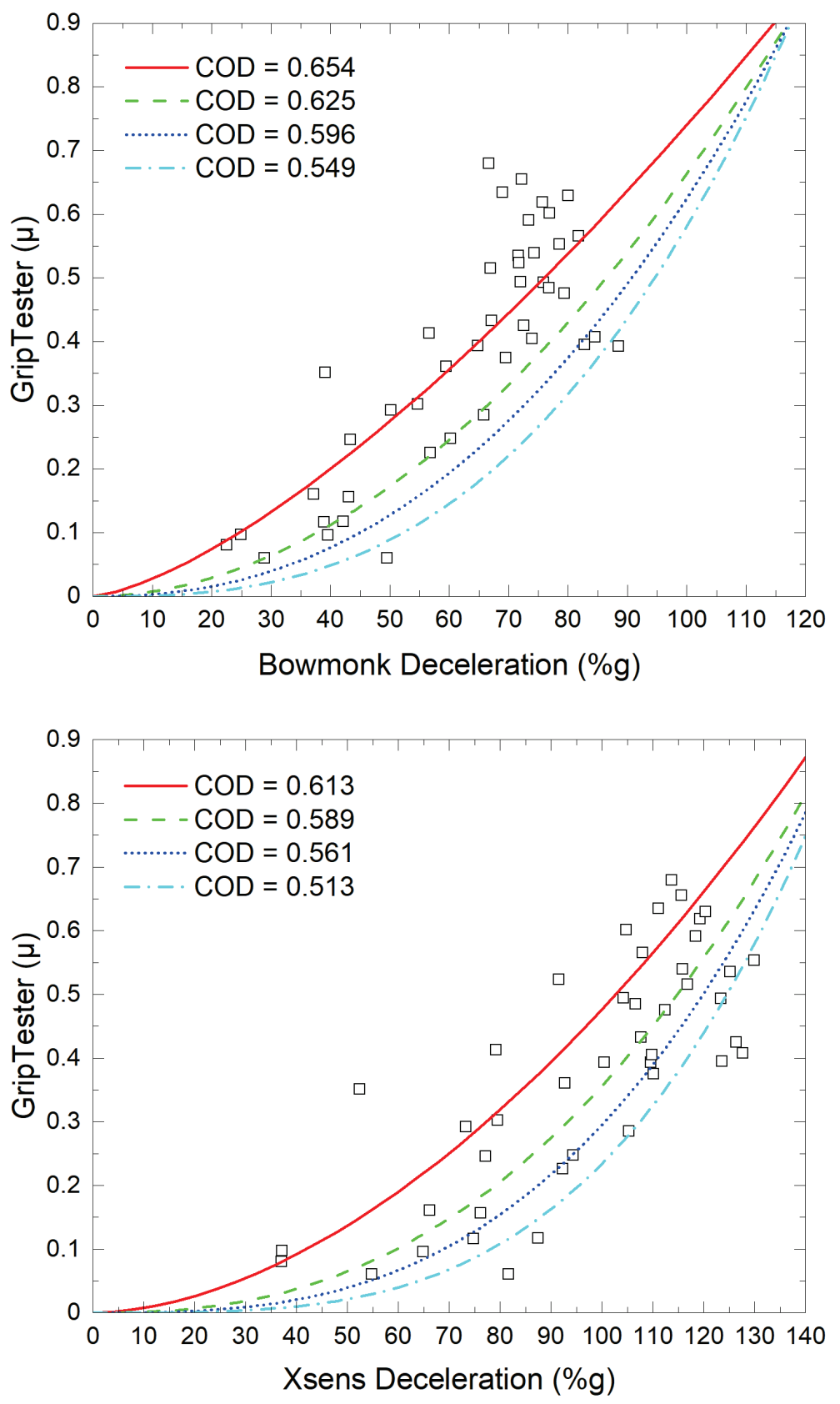

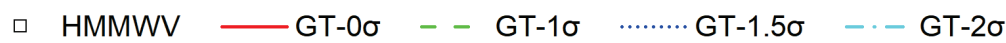


Table 23. Linear and power model parameters for the HMMWV.

\begin{tabular}{|c|c|c|c|c|c|}
\hline \multirow[t]{2}{*}{$\begin{array}{l}\text { Y-Data } \\
(\mu)\end{array}$} & \multirow[t]{2}{*}{$\begin{array}{l}\text { X-Data } \\
\text { (\%g) }\end{array}$} & \multicolumn{2}{|c|}{$\begin{array}{l}\text { Linear Model } \\
\qquad y=A+B x\end{array}$} & \multicolumn{2}{|c|}{$\begin{array}{l}\text { Power Model } \\
\qquad y=a x^{b}\end{array}$} \\
\hline & & A & $B$ & $a$ & $b$ \\
\hline \multirow[t]{6}{*}{ GT } & Bowmonk & -0.15717 & 0.00866 & 1.03E-3 & 1.4282 \\
\hline & Xsens & -0.27514 & 0.00755 & $1.204 \mathrm{E}-4$ & 1.7985 \\
\hline & iPhone 7 & -0.27591 & 0.00841 & 1.105E-4 & 1.86083 \\
\hline & V20 & -0.08786 & 0.00679 & 1.65E-3 & 1.28263 \\
\hline & iPhone 11 & -0.24312 & 0.00805 & $1.825 \mathrm{E}-4$ & 1.75 \\
\hline & S10 & -0.16175 & 0.00793 & 7.387E-4 & 1.47335 \\
\hline \multirow[t]{6}{*}{ GT-10 } & Bowmonk & -0.15717 & 0.00708 & $8.668 \mathrm{E}-5$ & 1.94199 \\
\hline & Xsens & -0.27514 & 0.0063 & 4.336E-6 & 2.45725 \\
\hline & iPhone 7 & -0.27591 & 0.00706 & 3.083E-6 & 2.59518 \\
\hline & V20 & -0.08786 & 0.00499 & 4.901E-5 & 2.00055 \\
\hline & iPhone 11 & -0.24312 & 0.00663 & $4.952 \mathrm{E}-6$ & 2.48705 \\
\hline & S10 & -0.16175 & 0.00628 & 3.153E-5 & 2.12215 \\
\hline \multirow[t]{6}{*}{ GT-1.5o } & Bowmonk & -0.15717 & 0.00628 & 1.630E-5 & 2.29177 \\
\hline & Xsens & -0.27514 & 0.00568 & $4.504 \mathrm{E}-7$ & 2.90808 \\
\hline & iPhone 7 & -0.27591 & 0.00639 & $2.604 \mathrm{E}-7$ & 3.10537 \\
\hline & V20 & -0.08786 & 0.00409 & $2.989 \mathrm{E}-6$ & 2.58004 \\
\hline & iPhone 11 & -0.24312 & 0.00592 & 3.798E-7 & 3.01568 \\
\hline & S10 & -0.16175 & 0.00546 & 3.047E-6 & 2.60851 \\
\hline \multirow[t]{6}{*}{ GT-20 } & Bowmonk & -0.15717 & 0.00549 & $2.186 \mathrm{E}-6$ & 2.71226 \\
\hline & Xsens & -0.27514 & 0.00505 & $2.818 \mathrm{E}-8$ & 3.45939 \\
\hline & iPhone 7 & -0.27591 & 0.00572 & $1.287 \mathrm{E}-8$ & 3.7262 \\
\hline & V20 & -0.08786 & 0.00319 & 6.697E-8 & 3.35962 \\
\hline & iPhone 11 & -0.24312 & 0.00520 & $1.540 \mathrm{E}-8$ & 3.67585 \\
\hline & S10 & -0.16175 & 0.00463 & $1.406 \mathrm{E}-7$ & 3.25094 \\
\hline
\end{tabular}


As for the smartphones tested, linear model predictions are seen in Figure 91, power model predictions are seen in Figure 92, and model parameters are listed in Table 23. Base GT linear model predictions vary for each device: CODs over 0.6 for the Apple devices and under 0.6 for the other two. Similarly, base GT power model predictions have CODs over or near 0.6 for the Apple devices and less than 0.6 COD for the Android devices. For both types of model prediction, roughly 50\% of the data exist below the prediction line.

Figure 91. Smartphone linear model predictions in the HMMWV.

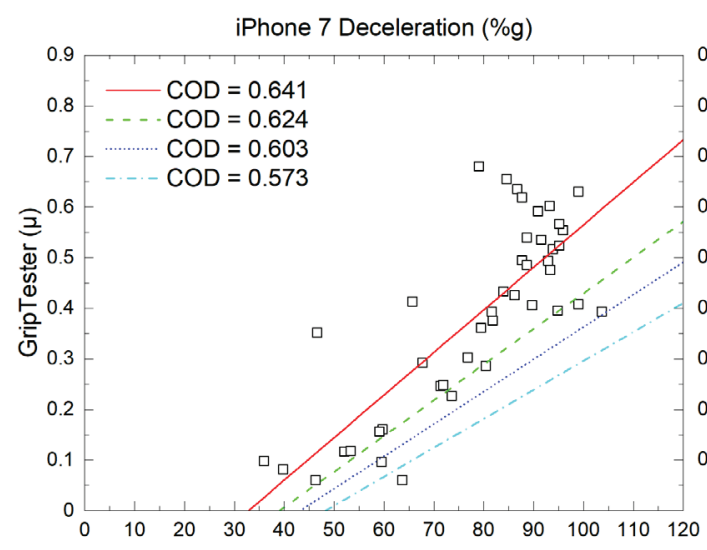

V20 Deceleration (\%g)
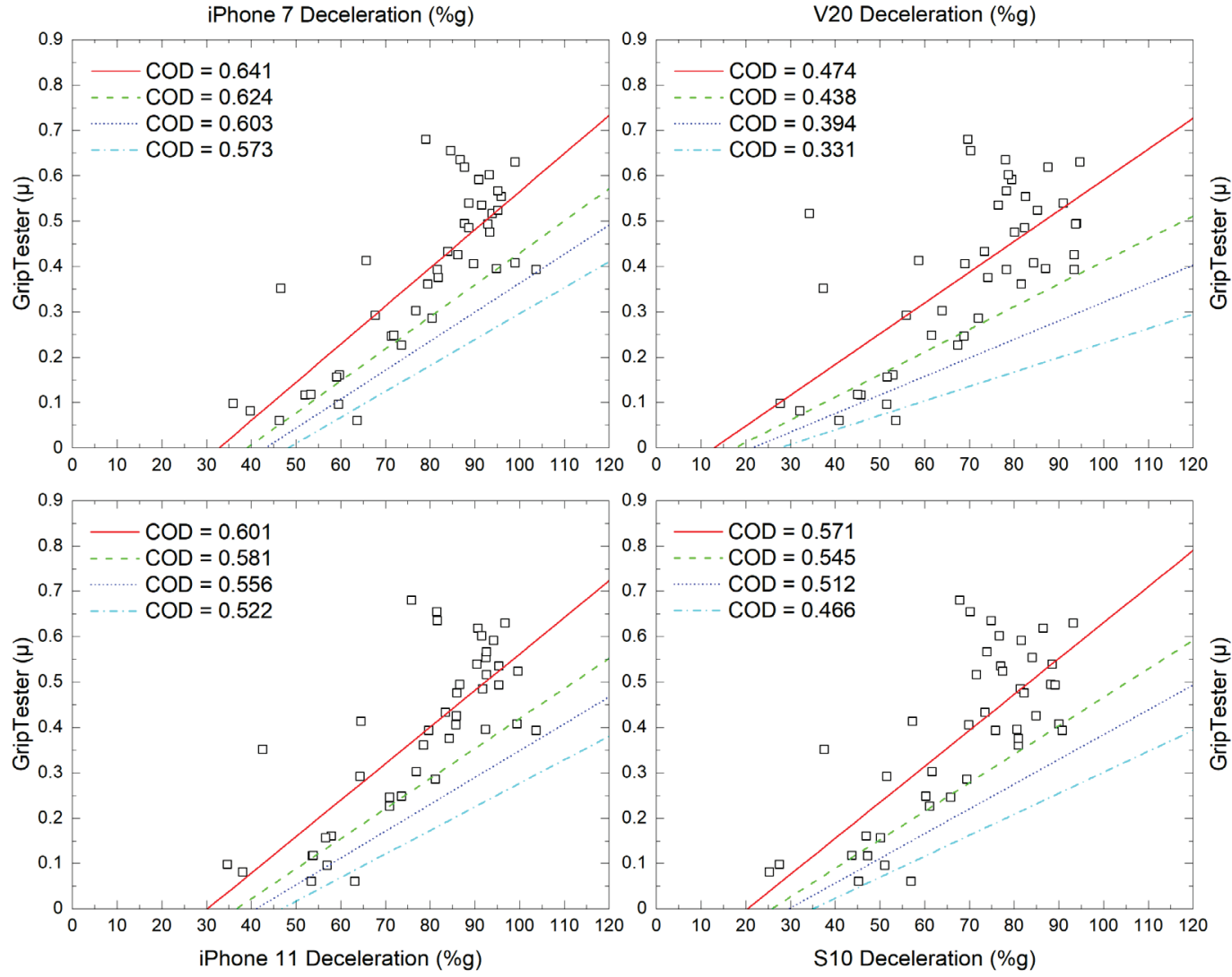

口 HMMWV

GT-10

GT-1.5o

GT-2 $\sigma$ 
Figure 92. Smartphone power model predictions in the HMMWV.
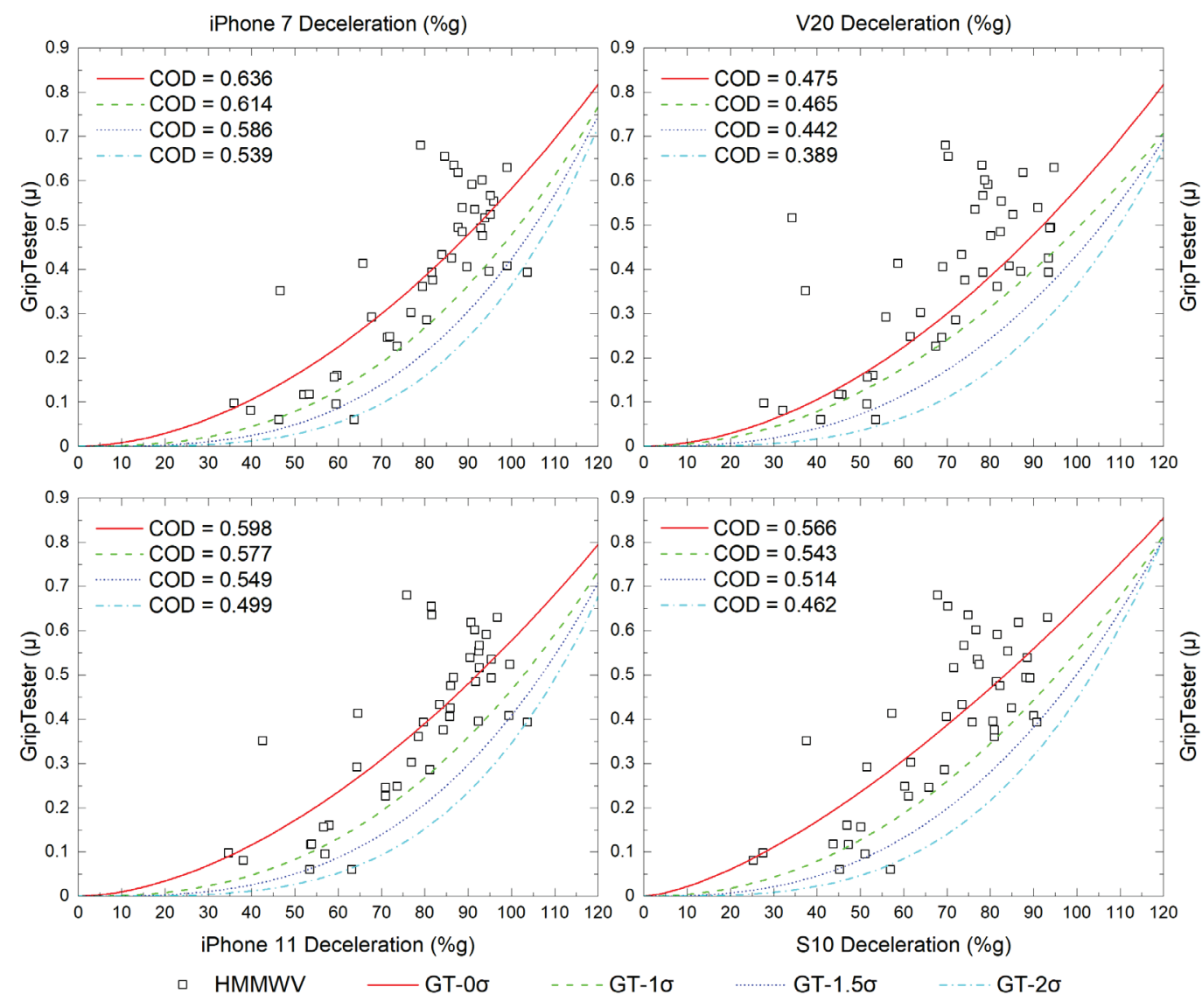

Reliability for all smartphones tested in the HMMWV is either roughly the same or better for power model predictions than for linear model predictions. In general, reliability for GT-10 predictions is around $90 \%$, and reliability for GT-1.50 predictions is around $95 \%$. Given this behavior, power model predictions are favored for the smartphones tested in the HMMWV, as the power model scales closer to actual data at higher surface friction values. Furthermore, GT-1.5 $\sigma$ predictions are favored over the other three variants, given a combination of high reliability and optimum conservatism. Linear model predictions at high surface friction ( $\sim 0.6$ to $0.7 \mu$ ) tend to be excessively conservative.

\subsubsection{Truck}

Linear surface friction prediction models for the Bowmonk and Xsens IMUs, collected from the 1/2-ton pickup truck, are presented in Figure 93; and power model predictions in the same vehicle are presented in Figure 94. Associated model parameters for each are presented in Table 24. 
Base GT linear and power prediction models for the Bowmonk are near 0.8 COD, whereas base linear and power prediction models for the Xsens are both over 0.6 COD. For both model types, roughly $50 \%$ of the data are below the base GT prediction line. The Bowmonk data exhibits low scatter compared to the other devices and other vehicles with a COD greater than 0.7 for all GT variations. The Xsens exhibits roughly the same scatter in the truck as it did in the HMMWV, with CODs around o.6 for all GT variations. Power model reliability for the Bowmonk ( $93 \%$ for GT-1 $\sigma$ and

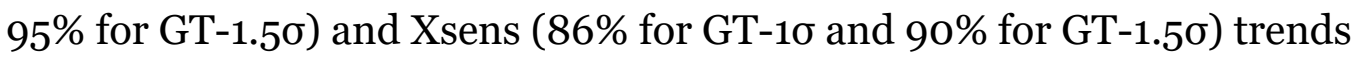
higher than that of the linear model reliability for the Bowmonk (90\% for GT-1 $\sigma$ and GT-1.5 $\sigma$ ) and Xsens (84\% for GT- $1 \sigma$ and $90 \%$ for GT-1.5 $\sigma$ ). 
Figure 93. Bowmonk and Xsens linear model predictions in the truck.
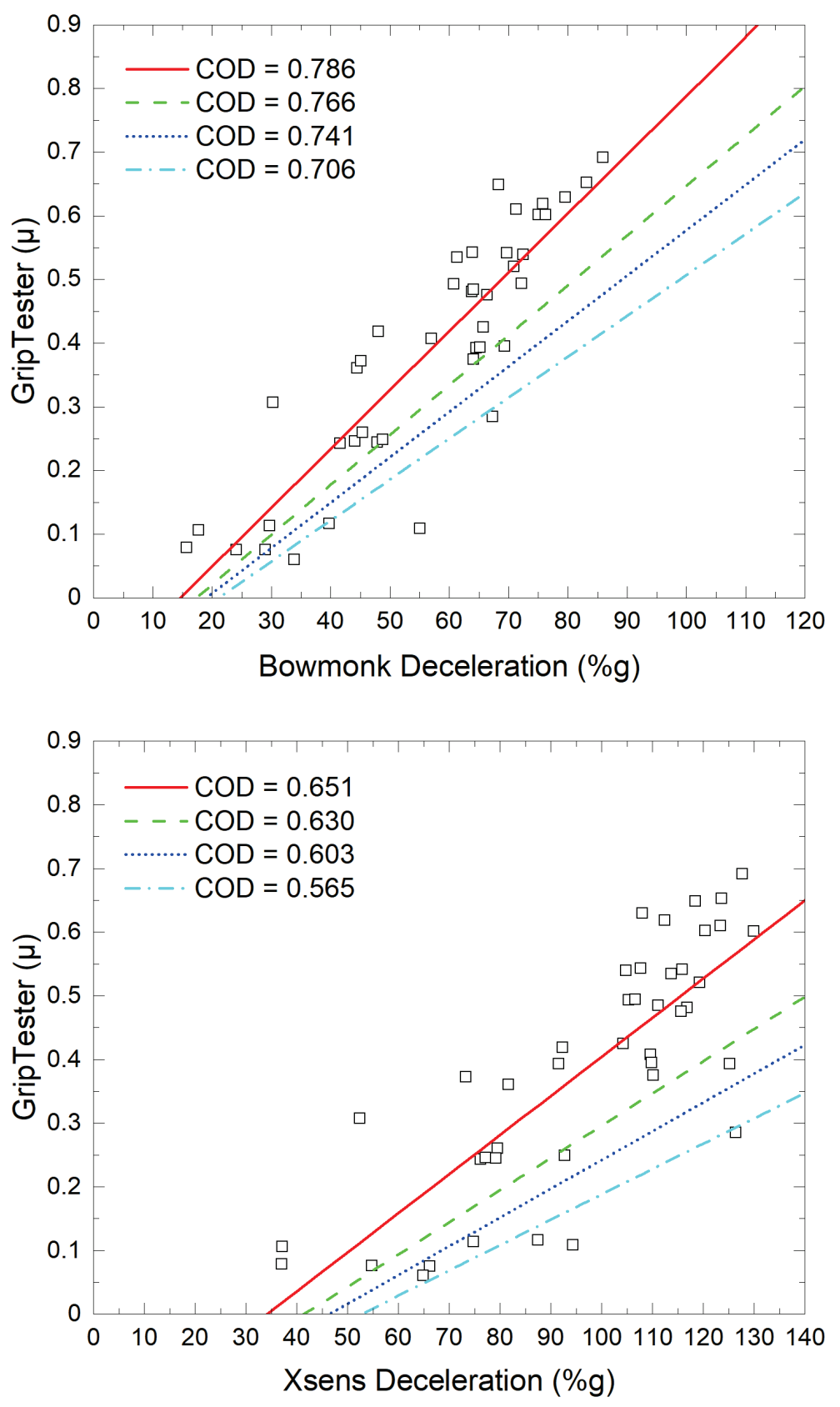

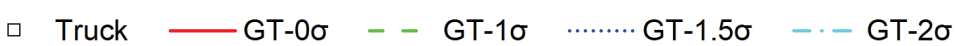


Figure 94. Bowmonk and Xsens power model predictions in the truck.
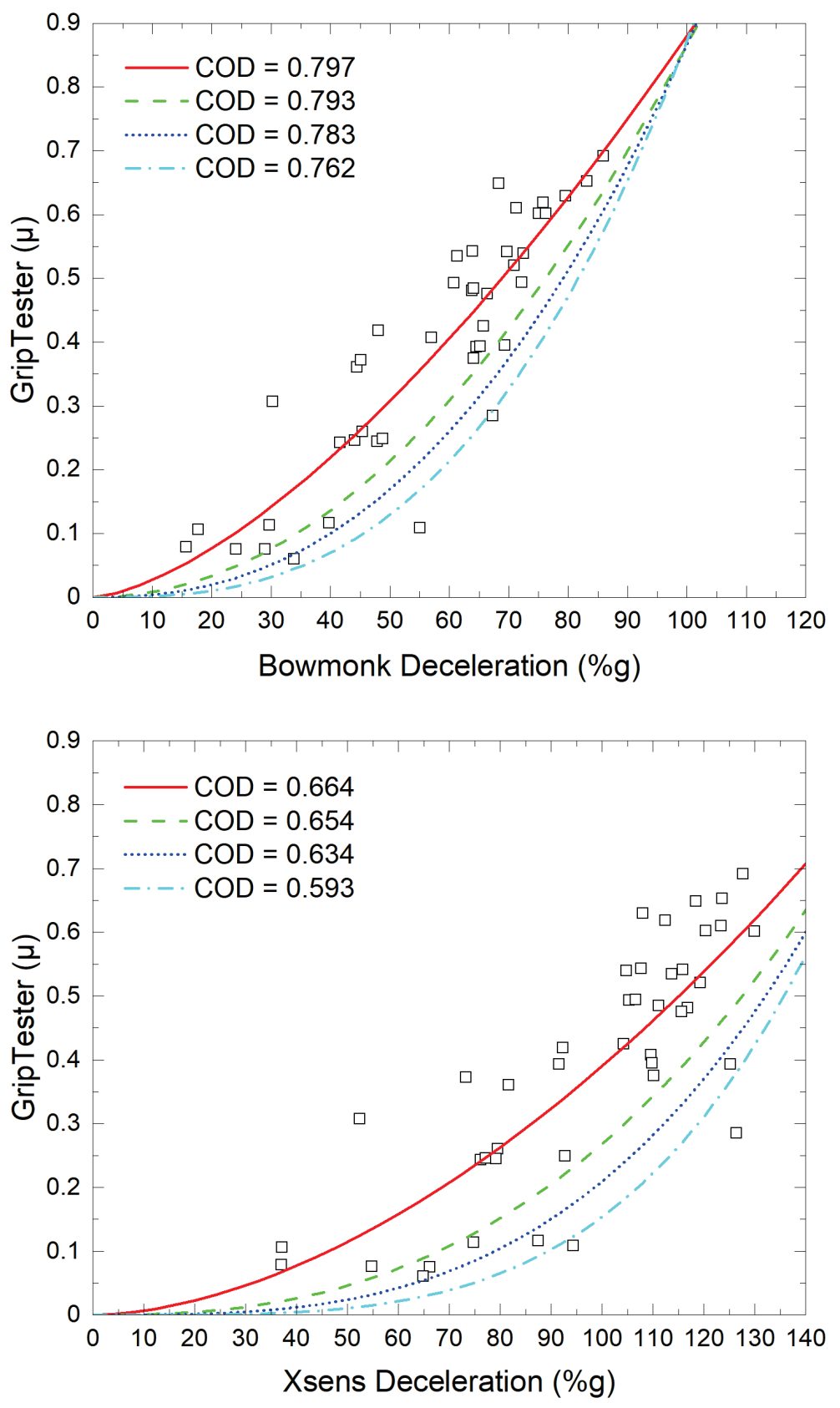

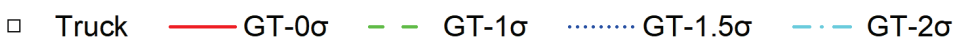


Table 24. Linear and power model parameters for the truck.

\begin{tabular}{|c|c|c|c|c|c|}
\hline \multirow[t]{2}{*}{$\begin{array}{l}\text { Y-Data } \\
(\mu)\end{array}$} & \multirow[t]{2}{*}{$\begin{array}{l}\text { X-Data } \\
\text { (\%g) }\end{array}$} & \multicolumn{2}{|c|}{$\begin{array}{l}\text { Linear Model } \\
\qquad y=A+B x\end{array}$} & \multicolumn{2}{|c|}{$\begin{array}{l}\text { Power Model } \\
\qquad y=a x^{b}\end{array}$} \\
\hline & & $A$ & B & A & $b$ \\
\hline \multirow[t]{6}{*}{ GT } & Bowmonk & -0.13544 & 0.00924 & $8.172 \mathrm{E}-4$ & 1.51615 \\
\hline & Xsens & -0.20983 & 0.00614 & $1.128 \mathrm{E}-4$ & 1.76945 \\
\hline & iPhone 7 & -0.18854 & 0.00728 & $1.565 \mathrm{E}-4$ & 1.77538 \\
\hline & V20 & -0.16500 & 0.00747 & 4.763E-4 & 1.54966 \\
\hline & iPhone 11 & -0.17536 & 0.00711 & $2.221 \mathrm{E}-4$ & 1.69652 \\
\hline & S10 & -0.16192 & 0.00779 & $4.844 \mathrm{E}-4$ & 1.56266 \\
\hline \multirow[t]{6}{*}{ GT-10 } & Bowmonk & -0.13544 & 0.00783 & $7.901 E-5$ & 2.01993 \\
\hline & Xsens & -0.20983 & 0.00506 & $2.064 \mathrm{E}-6$ & 2.55705 \\
\hline & iPhone 7 & -0.18854 & 0.00596 & $2.362 \mathrm{E}-6$ & 2.63898 \\
\hline & V20 & -0.16500 & 0.00603 & 1.616E-5 & 2.24276 \\
\hline & iPhone 11 & -0.17536 & 0.00580 & $3.851 \mathrm{E}-6$ & 2.52916 \\
\hline & S10 & -0.16192 & 0.00628 & 1.719E-5 & 2.25279 \\
\hline \multirow[t]{6}{*}{ GT-1.5o } & Bowmonk & -0.13544 & 0.00713 & $1.691 \mathrm{E}-5$ & 2.355 \\
\hline & Xsens & -0.20983 & 0.00452 & 1.147E-7 & 3.13066 \\
\hline & iPhone 7 & -0.18854 & 0.00530 & $9.024 \mathrm{E}-8$ & 3.31865 \\
\hline & V20 & -0.16500 & 0.00531 & $1.271 \mathrm{E}-6$ & 2.7698 \\
\hline & iPhone 11 & -0.17536 & 0.00514 & $1.682 \mathrm{E}-7$ & 3.17898 \\
\hline & S10 & -0.16192 & 0.00552 & $1.388 \mathrm{E}-6$ & 2.77943 \\
\hline \multirow[t]{6}{*}{ GT-20 } & Bowmonk & -0.13544 & 0.00643 & $2.674 \mathrm{E}-6$ & 2.75684 \\
\hline & Xsens & -0.20983 & 0.00398 & $2.904 \mathrm{E}-9$ & 3.86187 \\
\hline & iPhone 7 & -0.18854 & 0.00464 & $9.788 \mathrm{E}-10$ & 4.26557 \\
\hline & V20 & -0.16500 & 0.00459 & 4.620E-8 & 3.45966 \\
\hline & iPhone 11 & -0.17536 & 0.00449 & $2.484 \mathrm{E}-9$ & 4.05755 \\
\hline & S10 & -0.16192 & 0.00477 & 4.564E-8 & 3.49838 \\
\hline
\end{tabular}


For the smartphones tested in the truck, linear model predictions can be found in Figure 95; power model predictions in Figure 96; and associated model parameters in Table 24. While base GT linear model predictions vary for each device, they all have CODs over o.6. The same behavior is present in the base GT power model predictions except with higher CODs closer to 0.7. Furthermore, GT and GT-10 model predictions for all devices exhibit CODs over 0.6, indicating a stronger relationship between surface friction measurements and deceleration data collected from a pickup truck than those deceleration measurements collected in the HMMWV. For both model types and for all devices roughly, $50 \%$ of the data exist near or below the prediction line.

Figure 95. Smartphone linear model predictions in the truck.

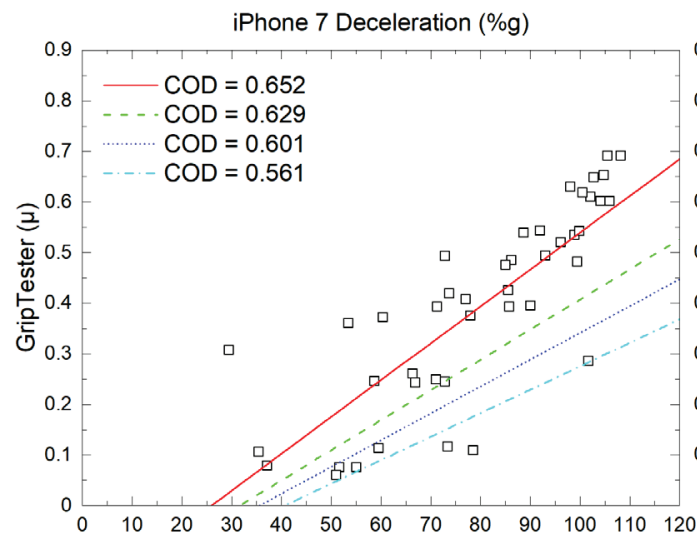

V20 Deceleration $(\% \mathrm{~g})$

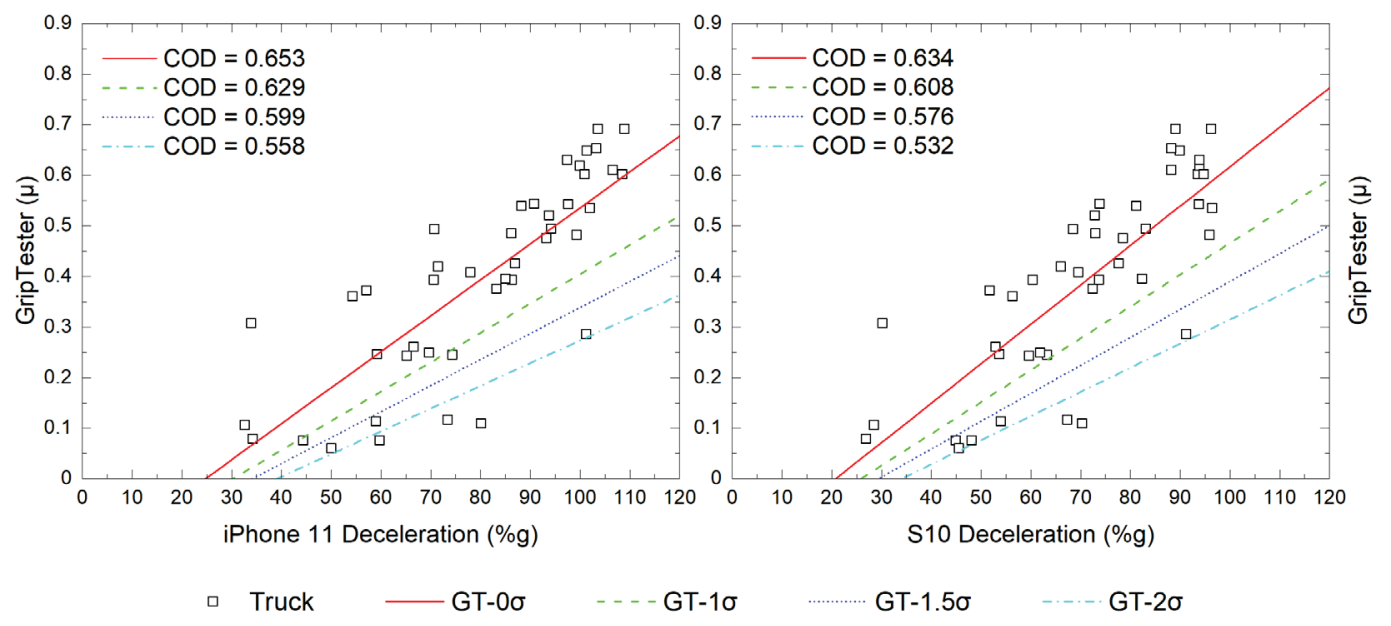


Figure 96. Smartphone power model predictions in the truck.

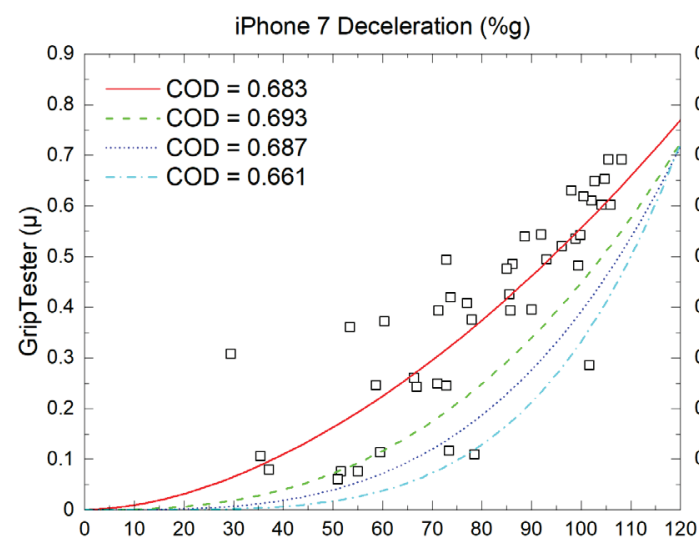

V20 Deceleration $(\% g)$

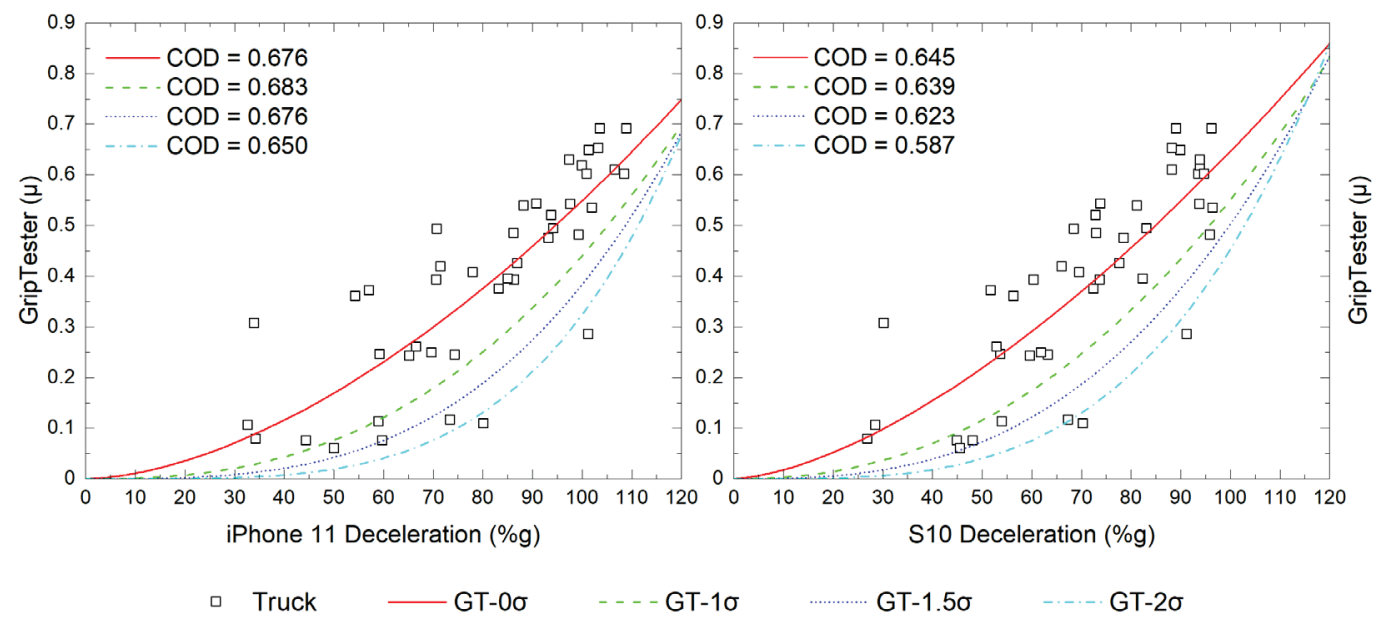

Reliability for all smartphones tested in the truck trends higher for the power model predictions than for the linear model predictions. In general, linear model reliability for the GT-10 predictions is around $85 \%$ for all devices and for the GT-1.5 $\sigma$ around 90\%. Similarly, power model reliability for the GT-10 predictions is around $87 \%$ for all devices and for the GT-1.5 $\sigma$ around 93\%. Much like the HMMWV smartphone prediction models, the GT-1.5 $\sigma$ power model predictions are preferred over other variants, given their combination of high reliability and optimum conservatism. Furthermore, the linear model predictions tend to be excessively conservative for higher GT values ( $\sim 0.6$ to $0.7 \mu$ ).

\subsubsection{SUV}

Linear surface friction prediction models for the Bowmonk and Xsens IMUs collected from the SUV are presented in Figure 97, and power model predictions in the same vehicle are presented in Figure 98. Associated model parameters for each are presented in Table 25. 
Base GT linear and power prediction models for the Bowmonk and Xsens IMUs exhibit CODs just over o.6. For both model types roughly 50\% of the data are near or below the base GT prediction line. Data scatter and model COD are roughly the same for both the Bowmonk and Xsens IMUs. Power model reliability for the Bowmonk ( $84 \%$ for GT-10 and 95\% for GT-

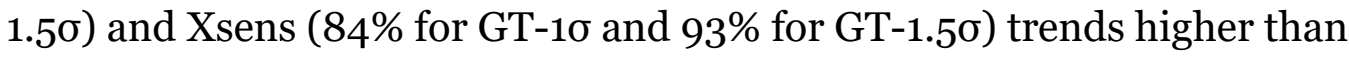
that of the linear model reliability for the Bowmonk (86\% for GT-10 and

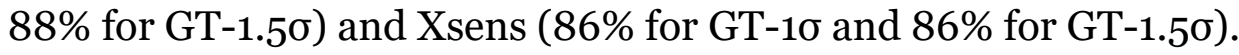


Figure 97. Bowmonk and Xsens linear model predictions in the SUV.
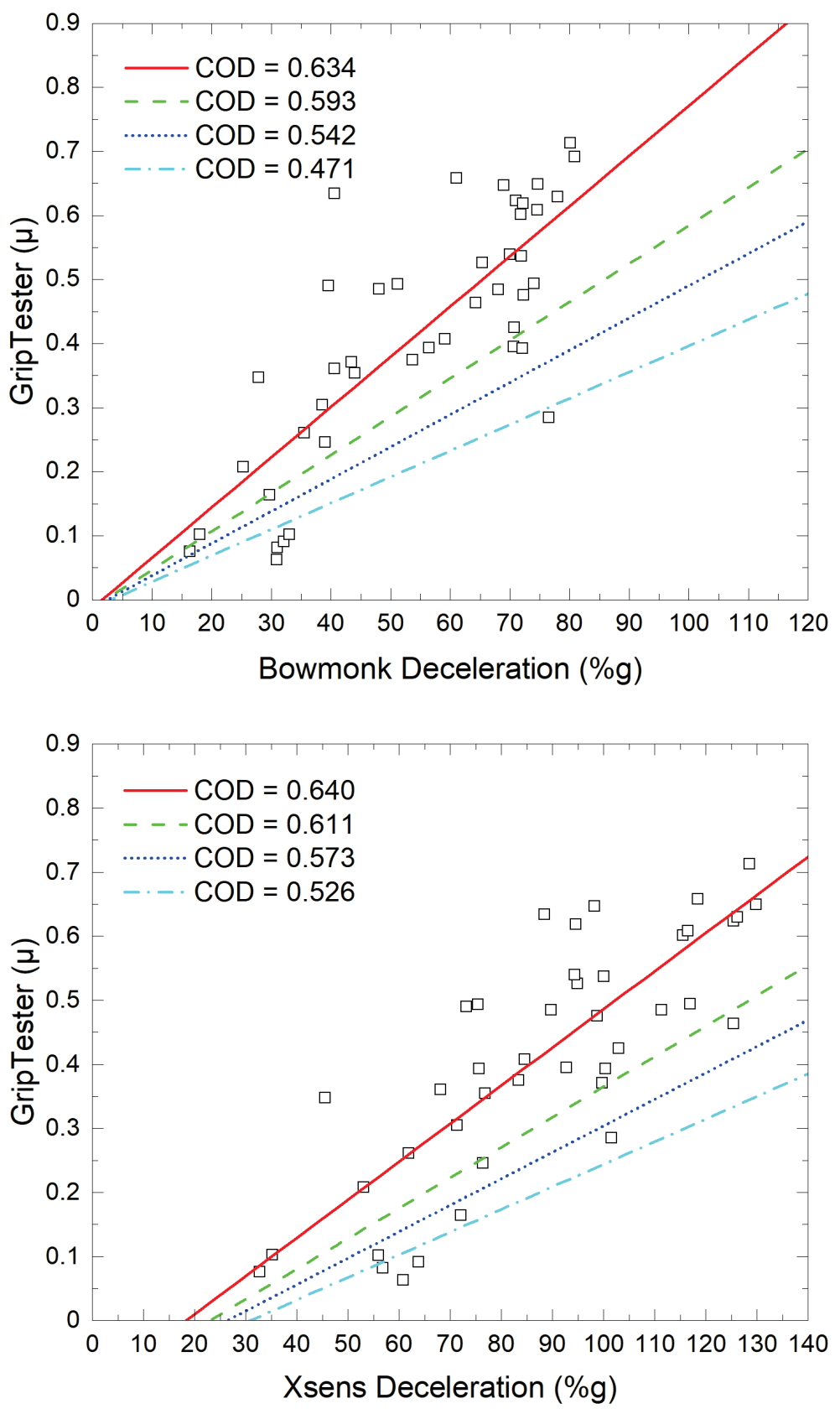

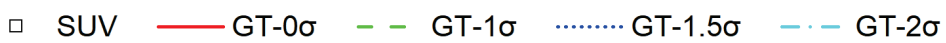


Figure 98. Bowmonk and Xsens power model predictions in the SUV.
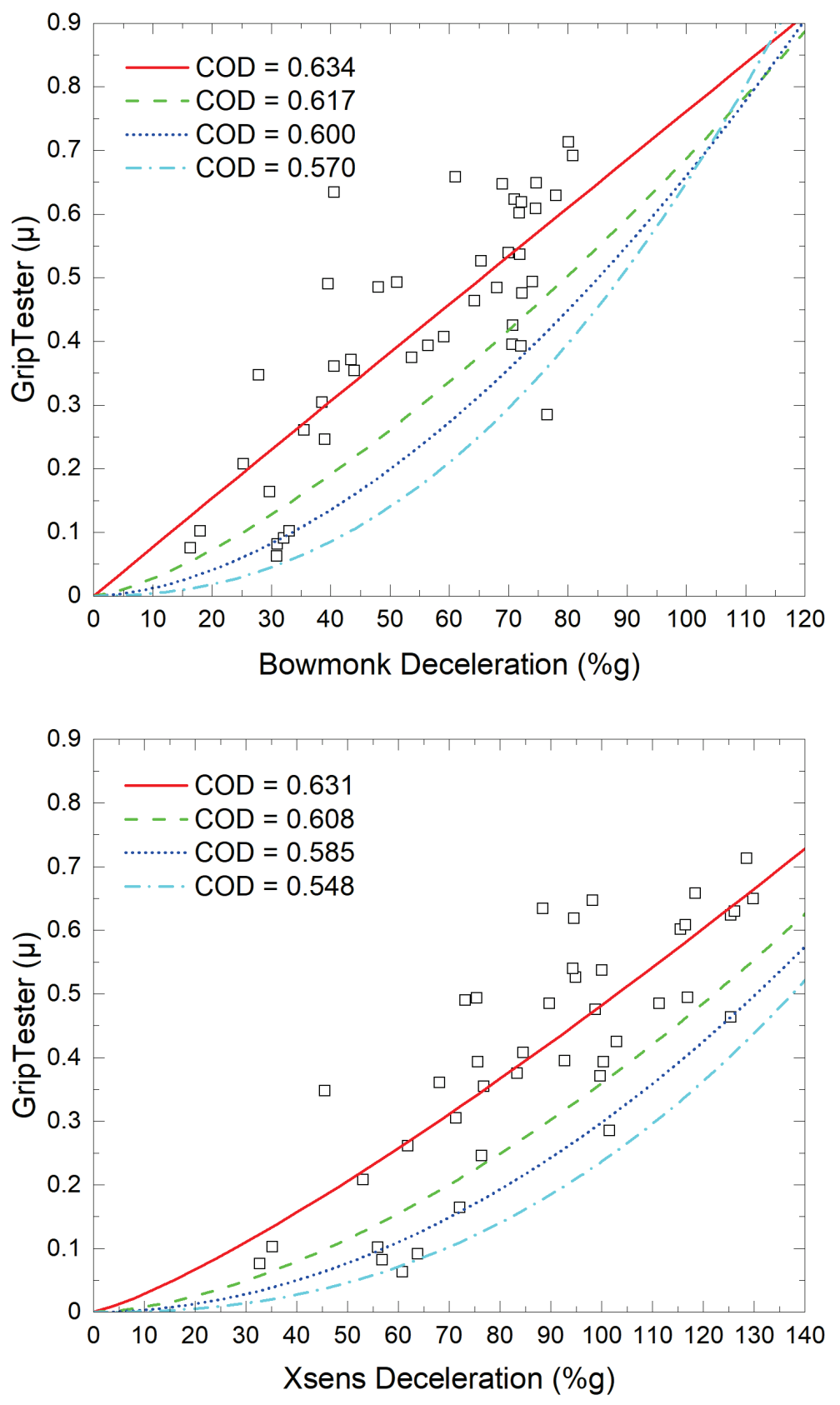

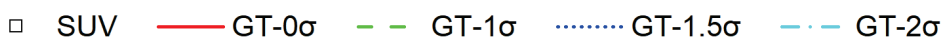


Table 25. Linear and power model parameters for the SUV.

\begin{tabular}{|c|c|c|c|c|c|}
\hline \multirow[t]{2}{*}{$\begin{array}{l}\text { Y-Data } \\
(\mu)\end{array}$} & \multirow[t]{2}{*}{$\begin{array}{l}\text { X-Data } \\
\text { (\%g) }\end{array}$} & \multicolumn{2}{|c|}{$\begin{array}{l}\text { Linear Model } \\
\qquad y=A+B x\end{array}$} & \multicolumn{2}{|c|}{$\begin{array}{l}\text { Power Model } \\
\qquad y=a x^{b}\end{array}$} \\
\hline & & $A$ & B & $a$ & $b$ \\
\hline \multirow[t]{6}{*}{ GT } & Bowmonk & -0.01246 & 0.00784 & 7.820E-3 & 0.9943 \\
\hline & Xsens & -0.10896 & 0.00595 & 1.700E-3 & 1.22633 \\
\hline & iPhone 7 & -0.10504 & 0.00720 & 2.050E-3 & 1.23877 \\
\hline & V20 & -0.08208 & 0.00732 & 2.830E-3 & 1.18028 \\
\hline & iPhone 11 & -0.10315 & 0.00717 & $2.060 \mathrm{E}-3$ & 1.23691 \\
\hline & S10 & -0.04980 & 0.00737 & $4.710 \mathrm{E}-3$ & 1.08047 \\
\hline \multirow[t]{6}{*}{ GT-10 } & Bowmonk & -0.01246 & 0.00597 & 1.100E-3 & 1.39796 \\
\hline & Xsens & -0.10896 & 0.00474 & $1.841 \mathrm{E}-4$ & 1.64541 \\
\hline & iPhone 7 & -0.10504 & 0.00589 & $2.704 \mathrm{E}-4$ & 1.63933 \\
\hline & V20 & -0.08208 & 0.00597 & $4.479 E-4$ & 1.54648 \\
\hline & iPhone 11 & -0.10315 & 0.00585 & $2.569 \mathrm{E}-4$ & 1.64982 \\
\hline & S10 & -0.04980 & 0.00587 & 8.481E-4 & 1.4195 \\
\hline \multirow[t]{6}{*}{ GT-1.50 } & Bowmonk & -0.01246 & 0.00503 & $2.308 \mathrm{E}-4$ & 1.7283 \\
\hline & Xsens & -0.10896 & 0.00413 & $3.761 \mathrm{E}-5$ & 1.94952 \\
\hline & iPhone 7 & -0.10504 & 0.00524 & $6.323 E-5$ & 1.93195 \\
\hline & V20 & -0.08208 & 0.00530 & $1.242 \mathrm{E}-4$ & 1.80533 \\
\hline & iPhone 11 & -0.10315 & 0.00518 & $5.722 \mathrm{E}-5$ & 1.95296 \\
\hline & S10 & -0.04980 & 0.00513 & $2.530 \mathrm{E}-4$ & 1.66326 \\
\hline \multirow[t]{6}{*}{ GT-20 } & Bowmonk & -0.01246 & 0.00409 & $2.434 \mathrm{E}-5$ & 2.21319 \\
\hline & Xsens & -0.10896 & 0.00353 & $4.758 \mathrm{E}-6$ & 2.34826 \\
\hline & iPhone 7 & -0.10504 & 0.00458 & $9.412 \mathrm{E}-6$ & 2.31937 \\
\hline & V20 & -0.08208 & 0.00463 & $2.417 \mathrm{E}-5$ & 2.13844 \\
\hline & iPhone 11 & -0.10315 & 0.00452 & 7.993E-6 & 2.35407 \\
\hline & S10 & -0.04980 & 0.00438 & $5.291 E-5$ & 1.98203 \\
\hline
\end{tabular}


For the smartphones tested in the SUV, linear model predictions can be found in Figure 99; power model predictions in Figure 100; and associated model parameters in Table 25. Base GT linear and power model predictions all exhibit CODs greater than 0.6 and close to 0.7 . Furthermore, GT and GT-1 $\sigma$ model predictions for all devices exhibit CODs greater than 0.6 , indicating a stronger relationship between surface friction measurements and deceleration data collected from the SUV than those collected from the HMMWV. For both model types and for all devices, roughly $50 \%$ of the data exist near or below the prediction line.

Figure 99. Smartphone linear model predictions in the SUV.
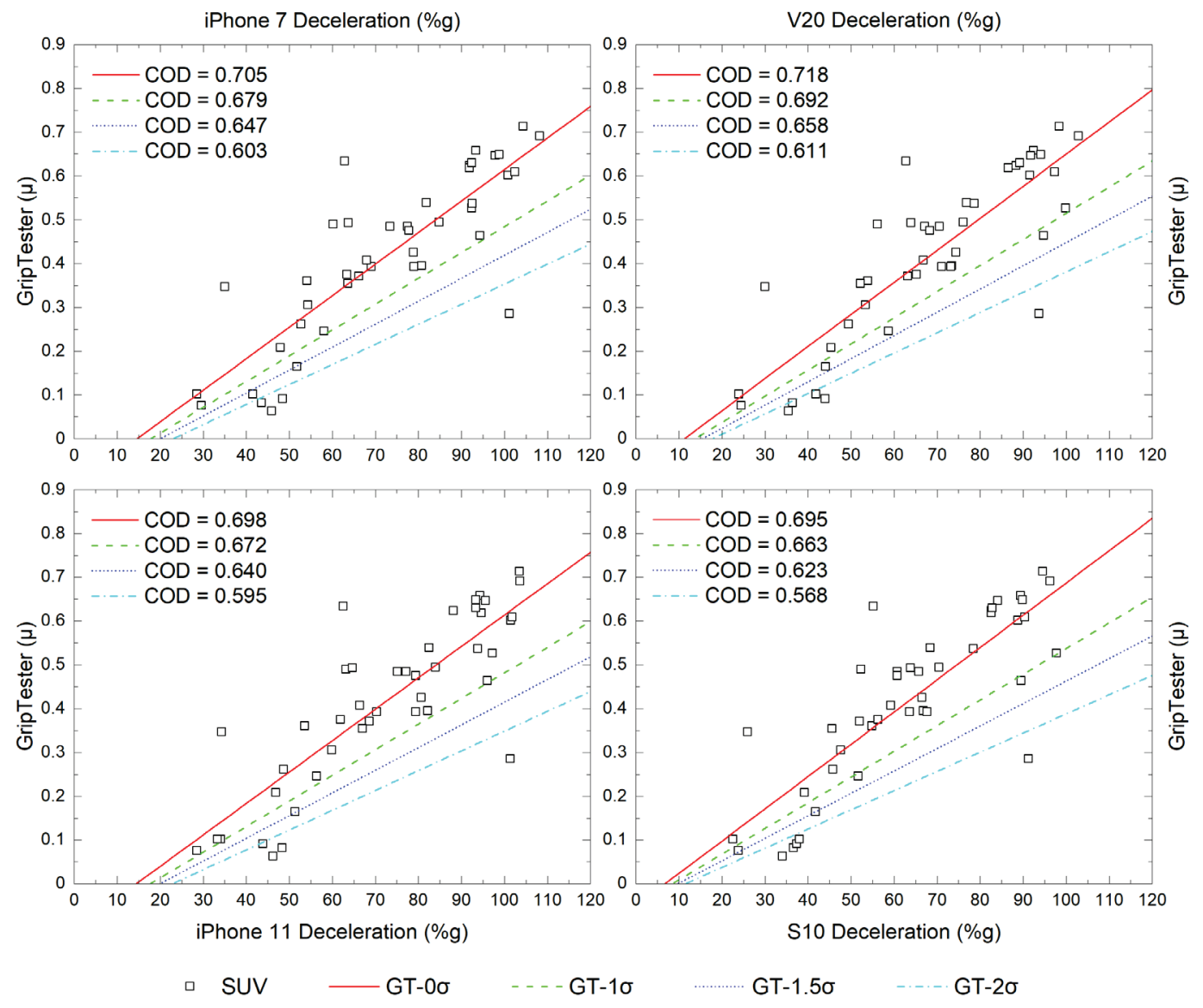
Figure 100. Smartphone power model predictions in the SUV.

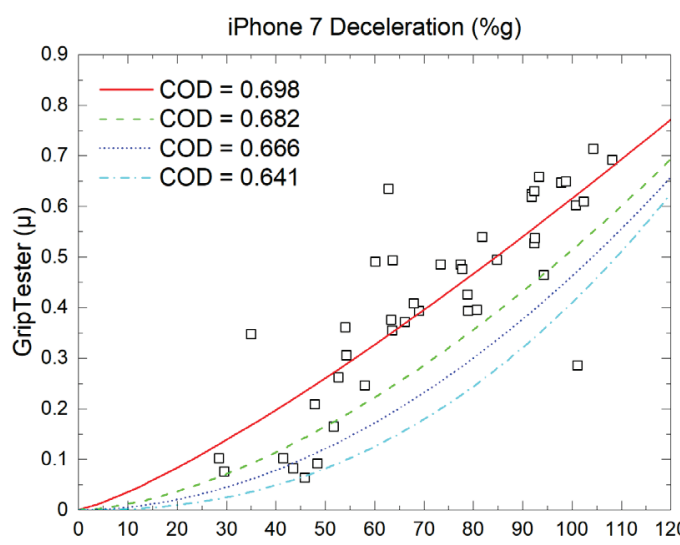

V20 Deceleration $(\% g)$

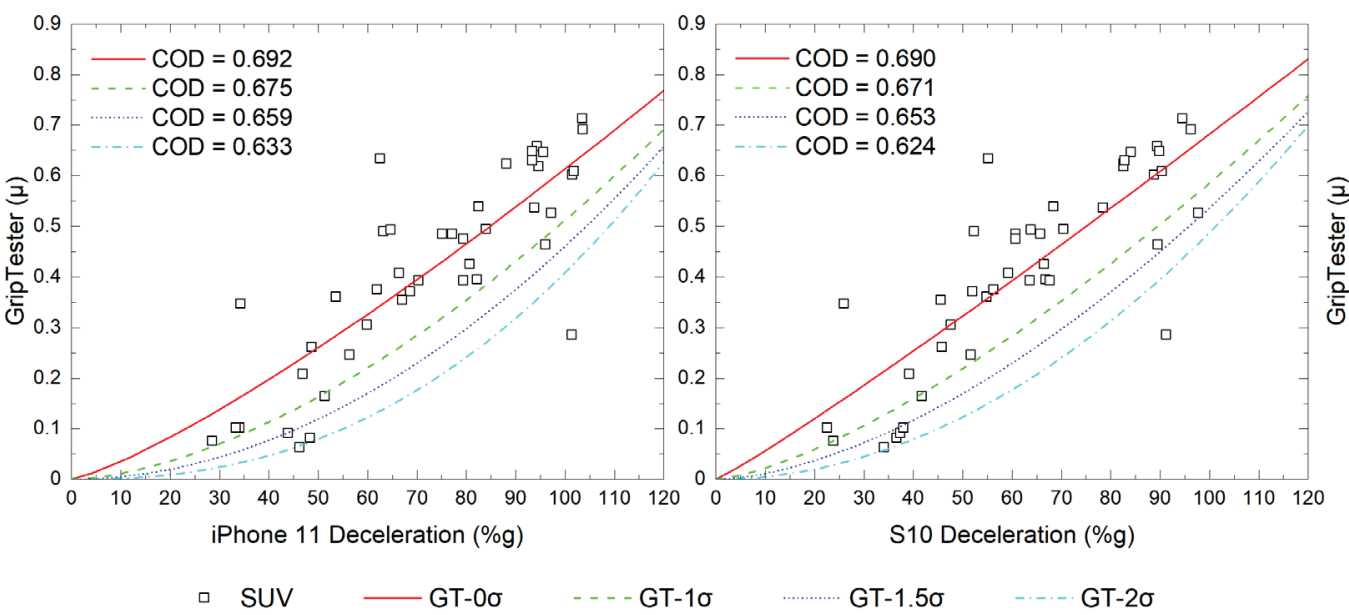

Reliability for all smartphones tested in the SUV trends higher for the power model predictions than for the linear model predictions. In general, linear model reliability for the GT-1 $\sigma$ predictions is around $86 \%$ for all devices and for the GT-1.50 around 90\%. Similarly, power model reliability for the GT$1 \sigma$ predictions is around $90 \%$ for all devices and for the GT-1.5 $\sigma$ predictions around 93\%. The GT-1.5 $\sigma$ power model predictions are preferred over other variants, given their combination of high reliability and optimum conservatism. Furthermore, the linear model predictions tend to be excessively conservative for higher GT values ( $\sim 0.6$ to $0.7 \mu$ ).

\subsubsection{Synthesized deceleration-based GT predictions}

As discussed in the three preceding sub-sections, the GT-1.5 $\sigma$ power model predictions are preferred over other variants. These models were developed for use with deceleration measurements made in units of percent acceleration of gravity (\%g). In order to support deceleration measurements made in alternative units, a series of final predictive models is presented in Table 26 below. 
Table 26. Final predictive models for all three test vehicles.

\begin{tabular}{|c|c|c|c|c|}
\hline Vehicle & Device & $\begin{array}{l}\text { Acceleration, a } \\
(\% g)\end{array}$ & $\begin{array}{c}\text { Acceleration, a } \\
(g)\end{array}$ & $\begin{array}{r}\text { Acceleration, a } \\
\left(\mathrm{m} / \mathrm{s}^{2}\right)\end{array}$ \\
\hline \multirow[t]{6}{*}{ HMMWV } & Bowmonk & $G T=0.0000163 a^{2.29177}$ & $G T=0.6248 a^{2.29177}$ & $G T=0.003335 a^{2.29177}$ \\
\hline & Xsens & $G T=0.0000004504 a^{2.90808}$ & $G T=0.2950 a^{2.90808}$ & $G T=0.0003854 a^{2.90808}$ \\
\hline & iPhone 7 & $G T=0.0000002604 a^{3.10537}$ & $G T=0.4230 a^{3.10537}$ & $G T=0.0003523 a^{3.10537}$ \\
\hline & V20 & $G T=0.000002989 a^{2.58004}$ & $G T=0.4321 a^{2.58004}$ & $G T=0.001194 a^{2.58004}$ \\
\hline & iPhone 11 & $G T=0.0000003798 a^{3.01568}$ & $G T=0.4082 a^{3.01568}$ & $G T=0.0004172 a^{3.01568}$ \\
\hline & S10 & $G T=0.000003047 a^{2.60851}$ & $G T=0.5022 a^{2.60851}$ & $G T=0.001301 a^{2.60851}$ \\
\hline \multirow[t]{6}{*}{ Truck } & Bowmonk & $G T=0.00001691 a^{2.355}$ & $G T=0.8672 a^{2.355}$ & $G T=0.004006 a^{2.355}$ \\
\hline & Xsens & $G T=0.0000001147 a^{3.13066}$ & $G T=0.2094 a^{3.13066}$ & $G T=0.0001646 a^{3.13066}$ \\
\hline & iPhone 7 & $G T=0.00000009024 a^{3.31865}$ & $G T=0.3915 a^{3.31865}$ & $G T=0.0002003 a^{3.31865}$ \\
\hline & V20 & $G T=0.000001271 a^{2.7698}$ & $G T=0.4403 a^{2.7698}$ & $G T=0.0007889 a^{2.7698}$ \\
\hline & iPhone 11 & $G T=0.0000001682 a^{3.17898}$ & $G T=0.3835 a^{3.17898}$ & $G T=0.0002700 a^{3.17898}$ \\
\hline & S10 & $G T=0.000001388 a^{2.77943}$ & $G T=0.5026 a^{2.77943}$ & $G T=0.0008810 a^{2.77943}$ \\
\hline \multirow[t]{6}{*}{ SUV } & Bowmonk & $G T=0.0002308 a^{1.7283}$ & $G T=0.6604 a^{1.7283}$ & $G T=0.01276 a^{1.7283}$ \\
\hline & Xsens & $G T=0.00003761 a^{1.94952}$ & $G T=0.2981 a^{1.94952}$ & $G T=0.003476 a^{1.94952}$ \\
\hline & iPhone 7 & $G T=0.00006323 a^{1.93195}$ & $G T=0.4622 a^{1.93195}$ & $G T=0.005610 a^{1.93195}$ \\
\hline & V20 & $G T=0.0001242 a^{1.80533}$ & $G T=0.5067 a^{1.80533}$ & $G T=0.008213 a^{1.80533}$ \\
\hline & iPhone 11 & $G T=0.00005722 a^{1.95296}$ & $G T=0.4608 a^{1.95296}$ & $G T=0.005331 a^{1.95296}$ \\
\hline & S10 & $G T=0.000253 a^{1.66326}$ & $G T=0.5366 a^{1.66326}$ & $G T=0.01203 a^{1.66326}$ \\
\hline
\end{tabular}




\section{Conclusions and Recommendations}

The smartphone deceleration-based models and methods detailed in this report reveal a number of useful results. The present work also reflects several existing assumptions about deceleration-based friction testing: deceleration-based friction testing requires numerous tests at a single location for a statistically significant result, deceleration-based friction testing is less accurate and exhibits higher error than fixed-slip friction testing, and smartphone-based deceleration results are less accurate than those produced by specialized devices such as the Bowmonk. Two key conclusions were reached following this study: the various decelerationbased devices tested here adequately correlate (COD > 0.6) to GT measurements, and the ability to develop improved correlation is primarily limited by poor inter-model repeatability between COTS smartphones. These two conclusions are reinforced by the results detailed in the previous section. Final predictive models for each device are listed in Table 26. Other conclusions of note are enumerated below.

\subsection{Conclusions}

- The Bowmonk AFM2 Mk3 decelerometer exhibited superior repeatability, reliability, and goodness-of-fit in the HMMWV (Figure 89 and Figure 90), truck (Figure 93 and Figure 94), and SUV (Figure 97 and Figure 98) compared to other deceleration-based devices tested. The superior performance is likely due to the Bowmonk's use of research-grade IMUs, whereas the smartphone devices use more costeffective MEMS-based IMUs.

- As in previous efforts, the smartphone-based deceleration measurement technique described here exhibits low inter-model repeatability. This is evident in the scatter present in the deceleration data between different smartphone models presented in Figure 81, Figure 83, and Figure 85.

- The median-based outlier removal technique (MAD) described in Section 6.1 was effective at removing extreme measurement values for all devices tested.

- The Xsens MTi-G-710 IMU, while dedicated for acceleration measurement, exhibited higher scatter than the Bowmonk AFM2 Mk3 in the HMMWV (Figure 89 and Figure 90), truck (Figure 93 and Figure 94), and SUV (Figure 97 and Figure 98). Its GT prediction CODs were 
comparable to the smartphone GT prediction CODs in all three vehicles. It is unknown why the Xsens IMU exhibited inferior performance compared to the Bowmonk IMU. Possible reasons are the smaller size of the Xsens IMU, the use of a lower-grade accelerometer, or the potential use of proprietary post-processing techniques in the specialized Bowmonk unit.

- While inter-model repeatability is low between smartphone models for the various smartphones tested, they do highly correlate with each other as evidenced by the high CODs in Table 19, Table 20, and Table 21.

- Of the three vehicles tested, the HMMWV exhibited higher scatter and lower GT prediction accuracy than the other two vehicles tested. This is evidenced by the lower power and linear prediction model CODs seen in Figure 91 and Figure 92.

- Lower GT prediction COD in the HMMWV is likely due to a variety of factors. The driveline braking system utilized in the vehicle is one such factor as the other two test vehicles use a slip-based ABS. Another significant contributing factor could be the heavy weight of the HMMWV (roughly 12,00o lb) compared to the truck (roughly 3,00o lb) and SUVs (roughly 5,000 to 6,000 lb). Finally, the HMMWV's use of aggressive tread tires could be a strong contributing factor as not only do the other two test vehicle types use less aggressive all-terrain tires, the GT itself utilizes a smooth test tire.

- The high intra-model repeatability of smartphone devices (as referenced in Ward et al. 2019) is further reinforced in Section 6.4, showing high mean COD, low MAE, and low pooled standard deviation values for all four smartphones tested (see Table 22 and Figure 88).

- Among all smartphones tested, the two Apple devices, iPhone 7 and iPhone 11 Pro, displayed superior accuracy and reliability in all three test vehicle types. Specifically, the two Apple devices exhibited higher deceleration-based predictive capability in all three test vehicles (highest mean COD and lowest sample standard deviation seen in Table 19, Table 20, and Table 21). The two Apple devices also exhibited better GT predictive capability in all three test vehicle types (highest power model COD seen in Figure 92, Figure 96, and Figure 100). It should be noted, however, that the two Apple devices were roughly comparable to the other smartphones tested regarding intra-model repeatability (see Figure 88 and Table 22).

- Finally, the correlation between cost and friction predictive capability should be noted. While the Findlay Irvine Mk2 GripTester exhibits superior accuracy and precision than the deceleration-based devices, it 
costs approximately $\$ 60,000$ and is not widely available. The Bowmonk exhibits superior friction predictive capabilities than the other deceleration-devices tested; however, it costs approximately $\$ 5,000$ and is also not widely available. The Xsens IMU exhibits accuracy roughly comparable to or worse than the smartphones tested and costs approximately $\$ 5,000$ and is somewhat more widely available than the GT and Bowmonk. The smartphones tested exhibit sufficient (COD > 0.6) friction predictive capability and cost $\$ 1,000$ or less and are very widely available.

\subsection{Recommendations}

It is recommended that the smartphone deceleration-based technique described here be tested in conjunction with actual C-17 operations, adhoc or planned, to confirm the cross correlation of C-17 RCR to ground vehicle peak braking deceleration through Mk2 GT surface friction measurements. Furthermore, it is recommended that a study be conducted to develop a universal smartphone accelerometer calibration procedure in order to remove the smartphone model and manufacturer as experimental controls. It is recommended that the Bowmonk AFM2 Mk3, should it be available and operational, be used in lieu of smartphone devices, given its higher repeatability and lower data scatter. For any device tested, it is recommended that, at minimum, no value further than two absolute deviations from the test sample median should be considered for analysis. Should higher correlation or lower data scatter be desired in the smartphone devices, it is recommended that a high number of replicate measurements be made (10-15) on a single test area prior to outlier analysis. 


\section{References}

ASTM (American Society for Testing and Materials). 2015. Standard practice for calculating international friction index of a pavement surface. Designation: E1960-07. West Conshohocken, PA: ASTM. . 2017a. Standard practice for classification of soils for engineering purposes (Unified Soil Classification System). Designation: D2487-17. West Conshohocken, PA: ASTM. . 2017b. Standard test method for determination of water content of soil and rock by microwave oven heating. Designation: D4643-17. West Conshohocken, PA: ASTM.

.2017c. Standard test methods for liquid limit, plastic limit, and plasticity index of soils. Designation: D4318-17. West Conshohocken, PA: ASTM.

. 2017d. Standard test methods for particle-size distribution (gradation) of soils using sieve analysis. Designation: D6913/D6913M-17. West Conshohocken, PA: ASTM.

. 2017e. Standard test method for particle-size distribution (gradation) of finegrained soils using the sedimentation (hydrometer) analysis. Designation: D7928-17. West Conshohocken, PA: ASTM.

. 2021. Standard test method for measuring the skid resistance of pavements and other trafficked surfaces using a continuous reading, fixed-slip technique. Designation: E2340/E2340M-11e1. West Conshohocken, PA: ASTM.

Bly, P. 2018. Semi-prepared airfield evaluation, Schoonover Landing Zone, U.S. Army Garrison Hunter Liggett, California. ATIIP AAF-18-06. Vicksburg, MS: U.S. Army Engineer Research and Development Center.

Bowmonk. 2016. Bowmonk AFM2 datasheet. www.bowmonk.com/uploads/files/2016/06/afm2.pdf.

Crenshaw, B. M. 1972. Aircraft landing gear dynamic loads induced by soil landing fields. Volume 1: Prediction model and wheel loads. AFFDL-TR-70-169.

Das, B. M. 2010. Principles of geotechnical engineering, $7^{\text {th }}$ ed. Stanford, CT: Cengage Learning, USA.

Descornet, G. 2004. The HERMES Project. Paper presented at $5^{\text {th }}$ Symposium on Pavement Surface Characteristics Conference, SURF 2004. Paris: World Road Association.

Federal Aviation Administration (FAA). 1997. Measurement, construction, and maintenance of skid-resistant airport pavement surfaces. Advisory Circular (AC) 150/5320-12C. Washington, DC: FAA. 
Flintsch, G. W., E. L. Izeppi, K. K. McGhee, and J. A. Roa. 2009. Evaluation of international friction index coefficients for various devices. Transportation Research Record: Journal of the Transportation Research Board 2094(2):136143 .

Grosch, K. A. 1963. The relation between the friction and visco-elastic properties of rubber. In Proceedings of the Royal Society of London, Series A 274, 21. London.

Henry, J. J. 2000. Evaluation of pavement friction characteristics. NCHRP Synthesis 291. Washington, DC: Transportation Research Board, National Research Council.

Huber, P. J. 2004. Robust statistics. Vol. 523. Hoboken, NJ: John Wiley \& Sons.

Kummer, H. W., and W. E. Meyer. 1962. Measurement of skid resistance. ASTM Special Technical Publication No. 326. West Conshohocken, NJ: ASTM International.

Lea, J., and D. Jones. 2007. Initial findings on skid resistance of unpaved roads. Transportation Research Record: Journal of the Transportation Research Board 2016 (2007):49-55.

Leu, M. C., and J. J. Henry. 1983. Prediction of skid resistance as a function of speed from pavement texture. Transportation Research Record 946. Washington, DC: Transportation Research Board, National Research Council.

National Aeronautics and Space Administration (NASA). 1969. Pavement grooving and traction studies. NASA SP-5073. Washington, DC: NASA.

Rado, Z. 1994. Analysis of texture profiles. PTI Report 9510. State College, PA: Pennsylvania Transportation Institute.

Rowe, R. S., and E. Hegedus. 1959. Drag coefficients of locomotion over viscous soils. Part II. Report No. 54. Washington, DC: Department of the Army, Ordnance Tank-Automotive Command, Land Locomotion Laboratory.

Tabor, D. 1959. The importance of hysteresis losses in the friction of lubricated rubber. In Proceedings of the $1^{\text {st }}$ International Skid Prevention Conference. Part 1, 211-218. Charlotttesville, VA: Virginia Highway Research Council.

Tingle, J. S., G. J. Norwood, and B. Cotter. 2017. Use of continuous friction measurement equipment to predict runway condition rating on unpaved runways. Transportation Research Record 2626(1):58-65.

Turnage, G. W. 1967. Performance of soils under tire loads. Reports 1-6. No. AEWESTR-3-666-8. Vicksburg, MS: U.S. Army Engineer Waterways Experiment Station.

Wambold, J. C., C. E. Antle, J. J. Henry, and Z. Rado. 1995. International PIARC experiment to compare and harmonize texture and skid resistance measurements. Final Report. Paris: Permanent International Association of Road Congresses (PIARC).

Ward, A. B., C. A. Rutland, and J. S. Tingle. 2019. Development of deceleration-based runway friction measurement methods. ERDC TR-19-10. Vicksburg, MS: U.S. Army Engineer Research and Development Center. 
Yager, T. J., W. P. Phillips, W. B. Horne, and H. C. Sparks. 1970. A comparison of aircraft and ground vehicle stopping performance on dry, wet, flooded, slush-, snow-, and ice-covered runways. NASA TN D-6098. Washington, DC: NASA.

Zakikhani, M., P. T. Gidley, and J. S. Tingle. 2017. Development of an engineering soil database. ERDC TR-17-15. Vicksburg, MS: U.S. Army Engineer Research and Development Center. 


\section{Unit Conversion Factors}

\begin{tabular}{|c|c|c|}
\hline Multiply & By & To Obtain \\
\hline cubic feet & 0.02831685 & cubic meters \\
\hline cubic inches & 1.6387064 E-05 & cubic meters \\
\hline degrees (angle) & 0.01745329 & radians \\
\hline degrees Fahrenheit & $(\mathrm{F}-32) / 1.8$ & degrees Celsius \\
\hline feet & 0.3048 & meters \\
\hline gallons (U.S. liquid) & 3.785412 E-03 & cubic meters \\
\hline inches & 0.0254 & meters \\
\hline microns & $1.0 \mathrm{E}-06$ & meters \\
\hline miles (U.S. statute) & $1,609.347$ & meters \\
\hline miles per hour & 0.44704 & meters per second \\
\hline pounds (force) & 4.448222 & newtons \\
\hline pounds (force) per square foot & 47.88026 & pascals \\
\hline pounds (force) per square inch & 6.894757 & kilopascals \\
\hline pounds (mass) & 0.45359237 & kilograms \\
\hline pounds (mass) per cubic foot & 16.01846 & kilograms per cubic meter \\
\hline pounds (mass) per cubic inch & $2.757990 E+04$ & kilograms per cubic meter \\
\hline pounds (mass) per square foot & 4.882428 & kilograms per square meter \\
\hline square feet & 0.09290304 & square meters \\
\hline square inches & $6.4516 \mathrm{E}-04$ & square meters \\
\hline square yards & 0.8361274 & square meters \\
\hline yards & 0.9144 & meters \\
\hline
\end{tabular}




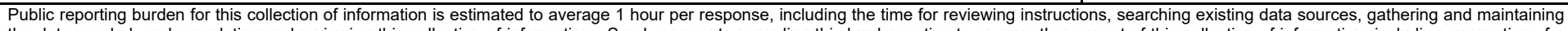

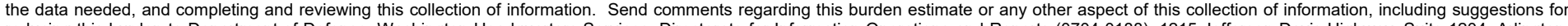

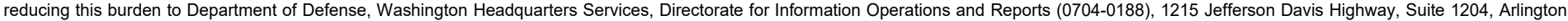

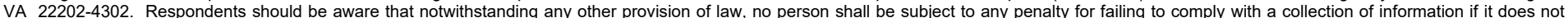

display a currently valid OMB control number. PLEASE DO NOT RETURN YOUR FORM TO THE ABOVE ADDRESS.

\begin{tabular}{l|l|l} 
1. REPORT DATE (DD-MM-YYYY) & 2. REPORT TYPE & 3. DATES COVERED (FrOm - To)
\end{tabular}

November 2021

Final

\section{TITLE AND SUBTITLE}

Development of Smartphone-Based Semi-Prepared Runway Operations (SPRO) Models and Methods

5a. CONTRACT NUMBER

5b. GRANT NUMBER

5c. PROGRAM ELEMENT NUMBER

5d. PROJECT NUMBER

\section{AUTHOR(S)}

Andrew B. Ward, Anthony J. Falls, and Craig A. Rutland

5e. TASK NUMBER

5f. WORK UNIT NUMBER

\section{PERFORMING ORGANIZATION NAME(S) AND ADDRESS(ES)}

8. PERFORMING ORGANIZATION REPORT NUMBER

Geotechnical and Structures Laboratory

U.S. Army Engineer Research and Development Center

ERDC/GSL TR-21-37

3909 Halls Ferry Road

Vicksburg, MS 39180-6199

Civil Engineering Branch, Engineering Division

Air Force Civil Engineer Center

Tyndall Air Force Base, FL 32403-5319

9. SPONSORING / MONITORING AGENCY NAME(S) AND ADDRESS(ES)

Headquarters, U.S. Air Force Civil Engineer Center

139 Barnes Drive, Suite 1

Tyndall Air Force Base, FL 32403-5319

10. SPONSOR/MONITOR'S ACRONYM(S)

11. SPONSOR/MONITOR'S REPORT NUMBER(S)

\section{DISTRIBUTION / AVAILABILITY STATEMENT}

Approved for public release; distribution is unlimited.

\section{SUPPLEMENTARY NOTES}

MIPR F4ATA49092JW01

\section{ABSTRACT}

The U.S. Army Engineer Research and Development Center (ERDC) has developed a method for predicting surface friction response by use of ground vehicles equipped with deceleration-based measurement devices. Specifically, the ERDC has developed models and measurement methods between the Findlay Irvine Mk2 GripTester and a variety of deceleration measurement devices: Bowmonk AFM2 Mk3, Xsens MTi-G-710, two Android smartphones, and two iOS smartphones. These models show positive correlation between ground vehicle deceleration and fixed-slip surface continuous surface friction measurement. This effort extends prior work conducted by the U.S. Army ERDC in developing highly correlative models between the Findlay Irvine Mk2 GripTester and actual C-17 braking deceleration, measured via the runway condition rating (RCR) system. The models and measurement methods detailed here are of considerable use to semi-prepared airfield managers around the world needing to measure safe landing conditions following inclement weather. This work provides the tools necessary for airfield managers to quantify safe landing conditions for C-17 aircraft by using easily obtainable equipment and simple test standards.

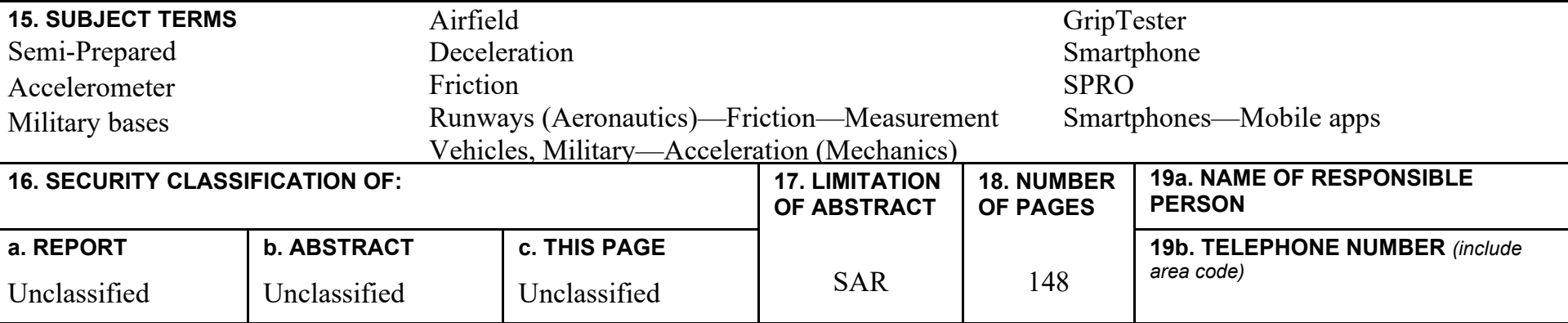


